\title{
The politics of advice in the European Parliament
}

Citation for published version (APA):

Ruiter, E. (2019). The politics of advice in the European Parliament: understanding the political role of group advisors. [Doctoral Thesis, Maastricht University]. Maastricht University. https://doi.org/10.26481/dis.20190313er

Document status and date:

Published: 01/01/2019

DOI:

10.26481/dis.20190313er

Document Version:

Publisher's PDF, also known as Version of record

\section{Please check the document version of this publication:}

- A submitted manuscript is the version of the article upon submission and before peer-review. There can be important differences between the submitted version and the official published version of record.

People interested in the research are advised to contact the author for the final version of the publication, or visit the DOI to the publisher's website.

- The final author version and the galley proof are versions of the publication after peer review.

- The final published version features the final layout of the paper including the volume, issue and page numbers.

Link to publication

\footnotetext{
General rights rights.

- You may freely distribute the URL identifying the publication in the public portal. please follow below link for the End User Agreement:

www.umlib.nl/taverne-license

Take down policy

If you believe that this document breaches copyright please contact us at:

repository@maastrichtuniversity.nl

providing details and we will investigate your claim.
}

Copyright and moral rights for the publications made accessible in the public portal are retained by the authors and/or other copyright owners and it is a condition of accessing publications that users recognise and abide by the legal requirements associated with these

- Users may download and print one copy of any publication from the public portal for the purpose of private study or research.

- You may not further distribute the material or use it for any profit-making activity or commercial gain

If the publication is distributed under the terms of Article $25 \mathrm{fa}$ of the Dutch Copyright Act, indicated by the "Taverne" license above, 


\section{THE POLITICS OF ADVICE IN THE EUROPEAN PARLIAMENT}


ISBN 978-94-6332-461-8

(C) 2019, Emmy Ruiter

Design: Emmy Ruiter and GVO drukkers \& vormgevers 


\title{
THE POLITICS OF ADVICE IN THE EUROPEAN PARLIAMENT
}

\section{Understanding the political role of group advisors}

\author{
DISSERTATION \\ to obtain the degree of Doctor \\ at the Maastricht University
}

on the authority of the Rector Magnificus Prof. dr. Rianne M. Letschert in accordance with the decision of the Board of Deans

to be defended in public on Wednesday,

13 March 2019 at 16:00 hours

by

\section{Emmy Ruiter}




\section{Supervisors:}

Prof. dr. T. Christiansen, Maastricht University

Prof. dr. C. Neuhold, Maastricht University

\section{Assessment Committee:}

Prof. dr. T. Conzelmann (chair), Maastricht University

Dr. A. Herranz Surrallés, Maastricht University

Dr. A-L. Högenauer, University of Luxembourg

Prof. dr. M. Shackleton, Maastricht University

Prof. dr. W. Wessels, University of Cologne 


\section{CONTENTS}

LIST OF FIGURES

LIST OF TABLES 10

LIST OF ABBREVIATIONS

$\begin{array}{ll}\text { INTRODUCTION } & 17\end{array}$

$\begin{array}{ll}\text { I. Context of the research question } & 17\end{array}$

II. State of play: review of the literature

on political delegation and advice 28

III. Scope \& Approach: analytical framework

for political advice 41

IV. Theoretical and empirical contributions of the study 44

V. Outline of the study 47

CHAPTER 1. THE CONTEXTUAL SETTING:

EUROPEAN PARLIAMENT STRUCTURES

1.1 The evolution of the European Parliament 52

1.1.1 The powers and position of the EP in an institutional context 53

1.1.2 The conception and consolidation of the EP party group system $\quad 57$

1.1.3 The political power balance within the EP 61

1.2 Key parliamentary structures and actors 66

1.2.1 EP leadership structures 66

1.2.2 The organisation of the party groups $\quad 69$

1.2.3 Parliamentary committees $\quad 72$

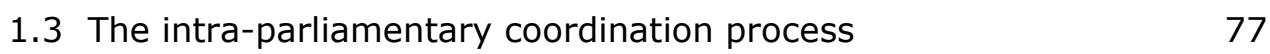

1.3.1 Intra-group coordination: theory and practice 78

1.3.2 Inter-group coordination: theory and practice 84

1.3.3 Inter-institutional coordination: theory and practice 88

1.3.4 Stages of the EP coordination process in legislative procedures 91

$\begin{array}{ll}1.4 \text { Concluding remarks } & 97\end{array}$ 


\section{CHAPTER 2. ANALYTICAL FRAMEWORK:}

\section{THE CONCEPTUALISATION OF POLITICAL ADVICE}

2.1 The definition of political advice

2.1.1 The technical and political dimensions of advice

2.1.2 Political advice: a mixed sphere of activity

2.1.3 Conceptualising the scope of political advice

2.2 Towards a typology: the functions and nature

of political advice

2.2.1 The function and nature of advice

2.2.2 A typology of political advice

2.3 Factors that affect the discretion of the advisor

\subsubsection{Personal factors}

\subsubsection{Contextual factors}

2.4 The analytical framework for political advice 126

2.5 Methodology 127

2.5.1 Mixed methods research $\quad 127$

2.5.2 Qualitative strands: document analysis and interviews $\quad 129$

2.5.3 Quantitative strand: survey design 134

2.5.4 Implementation: mixing the data 136

2.6 Concluding remarks

\section{CHAPTER 3. OPERATIONALISING POLITICAL} ADVICE IN THE EUROPEAN PARLIAMENT

3.1 Sources of internal advice in relation to the framework 144

3.1.1 Principal sources of advice at the disposal of MEPs 145

3.1.2 Academic discussion on advice in the EP 151

3.2 Background and profile of the EP group advisor in relation to the framework

3.2.1 Employment status, criteria and duration $\quad 159$

3.2.2 Educational, professional, and political background 165

3.2.3 Competencies of the EP group advisor 171

3.3 Activities of the EP group advisor

in relation to the framework 
3.3.1 Process management activities

3.3.2 Information management

3.3.3 Policy expertise

3.3.4 Brokering

\section{CHAPTER 4. PROCESS MANAGER}

4.1 The nature of process management in the EP 184

4.1.1 The theoretical dimensions of process management 185

4.1.2 Adoption of the Process Manager Role in practice 188

4.2 Assessment of the political scope of process management 197

4.2.1 Instructions and input from the MEP 198

4.2.2 Improvisation by the advisor 201

4.2.3 Process Management as a category of political advice 206

4.3 Impact of the factors on process management 209

$\begin{array}{ll}\text { 4.3.1 Personal factors } & 210\end{array}$

4.3.2 Contextual factors 216

$\begin{array}{ll}4.4 \text { Concluding remarks } & 221\end{array}$

CHAPTER 5. INFORMATION MANAGER 225

5.1 The nature of information management in the EP 226

5.1.1 The theoretical dimensions of information management 227

5.1.2 The adoption of the Information Manager role in practice 231

5.2 Assessment of the political scope of

information management 242

5.2.1 Instructions and input from the MEP 243

5.2.2 Improvisation by the advisor 246

5.2.3 Information management as a category of political advice $\quad 250$

5.3 Impact of the factors on information management 252

5.3.1 Personal factors 253

$\begin{array}{ll}\text { 5.3.2 Contextual factors } & 259\end{array}$

$\begin{array}{ll}5.4 \text { Concluding remarks } & 264\end{array}$ 
6.1 The nature of policy expertise in the EP 270

6.1.1 The theoretical dimensions of policy expertise 271

6.1.2 The adoption of the Policy Expert role in practice 274

6.2 Assessment of the political scope of policy expertise 281

6.2.1 Instructions and input from the MEP 282

6.2.2 Improvisation by the advisor 285

6.2.3 Policy expertise as a category of political advice $\quad 289$

6.3 Impact of the factors on policy expertise 291

6.3.1 Personal factors 292

6.3.2 Contextual factors 298

$\begin{array}{ll}6.4 \text { Concluding remarks } & 303\end{array}$

CHAPTER 7. BROKER $\quad \mathbf{3 0 7}$

7.1 The nature of brokering in the EP 308

7.1.1 Theoretical dimensions of brokering 309

7.1.2 Adoption of the Broker role in practice 312

7.2 Assessment of the political scope of brokering 322

7.2.1 Instructions and input from the MEP 322

7.2.2 Improvisation by the advisor 327

7.2.3 Brokering as a category of political advice 331

7.3 Impact of the factors on brokering 334

7.3.1 Personal factors $\quad 335$

7.3.2 Contextual factors 341

$\begin{array}{ll}7.4 \text { Concluding remarks } & 346\end{array}$

\section{CHAPTER 8. CONCLUSIONS:}

'UNPACKING' THE POLITICS OF ADVICE 351

8.1 Contribution to theoretical debates:

capturing the technical and political elements of advice 353

8.2 The political scope of the role of advisors 357

8.3 The distinct role of political advisors 364 
8.4 The pro-active behaviour of advisors

8.5 Three orientations of advice: compromise-oriented, policy-oriented, and procedure-oriented

8.6 Future research agenda

8.7 Final remarks

REFERENCES

VALORISATION ADDENDUM

401

NEDERLANDSE SAMENVATTING 409 ACKNOWLEDGEMENTS

APPENDIX I. Document analysis

APPENDIX II. Survey design

APPENDIX III. Survey response 


\section{LIST OF FIGURES}

Figure 1.1.3 Composition of the EP: 1979-2016 64

Figure 1.3a Preparatory stage of intra-parliamentary coordination 93

Figure 1.3b Committee stage of intra-parliamentary coordination 94

Figure 1.3c Inter-institutional negotiations 95

Figure 2.1.2 Mixed sphere of activity 107

Figure 2.1.3 Conceptualising the political scope

of the role of advisors $\quad 110$

Figure 3.2.2 Prior professional experience of group advisors 168

Figure 3.2.3 Most important qualities of group advisors 174

Figure 4.1.1 Theoretical dimensions of process management 188

Figure 4.1.2 Relative importance attached to process

management 189

Figure 4.1.2a Preparation of voting lists 194

Figure 4.2.3 Process management as a category

of political advice 209

Figure 5.1.1 Theoretical dimensions of information

management 231

Figure 5.1.2 Relative importance attached to information

management 233

Figure 5.1.2a Gathering information from external stakeholders 234

Figure 5.1.2b Filtering and analysing information 239

Figure 5.2.3 Information management as a category

of political advice 
Figure 6.1.1 Theoretical dimensions of policy expertise 274

Figure 6.1.2a Policy expertise in a specific area 276

Figure 6.1.2b Relative importance attached to policy expertise 277

Figure 6.1.2c Providing specialist policy advice 278

Figure 6.1.2d Drafting reports, opinions, resolutions, and amendments 280

Figure 6.2.2 Weighing and presenting policy options 286

Figure 6.2.3 Policy expertise as a category of political advice 291

Figure 7.1.1 Theoretical dimensions of brokering 312

Figure 7.1.2 Relative importance attached to brokering 313

$\begin{array}{lll}\text { Figure 7.1.2a Intra-group coordination } & 316\end{array}$

Figure 7.1.2b Inter-group coordination 318

Figure 7.1.2c Negotiating compromises on behalf of the group 319

Figure 7.1.2d Attending shadows' meetings 320

Figure 7.1.2e Participation in technical trilogues 321

Figure 7.3.3 Brokering as a category of political advice 334

$\begin{array}{lll}\text { Figure 8.2 } & \text { Advisors' potential to shape political decisions } & 359\end{array}$ 


\section{LIST OF TABLES}

Table 1.1 Political groups in the EP: 1979-2016 65

Table 1.2.2 Leadership structures of the groups 70

Table 1.2.3 Legislative activity of EP committees 75

Table 1.3 Composition of the EP party groups 84

Table $2.2 \quad$ Typology of political advice 114

Table 2.3 Factors that affect the discretion

of the advisor 125

Table 2.5.2a Initial sample interviewees 132

Table 2.5.2b Final sample interviewees 132

Table 2.5.3 Overview of survey respondents and interviewees 136

Table 2.5.4 Example of factor assessment table 138

Table 3.1.1 Distribution of staff during the EP's $7^{\text {th }}$ legislature 146

Table 3.2.1a Estimation of political group staff distribution 161

Table 3.2.1b Years of employment in current position $\begin{array}{ll}\text { as political advisor } & 164\end{array}$

Table 3.2.2 Highest obtained degrees political advisors 166

Table 4.3.1 Personal factor assessment for the

Process Manager role 216

Table 4.3.2 Contextual factor assessment for the

$\begin{array}{ll}\text { Process Manager role } & 220\end{array}$ 
Table 5.1 Contact frequency external stakeholders 235

Table 5.1a Contact frequency internal actors 237

Table 5.3.1 Personal factor assessment for the Information

Manager role 259

Table 5.3.2 Contextual factor assessment for the Information

Manager role

Table 6.3.1 Personal factor assessment for the Policy

Expert role 298

Table 6.3.2 Contextual factor assessment for the

Information Manager role 302

Table 7.3.1 Personal factor assessment for the Broker role 341

Table 7.3.2 Contextual factor assessment for the Broker role 346

Table 8.5 Political advice: empirical differences regarding

the differences between the EP party groups 


\section{LIST OF ABBREVIATIONS}

\begin{tabular}{|c|c|}
\hline AD & Administrator (type of contract EU civil service) \\
\hline AFCO & Constitutional Affairs \\
\hline AFET & Foreign Affairs \\
\hline AGRI & Agriculture \\
\hline ALDE & Alliance of Liberals and Democrats for Europe Group \\
\hline AST & Assistant (type of contract EU civil service) \\
\hline BA & Bachelor's degree \\
\hline BUDG & Budgets \\
\hline CONT & Budgetary Control \\
\hline CoP & Conference of Presidents \\
\hline CULT & Culture \& Education \\
\hline DEVE & Development \\
\hline DG & Directorate-General \\
\hline DROI & Human Rights (sub-committee) \\
\hline EC & European Commission \\
\hline ECON & Economic \& Monetary Affairs \\
\hline ECR & European Conservatives and Reformists Group \\
\hline ECSC & European Community of Steel and Coal \\
\hline EFD & Europe of Freedom and Democracy Group \\
\hline EFDD & Europe of Freedom and Direct Democracy Group \\
\hline EMPL & Employment \& Social Affairs \\
\hline ENF & Europe of Nations and Freedom Group \\
\hline
\end{tabular}




\begin{tabular}{ll} 
ENVI & Environment, Public Health \& Food Safety \\
EP & European Parliament \\
EPP & Group of the European People's Party \\
EPP-ED & $\begin{array}{l}\text { Group of the European People's Party and European } \\
\text { Democrats }\end{array}$ \\
EPRS & European Parliament Research Service \\
EPSO & European Personnel Selection Office \\
EU & European Union \\
FEMM & Women's Rights \& Gender Equality \\
GUE/NGL & European United Left/ Nordic Green Left Group \\
GREENS/EFA & Greens/ European Free Alliance Group \\
I & Interviewee \\
IND/DEM & Independence/ Democracy Group \\
IMCO & Internal Market \& Consumer Protection \\
INTA & International Trade \\
ITRE & Industry, Research \& Energy \\
JURI & Legal Affairs \\
LIBE & Civil Liberties, Justice \& Home Affairs \\
MA & Master's degree \\
MEP & Member of European Parliament \\
NI & Non-inscrits/ Non-attached members \\
PECH & Fisheries \\
PES & Group of the Party of European Socialists \\
PETI & Petitions \\
\hline
\end{tabular}


PhD Doctor of philosophy

REGI Regional Development

RoP Rules of Procedure

S\&D Socialists and Democrats Group

SEDE Security and Defence (sub-committee)

SQ Survey question

STOA Science and Technology Options Assessment

SR Survey respondent

TEU Treaty on the European Union

TFEU Treaty on the functioning of the European Union

TRAN Transport \& Tourism 




\section{INTRODUCTION}

This dissertation aims to improve our understanding of the preparation of political decisions, and the role of advice in decision-making processes, in the context of the European Union (EU). Generally, such practices remain undocumented and take place outside of public and political scrutiny. Yet, they form the groundwork for compromises. A deeper and more nuanced awareness of the informal stages of decision-making is therefore necessary to appreciate political negotiation and compromise-building. It is preeminently within these preparatory stages that advice is offered to politicians. The study focuses on the EU context and examines in-house political advice in the European Parliament (EP). This introduction contextualises the research question (I), reviews the relevant existing literature (II), discusses the scope and approach of the study (III), and proposes the potential theoretical and empirical contributions of the dissertation (IV).

\section{Context of the research question}

\section{The contextualisation of the politics of advice}

What is the role of advice in legislative decision-making processes? That is the broad topic that this dissertation deals with. How legislators are advised is part of a wider phenomenon that has remained rather eclipsed in the academic debate (Pegan, 2015). In shaping their views and decisions, politicians rely on (expert) advice that is presented to them in many shapes and forms. This assumption stems from the broadly accepted notion that elected actors simply do not have the time or the knowledge to master all issues in detail (e.g. Arnold, 1987; Hammond, 1984 and 1996). But is the advisor a Rasputin who calls the shots behind the scenes and pursues his 
or her own agenda, or merely a puppet that carries out the instructions of the politician?

The question how political decisions come about is not new. A substantial body of literature addresses the input by staff in the context of the US Congress, and more recently, the role of officials in other legislatures has also been explored. Scholars who address the issues tend to focus on exploring what drives the behaviour of actors and how elected actors (can) control the behaviour of non-elected actors (Hammond, 1984 and 1996; Arnold, 1987; Patterson, 1970; Moe, 2005; Olson, 2006; Page and Jenkins, 2005; and Gailmard and Patty, 2012). Although interpretations are abundant, political delegation is generally explained through efficiency reasons and a required degree of continuity in policy-making (Peters, 2009). The implications of what then constitutes delegation, and how it plays out in practice, vary significantly.

This study draws on the evidence provided by the existing literature that advice to legislators potentially has political implications (Fouilleux et al, 2005; Winzen, 2011; Dobbels and Neuhold, 2013; Neuhold and Dobbels, 2014; and Högenauer and Neuhold, 2015). A (potential) political dimension of advice raises important questions about the legitimacy of decisionmaking. Advisors operate in the 'background' (Wodak, 2009). As said above, their activities have been subject of debate since the 1980s. Further on in this introduction, a general review of the literature is included, discussing political delegation and the role of advice in various institutional settings. In the case of the European Union (EU), however, the issue of accountability is particularly sensitive with widespread critique of a 'democratic deficit' (Smismans, 2013; Kohler-Koch and Rittberger, 2007). As a supranational polity, the EU faces several democratic 'challenges' in relation to transparency and popular support (Ripoll Servent, 2018; Burns, 2013; Héritier, 2003). The empowerment of both the EP and national 
parliaments in EU decision-making was the response to this critique (see Rittberger, 2003 regarding the EP; and Christiansen et al, 2014 regarding national parliaments).

Relevant to the context of this study is that the role of 'back-stage' advisors has given rise to a normative debate regarding their influence or capacity to have an impact on EU policymaking (e.g. Neunreither, 2002; Christiansen, 2002; Dobbels and Neuhold, 2013; Neuhold and Dobbels, 2014; and Winzen, 2011 and 2014). A policy-shaping role by non-elected experts raises concerns for legitimacy prompted by the fact that their actions are secluded from scrutiny and public oversight (see e.g. Radaelli, 1999). This study sets out to contribute to a broader understanding of the politics of advice. Uncovering the role of advisors in the preparation of decisions and their day-to-day activities is instrumental for both the empirical and normative assessment of the political implications of their actions.

The role of advice pre-eminently manifests itself during the informal, preparatory stage of decision-making. During this process political positions and decisions are prepared outside of the formal structures of a legislative institution, thus outside of public and political scrutiny. These practices remain relatively unchartered territory, yet, are essential to explaining how decisions come about. The dissertation tries to fill that gap and shed light on the informal preparation of decision-making. To that end, it addresses questions like what defines and guides political advice, and what circumstances may enable or restrict advice.

In this respect, the dissertation makes three key contributions. First, the analytical framework developed in chapter 2 conceptualises a 'political' role of advice as part of informal decision-making. In this way, the framework contributes to theory building within the scope of legislative organisation 
and informal governance. Second, the empirical analysis regarding the provision of political advice in the EP increases our knowledge of the informal stages of decision-making. It is in the informal arena that the groundwork for compromises is laid down (Reh, 2012). A deeper and more nuanced awareness of the activities that support decision-makers contributes to an enhanced appreciation of political negotiation and compromise-building dynamics. Third, the findings offer novel insights that may evolve the normative assessment of the legitimacy of (informal) EU decision-making.

Gaining a better understanding of the politics of advice is increasingly significant against the backdrop of a changing public policy landscape. The advent of post-factual politics and the emergence of populist right-wing parties as mainstream have created a crisis of trust (Brack and Startin, 2015). Under the banner of 'alternative facts', the fading trust in expertise or objective knowledge substitutes rational proof with emotional appeals (Barbieri, 2018). This development is illustrated by the election of President Trump in the United States, the Brexit vote in the UK, Russian propaganda, and the electoral success of populist movements across Europe (Barbieri, 2018). These examples furthermore demonstrate a deteriorating sense of trust in the political establishment and a rise of anti-EU sentiments. In the context of the EU the decline is explained as a result from the economic, financial, and migration crises (Brack and Startin, 2015). These developments on the one hand raise the importance of the legitimacy of advice. On the other hand, internal resources that cater to the politician's information needs become ever more important for the navigation through a complex arena. The latter is illustrative of the trade-off between efficiency and legitimacy that characterises EU decision-making, as discussed below. 


\section{EU informal decision-making: a trade-off between efficiency and legitimacy?}

As the EU gained more competences, the extent to which EU decisionmaking can be considered democratic and legitimate became an important issue of discussion (Smismans, 2013; Bovens et al, 2010; Kohler-Koch and Rittberger, 2007). The so-called 'democratic deficit' relates to the transfer of powers from the national to the supranational level without appropriate democratic control. Not uncommon to multi-level governance systems, it often remains unclear who should be held responsible for what decisions. The complexity, informality, and consensus-oriented nature of EU decisionmaking not only hampers the identification of decision-makers and policy alternatives, but also falls short of a political forum that articulates the arguments in favour or against given policy choices (Brack and Costa, 2018; Christiansen and Neuhold, 2013; Reh, 2012, 2014; Heisenberg, 2005). These features of the EU system negatively affect the understanding and support of the public and aggravate the perception of backroom deals. The various treaty changes reflect the attempts to address these issues. A key solution that is envisioned lies in the gradual institutionalisation of the principles of a representative democracy (Rittberger, 2012). Since the inception of the EP, therefore, calls have been made to empower the institution (Rittberger, 2014). Not in the least, the EP itself has engaged in such appeals (Ripoll Servent, 2018; Burns, 2013).

With each new treaty the EP's legislative and supervisory powers have been strengthened (Rittberger, 2012). This gradual extension culminated in the Lisbon Treaty (2009) that designates co-decision between the Council of Ministers and the EP as the 'Ordinary Legislative Procedure' (Corbett et al, 2011: 5). The evolution of the EP's legislative powers turned the EU political system into a bicameral legislature (Bressanelli et al, 2016; Rasmussen, 2011). The widened scope of co-decision has extended the dialogue 
between the three institutions through 'trilogue meetings' to now cover virtually all policy domains. The European Commission (EC) represents the supranational interest and puts forward proposals for EU policy or legislatives initiatives. The Parliament and the Council constitute the legislative bodies, respectively representing the voice of the people and the national governments (Corbett et al, 2011: 4-7).

The intensified inter-institutional interaction has increased the informal dimension of decision-making. This is illustrated by the upward trend of socalled 'early agreements' (Ripoll-Servent, 2018). The possibility for the colegislators to 'fast track' the legislative procedure and come to an agreement in first reading was introduced in the Amsterdam Treaty (1999). In the $7^{\text {th }}$ Parliamentary term (1999-2014) 85 per cent of legislative files were concluded at first reading (EPRS, 2016). This move towards a secluded form of decision-making in which only a restricted number of actors are involved has given rise to an academic debate that does not paint a very positive outlook for the EP (Farrell and Héritier, 2004; Häge and Kæding, 2007; Héritier and Reh, 2012; Häge and Naurin, 2013; Bressanelli et al, 2016). With co-decision becoming the Ordinary Legislative Procedure, efficiency became a 'coping strategy' to deal with the increased, complex workload (Reh, 2012). Informal agreements are positively assessed for their problem-solving capacity. Decision-making through trilogues is said to reduce transaction costs and speed up the process (Reh, 2012). However, it appears to have come with a democratic cost (Farrell and Héritier, 2003, 2004; Rasmussen and Reh, 2013). The negotiations behind closed doors undermine transparency, accountability, and open debate (Reh, 2012; Burns, 2013; Christiansen and Neuhold, 2013; Brack and Costa, 2018). Due to the informal and secluded nature, the bargaining process is largely untraceable to the wider public. It thus not only affects public scrutiny, it also dilutes political contestation and public-opinion formation as policy choices remain unclear (Reh, 2012). For the EP, having predicated its calls 
for empowerment upon its status as a democratically elected body, the repercussions of informal decision-making practices are particularly tenuous (Burns, 2013; Ripoll Servent, 2018; Brack and Costa, 2018). Although heralded as a means to strengthen democratic legitimacy (Burns, 2013), the increase in powers has not been matched with strengthened (popular) legitimacy as the turnout in EU elections continues to drop (Brack and Costa, 2018). Moreover, the loss of transparency corrodes the practice of open decision-making that the institution proclaims.

When it comes to the normative assessment of informal governance, the evolution of the EP renders a mixed picture. On the one hand, the empowerment of the institution, finally formalised through treaty reform, is a product of 'unwritten rules' (Shackleton, 2000). Through its internal Rules of Procedure, the EP has managed to formalise informal practices that enhance both the efficiency and democratic accountability of EU decisionmaking (Ripoll-Servent, 2018). Kleine (2013) has provided a systematic analysis of the parallel development of formal rules and informal norms in the EU. She concludes that the combination reduces the EU'S democratic deficit because it allows negotiators to take on board those interests that are specifically relevant to, or affected by, the decisions they have to make.

On the other hand, the ensuing trend of early agreements is considered questionable from a democratic governance perspective. While previous studies in relation to 'early agreement' have concentrated on the democratic consequences and power shifts within and between the institutions, we still know little about the intra-organisational preparations of the interinstitutional negotiations. Roederer-Rynning and Greenwood (2015) made an important contribution in this respect. In their article, they disentangled the various informal processes that up until then were grouped under the general banner of 'trilogues'. The scholars identify three layers of trilogues, i.e. political, technical, and bilateral preparations. Their 'technical' layer 
suggests representation at staff level in the pre-negotiations, which can also be derived from the EP Rules of Procedure. The Code of Conduct that was adopted in 2008 as a way to 'formalise', or at least structure, the institution's participation in trilogues, stipulates that all party groups shall be represented in these negotiations, 'at least at staff level'. Moreover, it refers to an 'administrative support team'. This suggests the involvement of EP staff in the negotiations.

The academic awareness of the importance of the informal dimension of politics is increasing (Christiansen and Neuhold, 2013; Kleine, 2013). In the literature on EU governance, several studies have addressed the role of staff in decision-making (Christiansen, 2002; Neunreither, 2002; Winzen, 2011; Egeberg et al, 2013; Busby, 2013; Dobbels and Neuhold, 2013; Neuhold and Dobbels, 2014; Michon, 2014; Pegan, 2015). In these discussions, the study of political advisors so far has only received marginal scholarly consideration. The developments put forward above raise the value of such advice. Moreover, the trend towards informal decision-making elevates the importance of understanding the intra-institutional preparatory dynamics. With that in mind, this dissertation aims to unravel the backstage preparation of decisions by examining advice provided to Members of the European Parliament (MEPs) through a conceptual, empirical, and normative lens.

\section{Unravelling political advice in the context of the European}

\section{Parliament}

The dissertation sets out to examine the politics of advice in the context of the EP by addressing the question whether and under which conditions group advisors can assume a political role. Group advisors are hired to serve and contribute to the ideological priorities and objectives of a political party. As such, they constitute a distinct type of actor that is also encountered in 
national parliaments and that, up until now, has only received marginal scholarly attention. The EP is deemed a particularly suitable setting for the study of the politics of advice for several reasons, briefly set out below.

First of all, the nature of the institution and its position in the EU political system amount to a consensual style of decision-making characterised by intensive intra-parliamentary coordination. The EP comprises elected representatives from the 28 Member States emanating from over 200 national political parties. This fact alone illustrates that EP decision-making is an intricate balancing act. Since the European Union does not have a government-opposition structure, no systematic support or stable coalitions emerge from Parliament. Instead, coalitions are struck on a case-by-case basis and each vote in Parliament requires a new quest for a majority. Moreover, the party groups do not rest on a collective electoral mandate, which further motivates the common practice to seek widespread agreement (Corbett et al, 2011). The process of compromise building between the EP party groups takes place prior to the actual negotiations and decision-making. Gaining insight into the informal dynamics within and between the groups is essential for the understanding of how decisions at EU level come about.

The legislative empowerment of the EP and ensuing trend of so-called early agreements make intra-parliamentary political coordination ever more crucial (EPRS, 2016). Not only does the expanded workload mean that there simply is more to coordinate, the EP's negotiation position vis-à-vis the Council hinges on the extent to which a unified position is reached. The augmented inter-institutional dialogue on the one hand politicises EU decision-making while at the same time it causes concern for a secluded form of decision-making in which only a small fraction of MEPs is closely involved (Bressanelli et al, 2016; Brandsma, 2015; Rasmussen et al, 2013; Reh et al, 2013; Héritier and Reh, 2012; Judge and Earnshaw, 2011; Farrell 
and Héritier, 2004; Häge and Kæding, 2007). These developments illustrate the need and urgency for extensive intra-parliamentary coordination, which is further considered in chapter 1.

The significance of disclosing informal intra-parliamentary mechanisms can also be viewed in light of the current renewed EU integration efforts. In the aftermath of the Brexit vote and in view of economic recovery, there seems to be momentum for a sense of optimism (Eichengreen, 2018). In March 2017, the EC published a vision for the future setting out five scenarios for the EU by 2025. The scenarios range from maintaining the status quo (scenario 1) to a significant increase in integration (scenario 5). In the face of internal and external challenges, the Commission calls upon the leaders of the 27 Members States - thus excluding the United Kingdom - to decide on the way forward in a spirit of solidarity (European Commission, 2017a). The renewed optimism notably resonated in the State of the Union address, delivered by EC President Juncker to the EP on 13 September 2017. He claimed that 'the wind is back in Europe's sails' producing a renewed capacity for the bloc to face its many challenges (European Commission, 2017b). The process of redefining the Union's direction (further) politicises the EU governance debate and with that the role of the EC. Such politicisation has the potential to (further) increase the value of the EP party groups as vehicles of political contestation (Marks and Steenbergen, 2004).

Since its inception, the EP has evolved significantly in terms of political authority, legislative powers, and hence in workload and internal organisation (Corbett et al, 2011: 3). In recent years, it has devoted particular attention to developing its in-house resources to deal with its changing role and to increase the overall transparency of EP decisionmaking (EPRS, 2017). An important explanation for the seemingly strong reliance on internal resources in relation to policy advice lies in safeguarding the institution's independence from the executive (Ringe, 2010; Dobbels 
and Neuhold, 2014). In this regard, the formation of the European Parliament Research Service (EPRS) was aimed at strengthening the internal policy support structures (EP Secretary General, 2013). In the context of a cumulative extension of the legislative powers of the EP, scholars turned to exploring its internal organisation and structures (e.g. Hix and Lord, 1997; Kreppel, 2002; Héritier and Reh, 2012; Ripoll Servent, 2012). Discussions for example reflect on MEP voting patterns (Hix and Noury, 2009) and political cleavages between the party groups (Hix et al, 2007). Driven by the need for efficiency and coordination, the growing impact on legislative outcomes augmented the role of the EP party groups (Raunio, 1999; Kreppel and Tsebelis, 1999). In the early 2000s we therefore see academic consideration shifting from the national political parties to the transnational party groups as central actors in the EP organisation (Hix et al, 2007). Examinations of the workings of the EP administration considered the form of legislative assistance (Neunreither, 2002; Pegan, 2015) and the role of parliamentary committees (Neuhold, 2001; Neuhold and Settembri, 2007; Yordanova, 2013).

This study construes political advice as advice offered to politicians by nonelected actors. In the context of the EP various internal and external sources of such advice are conceivable. The focus on internal mechanisms and thus on internal political advice is motivated through the expectation that EP staff act as gatekeepers for information from the outside world (cf. Busby, 2013; Corbett et al, 2016). In the preparation of legislation and policy, MEPs rely on three major internal sources of advice (Neunreither, 2002; Egeberg et al, 2013; Busby, 2013, Pegan, 2015; Corbett et al, 2016; Ripoll Servent, 2018):

(i) The EP General Secretariat

(ii) The group secretariats

(iii) Their personal assistants 
Chapter 3 of the dissertation provides a more in-depth discussion of these sources of political advice (see 3.1.1). Yet, to highlight the distinct role of group advisors it is important to note the following findings here. Neunreither (2002) found that they have a specific intermediary role to play. The EP General Secretariat, on the one hand, constitutes the 'independent non-partisan service' and acts in the general interest of the institution. MEPs' personal assistants, on the other hand, look out for the specific interests of MEPs. Egeberg and colleagues (2013) conclude that group advisors are more likely to facilitate compromises within the EP than other supporting staff. Moreover, EP party groups are at the heart of majority-building processes and considered the pivotal centres of influence (Corbett et al, 2011; Hix et al, 2007). The internal organisation and division of labour is structured around the groups. By extension, group advisors' involvement in intra-parliamentary coordination mechanisms is expected to be substantial.

Although studies have identified group advisors and MEP assistants as the political sources MEPs turn to for support, the political dimension of such support calls for further conceptualisation. In addition to exploring the contribution of political advice to the preparation of decisions, the research aim is to examine the discretion and room for improvisation that advisors have, and the circumstances at play that enable or restrict their role. Before elaborating on the approach and scope of the study a review is presented of the literature that considers the relationship between elected and nonelected actors, and the function and nature of advice.

\section{State of play: review of the literature on political delegation and advice}

To address the research question the dissertation develops an analytical framework in chapter 2 . The concepts that are defined in the framework 
draw and build on the scholarly debate on political delegation and the role of non-elected actors. As part of this introduction, therefore, a general discussion of this literature is presented below.

Delegation and bureaucratic control have been recurring themes in the political sciences and public administration literature. The notion that politicians rely on advice stems from the unequivocal reality that they lack the time and knowledge to master all issues in detail (see e.g. Arnold, 1987). Already in the 1970s the significance of the contribution of officials is recognised among scholars, as Hammond's review of the literature on legislative staff in the US Congress demonstrates (1984 and 1996). Officials do more than simply process information and are designated as 'important intervening variables in the legislative process' (Hammond, 1984).

From the discussion, it can be inferred that delegation is generally tied to the information needs of legislators and motivated through a lack of resources, notably time and expertise. Both aspects are addressed in further detail below. First, the academic debate on the relationship between elected and non-elected actors is reviewed. Next, the function and nature of advice are considered in relation to legislators' need for information and expertise.

\section{The relationship between elected and non-elected actors}

A traditional rationalist premise that follows from delegation is the notion that political actors try to control or monitor the actions and behaviour of their non-elected advisors (e.g. Arnold, 1987; Moe, 2005). However, in practice time limits prevent politicians from closely watching officials' every move (e.g. Arnold, 1987). Closely related, a large body of literature discusses what drives actors, setting out to theorise and compare the motivations and 'preferences' of the politician versus those of the official 
(principal-agent theory). A third important element of the context of delegation lies in what is thought acceptable in the eyes of the elected politician and his or her electorate. In sum, academic studies on the relationship between elected and non-elected actors discern questions or concerns around accountability, preferences, and control. Each of these approaches to delegation is briefly reviewed below.

In the study of public administration and accountability Max Weber's analysis of bureaucratic organisation is generally taken as the starting point. In the Weberian model bureaucratic design ensures equal treatment of citizens and administration of records (Weber in: Peters 2009). Moreover, the civil service is theorised to be stable and predictable whereas politicians come and go. In line with this view, delegation theory first of all justifies the position of officials in public administration for efficiency reasons. Furthermore, the bureaucracy is said to ensure a certain degree of continuity and therefore reduce arbitrariness in policy-making.

Rational-choice theory studies the strategic interaction between individuals and gives predictions about their behaviour. Actors' preferences and objectives are perceived as fixed and the ultimate goal is to maximise or optimise one's own interests (Hague and Harrop, 2010). Rationalist scholars discussing the principal-agent relationship build on the assumption that both actors have and act according to a set of 'fixed, exogenous, and commonly known ideal outcomes' (e.g. Gailmard and Patty, 2012). Principals grant more discretion to agents whose 'ideal outcomes' lie close to or converge with their own, which basically means that politicians' objective is to ensure that 'administrative decisions' remain as close as possible to their own values and ideas (Arnold, 1987). The sociological institutionalist logic of appropriateness rejects such rationalist assumptions and argues instead that actors have multiple and endogenous preferences. They rely on socially constructed roles and institutional rules and ask what 
the appropriate course of action is in a given situation. Following this school of thought, political tasks are delegated not as a result of functional logic (or 'consequentialism'), but rather because it is widely accepted as legitimate or appropriate (Hague and Harrop, 2010).

Principal-agent theory is aimed at explaining how politicians exercise control over the behaviour of their supporting staff. Information is considered a source of 'bureaucratic power' and studies set out to examine how political principals can overcome the 'information asymmetry' (Arnold, 1987; Moe, 2005; and Gailmard and Patty, 2012). From a more optimistic perspective, information is approached as a service that officials provide and on which politicians rely (Hammond, 1984 and 1996). In this view, officials contribute to the efficiency and legislative capacity of Parliament, which as an independent institution cannot rely on the executive for information and expertise. From the rationalist line of reasoning that builds on Weber's ideal-type bureaucracy in which behaviour is determined by utility, the issue of who is in control leads to a continuous struggle between politicians and their technical experts. In contrast, emulating the institutionalist logic of appropriateness, Olsen (2006) argues that public administration should not only be assessed as the 'rational tool' for executing politicians' instructions. Instead, he argues that 'codes of appropriate behaviour' guide actions and that public servants are expected to use their expertise and experience in the performance of their tasks. Along similar lines, Page and Jenkins (2005) argue that UK ministry officials pro-actively seek political control ('invited authority'). The scholars reject Weber's definition of a bureaucracy characterised by a strict hierarchical organisation and determined by structures and rules. Alternatively, their claim is that officials anticipate the preferred line of action ('cue-taking'). In his discussion of the role of staff in Congressional committees, Patterson (1970) correspondingly upholds that to be effective officials must learn to predict the reactions of the committee chair. 
In sum, the academic debate on the influence of officials appears to concentrate on (questioning) the control and authority of elected actors with limited attention for the potential positive effects of political delegation. First, discussions tend to emphasise officials' influence on outcomes rather than their contribution to the process leading up to a decision. Moreover, there appears to be an overall perceived competition for power where the increased influence of officials implies a decreased influence of politicians. Consequently, legislative organisation studies generally take a defensive stance in legitimising the role of staff through the resources they provide, i.e. tying their contribution to informational advantages, problem-solving capacities, increased efficiency, and secured continuity and stability (Hammond, 1984 and 1996). In the discussion so far there has been little consideration for the idea that influential officials might strengthen the position of the legislator and vice versa. This study proposes that political advice does not amount to a power struggle. Instead, the relationship between the advisor and the politician is construed to be of an interdependent nature, where advisors' role is linked to the position (reputation or authority) of the politician they represent. In reverse, they can reinforce the position of the politician by providing tailored information or expertise.

The reviewed literature on the relationship between elected and non-elected actors offers useful insights into the context of political delegation. Legislators' prevailing needs for expertise or information are found to determine the role of advisors. How this affects the function and nature of advice is addressed below. Previous studies have shown that officials anticipate priorities and preferences of the politician and base their actions on these insights (Patterson, 1970; Page and Jenkins, 2005; Olsen, 2006). The anticipation logic theorises that advisors construct their role according to what the circumstances demand. It is therefore expected that multiple (political) roles exist and that the adoption of a given role depends on 
several personal and contextual factors. The institutionalist theory regarding role construction and adoption thus allows for the investigation of how advisors deal with delegated political responsibilities and what factors may play a role in this process. The rationalist approach is more limited in that sense and concentrates on individual (fixed) interests and outcomes while paying less attention to the process of achieving such outcomes. Not only would it be hard to verify individual interests or preferences, studying the informal process of role construction and adoption allows for comparison of various institutional settings, or of different political processes within the same institution.

\section{The function and nature of advice}

According to the logic of appropriateness theory, actors choose their role based on what specific situations may require (Busby, 2013: 99). Drawing on the assumption that the activities of officials are determined by politicians' information needs, a clearer understanding and categorisation of these needs is necessary to explore the (multiple) role(s) from which advisors can choose. Policy advice is provided in different institutional settings. The following literature review defines the state of play that this dissertation builds on. The discussion entails studies that set out to understand the role of officials at the executive level (Page and Jenkins, 2005; Peters, 2009), in the US Congress (Patterson, 1970; Price, 1971; Fox and Hammond, 1977; Burks and Cole, 1978; Hammond, 1984 and 1996;), in EU Member State parliaments (Blischke, 1981; Campbell and Laporte, 1981; Ryle, 1981; Winzen, 2014; and Högenauer and Neuhold, 2015); in the Council of Ministers (Christiansen, 2002; Tallberg, 2004; Fouilleux et al, 2005), and in the EP (Provan in: Neunreither, 2002; Winzen, 2011; Dobbels and Neuhold, 2013; Busby, 2013; Neuhold and Dobbels, 2014). 
Peters (2009) categorises the activities of civil servants at the executive level into five roles from which officials given the circumstances select the appropriate response. The 'Bureaucrat' simply implements policies or instructions in a loyal and predictable manner. The 'Manager' focuses on efficiency and providing direction to others. The 'Policy-Maker' role relates to officials' involvement in policy-making by giving advice to their political superiors. Here Peters notes that public servants have considerable discretion to the extent that it has spurred bureaucratic control. The 'Negotiator' is a mediating role through which officials build and maintain relationships with the public sector and form the linking pin between decentralised and central processes. In negotiating and managing these relationships they are a stable point of contact to third parties. Finally, the 'Democrat' role is linked to (increasing) public participation and implies the official being aware and in touch with the broader interests at stake.

Page and Jenkins (2005) made an important contribution to the mapping of the types of activities officials engage in with their examination of what officials working in UK ministries actually do and how they do it. They describe 'bureaucrats' as generalists overviewing the whole process of policy and decision-making and categorise 'policy work' by the type of activity. These activities range from drafting documents (production role), managing the implementation of policies (maintenance role), to offering advice in terms of knowledge and skills to the policy makers (service role). The scholars argue that each role involves different 'decisions' and that officials choose to adopt a role on the basis of 'improvised expertise' and 'invited authority', stressing the informality of the organisational structure. According to this view expertise is not 'subject-based' or 'technical'. Civil servants are generalists and possess a set of 'transferable skills'. They are experts in signalling and recognising political and administrative cues to anticipate ministerial intent. 
The (large) body of literature discussing the position and influence of officials in the US Congress offers valuable insights as to how academia has been approaching the topic over the past decades (e.g. Patterson, 1970; Price, 1971; Fox and Hammond, 1977; Burks and Cole, 1978; Hammond, 1984 and 1996). Although not directly employed by the Republican or Democratic Parties, Congressional staff members are known to generally hold strong political affiliation and directly answer to Congress members (European Parliament, 2000). Because expertise has to be independent from the Executive, a range of Congressional offices provides expertise throughout the pre-legislative, legislative, and oversight cycles. Among these are the 'Research Service' that provides policy-oriented briefings to the members; the 'Office of the Legislative Counsel' that can support in the drafting of proposed legislation; and the 'Office of the Parliamentarian' that provides advice on parliamentary rules and procedures (European Parliament, 2000).

Hammond's review of the literature on legislative staff in Congress (1984 and 1996) concludes that legislators need to be informed and maintain an independent position from the executive. As their workload increases, so does the need for advice and assistance. At the end of the 1970s and throughout the 1980s, research on legislative staff shifted towards the analysis of staff influence and their role in the legislative process. Hammond explores various typologies regarding the role of staff in the US Congress. An important contribution to this body of literature is Patterson's discussion of the role of staff in Congressional committees (Hammond, 1984). Based on a set of interviews, he categorises the contribution of 'professional staff' according to four 'capabilities': (1) Intelligence - professional staff takes care of the processing and distribution of information; (2) integration close collaboration and interplay at staff level contributes to intrainstitutional as well as inter-institutional integration, avoiding that certain committees, chambers or institutions work in isolation; (3) innovation - 
officials have the opportunity to initiate policy or to help shape policy; and (4) influence - officials are influential because they gather and analyse information upon which policy is based, organise public hearings, and draft legislation (Patterson, 1970). According to Patterson, intelligence is the central element of their role. Although officials are well aware of their delegated influence, they realise that they need to work within the general guidance of the politician in charge.

Price (1971) builds on Patterson's 'innovation capability' and distinguishes three staff orientations: (1) 'Pure policy entrepreneurs' are construed as partisan officials who actively go in search of opportunities to take initiative; (2) 'professionals' are understood to be non-partisan, neutral and reactive officials who analyse and present policy alternatives; and (3) 'mixed' officials can still push for proposals but have less room for manoeuvre. Burks and Cole (1978) further explore the 'entrepreneur-professional' role orientations in congressional policy-making. By way of a survey probing officials' perception of their role, the authors conclude that a mixture of the two types prevails and that officials perceive themselves particularly influential in organising 'floor support' for committee legislation (Burks and Cole in: Hammond, 1984). Drawing from a survey among US Senate staff, Fox and Hammond (1977) identify a range of 'activity patterns' that they find to be 'typical staff positions' for the US Congress. These categories include 'Interactors' who meet with lobbyists or interest groups and 'Supporters' who are responsible for legislative research and drafting speeches (Fox and Hammond, 1977).

The literature discussing EU Member States' parliamentary staff is limited, overall descriptive and generally focuses on how members of parliament are provided with information independent from government. It does, however, offer some insights into common activities and confirm the presence of 'political advisors' in these parliaments (e.g. Blischke, 1981; 
Campbell and Laporte, 1981; and Ryle, 1981 who respectively discuss legislative staff in the German Bundestag, French Assemblée Nationale, and the British House of Commons). In EU national parliaments, officials are subdivided into research staff and committee staff (European Parliament, 2000). The first group is organised thematically and prepares studies that 'do not contain any political value judgements' (Blischke, 1981). In the Bundestag administration, committee staff is responsible for organising the committee meetings and providing members of parliament with information regarding the issues under discussion. These officials hold a 'double status' in the sense that they are (neutral) civil servants while at the same time they are assigned to a committee chair. In the UK, the principal roles of parliamentary officials are to provide 'advice on parliamentary procedure', 'administrative services', and 'research' (Ryle, 1981). In France the role of committee staff is to assist rapporteurs in their examination of legislative proposals. The administration of national parliaments is typically nonpartisan and their role is expected to be neutral (Campbell and Laporte, 1981).

Different, however, is the role of personal assistants and political party staff members. Members of parliament traditionally have personal assistants who share the same political orientation. In addition, political parties employ their own staff. A study by the EP on organisational and administrative arrangements in EU national parliaments (2000) reports the practice of political group staff in Finland, France, Germany, Greece, The Netherlands, Portugal, Spain, Sweden, and the UK. Staff members are recruited by the political groups and assist group members in their daily 'political work'. The party secretariats are usually financed by annual contributions from Parliament and assigned office space. In the German Bundestag, party officials either assist a member of the party leadership or are 'subject specialists' attached to one working group. According to Blischke (1981), they provide 'personal', 'substantive', and 'political' 
advice', categories which are not particularised in the article. Parliamentary party officials are expected to take initiative and have considerable discretion in the preparation of motions, interpellations and questions to the federal government. As part of their 'political task' they cooperate with the extra-parliamentary party organisation. Political parties in the House of Commons also have a small staff, consisting of research staff, administrators, and secretaries (Ryle, 1981). For opposition parties, these services are financed by annual grants. The EP report provides no information as to staff working for political groups in Italy and Luxembourg and indicates that Irish political parties do not employ their own staff (European Parliament, 2000).

Högenauer and Neuhold (2015) raise the question of the extent to which parliamentary administrations play an active part in the scrutiny of EU affairs with a particular emphasis on whether their tasks are purely 'technical' or have the potential to shape the actual outcome. From the literature on delegation and administrative roles and from their data gathered through interviews, the scholars develop five ideal-typical roles. The 'Administrative Assistant' simply gathers and forwards (summarised) information. The 'Analyst' offers legal and procedural advice. The 'Advisor' provides content-related advice and interpretation. Both the 'Analyst' and the 'Advisor' can draft documents. The distinction between the two roles is tied to whether the drafting takes place based on the debate (Analyst) or if the document concerns information presented before a debate (Advisor). The latter evidently offers more room to 'steer' the political discussion. The fourth role of 'Agenda Shaper' involves the pre-selection of information. And finally, the 'Coordinator' role relates to a liaison or mediation function with other institutions.

In the EU governance context, we find legislative staff in the Council of Ministers and in the EP. In the context of a study probing the role of 
'unelected legislators', Christiansen (2002) finds that Council secretariat officials can play an important mediating function in the search for compromise between member states. Cooperation and the exchange of information between the Council secretariat and Commission officials facilitate the process. In an advising capacity (to the Council Presidency), they are in a good position to mediate different positions taken by the national delegations.

Drawing from general bargaining theory and rational choice institutionalism, Tallberg (2004) presents a theory of the demand for, and supply of, brokerage by the chair to explain the influence of the Council Presidency. He claims that the involvement of a third party - a broker - is the functional solution to the amplified 'bargaining problem' that follows from the multilateral setting where the exchange of preferences between a large number of actors is complex. Brokerage by the Presidency is facilitated by the Council Secretariat's expertise, which he describes as a 'set of informational and procedural resources'.

Fouilleux and colleagues (2005) examine the interaction of national civil servants and ministers in Council working groups - the arenas in which negotiations on draft legislation take place and 'sites for inter-member state, inter-institutional and ideological mediation'. They find that officials in working groups can negotiate compromises that form the basis of Council decisions.

In the context of the EP, Winzen (2011) points to the efficiency problems of EU decision-making, showing parliamentarians need administrative capacity to deal with the 'information overload'. Similarly, Busby (2013) argues MEP assistants act as an 'information interface', filtering information and liaising with other stakeholders. Winzen (2011) contends parliamentary officials in the EP committee secretariats contribute to the shaping of 'the 
information foundation' of EP positions and identifies two types of activities in which EP officials are involved. First, 'Process Managers' referring to officials' role of managing the policy process, structuring the agenda and organising meetings. Second, 'Informants' relays to the function of providing information and expertise regarding the substantive content of policy proposals. Political aspects of their activities include the pre-selection of relevant issues and actor involvement.

Dobbels and Neuhold (2013) build on Page and Jenkins' categorisation of a production, maintenance, and service role. To explore the role of EP officials in the committee secretariats, they add a fourth 'steering' or 'policy-making' role that goes beyond the production or service roles in the sense that officials can perform policy-shaping tasks. For example, they argue, in policy areas where MEPs have not yet built up a certain amount of expertise or where the political stake might be lower than in other policy areas.

In a proposal to reform legislative assistance in the EP, then EP VicePresident James Provan distinguishes between political and administrative roles, categorising the assistance as follows: (1) 'technical-administrative' assistance, including organisational support for meetings; (2) 'technicalsubstantive' assistance, such as advice on procedures, legal issues, and document drafting; (3) 'research' assistance, e.g. background information, impact assessment; and (4) 'political' assistance, referring to policy definitions, political coordination within the political group, with other groups, national delegation, party constituency, and suchlike (Provan in: Neunreither, 2002).

The review confirms that the officials' input into the legislative process can take various forms. Previous studies have shown that officials can perform tasks that go beyond the technical or administrative sphere of activity in the US Congress (Hammond, 1984 and 1996), in the Council of Ministers 
(Christiansen, 2002), in the EP (Dobbels and Neuhold, 2013; Neuhold and Dobbels, 2014), and in the case of EU Member State parliaments (Winzen, 2014; and Högenauer and Neuhold, 2015). Yet, for the study of political advice several issues call for additional consideration. First, the analytical delineation of what is construed as overtly 'technical' or 'political' requires further examination in order to come up with a definition of what exactly characterises 'political advice'. Second, some of the categories appear to unite several activities in one 'role'. For example, Provan's category 'political assistance' entails the formulation of policy definitions as well as the coordination of political positions. Although these activities both entail political elements, they are likely to require very different things from the advisor. Winzen's 'Informant' comprises the processing of information as well as the provision of substance-related expertise. Again, this may call for different skills or efforts on the part of the advisor. Third, the literature review shows that in exploring the role of staff, the emphasis lies on officials who are deemed to fulfil a neutral or administrative role. The 'political advisor' forms a distinct type of actor who can neither be classified as a civil servant nor as a political actor. Further tied to the fact that this particular group of actors has remained rather eclipsed in the academic debate, no fitting theory to study this type of advice exists. To tackle these issues, and build on the reviewed body of literature, a framework is developed for the study of political advice as a separate category in which technical and political functions 'meet'.

\section{Scope \& Approach: analytical framework for political advice}

The study sheds light on informal intra-parliamentary compromise building and the role of advice therein. Legislative unity is something that has to be 'manufactured' and the ability to form and maintain a position in interinstitutional negotiations is determined by the contribution of the 
institution's internal organisation (Bowler and Farell, 1995). The focus lies on political coordination in the EP, which is needed for the construction of a unified position. Political coordination is understood as processes in which decisions are prepared and priorities are defined as part of a bargaining practice between different groups of actors. It therefore encompasses all coordination efforts within and between the party groups that take place prior to any vote in committee or plenary. In this informal and exploratory setting the role of advice is expected to be most prominent. The scope of the dissertation is limited to the legislative function of the EP, leaving the control and budgetary powers aside. As such, the parliamentary activities in the standing EP committees take centre stage. It is within the scope of these arenas that positions on legislation or policy are coordinated. Chapter 1 discusses intra-EP coordination and decision-making in further detail.

The purpose of the study is to analyse the function and nature of advice and the circumstances that may affect its provision. Measuring or determining the influence of political advisors, as well as questioning (final) authority are all issues that fall outside the defined scope. The starting point is the assumption that while advisors have a certain influence on the political process, MEPs have the final say. The emphasis thus lies on the politician's delegation of the process to the advisor, not on the delegation of the decision (cf. Page and Jenkins, 2005: 'delegation of policymaking rather than the implementation of policy goals'). This remains a relatively unexplored field in the literature on the role of staff. This process-oriented approach sets out to identify activity and behaviour patterns in the provision of advice, rather than focusing on individual differences between advisors.

'Political advisors' form a distinct subset of officials who are explicitly employed to play a partisan role. In discussions of legislative organisation they remain an understudied group of actors. These advisors form part of a larger phenomenon: non-elected actors who are employed to assist in 
articulating and securing political positions. In this role, they negotiate with other actors (political and non-political) regarding these positions. The 'political role' of advisors differentiates them from the 'neutral' officials or civil servants that are expected to serve the general interest of the institution. In addition, these advisors as a rule do not work for one specific politician, which sets them apart from personal advisors who may also perform political roles. Although the analysis centres on advisors working within the EP party group secretariats (from now on referred to as 'advisors' or 'group advisors'), the developed framework is designed in such a way that it can be applied to other legislator-advisor relationships. Since the data collection took place in the period 2013-2014, the empirical analysis only covers the seven political groups represented in Parliament at that time. ${ }^{1} \mathrm{~A}$ detailed description of the methods is included in chapter 2 .

As was inferred from the literature review, a conceptual approach to the politics of advice first of all requires the definition of what the concept entails. In this respect, political advice is considered as an alternative category that unites technical and political functions. As chapter 2 will address, the analytical separation of these functions is more than a difference in responsibility and tasks alone. It comprises the anticipation of ideological priorities or desired outcomes and involves the use of tactics to formulate and execute strategies to realise these desired outcomes. Political advice is theorised to manifest itself in three incremental modes of discretion - routine, reactive, and pro-active - according to the degree to which activities are guided by a mandate (instructed) or by the advisor's interpretation and judgement (improvised).

\footnotetext{
${ }^{1}$ Group of the European People's Party (EPP), Group of the Progressive Alliance of Socialists and Democrats (S\&D), Group of the Alliance of Liberals and Democrats for Europe (ALDE), European Conservatives and Reformists Group (ECR), Group of the Greens/ European Free Alliance, Con-federal Group of the European United Left - Nordic Green Left (GUE/NGL), Europe of Freedom and Democracy Group (EFD).
} 
The discussion on the function and nature of advice furthermore demonstrated the need for clearly defined analytical categories. Building on the reviewed classifications of the role of staff, a typology of political advice therefore developed that translates into four non-exclusive ideal-type roles: Process Manager, Information Manager, Policy Expert, and Broker. The proposition is that advisors may adopt all four roles depending on what the circumstances require. To explore the circumstances that enable or restrict the adoption of a political role seven factors that affect political delegation are distilled from the literature. A combination of the personal and contextual factors is expected to affect the likelihood that advisors assume the roles, or the inclination of politicians to delegate. The idea is that the factors are instrumental in predicting the (optimal) circumstances in which political advice may be provided.

The framework is then implemented to explore how political advice contributes to the informal process of coordinating political positions and decisions in the EP. This is done by way of applying the collected quantitative and qualitative data to the concepts of the framework. This amounts to the following analytical steps for each of the ideal-type roles: First, the collection of data is applied to establish whether the technical and political functions of the role are indeed assumed. Second, the political scope of the role is considered by examining advisors' mandate and the extent to which they have room to improvise in the provision of political advice. Third, the extent to which the factors affect role construction and adoption is assessed.

\section{Theoretical and empirical contributions of the study}

As introduced above, the study of 'political advice' raises valuable theoretical questions. The existing literature has demonstrated that policy advice can entail a variety of activities (Page and Jenkins, 2005), and that 
depending on the circumstances, these activities may involve political aspects. Nonetheless, studies attempting to delineate what are overtly 'technical' or 'political' tasks have shown that the two spheres are difficult to disentangle (Fouilleux et al, 2005; Winzen, 2011). The dissertation builds on these studies and approaches political advice as an intermediate, separate category (Romanyshyn and Neuhold, 2013). In this way, it adds a new dimension to the scholarly debate on the role of officials by conceptualising what a 'political role' by advisors might entail. The developed framework draws on the body of literature examining the role of officials in a legislative setting. It explores the input provided by officials working for a political group in Parliament, a type of actor that thus far has only received marginal scholarly attention. The theoretical part of the dissertation introduces 'political advice' as a distinct category, defined as a mixed sphere of activity in which technical and political functions meet. It builds a theory to study this type of advice in a structured manner. The conceptualisation includes a typology of advice and the delineation of three incremental modes of discretion (routine, reactive and pro-active) depending on the advisor's mandate and room for improvisation in the provision of advice. Along the lines of anticipation logic, advisors are believed to base their actions, or construct their role, on what the circumstances demand. Both the context and the personality of the advisor will affect this assessment. The empirical analysis applies the framework and draws conclusions regarding the circumstances that facilitate or restrict the provision of political advice. Potential theoretical implications of the framework for political advice are conceivable in the sense that it is designed in such a way that it allows for the study of, or comparison between, role construction and adoption in various legislative contexts.

A second novelty lies in the process-oriented approach of the inquiry. While scholars have offered valuable insights into the political structures and outcomes in the context of the EP, a thorough understanding of informal 
practices related to the preparation of political negotiations and compromises in the EP calls for a process-oriented approach. The empirical evidence regarding the internal organisation of the EP tends to narrow its focus on explaining outcomes and has not yet uncovered how political coordination takes place at the everyday level (Busby, 2013). Whereas previous research has explored voting behaviour, the structure of party politics, the relationship with and influence of national political parties, as well as the EP's position relative to the other EU institutions, the (informal) dynamics related to these issues are largely overlooked. Nonetheless, academic attention for the informal dimension of politics is increasing, notably in relation to the practice of trilogues (e.g. Shackleton and Raunio, 2003; Huber and Shackleton, 2013; Roederer-Rynning et al, 2015). And several studies have addressed the role of staff in EU decision-making (Christiansen, 2002; Neunreither, 2002; Winzen, 2011; Egeberg et al, 2013; Busby, 2013; Dobbels and Neuhold, 2013; Neuhold and Dobbels, 2014; Michon, 2014; Pegan, 2015). Yet, the input into the informal decision-making process by way of political advice remains rather unchartered territory. A second key contribution of the dissertation therefore emanates from the empirical analysis that puts the role of advice in the informal intra-parliamentary coordination process under a magnifying glass. The developed framework offers a new way of explaining the informal aspects of intra-parliamentary decision-making. And the findings shed light on how the politics of advice play out in practice.

For compromise deals to be acceptable to the other institutions, cooperation in pursuit of broad consensus appears to be the norm. Given this consensual style of EP decision-making, a caveat in research regarding EP decisionmaking appears to be that the votes on the final outcomes are taken as a measure when in fact these are votes on compromises struck beforehand. This makes the final vote in the House a difficult yardstick for measuring influence in Parliament or explaining the dynamics of political negotiations. 
These issues underline the empirical importance of studying the organisation and functioning of the intra-parliamentary process in practice.

Finally, the study contributes to the normative debate about the impact of informal governance on the democratic legitimacy of EU decision-making. Political coordination, for the greater part, remains unrecorded and takes place outside the formal parliamentary structures of committee meetings and the plenary. By definition, advisors operate in the shadows of decisionmakers. This calls for a broader understanding of what guides the behaviour of advisors. The developed analytical framework offers the analytical tools to assess the scope of delegation and the likelihood that the politician accepts political advice. It furthermore adds to the academic debate on the role of staff by theorising a positive relation between the contribution of the advisor on the one hand and the position of his/her political superior on the other hand. Previous studies have shown that officials anticipate priorities and preferences of the politician and base their actions on these insights (Patterson, 1970; Page and Jenkins, 2005; Olsen, 2006). The dissertation advances the anticipation logic by demonstrating a relationship of interdependent strength. Not only is the role of the advisor tied to the position and authority of the politician, advisors can in reverse reinforce the position of the politician by providing expertise tailored to his or her needs.

\section{Outline of the study}

Chapter 1 provides the contextual setting and discusses the evolution of the EP's legislative powers (1.1), the key parliamentary structures and actors (1.2), and the intra-parliamentary coordination process (1.3). It demonstrates that the pursuit for compromise and the strengthened position of the EP in the inter-institutional triangle highlight the significance of intra-parliamentary coordination. In the (informal) preparation of these compromises (group) advisors are expected to play an important role. 
Chapter 2 develops an analytical framework for the study of political advice. As part of the framework, the concept of political advice is defined (2.1), a typology of four analytical categories of advice is conceptualised (2.2), and a set of factors hypothesised to enable or restrict the provision of political advice is distilled from the literature (2.3). The chapter concludes with a section on methodology (2.5). Chapter 3 operationalises political advice for the specific case of the EP. It first discusses the major potential sources of political advice at the disposal of MEPs. This is then followed by a presentation of the acquired background information on the profile, knowledge, skills, and experience of EP group advisors, which is discussed in relation to the various concepts of the theoretical framework. Chapters 4-7 present the empirical analysis by applying the collected qualitative and quantitative data to the analytical framework. Consecutively, each of the ideal-type roles is examined in detail: Process Management (chapter 3), Policy Expertise (chapter 4), Information Management (chapter 5), and Brokering (chapter 6). The analysis is built around the following steps: First, the data are applied to the four roles to establish whether each of the idealtypes is indeed assumed. Second, the political scope of the role is considered by examining advisors' mandate and the extent to which they have room to improvise in the provision of political advice. Third, the extent to which the seven identified factors impact role construction and adoption is assessed. Finally, chapter $\mathbf{8}$ offers the overall conclusion by synthesising the findings and reflecting on the theoretical and empirical contributions and implications. 




\section{CHAPTER 1. THE CONTEXTUAL SETTING: EUROPEAN PARLIAMENT STRUCTURES}

In order to shed light on the backstage practices that precede any legislative outcome in the European Parliament (EP), a general understanding of the functioning of intra-parliamentary coordination and decision-making is required. This chapter therefore presents background information regarding the evolution of the EP's legislative powers (1.1), the key parliamentary structures and actors (1.2), and the intra-parliamentary coordination process (1.3).

The first section discusses the EP's development from merely a consultative assembly to the current position of full-fledged co-legislator (1.1.1). Next, the conception and consolidation of the EP party groups is addressed (1.1.2), followed by a brief reflection on the internal power balance between the groups (1.1.3).

The second section introduces a number of key organisational structures along with the key actors at the political level. First, the election and duties of the EP leadership structures are discussed (1.2.1). Next, the formation, leadership structures and activities of the EP party groups are presented (1.2.2). And, the relevance, composition, and legislative activity of the parliamentary committees are explored (1.2.3). In this chapter the focus lies on formal structures and actors. Chapter 3 introduces the supporting staff at the disposal of these key actors. The empirical findings in regards the informal practices are further addressed in chapters 4-7.

The final section of the chapter presents the intra-parliamentary coordination process and demonstrates that the institution's strengthened position in the EU political system and expanded workload increase both 
the significance and amount of political coordination in the EP. The various levels of coordination are considered, presenting the existing literature and prevailing working methods for intra-group (1.3.1), inter-group negotiations (1.3.2), and inter-institutional coordination (1.3.3). Finally, the main stages of the intra-parliamentary coordination process are discussed (1.3.4).

\subsection{The evolution of the European Parliament}

Since its inception in the 1950s, the Parliament has evolved significantly in terms of political authority, legislative powers, and hence in workload and internal organisation. The institution that once started out as a consultative assembly, with delegates appointed from the national parliaments, has now turned into a full-fledged co-legislator (Corbett et al, 2011: 3; Ripoll Servent, 2018).

Sparked by the cumulative extension of the EP's legislative powers, scholars turned to its internal organisation and structures in the 1990s. An important question is how the institution is dealing with its new powers and what has been done to fully exploit the potential of its role. Studies for example show that as the impact of the EP on legislative outcomes grew, the role of the political party groups augmented driven by the need for efficiency and coordination (Hix and Lord, 1997; Raunio, 1999; Kreppel and Tsebelis, 1999). In the early 2000s we therefore see a shift in academia previously focusing on national political parties to the contemporary focus on the transnational party groups as central actors in the EP organisation (Hix et al, 2007).

In order to allow for a general understanding of how the EP operates and to grasp the (potential) impact of EP party groups, the section provides a global historical overview of the incremental increase of the legislative role 
of the Parliament in the EU political system (1.1.1); the consolidation of the party groups as key organisational actors (1.1.2); and the institution's political spectrum (1.1.3).

\subsubsection{The powers and position of the EP in an institutional context}

The history and evolution of the EP's powers have been explored extensively (see e.g. Ripoll Servent, 2018; Corbett et al, 2016; Hix et al, 2007; Earnshaw and Judge, 2003; Rittberger, 2003). Given that the aim of the study is to explore political advice in relation to the coordination of legislative texts, the discussion below presents only a global overview of the gradually increased legislative function of the institution, leaving its budgetary and scrutiny powers aside.

Treaty changes: from consultation to co-decision

The development of the European Union cannot be separated from the ubiquitous debate on the legitimacy and accountability of the institutions and its actors (Hix et al, 2007; Kohler-Koch and Rittberger, 2007). Efforts to address these concerns have strengthened the relative position of the EP, which with each Treaty change saw its legislative and supervisory powers extended during the thirty years after its first direct elections in 1979 (Rittberger, 2012).

The founding fathers did not seem to have high aspirations for the EP's forerunner, the Assembly of the European Coal and Steel Community (ECSC). Established as a platform for exchange and debate in 1952, it convened 78 delegates from the national parliaments and was only consulted on a minor range of legislative proposals without real impact on legislative outcomes (Corbett et al, 2011: 3). The fact that the name change to European Parliament (1962) came about on the initiative of the assembly itself is just one of the indications that the political forces represented within 
the institution thought otherwise (Kreppel, 2002). In 1979 the first direct elections took place and concomitant with several rounds of enlargement the number of seats in Parliament increased.

Treaty revisions in the 1980s and 90s steadily expanded the institution's consultative and legislative role. The cooperation procedure added a second reading to the traditional consultation procedure. The Council's position was to be referred back to the EP that had three months to approve it. In case of rejection the Council was only able to overrule Parliament by a unanimity vote. The adoption of this procedure allowed Parliament a position to push for the incorporation of EP amendments into the legislative text and was a 'stepping stone to the full co-decision procedure' (Corbett et al, 2011: 263). The co-decision procedure gradually replaced the cooperation procedure until it was finally abolished in 2009. Co-decision puts the Council and the EP on equal footing. As a last resort, a conciliation committee is brought in to negotiate a compromise when no agreement has been reached after two readings.

The scope of the co-decision procedure was steadily extended and reformed in the EP's favour culminating with the naming of co-decision as the 'Ordinary Legislative Procedure' in the Treaty of Lisbon in 2009 (Corbett et al, 2011: 5). Today, the EP is a fully recognised co-legislator with the ability to amend, delay or block legislation in virtually all areas of EU legislative competence (Dobbels, 2013: 23-24). ${ }^{2}$

Position in the EU political system and informal powers

Owing to its extended legislative role in the EU political system, the EP'S political authority continues to grow and the institution has become a

\footnotetext{
2 The Council can still act as the sole legislator regarding e.g. internal market exemptions, competition law or common external tariffs.
} 
political arena where policy objectives are pursued through legislative action (Kreppel, 2002). The developments described above have turned the EU political system into a bicameral legislature where the EP and the Council share the power to adopt and amend legislative proposals (Kreppel, 2018; Bressanelli et al, 2016; Rasmussen, 2011). The former represents the voice of the people through transnational political party groups. The latter is the voice of the Member States, assembling national ministers according to policy area.

The designation of co-decision as the 'Ordinary Legislative Procedure' has had a profound effect on inter-institutional relations, both in terms of frequency and informality (Burns, 2013). The amount of legislation having to be passed in tandem with the Council has led to the common practice of the co-legislators working in parallel by way of 'trilogue' meetings in which representatives of the European Commission (EC) also take part. The Amsterdam Treaty (1999) introduced the possibility for the co-legislators to agree in first reading, the so-called 'fast track procedure'. Since that time, a substantial rise in inter-institutional negotiations is observed. The upward trend of first-reading agreement between 1999 and 2014 is illustrated by the figures: 85 per cent of legislative files were concluded at first reading during the $7^{\text {th }}$ Parliamentary term (EPRS, 2016) compared to 72 per cent of all co-decision procedures in $6^{\text {th }}$ and only 28 per cent in the $5^{\text {th }}$ legislature (Corbett et al, 2011: 240-241). Reaching agreement in first reading through inter-institutional negotiations is now actually said to have become the 'usual working method for reaching legislative agreements' (European Parliament, 2015) and can be organised at any stage of the legislative procedure (see 1.3.4 for a description of the various stages). The augmented inter-institutional dialogue throughout the legislative cycle politicises EU decision-making while simultaneously causing concern for a secluded form of decision-making in which only a small fraction of the Members of the EP (MEPs) is closely involved (Farrell and Héritier, 2004; 
Häge and Kæding, 2007; Héritier and Reh, 2012; Häge and Naurin, 2013; Bressanelli et al, 2016). The informal nature of these negotiations faces a trade-off between efficiency and legitimacy, which is much debated (see Introduction). Section 1.3 discusses how the EP deals with the fast track procedure in practice and how the trilogue negotiations are laid down in its internal Rules for Procedure (see 1.3.3).

Finally, perhaps the 'most renowned occasion' in which the EP has managed to strengthen its position in the EU political system is the appointment of the EC (Dobbels, 2013: 25). In addition, the terms of office of the EC and the EP were aligned in order to strengthen the link between the two institutions (Ripoll Servent, 2018). In the 1990s, Parliament had already succeeded in formalising its consultative role in the nomination of the EC President into a vote of confidence in the entire College of Commissioners (Corbett et al, 2011: 293-294). In an attempt to further strengthen the accountability of the EC, the Lisbon Treaty (2009) stipulates that Member States need to take into account the EP election results in their proposal for a new EC President and that the candidate is 'elected' by the EP (article 17 (7)). Although this did not change the procedure in a revolutionary way, the EP's interpretation of the treaty change had significant impact on the nature of the 2014 election campaigns and the final nomination of the EC President (Christiansen, 2016). Ahead of the elections, EP party groups set forth leading candidates for the position of EC President. For the first time in history, the European electorate was provided with the opportunity 'to determine not only the composition of the European legislature, but also the leadership of the EU's executive' (Christiansen, 2016). This Spitzenkandidaten model is seen to be a step forward in the further democratisation and politicisation of the EU political system (Corbett et al, 2016: 345-346). However, the creation of a truly parliamentary system would require Member States to give up their right to appoint Commissioners, something that seems very unlikely (Ripoll Servent, 2018). 
An example of open deliberation between the EP and the Commission is the agreement on a set of predetermined political priorities (Christiansen, 2016). In the EP, these political priorities were agreed at party-group level. The conception and consolidation of these groups is discussed next.

\subsubsection{The conception and consolidation of the EP party group system}

In 1953 the mainstream party families of Western Europe formed the first transnational political factions. To structure the activities of what was then the ECSC Assembly, Christian Democrats, Socialists, and Liberals from the six founding Member States decided to join forces. The formation of transnational groups was unprecedented in the tradition of international assemblies and at the outset no formal measures were taken to politicise the assembly. Instead, structures were created to accommodate potential national differences and organisation along national lines rather than ideological affiliation (Hix and Lord, 1997; Kreppel, 2002). For that reason the delegates were initially seated in alphabetical order and five VicePresidents were nominated to guarantee the representation of each Member State in the assembly's leadership. Yet, shortly after its constitutive meeting, the political groups initiated the incorporation in the Assembly's first Rules of Procedure of a committee distribution balanced on nationality as well as on political affiliation. The proposal was adopted without debate. The Rules furthermore stated that groups of at least nine (out of 78) members could be formed according to 'political persuasion' (Kreppel, 2002).

\section{Central importance of EP party groups}

During the following decades the tradition of political groups further developed and their position as the main organisational entities of Parliament became universally recognised (Kreppel, 2002; Hix et al, 2007). 
Scholars have offered several explanations for the reasons behind the establishment of the party groups at European level. First, for delegates who simultaneously sat in national parliaments it seemed natural to cooperate with like-minded politicians from other countries rather than fellow nationals pertaining to competing parties at the domestic level (Kreppel, 2002).

Second, in consonance with the rational choice theory of legislative organisation, it is argued that members advocated a party group structure to overcome collective action problems (Hix et al, 2003). Collaboration in party groups advances legislators' opportunities to realise their preferred policy outcomes and reduces the transaction costs of coalition formation. It is through the groups that political majorities are built (Corbett et al, 2011: 78). Unlike national political parties, EP party groups do not support or oppose a government and coalitions are struck on a case-by-case basis (Dinan, 2005). This implies that EP decision-making is characterised by continuous and compromise-oriented negotiations between the groups (Ripoll Servent, 2018; Burns, 2013). Hix and colleagues found that the consolidation of the EP party system has strengthened as the EP's powers expanded. The increased role in the formulation of EU legislation simultaneously intensified political group cohesion and ideological competition. This finding is in line with the theoretical explanation that parties are incentivised to structure and pool their efforts as the potential influence on a preferred outcome increases. Recent research on the effect of early agreements on legislative behaviour in the EP has suggested that 'centrist parties' (Christian Democrats, Social Democrats, and Liberals) invest more in coordination and have become more cohesive (Bressanelli et al, 2016). Consequently, the informalisation of co-decision seems to strengthen these groups. The process of intra-parliamentary coordination is further explored in 1.3. 
A third reason for the institutionalisation of the transnational party groups is that support for the politicisation of the EP was a symbolic move to counter intergovernmentalism (Kreppel, 2002). The politicisation of EP processes - based on ideological competition in a consolidated party group system - elevates the political authority of the elected institution and is therefore considered positive for the democratic level of EP decision-making (Pridham and Pridham, 1981). The informalisation of co-decision has accentuated the EP's sense of responsibility to foster transparency and accountability of decision-making (see Introduction and 1.1.1). Studies have shown that - owing to strengthened intra-parliamentary coordination practices - the trilogue negotiations are predicated on specific mandates and underpinned by a set of norms, standard operating procedures, practices, and oversight mechanisms (Rasmussen 2012; Reh et al. 2013; Ripoll Servent 2014; Roederer-Rynning and Greenwood, 2015). In this way, Parliament is considered to advance 'norms of public accountability' and use them as leverage over the Council (Roederer-Rynning and Greenwood, 2015).

Finally, from a practical point of view it is important to note that both material and procedural benefits are allotted to the EP party groups. Apart from financial support, office space and staff entitlements allocated to the party groups, they determine the institution's internal organisation. Groups control the division of labour in the standing parliamentary committees and are decisive in the distribution of all influential positions in parliament such as the president, vice-presidents, committee chairs and rapporteurs (authors of EP positions on pieces of draft legislation). These practices have incentivised groups of previously non-attached MEPs to enter into 'a marriage of convenience', based on technical rather than ideological grounds (Dinan, 2005). The central importance of the groups is thus illustrated by the 'powerlessness of those non-attached members' (Corbett et al, 2011: 78). Section 1.2 further discusses the key parliamentary 
structures and positions including the internal organisation of the party groups (see 1.2.3).

In sum, party groups control the EP's internal organisation and are instrumental for influence on EP decision-making. Not surprisingly therefore, the evolution of the EP'S position in the EU decision-making process went hand-in-hand with the consolidation of the party group system. Deduced from a lacking collective electoral mandate and low election turnout, it is often pointed out that compared to traditional political party systems the EP system is weak (e.g. Hix and Lord, 1997; Kreppel, 2002; Brack and Costa, 2018). European elections generally revolve around national issues and are marked by a low and ever-declining turnout (Brack and Costa, 2018; Burns, 2013). The weak European public sphere makes for only a limited shared public debate about European politics (Smismans, 2013: 344). Nevertheless, a competitive party system with hierarchically organised parties behaving in a cohesive way has emerged (see 1.2.3 and 1.3). Studies have shown voting behaviour in the EP to become increasingly structured around the political groups since 1979 (Raunio, 1999; Hix et al, 2007). The potential impact on legislative outcomes boosted political competition, which in turn promoted the role of the groups to aggregate ideological preferences and secure policy outcomes that are as close as possible to these preferences (Hix et al, 2007).

\section{European party federations}

In addition to the political groups that operate inside the EP, European party federations operate outside of the EU institutions. The development of the EP party groups preceded the transnational mobilisation of European political party federations bringing together national parties with a shared ideology. The institutional reforms of the 1980 s and 90 s that led to a more direct impact of the party groups on the EU decision-making process stirred 
the further extra-parliamentary organisation of the federations (Hix and Lord, 1997). In addition, the Maastricht Treaty (Article 138a) formally recognised political parties at EU level as an important factor for integration and the creation of European awareness. Although the change was mainly symbolic, most of the European political federations changed their name to 'party' following the entry into force of the treaty. In response to the socalled 'Party article' federations jointly set out to draw up a Political Party Statute. Although first attempts failed, the adoption of a European statute was included in the Treaty of Nice (2003). Subsequently, Parliament and Council agreed on a Regulation on political parties providing for transparency and openness of accounts, and access to EP funding that can be used to finance campaigns for the European elections, conferences, publications, administrative and some other costs. Yet, most significant is probably the role of the party federation as a coordination platform (Ripoll Servent, 2018). The party summits - a practice established in the 1990s bring together all EU-level actors affiliated to a federation ahead of European Council meetings (Corbett et al, 2016: 146-147). For EP group leaders this provides an opportunity to interact and align positions with their counterparts in the other EU institutions.

\subsubsection{The political power balance within the EP}

The EP has several unique features that leave their mark on the internal organisation of parliamentary activities (Corbett et al, 2011: 2). It is the only directly elected international assembly and has the largest transnational electorate in the world. Different to most national parliaments and similar to the US Congress the EP knows fixed-term elections that take place once every five years. Parliament comprises elected representatives from the 28 Member States emanating from over 200 national political parties. Unlike traditional western parliamentary democracies, the EU is characterised by a separation of powers so as to that no government arises 
directly from the EP elections (Corbett et al, 2016: 141). A majority in Parliament is thus not automatically tied to support for the executive, nor does a single group hold the absolute majority of seats (Corbett et al, 2016: 11). The EP is overall characterised by a consensual style of decisionmaking (Ripoll Servent, 2018). The lack of government-opposition dynamics is said to intensify the 'spirit of collaboration' in the EP to advance the institutional agenda (Dinan, 2005). The intra-parliamentary process of coordinating political positions is further discussed in section 1.3. Below the relative numerical strength of the political groups represented in Parliament is introduced.

Until 1965 only three groups were represented and - albeit their names and composition have changed over time - the Christian Democrats, Social Democrats, and Liberals continue to exist today. Before the 1979 direct elections, Christian Democrats were the principal group in the EP. Between the first and the fifth legislature (1979-1999), the Social Democrats (PES and later S\&D) accounted for the largest number of seats in the assembly. Consisting of the mainstream Socialist and Social Democratic parties in all Member States, the composition of the group has always been the most straightforward of the EP party groups (Corbett et al, 2011: 94). Ever since the 1999 elections, the Christian Democrats (EPP) remains the biggest party group. The EPP and S\&D combined have unceasingly held over 50 per cent of the seats and this percentage even raised above 60 per cent between 1994 and 2014. The Liberals traditionally play a pivotal role within the majority-building process as third or fourth largest group. Positioned in the centre of the EP political spectrum the group can often determine whether a compromise is constructed towards the left (with S\&D) or the right (with EPP) of the EP spectrum.

Other political families that remain represented in the EP since the first legislature are the radical-left - drawing from (former) Communist and left 
Socialist parties - and the European Conservatives although the group joined the EPP between 1994 and 2009. A group of European right-wing parties was formed after the 1984 elections that apart from the $7^{\text {th }}$ term and several changes in name and composition remains a presence in the EP. Since 1989 the Greens and regionalist parties collaborate holding a steady fourth or fifth position in the House. From 1999 onwards, a Eurosceptic group exists emphasising the role of individual nation states and opposing further integration. During the $5^{\text {th }}$ and $6^{\text {th }}$ legislature the group - respectively EDD and IND/DEM - included several left of centre parties. Its successor - Europe of Freedom and Democracy (EFD) - had a clear right-wing orientation as does the current Europe of Freedom and Direct Democracy group (EFDD). In the current legislature around 98 per cent of MEPs sit in one of the eight political groups, while the remainder is non-attached. Groups can and do change their formation or name from time to time, and national political parties can switch their affinities. Figure 1.1.3 and Table 1.1 provide an overview of the political groups in the EP between 1979 and 2016. 
Chapter 1

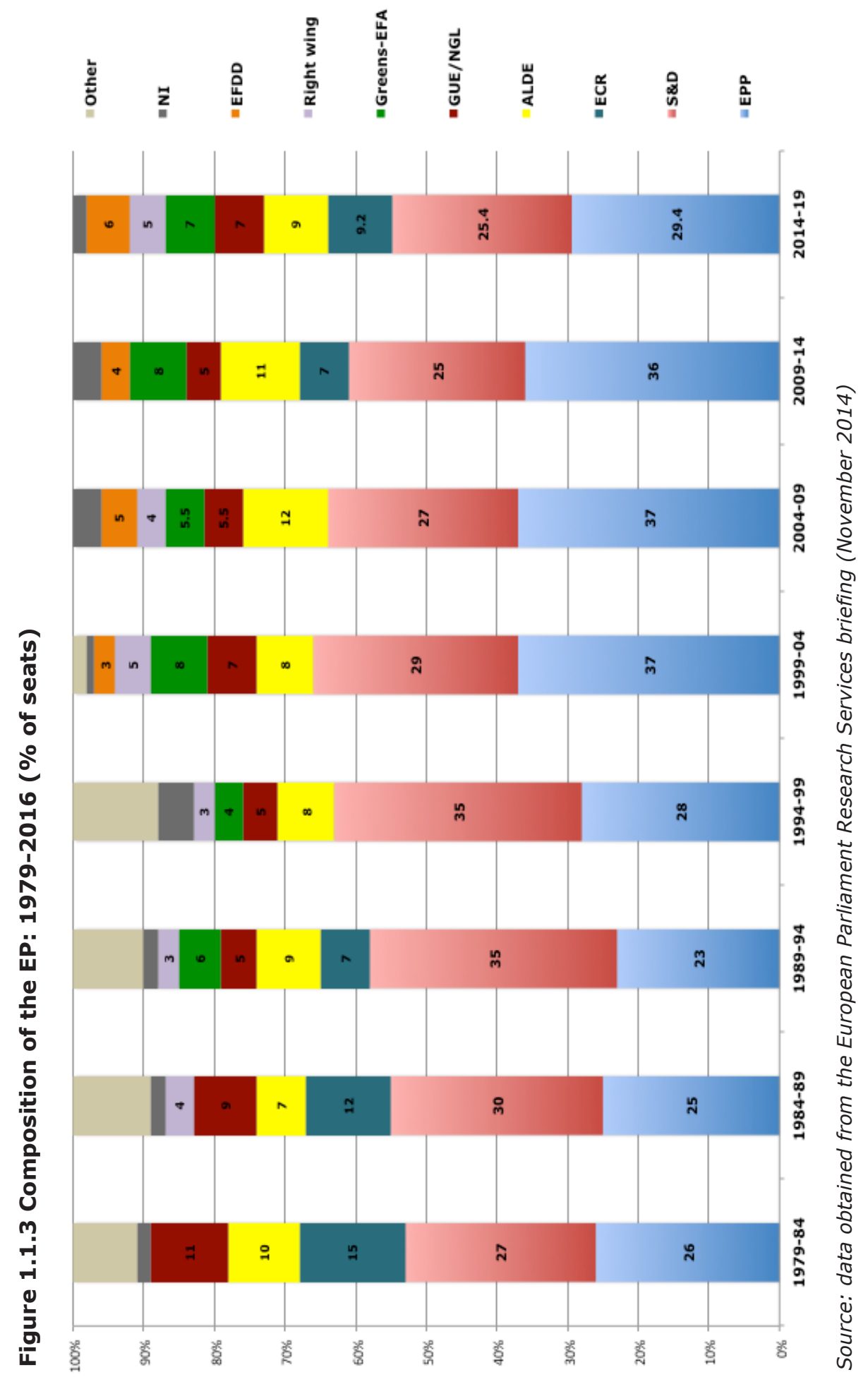


Table 1.1 Political groups in the EP: 1979-2016

\begin{tabular}{|c|c|c|}
\hline Group & Years active & Ideology \\
\hline $\begin{array}{l}\text { EPP: European People's Party (EPP) } \\
\text { EPP and European Democrats (EPP-ED) }\end{array}$ & $\begin{array}{l}1979-89 \text { / 2009- } \\
1989-2009\end{array}$ & $\begin{array}{l}\text { Centre-right/ } \\
\text { Christian } \\
\text { Democrats }\end{array}$ \\
\hline $\begin{array}{l}\text { S\&D: Socialist Group } \\
\text { Party of European Socialists (PES) } \\
\text { Progressive Alliance of Socialists and Democrats (S\&D) }\end{array}$ & $\begin{array}{l}1979-1984 \\
1984-2009 \\
2009-\end{array}$ & $\begin{array}{l}\text { Centre-left/ } \\
\text { Social } \\
\text { Democrats }\end{array}$ \\
\hline $\begin{array}{l}\text { ECR: European Democratic Group (ED) } \\
\text { European Conservatives and Reformists (ECR) }\end{array}$ & $\begin{array}{l}1979-1994 \\
2009-\end{array}$ & $\begin{array}{l}\text { Centre-right/ } \\
\text { 'Eurorealists' }\end{array}$ \\
\hline $\begin{array}{l}\text { ALDE: Liberal and Democratic Group } \\
\text { Liberal and Democratic Reformist Group } \\
\text { European Liberal, Democrat and Reform Party (ELDR) } \\
\text { Alliance of Liberals and Democrats for Europe (ALDE) }\end{array}$ & $\begin{array}{l}1979-1984 \\
1984-1994 \\
1994-2004 \\
2004-\end{array}$ & Liberals \\
\hline $\begin{array}{l}\text { GUE/NGL: Communist and Allies } \\
\text { European United Left (GUE) } \\
\text { European United Left/ Nordic Green Left (GUE/NGL) }\end{array}$ & $\begin{array}{l}1979-1989 \\
1989-1999 \\
1999-\end{array}$ & Far-left \\
\hline $\begin{array}{l}\text { Greens/EFA: Green Group (V) } \\
\text { Greens/European Free Alliance (Greens/EFA) }\end{array}$ & $\begin{array}{l}1989-1999 \\
1999-\end{array}$ & $\begin{array}{l}\text { Left of } \\
\text { centre }\end{array}$ \\
\hline $\begin{array}{l}\text { Right-wing parties: European Right (DR) } \\
\text { Europe of Nations (EDN) } \\
\text { Union for Europe of Nations (UEN) } \\
\text { Europe of Nations and Freedom (ENF) }\end{array}$ & $\begin{array}{l}1984-94 \\
1994-1999 \\
1999-2009 \\
2015-\end{array}$ & $\begin{array}{l}\text { Far-right/ } \\
\text { Eurosceptic/ } \\
\text { nationalists }\end{array}$ \\
\hline $\begin{array}{l}\text { EFDD: Europe of Democracies and Diversities (EDD) } \\
\text { Independence/Democracy Group (IND-DEM) } \\
\text { Europe of Freedom and Democracy (EFD) } \\
\text { Europe of Freedom and Direct Democracy (EFDD) }\end{array}$ & $\begin{array}{l}1999-2004 \\
2004-2009 \\
2009-2014 \\
2014-\end{array}$ & Eurosceptic \\
\hline
\end{tabular}

NB: Progressive Democrats (5\% of seats in 1979-84) became European Democratic Alliance (4-7\% throughout 1984-99) and joined the EPP-ED in 1999. Heterogeneous groups that assembled non-attached members (NI): Technical group (respectively $2.7 \%$ and $2.8 \%$ of seats in $1979-84$ and $1999-2001$ ) and Rainbow group (respectively $6 \%$ and $2.5 \%$ of seats in $1984-89$ and $1989-94)$.

Source: EP website, section 'past election results' (consulted, August 2017) 


\subsection{Key parliamentary structures and actors}

The aim of the section is to introduce the institutional machinery of the EP: parliamentary structures, rules of procedure and political actors that are key to the intra-parliamentary coordination process. This process is examined in further detail in the next section (1.3). The main sources of advice that the key actors have at their disposal are discussed in chapter 3 (3.1).

First, the election and duties of the EP leadership structures are discussed (1.2.1). Next, the formation, leadership structures and activities of the EP party groups are presented (1.2.2). Finally, the relevance, composition, and legislative activity of the parliamentary committees are explored (1.2.3).

\subsubsection{EP leadership structures}

Parliament organises its work independently and adopts Rules of Procedure, acting by a majority of its component members (Article 232 TFEU). At the start and midway of each parliamentary term, the EP plenary by absolute majority elects its President, 14 Vice-Presidents and five Quaestors. The terms of office of the formal office holders thus is two and a half years. The EP President is responsible for the day-to-day running of the administration, presiding over parliamentary sittings, referring EC proposals to the appropriate committees (designated 'committee responsible'), and ensuring that all activities of Parliament and its bodies are conducted properly according Rule 22 of the EP Rules of Procedure (RoP). ${ }^{3}$ The President furthermore has an external, representative role and attends European Council meetings. These tasks may be delegated to the Vice-Presidents. The Quaestors look after the administrative and financial interests of the members, which include a wide range of matters from members' facilities

\footnotetext{
${ }^{3}$ References are to the January 2017 version of the RoP, as published on the EP website.
} 
and security issues to for example cultural and artistic events sponsored by members (RoP, Rule 28).

The groups normally put forward nominations for the EP office holders, but a minimum of 40 members may also submit candidates (Corbett et al, 2011: 136). In addition, the RoP state that in the election of the President, Vice-President, and Quaestors 'account should be taken of the need to ensure an overall fair representation of Member States and political views' (Rule 15). Party groups' nominees are almost always elected and customarily the posts are shared out among the groups on account of their numerical size using a points system (d'Hondt, see below). Since the third legislature (1989-1994), the two largest groups - Socialists and Christian Democrats - have struck a deal to alternate the Presidency, much to the lament of the smaller groups (Corbett et al, 2011: 137). ${ }^{4}$

The main decision-making bodies in the EP are the plenary (the total of MEPs), the Bureau and the Conference of Presidents. The Bureau consists of the President and Vice-Presidents. Quaestors attend meetings in an advisory capacity (RoP, Rule 24). The Bureau is responsible for all organisational, administrative and financial matters concerning the internal organisation of the EP, its members and its bodies (RoP, Rule 25). The Conference of presidents (COP) assembles the EP President and the leaders of the EP party groups (RoP, Rule 26). Non-attached members are represented by way of an observer without voting rights. This body is among others responsible for matters concerning the other institutions. It decides on the organisation of the institution's work and legislative planning, the composition and competence of parliamentary committees,

\footnotetext{
${ }^{4}$ With the exception of the 5th legislature (1999-2002) - where the EPP for the first time won the elections and negotiated a deal with the Liberals - the deal to share the presidency still exists today.
} 
and the agenda of the plenary (RoP, Rule 27). The CoP also 'defines the general political direction of the institution' (EPRS briefing, 2014).

Other important bodies for the functioning of Parliament are the Conference of Committee Chairs and the Conference of Delegation Chairs. ${ }^{5}$ Committees elect a bureau consisting of a chair and a maximum of four vice-chairs. The chairs of the parliamentary standing and special committees usually meet once a month to discuss developments in the work of committees based on which they may make recommendations to the CoP (Corbett et al, 2011: 144). They are part of the team representing the EP in inter-institutional negotiations (see 1.3.3).

Yardstick for the allocation of leadership positions in the EP is a balanced distribution among the groups. This practice is implemented based on the d'Hondt method. The party groups choose posts in an order determined according to their size. This allocation method ensures a roughly proportional distribution, resulting in a situation where the EPP and the S\&D hold the lion's share of influential positions (Ripoll Servent, 2018). In practice, the groups share out the influential (and less influential) posts through an informal 'package deal' agreement (Corbett et al, 2011: 148). These negotiations are carried out during the month before the first plenary session, resulting in a set of nominations for committee chairs and vicechairs. The confirmation of these nominees is usually only a formality and takes place by a majority vote in the committees' constituent meetings. Internally, the groups follow a similar procedure to divide the positions among their respective national delegations. In addition to size, experience and expertise of the candidates are considered, as well as the allocation of other positions among delegations within the group (Ripoll Servent, 2018;

\footnotetext{
${ }^{5}$ Since the focus of this dissertation lies on legislative activities only, the EP delegations are not further discussed.
} 
Corbett et al, 2011). The whole process is repeated mid-term (RoP, Rule 19).

\subsubsection{The organisation of the party groups}

The formation, activities, and legal situation of political groups are laid down in the EP Rules of Procedures (EP RoP, Rule 32 and 33). ${ }^{6}$ Formation is according to political affinity and a minimum of 25 members is needed from at least one quarter of the Member States. The rules furthermore stipulate that party groups are provided with a secretariat, administrative facilities, and allocated EP budget appropriations. Party groups and the remaining group of non-attached members receive an annual share based on the amount of members and languages represented in the group. Other resources allocated to the groups include staff entitlements, offices, meeting rooms and technical support. The composition and functioning of the group secretariats differs significantly both in terms of size and responsibilities and is further examined in chapter 3 (see 3.1.1).

Although the internal organisation remains at the discretion of the groups, the EP structures laid down in the RoP have a significant effect on how the groups operate (EPP, S\&D, ALDE and Greens/EFA Rules of procedure; group websites, consulted August 2016). The fact that groups are required to carry out the tasks specified in the EP ROP obligates them to appoint members in predetermined posts, held for two and a half years in line with the term of EP office holders. In general, groups' hierarchy therefore comprise a president or chair, several vice-chairs, a bureau that includes the group presidency, a treasurer and usually the heads of the various national delegations represented in the group. The Greens and EFD groups

\footnotetext{
${ }^{6}$ References to the EP's Rules of Procedure (RoP) refer to the rules adopted for the $8^{\text {th }}$ parliamentary term, January 2017 version (available online: www.europarl.europa.eu/sipade/rulesleg8/Rulesleg8.EN.pdf, consulted March 2018). Significant changes to the RoP between the $7^{\text {th }}$ and $8^{\text {th }}$ terms will be cited.
} 
know a tradition of co-chairs and following its constitution in 2015 the ENF group also appointed two chairs. Table 1.2 gives an overview of the composition of the groups' central decision-making bodies.

Table 1.2.2 Leadership structures of the groups, $8^{\text {th }}$ parliamentary term

\begin{tabular}{|c|c|c|c|}
\hline & $\begin{array}{l}\text { Group } \\
\text { Assembly }\end{array}$ & $\begin{array}{l}\text { Presidency } \\
*\end{array}$ & Bureau \\
\hline EPP & $\begin{array}{l}216 \\
\text { members }\end{array}$ & $\begin{array}{l}1 \text { chair } \\
10 \text { vice- } \\
\text { chairs }\end{array}$ & $\begin{array}{l}\text { Presidency, national delegation leaders, } 1 \\
\text { member for every } 10 \text { members of a delegation, } \\
\text { members fulfilling a post in the EP's governing } \\
\text { bodies, political coordinators of the } \\
\text { parliamentary committees, president and } \\
\text { secretary-general of the European People's Party } \\
\text { federation. }\end{array}$ \\
\hline S\&D & $\begin{array}{l}187 \\
\text { members }\end{array}$ & $\begin{array}{l}1 \text { chair } \\
9 \text { vice-chairs }\end{array}$ & Presidency and treasurer. \\
\hline ECR & $\begin{array}{l}73 \\
\text { members }\end{array}$ & $\begin{array}{l}1 \text { chair } \\
6 \text { vice-chairs }\end{array}$ & Presidency, national delegation leaders. \\
\hline ALDE & $\begin{array}{l}69 \\
\text { members }\end{array}$ & $\begin{array}{l}1 \text { chair } \\
8 \text { vice-chairs }\end{array}$ & $\begin{array}{l}\text { Presidency, national delegation leaders, } \\
\text { members fulfilling a post in the EP's governing } \\
\text { bodies. }\end{array}$ \\
\hline $\begin{array}{l}\text { GUE/ } \\
\text { NGL }\end{array}$ & $\begin{array}{l}52 \\
\text { members }\end{array}$ & $\begin{array}{l}1 \text { chairs } \\
3 \text { vice-chairs }\end{array}$ & $\begin{array}{l}\text { Presidency, treasurer, national delegation } \\
\text { leaders, group's secretary-general and deputy } \\
\text { secretaries-general. }\end{array}$ \\
\hline $\begin{array}{l}\text { Greens } \\
\text { /EFA }\end{array}$ & $\begin{array}{l}50 \\
\text { members }\end{array}$ & $\begin{array}{l}2 \text { chairs } \\
7 \text { vice-chairs }\end{array}$ & $\begin{array}{l}\text { Presidency, group's secretary-general and } \\
\text { deputy secretaries-general, EP vice-president } \\
\text { belonging to the group. }\end{array}$ \\
\hline EFDD & $\begin{array}{l}45 \\
\text { members }\end{array}$ & $\begin{array}{l}2 \text { chairs } \\
7 \text { vice-chairs }\end{array}$ & $\begin{array}{l}\text { Presidency, bureau chair, treasurer, } \\
\text { representatives from each national delegation. }\end{array}$ \\
\hline ENF & $\begin{array}{l}39 \\
\text { members }\end{array}$ & $\begin{array}{l}2 \text { chairs } \\
8 \text { vice-chairs }\end{array}$ & $\begin{array}{l}\text { Presidency, representatives from each national } \\
\text { delegation. }\end{array}$ \\
\hline
\end{tabular}

Source: EP and party groups' websites (consulted, November 2016)

* Presidency includes a treasurer if not mentioned separately under Bureau.

Group leaders are elected by the group members - referred to as Plenary Assembly - and represent the group in the EP's Conference of Presidents, 
in informal meetings of group chairs in which many deals are struck, and in the respective European party federations. Group Bureaux prepare strategic and political decisions and deal with the administration and management of the group (EPP, S\&D, ALDE and Greens/EFA Rules of procedure; group websites, consulted August 2016).

Although it varies across the groups, national delegations are considered to play an influential role forming the link to the national parties (Ripoll Servent, 2018). Despite the institutionalisation of the EP party groups (see 1.1.2), national parties constitute the main reference point for MEPs (Raunio, 1999; Faas, 2003). In order to reach a coherent group position compromises therefore need to be negotiated among the national delegations. In cases where groups fail to vote cohesively the reason usually lies in one or several national delegations opting out of the group's position (Corbett et al, 2016: 139). Nonetheless, studies have shown a high level of voting cohesion on account of group members sharing similar values and ideals (e.g. Hix et al, 2007). The academic debate on EP party groups shows agreement on the authority of the national delegations: Not the group leadership but rather national delegations control the division of influential posts. The main argument is that the former has no power to control, sanction or reward the behaviour of individual MEPs (Hix and Lord, 1997; Kreppel, 2002). Therefore, benefits such as positions within the groups' internal structures and within the EP structures are usually shared among the constituent national delegations (Corbett et al, 2016: 139; Ripoll Servent, 2018).

The extent to which the groups coordinate activities and positions in parliament varies considerably (see 1.3.1). However, there are certain similarities in the organisational structures of the EPP, S\&D and ALDE, which appear to be the most sophisticated and subdivide the parliamentary work into 'Working Groups' (EPP, ALDE) or 'Units' (S\&D) in which cross- 
committee coordination takes place (ALDE, EPP, and S\&D Rules of Procedure). In addition to the parliamentary activities, the groups have their own political activities. They can for example receive visiting delegations from national parties, organise seminars or conferences, command studies, and publish newsletters (Corbett et al, 2016: 139). On behalf of its national parties, in particular concerning governing parties in the Member State that holds the presidency of the Council, groups may organise special briefings for ministers or shadow ministers. In this way, especially for the smaller Member States, groups offer 'a valuable alternative source of information to national civil servants' (Corbett et al, 2016: 139).

However, this project concentrates on intra-parliamentary coordination practices aimed at passing and amending EU legislation through codecision, discussed in section 1.3. The groups' activities within the scope of the parliamentary committees therefore take centre stage, discussed below in 1.2.3.

\subsubsection{Parliamentary committees}

EP activities take place in twenty standing committees. ${ }^{7}$ These committees deal with legislative proposals through the adoption of reports. They propose amendments to the plenary and appoint a negotiation team to conduct negotiations with the Council that are subsequently voted on in the plenary. In addition, committees adopt own-initiative reports, organise hearings with experts and scrutinise the other EU bodies and institutions

\footnotetext{
7 AFCO (Constitutional Affairs), AFET (Foreign Affairs), AGRI (Agriculture and Rural Development), BUDG (Budgets), CONT (Budgetary Control), CULT (Culture and Education), DEVE (Development), ECON (Economic and Monetary Affairs), EMPL (Employment and Social Affairs), ENVI (Environment, Public Health and Food Safety), FEMM (Women's Rights and Gender Equality), IMCO (Internal Market and Consumer Protection), INTA (International Trade), ITRE (Industry, Research and Energy), JURI (Legal Affairs), LIBE (Civil Liberties, Justice and Home Affairs), PECH (Fisheries), PETI (Petitions), REGI (Regional Development), TRAN (Transport and Tourism).
} 
(EP website, consulted March 2018). The work of committees is supported by a secretariat, which is discussed in chapter 3 (see 3.1.1). Overall, the bulk of the parliamentary activities relates to drafting legislation (Yordanova, 2013: 4; EPRS briefing, 2014). The scope of this study is therefore delimited to intra-parliamentary coordination activities aimed at passing and amending EU legislation through co-decision - now the Ordinary Legislative Procedure (see 1.1.1). Accordingly, this sub-section addresses the relevance, composition, and legislative activity of the parliamentary committees. The coordination on legislative texts, taking place within and between the groups, is explored in the next section (see 1.3).

Together with the EP party groups, committees are the institution's key organisational structures (Neuhold, 2001; Hix et al, 2003b; Ripoll Servent, 2018). In the literature, there is broad agreement that in practice the Parliament's positions to a large extent are decided in committee (Bowler and Farrell, 1995; Neuhold, 2001; Kreppel, 2002; Hix et al, 2003b; Ringe, 2010). Committees are the arenas for political deliberation through which majorities are developed (Neuhold, 2001). They have agenda-setting power and it is uncommon for committee reports to be substantially modified or rejected in plenary (Bowler and Farrell, 1995).

The size of committees varies considerably. A committee consists of between 25 and 73 full members and an equivalent number of substitutes (EP website, consulted March 2018). As described above, groups submit a proposal for the distribution of committee seats taking into account the EP RoP stipulating that the composition of committees must - 'as far as possible' - reflect the political configuration of parliament (RoP, Rule 199). Overall, MEPs serve on one committee as a full member and on another one or two committees as a substitute member. In their capacity as a substitute 
for an absent member, MEPs enjoy full speaking and voting rights and can even be rapporteurs.

EP committees enjoy a high level of autonomy and thus vary a great deal in terms of activities, norms of conduct, strength, and prestige (Neuhold, 2011; Corbett et al, 2016: 168; Ripoll Servent, 2018). Traditionally, the Foreign Affairs (AFET) committee appeals to many members and has the reputation of holding influential MEPs, yet enjoys relatively few formal powers (Neuhold, 2001). The strength of committees is often considered in relation to their influence on the budget and on legislative outcomes (e.g. Kreppel, 2002; Whitaker, 2011; Yordanova, 2013). Following this line of reasoning, committees with the largest amount of legislative reports adopted are the most influential (Yordanova, 2013). Consequently, MEPs that sit in these committees, or act as (shadow) rapporteur, have the 'best opportunity' to influence legislation (Whitaker, 2011). Moreover, committees with a bigger legislative workload attract more attention from national political parties, which allows MEPs to build a profile (Whitaker, 2011). In the EP, the legislative workload is unevenly distributed across the 20 standing committees (Neuhold, 2001; Whitaker, 2011). ${ }^{8}$ Table 1.2.3 highlights the respective share of committees with the strongest legislative activity in the $7^{\text {th }}$ parliamentary term. The top five of committees accounted for respectively 40 per cent of all legislative opinions adopted in committee, and for 55 per cent of all trilogue meetings held. As the table reflects, these proportions have decreased slightly since the start of the $8^{\text {th }}$ term, though the same eight committees continue to carry the biggest legislative workload.

${ }^{8}$ See footnote 7 for an overview of the 20 standing committees of the EP. 
Table 1.2.3 Legislative activity of EP committees ${ }^{9}$

\begin{tabular}{|c|c|c|}
\hline & \multicolumn{2}{|c|}{ Share of total legislative opinions adopted } \\
\hline EMPL & $8 \%$ & $3 \%$ \\
\hline ENVI & $7 \%$ & $7 \%$ \\
\hline IMCO & $7 \%$ & $4 \%$ \\
\hline ITRE & $9.5 \%$ & $5 \%$ \\
\hline JURI & $8.5 \%$ & $13 \%$ \\
\hline
\end{tabular}

*In addition, LIBE (22\%) and ECON (9\%) hold a significant share of the legislative opinions adopted thus far.

\begin{tabular}{l|l|l} 
& $\begin{array}{l}\text { Involvement in trilogues } \\
7^{\text {th }} \text { term }(2009-2014)\end{array}$ & $8^{\text {th }}$ term (2014-2017)* \\
\hline AGRI & $7 \%$ & $5 \%$ \\
\hline ECON & $21 \%$ & $9 \%$ \\
\hline ENVI & $11 \%$ & $10 \%$ \\
\hline ITRE & $6 \%$ & $2 \%$ \\
\hline LIBE & $11 \%$ & $20 \%$ \\
\hline
\end{tabular}

*EMPL (3\%) and IMCO (2\%) also belong to the committees most involved in trilogues in the $8^{\text {th }}$ term (until April 2018).

Source: EPRS briefings, November 2014 and April 2018

There are several smaller committees with fewer legislative proposals to consider. They either focus on so-called 'own-initiative reports', as is the case in for example the committee on Women's Rights (FEMM). Or they carry out 'specialised tasks' like the committee on Petitions (PETI). In the empirical part of this study both the legislative committees and committees where the parliament has few or no formal powers are explored. It will be interesting to see whether the role of advisors, at least in part, hinges on

${ }^{9}$ See footnote 7 for an overview of the 20 standing committees of the EP. 
the type of committee, something that is to be expected because committees are likely to require distinctive resources.

Several scholars in their exploration of the role of EP committees have pointed to specialisation (Bowler and Farrell, 1995; Corbett et al, 2011: 147; Yordanova, 2013). The trend of further specialisation is reinforced by the EP's expanded legislative responsibilities calling for an efficient division of the workload among several key players in the standing committees, increasingly controlled by the party groups. These players are central to the intra-parliamentary political coordination process (see 1.3). A rapporteur is responsible for a certain topic on behalf of the lead committee in the EP and sets out to synthesise the present views as much as possible in a draft report. Party groups may appoint a shadow rapporteur to negotiate the topic with the rapporteur. Their task is to follow the progress of the report in question, lead discussions within their group, and attempt to find compromises within committee on behalf of their group (Rule 205a, EP RoP). In addition, they represent the group in inter-institutional negotiations. Needless to say, these actors take a very influential and visible role, and therefore, groups dominate the allocation process and strongly compete over the appointment of rapporteurs (Whitaker, 2001; Benedetto, 2005; Yordanova, 2013). For each committee, the groups designate a coordinator to manage the work of the group's members in the respective committee (EP RoP, Rule 205). These MEPs take the lead in developing the group's position on issues tabled in the committee and work closely together with the rapporteurs and shadow rapporteurs (Ripoll Servent, 2018). Moreover, they act as the group's leader and spokesperson in committee both internally, with the other groups, and to the outside world. If necessary, group coordinators convene to prepare decisions and negotiate compromises, notably regarding decisions on procedure and the appointment of rapporteurs (Corbett et al, 2011: 151). 
Similar to leadership positions in the EP, rapporteurships are allotted by a points system. Each group receives a quota of points and the final allocation of subjects is generally a consensual process based on an inter-group shareout of posts (Corbett et al, 2011: 151). It is common for important reports to rotate between the larger groups or for them to be shared through the appointment of co-rapporteurs (Benedetto, 2005). Although the allocation system leads to a proportional distribution of reports between the party groups, dissimilarities within individual groups and between nationalities are observed (Benedetto, 2005). By the use of case studies, Benedetto (2005) finds that 'nationalities and parties with a traditionally high commitment to the EP' attach greater value to attaining reports as a way to influence legislative outcomes. This discussion of the parliamentary structures and actors shows that the party groups play an important role in intra-parliamentary decision-making. The various levels of coordination within this process are considered below.

\subsection{The intra-parliamentary coordination process}

This section demonstrates that the institution's strengthened position in the EU political system and expanded workload increase both the significance and amount of political coordination in the EP. In the context of this study 'political coordination' is understood as the process during which decisions are prepared and made; and priorities are defined as part of a bargaining exercise between different groups of actors. It thus comprises both the formal and informal mechanisms that are needed to reach agreement.

The importance of intra-parliamentary coordination increases the role of the party groups, as they take centre stage in this process (see 1.1.2). The expanded workload means that there simply is more to coordinate within and between the groups. The literature and EP practice regarding intragroup and inter-group coordination are discussed in respectively 1.3.1 and 
1.3.2. Sub-section 1.3.3 considers inter-institutional coordination. The Parliament's negotiation position vis-à-vis the other institutions hinges on the extent to which a unified EP position is reached. Beyond these strategic considerations there are concerns regarding the safeguarding of democratic and transparent decision-making, which require extensive political coordination and negotiation within the Parliament. Rise to such concerns is the practice that inter-institutional negotiations take place in camera and the fact that the EP negotiation team only involves a small number of actors. These developments have generated further politicisation and formalisation in the EP's Rules of Procedure of the intra-parliamentary coordination process that is explored in 1.3.4.

\subsubsection{Intra-group coordination: theory and practice}

Theory

Existing research on the groups has exposed two main 'discoveries' about the functioning of party politics in the institution (Hix, 2009): Party groups increasingly vote in a cohesive way and coalitions are mainly formed along left-right lines (Hix et al, 2007). The first implies that intensive intra-group coordination takes place in the EP, which is discussed below. The second relates to inter-group coordination and is considered in the next subsection.

Scholars have found voting behaviour to become increasingly structured and party group cohesion to strengthen (Hix et al, 2007; Kreppel, 2002; McElroy and Benoit, 2012). Research by VoteWatch Europe examining roll call votes between 2004 and 2014 shows that EPP, S\&D, and the Greens/EFA all have over 90 per cent cohesion, with the Greens/EFA accounting for the most cohesive group (Corbett et al, 2016:142). For the $7^{\text {th }}$ parliamentary term, the EFD group has the lowest group cohesion, namely 48.6 per cent. 
Hix and colleagues (2007) measure cohesion by use of an 'Agreement Index' considering ideological closeness in the voting behaviour of the members of a given group relative to the cohesion of the EP as a whole. They find very high levels of cohesion across the board: The average relative cohesion rose from 81.4 to 88.9 per cent between the first and $5^{\text {th }}$ Parliament. Problematic for the formulation of a coherent group position is the fact that there is no direct electoral mandate and no group discipline (Corbett et al, 2016: 141-142). The party groups bring together preexisting national political parties that are the direct link to the electorate. Therefore, the political authority as well as MEPs' loyalty remains with the national party (Hix and Lord, 1997; Kreppel, 2002). EP groups have no carrots or sticks to reward or discipline their members other than the shared objective of maximising the group's influence on the final outcome. Future rapporteurships could be denied, but existing rapporteurships cannot be withdrawn. Moreover, the decision for re-nomination lies with the national party. In practice, therefore, national delegation leaders determine the allocation of committee membership and key positions in the Parliament's governing bodies (Ripoll Servent, 2018; see also 1.2.1).

The fact that despite these circumstances group cohesion in the EP remains surprisingly strong has led scholars to investigate how cohesive voting behaviour can be explained. According to Kreppel (2002), group cohesion relies on members sharing similar values and ideals (page 208). Corbett et al (2016: 142) claim that most MEPs realise that their main objectives are more likely to be achieved through effective structures and coordinated action with those politically close to them. In their statistical analysis of the determinants for the changing patterns of cohesion in the EP, Hix and colleagues (2007) show that policy preferences of MEPs and national political parties alone cannot explain variations in party cohesion. They find that despite growing internal ideological diversity between the groups' constituting national political parties the EP party groups have become 
increasingly cohesive. Moreover, their study shows that an increase in political group size leads to higher cohesion. Hence, the main motivation for cohesive behaviour appears to be tied to the strategic behaviour of national political parties to maximise their political influence. Larger groups evidently have more impact on parliamentary outcomes, thus providing more incentive to act in a cohesive manner.

Group discipline as a strategy for influence may gain importance in light of the increase of early agreements between the EP and the Council (see Introduction). Bressanelli et al (2016) found the informalisation of EU decision-making to increase voting cohesion of the mainstream party groups (ALDE, EPP, S\&D). The scholars suggest that these groups invest more (successfully) in coordination and discipline for votes on legislation that is pre-agreed in trilogues. Brack's elaborate study (2015) of the behaviour of Eurosceptic MEPs shows anti-establishment or Eurosceptic party groups are characterised by their limited (or lack of) involvement in the traditional aspects of parliamentary activities. Their focus is rather on denunciating EU integration. Notwithstanding, this could very well be a strategy too. The formation of the ENF, following the success of Eurosceptic national parties in the 2014 elections, imparted the group with material and procedural resources. For example, groups enjoy more speaking time in plenary, control the appointment of leadership positions, and the allocation of reports (Ripoll Servent, 2018). These benefits are not available to individual (non-attached) MEPs. Joining forces thus advances their objectives to (collectively) criticize EU policy and decision-making.

A different way of approaching the high level of group cohesion draws from the notion that not all members can be knowledgeable on every issue, nor have the time to develop an individual position on each amendment. For this reason, MEPs who are 'non-experts' generally adopt the position of trusted 'expert' peers with whom they share a common set of preferences 
regarding political outcomes (Ringe, 2010). In the case of the EP, MEPs trust the judgement of their fellow group members in the committee responsible and therefore follow the party voting line. In sum, existing research regarding the intra-group coordination process has revealed high levels of group cohesion and provided several explanations as to why members follow the group line. Cooperation is ideology or policy-driven, however the main impetus appears to be strategic behaviour to either maximise the influence on legislative outcomes, or pursue a common objective. This study builds on these findings by shedding light on how coordinated group positions come about in the day-to-day (informal) processes of Parliament. The practice of intra-group coordination is briefly introduced below and explored in detail in chapter 7 .

\section{Working methods in practice}

Intra-group coordination refers to all activities that take place to formulate a group's position. The following discussion is based on the literature, EP and group RoPs, as well as the in-depth interviews held with group advisors (see 2.5.3).

The intra-group coordination process is prepared in a collaborative way through internal discussions and negotiations involving the leadership, the political coordinator of the committee responsible, and usually the leaders of the national delegations of the group (Corbett et al, 2016: 141). Ideally, this is a consensual process during which the specific interests and sensitivities within a group are weighed and aligned, resulting in a group position that on the whole is acceptable to most members.

There are several mechanisms in place to establish a group line and maintain coherence. First, all groups appoint political coordinators to act as their main spokesperson in the parliamentary committees. They are 
responsible for formulating and safeguarding the group's position and manage the intra-group coordination process (RoP, Rule 205). This process starts during the committee phase during which coordinators convene the members of their group ahead of committee meetings - in 'Committee Prep' - to discuss the group line (Busby, 2013: 197 and I.0.1, 0.5, 1-3, 22). The preparation of such meetings is found to be the core business of group advisors and involves rounding up support within the group, as well as negotiating with the other groups (I.0.1, 0.5, 1-3, 22).

Party groups have their own rules and practices and the extent to which they coordinate activities and positions varies considerably (see 1.2.2). A commonality in the ALDE, ECR, EPP, Greens and S\&D groups, however, is encountered regarding the coordination through thematic cross-committee 'working groups' (interviews with EPP, S\&D, and ALDE advisors). This enables broader discussion in the group and allows members to make use of each other's expertise as some files relate to several policy areas, and thus committees. Moreover, these structures are set in place to safeguard support for the group position in plenary. These meetings are open to all the group's MEPs and decisions reached cannot be revisited in group plenary (Busby, 2013: 197-198). The Greens/EFA interviewees stress that the functioning of these working groups is relatively informal in comparison to the other groups.

With regard to the plenary phase of EP decision-making, one week a month is dedicated to group deliberations. These so-called 'Group Weeks' take place the week before plenary sessions and are used to consider the plenary agenda, to discuss group activities such as conferences and publications, or to hold political debates on major issues or broader political strategy (Corbett et al, 2016: 136). The group leadership and secretariat use these weeks as 'an early warning system' to work towards a group line that is acceptable to the majority of its members (Busby, 2013: 198). In addition, 
groups generally convene during the plenary week in Strasbourg on Mondays, Tuesdays, Wednesdays, and occasionally on Thursdays. Most national delegations, especially from the larger groups, meet during the Group Week and again during plenaries (Corbett et al, 2016: 136). Interviewees underline that advisors' role is crucial during Group Weeks as it is the final chance to get a unified position or change things. In addition, plenary votes are pre-eminently considered 'group business' for which advisors prepare briefings and voting indications. As opposed to the committee stage in which personal assistants may take over. These activities are addressed in detail in chapters 4-7.

Table 1.3 shows that some groups are more heterogeneous than others. A high degree of ideological and national diversity within groups is likely to require more coordination efforts. This is one of the issues further explored in the empirical analysis (chapters 4-7). For groups to maximise their impact on a legislative outcome it is important to synthesise the views of the composing national delegations as much as possible. In addition to the number of national political parties a group comprises, the power balance within the group is an important factor for establishing a group position (Corbett et al, 2016: 143-144). In some groups, positions are likely to be dominated by several national delegations as they account for a large share of the group's seats in Parliament. This could imply that intra-group coordination requires less effort in these groups. For example in the Greens, the German and French national delegations each held a quarter of the group's seats in the $7^{\text {th }}$ parliamentary term. However, the French share dropped to 12 per cent in the next term. And within the ECR the UK and Polish national delegations dominate the group with respectively 46 and 28 per cent of the seats in the $7^{\text {th }}$ term and 27 and 26 per cent in the $8^{\text {th }}$ term. UK and Italian delegations steadily hold the leading position in the EFDD group. The UK's share grew from 41 to 48 per cent between the $7^{\text {th }}$ and 8 
terms and the Italian stake from 28 to 37 per cent. In the ENF French Front National takes the lead with no less than 51 per cent of the group's seats.

Table 1.3 Composition of the EP party groups

\begin{tabular}{l|ll|ll}
\hline & \multicolumn{2}{l|}{ 7 $^{\text {th }}$ term (2009-2014) } & \multicolumn{2}{l}{$\mathbf{8}^{\text {th }}$ term (2014-2019) } \\
\hline & Member & National & Member & National \\
& States & political parties & States & political parties \\
\hline EPP & 26 & 45 & 27 & 47 \\
S\&D & 27 & 31 & 28 & 39 \\
ALDE & 19 & 29 & 21 & 34 \\
GREENS/EFA & 14 & 21 & 17 & 26 \\
GUE/NGL & 13 & 16 & 14 & 19 \\
ECR & 8 & 10 & 18 & 24 \\
EFD(D) & 9 & 9 & 8 & 8 \\
ENF & & & 9 & 9 \\
NI & 9 & 14 & 7 & 11 \\
\hline
\end{tabular}

Source: EP website (consulted, January 2014 and November 2016)

\subsubsection{Inter-group coordination: theory and practice}

Theory

In political science there are two central explanations of party competition and coalition formation (Hix et al, 2007). The first approach takes the desire to maximise the influence of the party or MEP on the legislative outcome as the main factor for predicting behaviour. Following this view, coalitions are determined by the relative size of the groups. In the second approach policy preferences take centre stage and the ideological distance between parties, delegations, or MEPs drives coalition formation. It is likely that coalitions in the EP are controlled by a combination of relative power and the closeness of preferences (Hix et al, 2007).

Studies on inter-group coordination in the EP show that the main dimension of competition is the traditional left-right divide and the principal predictor for coalition formation is ideological distance. Several analyses of voting 
patterns and the level of cooperation between the EP party groups have confirmed this traditional picture of politics (Kreppel and Tsebelis, 1999; Hix and Noury, 2009; Hix et al, 2007; Hix, 2009; McElroy and Benoit, 2012). A second, though less prominent, dimension is pro-anti EU attitude (Hix and Lord, 1997; Kreppel and Tsebelis, 1999; Hix et al, 2007, Corbett et al, 2011). Recent research has suggested that this dimension may have strengthened with the introduction of the Spitzenkandidaten model, predicting a coalition of 'pro-European groups' (Brack and Costa, 2018).

Yet, for several reasons it is unlikely that any particular coalition in the EP remains stable across all issues. First, as the European Union does not have a government-opposition structure, no systematic support or permanent coalitions emerge from Parliament. Instead, coalitions are struck on a caseby-case basis and each vote in Parliament requires a new quest for a majority (Corbett et al, 2016: 143). Second, the fragmented nature of the EP's political spectrum with currently eight groups does not allow for rightor left-centred majorities to be the standard and a majority is difficult to achieve on a narrow left or right basis. More importantly, a narrow majority (divided Parliament) weakens the EP's position in the inter-institutional negotiations. Third, a lot of the legislative work is highly technical which blurs the line between left- versus right-wing arguments. Finally, owing to the EU's wide range of Member States, regional and sectoral interests, it is common to seek widespread agreement. All of these factors command a consensual approach. Therefore, the EP's rapporteur system is designed to work towards finding a consensus in parliament (Corbett et al, 2016: 143).

With Parliament gaining power in the EU's political system, the need for a coordinated position has become more critical than ever before. In order to make compromise deals acceptable to the other institutions, cooperation in pursuit of broad consensus and hence the role of EP party groups have strengthened (Corbett et al, 2016: 144). Although intra-parliamentary 
coordination is a consensual and cooperative process characterised by shifting coalitions and the search for compromise, certain patterns can be discerned as to what constitute the likely coalitions and who drives the coordination process. The Christian Democrats and the Socialists are the only two groups that together hold an absolute majority. Together often referred to as the 'grand coalition', they can generally control the coordination process as any deal struck between the EPP and S\&D is likely to achieve the necessary majority (Kreppel and Tsebelis, 1999; Corbett et al, 2016). Notwithstanding, the left-right cleavage is apparently strong with regard to economic issues, which frequently amounts to the disappearance of the grand coalition (Kreppel and Tsebelis, 1999). The Liberals have a high coalition potential being situated in the centre of the political spectrum and therefore often hold a strategic position (Corbett et al, 2016: 143). A VoteWatch Europe special report (2015) finds that in the first six months of the $8^{\text {th }}$ parliamentary term, the coalition EPP-S\&D-ALDE is more frequent in votes compared to the previous terms. Academic findings are congruent in that overall the grand coalition is most successful. Moderate-left or -right coalitions are next and extremes are basically unsuccessful (e.g. Kreppel and Tsebelis, 1999; VoteWatch Europe, 2015).

A caveat in research regarding voting behaviour, however, is that the votes on the final outcomes are taken as a measure when in fact these are votes on compromises struck beforehand. This make the final vote a difficult yardstick for measuring influence in Parliament. What is more, the informal intra-parliamentary process enables all groups, and even individual members, to be closely involved in defining Parliament's position. The practice of inter-group coordination is briefly introduced below and explored in detail in chapter 7 . 


\section{Working methods in practice}

Inter-group coordination refers to all activities that take place to identify and approach potential partners and the ensuing negotiations to reach agreement on specific legislative texts. As discussed above, the relationship between the EPP and S\&D groups is of central importance in the EP'S consensual working method. Compromise deals are usually negotiated between the two largest groups, either at MEP or staff level, and smaller groups are subsequently confronted with the outcomes on a or leave-it basis (Corbett et al, 2016: 144). It is also common for several groups to agree to support certain of each other's amendments (I.5, 6, 10). Not surprisingly therefore, the practice of 'compromise negotiations' is organised in detail. EP party groups take six-month rotating turns in organising and chairing these negotiations (Corbett et al, 2011: 202). The EP RoP do not specify the precise functioning of these meetings, nor is it fixed who represents a political group. Usually, at least the political coordinators on the issue at hand are involved (Corbett et al, 2011: 202).

EP legislative negotiations are structured by the allocation of committee membership, (shadow) rapporteur and coordinator positions (Jensen and Winzen, 2012). Generally, these actors take a central role in inter-group coordination processes. The rapporteur of a dossier is responsible for sounding out what is acceptable across the groups and synthesising the present views as much as possible. The appointed shadow rapporteurs of the other groups are his or her main interlocutors (Corbett et al, 2016; Jensen and Winzen, 2012). They meet during the committee phase in socalled 'shadows' meetings' to prepare the report and during the plenary phase to negotiate final compromise amendments. In addition to these key actors, all types of supporting staff can be involved in inter-group coordination, i.e. the committee secretariat, group advisors, and MEP assistants (see 3.1.2 for an in-depth discussion of MEPs' sources of political 
advice). The empirical research corroborates the involvement of group advisors in these shadows' meetings. They participate or even replace the designated MEP of their group. The rapporteur is normally there, yet not all of the groups provide shadow rapporteurs for each file. This may be dealt with at staff level (see 7.1.2).

\subsubsection{Inter-institutional coordination: theory and practice}

\section{Theory}

Inter-institutional negotiation through trilogue meetings has become the common working method for reaching legislative agreements' (EP Secretary General, 2015). During the $7^{\text {th }}$ parliamentary term 85 per cent of legislative files were concluded at first reading (EPRS, 2016). Trilogues typically take place behind closed doors, i.e. outside of public and political scrutiny. This upward trend of so-called 'early agreement' has increased the informal dimension of decision-making (Ripoll-Servent, 2018). The move towards a secluded form of decision-making in which only a restricted number of actors are involved has given rise to an academic debate that does not paint a very positive outlook for the EP (see Introduction, and: Farrell and Héritier, 2004; Häge and Kæding, 2007; Héritier and Reh, 2012; Jensen and Winzen, 2012; Bressanelli et al, 2016). Dealing with its extended legislative powers has proved to be a 'competition' between efficiency and transparency (Huber and Shackleton, 2013). One the one hand, it is perceived as a 'coping strategy' to deal with an increased, complex workload (Reh, 2012). However, the exponential increase of early agreements through trilogues is critiqued for a lack of inclusiveness and the disproportional control of a small group of actors over the flow of information and the negotiation process (e.g. Farrell and Héritier, 2003, 2004). 
Several studies have nonetheless demonstrated that the influence of such actors is only limited as the EP developed 'informal rules and norms' that serve to constrain the behaviour of the lead negotiators (Shackleton and Raunio, 2003; Roederer-Rynning and Greenwood, 2015). Moreover, their chances for success are linked to an accurate representation of the (majority) position of the EP (Judge and Earnshaw, 2011; Rasmussen, 2011; Rasmussen and Reh, 2013).

The debate on early agreements and trilogues has many dimensions, yet one thing is uncontested: The informalisation of EU decision-making increases both the importance and extent of intra-parliamentary coordination. This is reflected in the EP RoP and working practices, as is discussed next.

\section{Working methods in practice}

In response to the abovementioned concerns for transparency and legitimacy, several changes to the EP RoP were adopted throughout the $7^{\text {th }}$ and $8^{\text {th }}$ parliamentary terms. ${ }^{10}$ In particular, the procedure to establish the mandate of the EP negotiating team was formalised in the rules. In addition, the room for involvement and intervention by the plenary has increased significantly (see 1.3.4).

The EP RoP stipulate that the Code of Conduct as laid down by the Conference of Presidents (2008) guides inter-institutional negotiations. The

\footnotetext{
10 Subsequent changes to the rules in 2016 and 2017 further formalised the practice of trilogues into the RoP. In 2017, the RoP's Title II chapters 'First Reading', 'Second Reading', 'Third Reading', and 'Conclusion of the Legislative Procedure' (2016 version RoP) were substituted by a new chapter 'Ordinary Legislative Procedure'. This chapter now includes a separate section on inter-institutional negotiations (RoP 2017, Rules 69b-f).
} 
code prescribes that 'political balance shall be respected and all political groups shall be represented at least at staff level in these negotiations.' Whereas the RoP of the $7^{\text {th }}$ parliamentary term did not refer to the specific composition of the EP negotiating team, this was included in the rules of the $8^{\text {th }}$ term. The rules stipulate that the negotiating team is led by the rapporteur, presided over by the committee chair and comprises at least the 'shadow rapporteurs' from each political group that wishes to participate (Rule 69f). The negotiating team thus only roughly accounts for one per cent of the members. Considering that the responsible committee reflecting the EP's political composition - serves as a sounding board, still no more than 10 per cent of Parliament is involved in the inter-institutional negotiation process.

The Code of Conduct furthermore refers to an 'administrative support team' that at least includes the committee secretariat, the political advisor of the rapporteur, the co-decision secretariat and the legal service (see 3.1.1 for an introduction to the EP supporting staff). While previous studies in relation to early agreements have concentrated on the democratic consequences and power shifts within and between the institutions, we still know little about the intra-organisational preparations of the inter-institutional negotiations. Roederer-Rynning and Greenwood (2015) made an important contribution in this respect. In their article, they disentangled the various informal processes that up until then were grouped under the general banner of 'trilogues'. The scholars identify three layers of trilogues, i.e. political (MEPs), technical (staff), and bilateral preparations. The collected empirical data corroborate the involvement of group advisors in these preparations and are further discussed in chapter 7. 


\subsubsection{Stages of the EP coordination process in legislative procedures}

The focus of the study lies on informal coordination and the scope is limited to intra-parliamentary decision-making. This process encompasses all coordination efforts - intra- and inter-group - that take place throughout the legislative decision-making procedure, i.e. from the moment a proposal is submitted to the Parliament until a decision is reached. This sub-section introduces the four common stages of EP legislative procedures.

The thesis sets out to shed light on intra-parliamentary compromise building and the role of advice therein. The focus of the discussion below therefore lies on the coordination mechanisms that the EP has in place to reach a unified position across the party groups. Four common stages of how legislative files progress through Parliament in the Ordinary Legislative Procedure can be identified: Preparatory stage, committee stage, interinstitutional negotiations, and the plenary stage. As political advice may be provided in each of these stages, they are globally introduced below. ${ }^{11}$

Although the agenda-setting powers fall outside of the scope of this study, it is important to briefly mention the various possibilities in this regard. In contrast to many national parliaments, the EP does not enjoy the formal right to initiate legislation (Ripoll Servent, 2018). ${ }^{12}$ The European Council, which assembles the leaders of the EU Member States, defines the EU's general political direction and priorities (article 15 TEU). The EC is responsible for the translation of these priorities into specific legislative proposals (Ripoll Servent, 2018). Nonetheless, this does not give the EC 'a

\footnotetext{
${ }^{11}$ For a more detailed discussion of the legislative procedure, see Corbett et al, 2016 and Ripoll Servent, 2018.

12 Apart from some formal rights under the treaties: for the purposes of adopting a uniform electoral procedure for EU elections and the Statutes for its members and for the Ombudsman (Corbett et al, 2016: 310).
} 
monopoly on ideas' (Corbett et al, 2016: 311). Both the Council and the Parliament may request the submission of any 'appropriate proposals' (respectively articles 241 and 225 TFEU). Furthermore, the EP has developed several instruments to influence the EC's annual and multiannual work programmes (European Parliament, 2015). First, (legislative) own-initiative reports are an important political tool to shape the agenda in the early phase of the legislative cycle (EP RoP, Rule 52). The EP can furthermore draft strategic reports in relation to the EC's Work Programme, monitoring reports, and implementation reports. Yet, the bulk of the EP's output consists of amending and passing EU legislation. Since this is also the primary focus of inquiry, the key stages of intra-parliamentary coordination are set out below.

\section{Preparatory stage}

Normally the legislative procedure starts with a proposal from the EC to the Council and the EP. The EP president then refers it to 'the committee responsible'. Other committees may be asked, or take the initiative to deliver an 'opinion', consisting of amendments to be voted on in the lead committee (EP RoP, Rule 53). If a rapporteur has not previously been nominated based on the annual EC work programme, one is appointed at this time (EP RoP, Rule 49). The practice of naming rapporteurs at an early stage is designed to allow rapporteurs to begin their preparatory work in advance of the publication of the legislative proposal, providing for the opportunity to liaise with the EC and the Council beforehand. The remaining groups appoint shadow rapporteurs to speak and negotiate on behalf of their group, a working method that relieves the group coordinators (Corbett et al, 2016: 185). In preparation of the drafting phase, rapporteurs seek background information from a wide range of sources within and outside the EP to obtain a good understanding of the different interests at stake 
(Corbett et al, 2016: 186). Chapter 3 includes a discussion of MEPs' sources of advice (see 3.1.2).

\section{Committee stage}

In its first reading, Parliament examines an issue in detail, obtains expertise and advice from stakeholders and discusses various policy options internally. Apart from some exceptional cases of urgency - e.g. during the busy period towards the end of a parliamentary term - there is a period of several months of committee discussion before a draft text is produced (Corbett et al, 2016: 189). According to parliamentary practice, rapporteurs only present a draft text after a stocktaking exercise and exchange of views in committee.

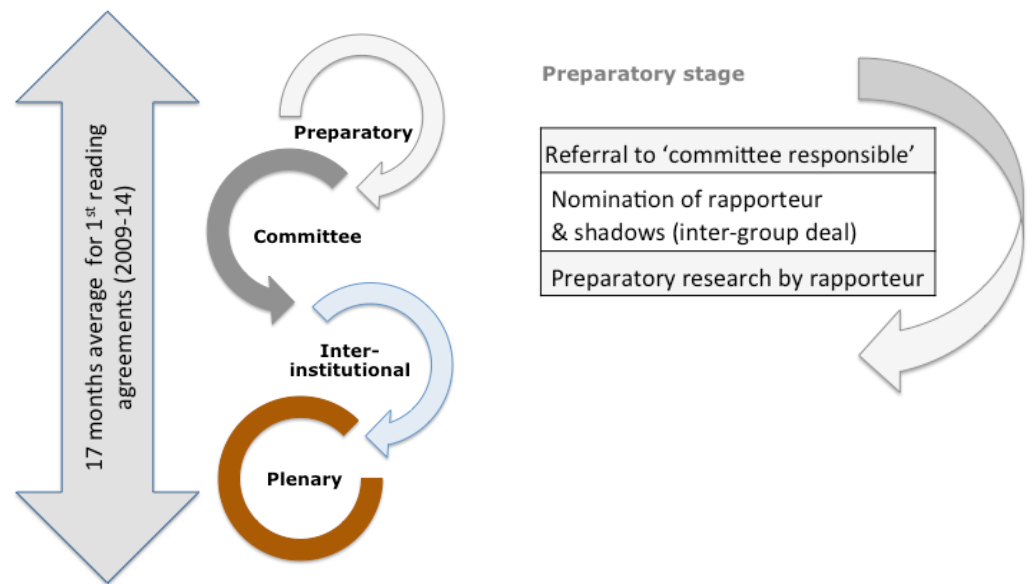

Figure 1.3a Preparatory stage intra-parliamentary coordination

Source: figure created for the purpose of this thesis. Average duration of concluded firstreading agreements obtained through the EPRS briefing, November 2014.

The first step is a debate in committee where an EC representative is usually invited to present the key issues of the text (Ripoll Servent, 2018). During the preparation of the report, a series of informal meetings take place during which the rapporteur coordinates with the shadow rapporteurs, and 
with other EU institutions (Ripoll Servent, 2018). The rapporteur then presents and discusses the proposed amendments to the legislative proposal in committee. Subsequently, informal inter-group negotiations take place and amendments may be submitted (Ripoll Servent, 2018).

After the deadline for tabling amendments has passed, the rapporteur either decides to amend his or her text based on the suggested changes, negotiate compromise amendments, or to proceed to the committee vote on the amendments and the proposal as a whole (Corbett et al, 2016: 190). Before the report is tabled in plenary, the rapporteur draws up the final report taking into account the adopted amendments. Committees can also decide to open inter-institutional negotiations (see below) and thus determine the mandate for the EP negotiation team (EP RoP, Rule 69c).
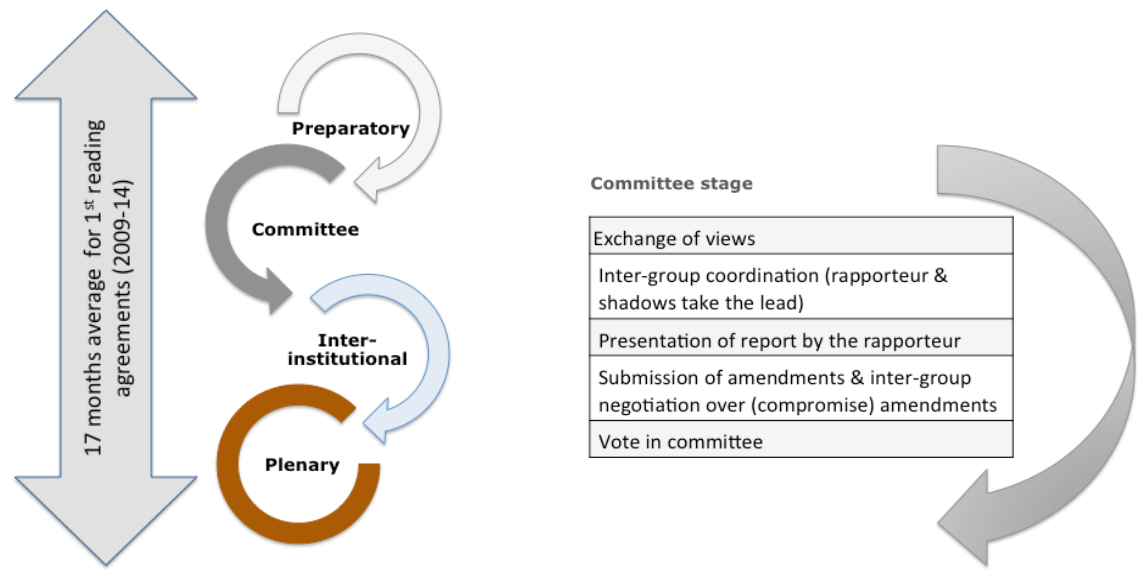

\section{Figure 1.3b Committee stage intra-parliamentary coordination}

Source: figures created for the purpose of this thesis. Average duration of concluded firstreading agreements obtained through the EPRS briefing, November 2014. 


\section{Inter-institutional negotiations}

Once a committee has adopted a legislative report, it may decide by majority vote to enter into negotiations (Rule 69c). Up until 2017, a plenary debate and vote on the issue could only take place at the request of one of the groups (RoP 2016, Rule 74). This has changed and now the decision of the lead committee to open trilogues must be announced at the first plenary session following that decision. Party groups may call for a vote that would then take place the next day of the same session (Rule 69c). If Parliament rejects the committee's decision to enter into negotiations with the Council, a deadline for amendments is set and the draft report of the committee responsible is put up for a vote during the next plenary session (Rule 69c). Thus either the report adopted in the lead committee or in plenary at first reading constitutes the mandate of the negotiation team. Before the 2017 changes of the RoP, the mandate was formed by the report adopted in the committee responsible, or failing that, a mere set of amendments, objectives, priorities or orientations (RoP 2016, Rule 73).
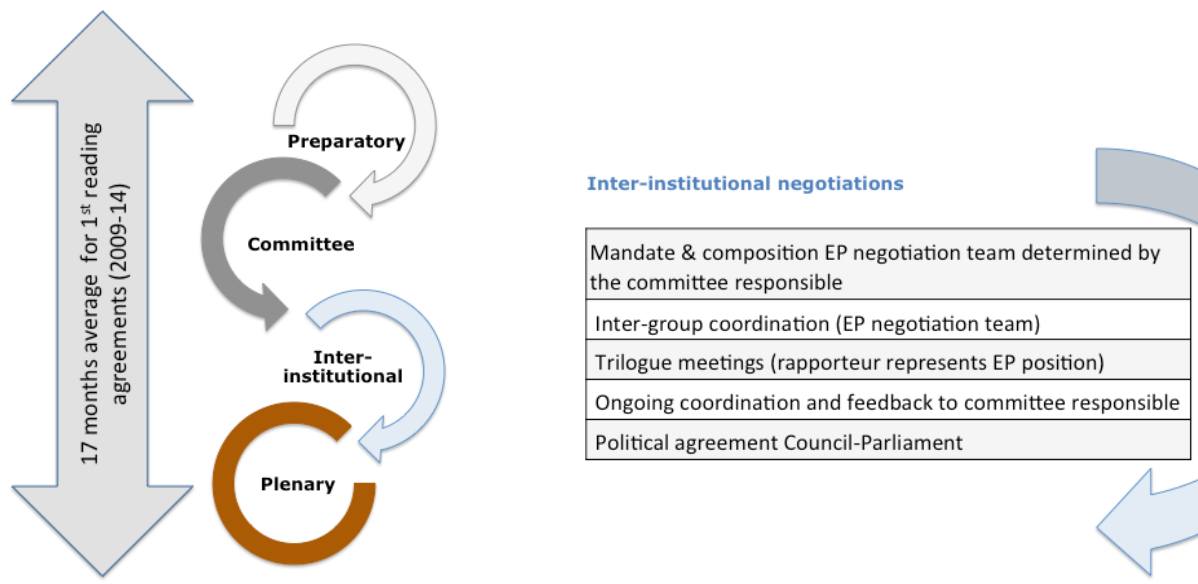

Figure 1.3c Inter-institutional negotiations

Source: figure created for the purpose of this thesis. Average duration of concluded firstreading agreements obtained through the EPRS briefing, November 2014. 
Because these inter-institutional negotiations start in the committee phase extensive intra-parliamentary political coordination is needed before and throughout the negotiations in order to formulate and uphold a unified Parliament's position. Generally, a meeting between the rapporteur and 'shadows' takes place prior to a trilogue in order to coordinate the EP's position in the negotiations. The negotiating team is required to report back to the committee and immediately notify their colleagues once a compromise is reached. When the lead committee receives the Council position at first reading, it may provide the EP negotiating team with 'guidelines' or amendments for the elements that are not covered by the Parliament's position at first reading (Rule 69e).

\section{Plenary stage}

For the conclusion of a legislative procedure in plenary, inter-group negotiations take place to reach compromise amendments. Usually, either agreement is reached to replace several amendments by one composite text, or a deal is struck to support some of each other's amendments (Corbett et al, 2011: 202-203). The plenary vote is based on the position adopted in committee and amendments tabled by the groups or at least 40 members. However, at this stage, the submission of new amendments is rare (Ripoll Servent, 2018). In case of early agreement with the Council (see above), the plenary votes to adopt or reject a package of amendments resulting from the trilogue negotiations.

A typical plenary process involves a presentation by the rapporteur setting out the view of the committee responsible, followed by a response from the EC and the Council (RoP, Rule 59). Next, opinions from other committees may be heard as well as from spokespersons from each of the other groups (shadow rapporteurs or coordinators). Once all the views are presented, the 
EC representative responds to the report and amendments. Finally, the rapporteur may take the floor (Corbett et al, 2011: 197).

The empirical analysis in chapters 4-7 comes back to the various stages of decision-making as political advice may be provided throughout each of them.

\subsection{Concluding remarks}

The discussion of the evolution of the legislative powers of the EP showed two related characteristics that are key to the study. First, the institution is known for its consensual style of decision-making. The need for a unified Parliament has become ever more significant now that the institution's legislative powers cover virtually all policy domains and the vast majority of EU legislation is agreed in trilogues. Second, the expansion of the EP's legislative powers went hand-in-hand with an increasing importance of the EP party groups and increasing informalisation of EU decision-making.

The trilogues only involve a fraction of decision-makers. From a normative point of view, the intra-parliamentary coordination practices are therefore crucial to safeguard the democratic legitimacy of EU decision-making. To tackle the concerns for transparency, the EP has taken measures to strengthen the mandate of its negotiating team and the room for intervention by the plenary. The pursuit for compromise and the strengthened position of the EP in the inter-institutional triangle highlight the significance of intra-parliamentary coordination. All compromises require considerable coordination efforts, within the groups and between them. Group advisors are expected to play an important role in the (informal) preparation of these compromises, and are involved in the preparations of inter-institutional negotiations. The following chapter develops a framework to study this role. 



\section{CHAPTER 2. ANALYTICAL FRAMEWORK: THE CONCEPTUALISATION OF POLITICAL ADVICE}

Political advice is construed as advice provided to politicians by non-elected actors. In general terms, the 'political advisor' forms a distinct type of actor who can neither be classified as a civil servant nor as a political actor. (S)he is hired to serve and contribute to the political priorities and objectives of the politician or political party they work for. Further tied to the fact that this particular group of actors has remained rather eclipsed in the academic debate, no fitting theory to study this type of advice was encountered. Therefore, for the study of political advice, this chapter develops an analytical framework. It develops the theoretical concepts to address the question under which conditions advisors can assume a political role. As part of the framework, the concept of political advice is defined (2.1), a typology of four analytical categories of advice is conceptualised (2.2), and a set of factors deemed to affect the provision of political advice is distilled from the literature (2.3). The operationalisation of these general concepts to the specifics of the European Parliament (EP) is presented in chapter 3.

Section 2.1 develops a definition for the concept political advice, drawing from and building on the literature reviewed in the Introduction (section II). The analytical delineation of what is considered overtly 'technical' or 'political' is the main challenge in this respect (2.1.1). Political advice is conceptualised to entail both and is therefore approached as an alternative category (2.1.2). The political scope of advisors' role is construed in relation to their room for manoeuvre. From the literature three incremental modes of discretion are inferred (2.1.3). 
The function and nature of political advice are further conceptualised in section 2.2. This chapter shows that political advice manifests itself in various ways (2.2.1). Drawing from the body of literature that explores legislators' needs for information and expertise the activities that political advice may comprise are categorised into four types of advice (2.2.2). From this typology four distinct, yet non-exclusive, ideal-type roles are developed that advisors may adopt, each containing technical and political elements.

To explore the circumstances under which advisors may assume these roles, section 2.3 identifies seven factors from the literature. The extent to which each factor affects delegation by the legislator is assessed per role in chapters 4-7. The various concepts that are defined in sections 2.1-2.3 form the analytical framework and are summed up in section 2.4.

Finally, the methodological approach to the implementation of the framework is discussed in section 2.5. The next chapter operationalises the concepts of the framework for the case of the European Parliament (EP) and chapters 4-7 then present the empirical analysis.

\subsection{The definition of political advice}

Previous studies have shown that officials' input into the legislative process can take various forms and that officials can perform tasks that go beyond the technical or administrative sphere of activity (see Introduction, section II). Yet, in order to examine how advisors contribute to political processes it is necessary to first conceptually disentangle the political and the technical dimensions of activity. ${ }^{13}$ The first sub-section considers how scholars have been dealing with the issue and concludes that the two

\footnotetext{
13 Being aware of the multiple connotations of 'technical', and lacking a more appropriate word, the concept is used in this study to provide an analytical category to the alternative to the political dimension of advice.
} 
dimensions overlap and 'meet' in the informal processes in which political positions or decisions are prepared. As no definition is available for what exactly characterises 'political advice', one is developed in 2.1.2.

Building on the existing literature, it is inferred that within the category of political advice the political scope of activities can differ. To assess the extent to which the role is political, 2.1.3 develops three incremental modes that are tied to the discretion of the advisor: routine, reactive, and proactive behaviour.

\subsubsection{The technical and political dimensions of advice}

In the discourse of legislative organisation scholars uphold that officials make a significant contribution to the coming about of decisions taken by the elected representatives (Patterson, 1970; Arnold, 1987). In this respect, previous studies have shown that officials can perform tasks that go beyond the technical or administrative sphere of activity in the US Congress (Hammond, 1984 and 1996), in the Council of Ministers (Christiansen, 2002; Fouilleux et al, 2005), in the EP (Winzen, 2011; Dobbels and Neuhold, 2013; Neuhold and Dobbels, 2014), and in the case of national parliaments (Winzen, 2014; and Högenauer and Neuhold, 2015). Drawing from these contributions it is inferred that officials may perform tasks of a political nature: Activities that require political assessments or have a potential impact on the political process. Yet, what then is considered purely 'technical' or 'political' proves difficult to disentangle (Fouilleux et al, 2005; Winzen, 2011). The ambiguity is not related to authority as it is clearly demonstrated that the final say in decision-making remains the prerogative of the elected representatives. Instead, the overlap is tied to the informal process in which political decisions are prepared. To demonstrate how this conclusion is reached, below the literature that explores how advice may enter the political sphere of activity is reviewed. 
The endeavour to separate the two spheres of activity dates back to the Weberian tradition and remains one of the most challenging questions in public administration research. Politics-administration dichotomy theory is grounded on the proposition of a division of labour and authority between the political (elected) and technical (non-elected) spheres of activity. The 'technical' function is linked to expertise and understood as the knowledge and skills needed to provide support and advice to legislators. The 'political' function relates to providing technical experts with political guidance and controlling their actions. The political dimension lies in the assessment of ideological values and choices, as well as tactics and strategy to pursue a certain outcome. Generally this function is considered the turf of elected actors or appointed visible representatives who can be held accountable for their actions. Administrative staff is supportive and their tasks depend on the authority and instructions of the political principal. ${ }^{14}$ Despite substantial critique (see e.g. Demir and Nyhan, 2008), the continued academic interest for the position of administrators in relation to politics is explained by the legitimising premise of legislative authority and autonomy resting with the elected representatives. Although responsibility and authority are clearly separated - i.e. the preparations versus the actual decision-making - it is with officials' political assessments and the potential political implications thereof that the distinction becomes fuzzy. The need for such judgement seems likely in the preparation of political positions, negotiations, and decisions.

Radaelli (1999) also approaches the 'technical' dimension in connotation to expertise. In line with Weber, he defines politics in terms of 'value choices' and technocracy as 'behaviour based upon expertise'. According to Radaelli, the European policy debate is characterised by a 'battle of ideas' through

\footnotetext{
${ }^{14}$ For a more in-depth discussion of the dichotomy discussion please refer to: Roth and Wittich (1978), Demir and Nyhan (2008), Peters (2009), and Sager and Rosser (2009).
} 
which knowledge provided by experts enters the sphere of politics. In his discussion of the 'political role of expertise' he underlines the two sides of technical expertise: a concept, on the one hand, associated with virtuous problem-solving capacities, and on the other hand a pejorative representation of the intransparency of EU decision-making. The solution of this 'paradox' lies in making expertise more accountable in a politicised environment, Radaelli argues.

Romzek and Utter (1977) provide a different approach to expertise with their examination of 'professionalism' among Congressional legislative staff. By applying data gathered through interviews to Brante's sociological typology of professions (1990), they find that Congressional aides fit the category of 'political profession' comprising government and political elites, and higher civil servants. According to Brante's typology, 'political professionals' have gone through a process of socialisation and as a result these officials can operate with relative autonomy based upon 'specific expertise' (Brante in: Romzek and Utter, 1997). This expertise is drawn from a set of 'unwritten, tacit knowledge' that is inaccessible to the general public.

Fouilleaux et al (2005) find that actors develop strategies to either politicize or depoliticize issues. In their view the 'political' and 'technical' spheres overlap in practice. They argue that the overlap stems from the institutional nature of the EU decision-making system. The ambiguity of the politicaltechnical distinction allows for a certain amount of flexibility that is necessary to reach compromises at EU level, a process in which administrators are instrumental. The nature of EU decision-making thus leads to a politicisation of the 'technical sphere' through increased interaction between officials of the different EU institutions. 
While the activities of officials are labelled as influential and potentially have political impact, the common thesis is that they ultimately remain subordinate. The distinction between administrative and political activity thus primarily is considered as a difference in 'responsibility' (Page and Jenkins, 2005). Politicians' prevailing needs for information and expertise define the role of officials in political processes and their contribution is legitimised by the provision of such expertise. However, expertise is not by definition non-political and advisors can build and use political competence (Romanyshyn and Neuhold, 2013).

In the analytical model of Romanyshyn and Neuhold (2013) 'political competence' includes the 'generation of ideas', 'the interpretation of interests', and policy-related advice provided to negotiators on how to achieve compromise solutions. They find that the distance between the domains of the politician and the official are increasingly shrinking, which gives cause for concern of the conceptual boundaries. They therefore raise the suggestion that 'political advisors' could be the alternative category situated between the concepts civil servant and politicians (Carboni, 2010; Eichbaum \& Shaw, 2010 in: Romanyshyn and Neuhold, 2013).

Dobbels and Neuhold (2013) and Winzen (2011) confirm the notion that the final say always remains with the politician who can restrict the role of the official. The authors nonetheless pinpoint some political functions of the procedural and informational work of EP officials in committee secretariats. Political assessments include for example the pre-selection of relevant issues for the committee agenda, the assessment of the feasibility of or support for given policy options, and the facilitation of an exchange of views to work towards compromises (Winzen, 2011). In a series of case studies exploring the type of tasks delegated, Dobbels and Neuhold (2013) find that EP officials in the committee secretariats draft compromise amendments, prepare trilogue meetings (albeit with a clear mandate from the rapporteur) 
and actively take part in the intra-parliamentary negotiations. In a proposal to reform legislative assistance in the EP, then EP vice-president James Provan describes that there is an 'amalgam of technical-administrative and political functions' with no clear solution at hand (Provan in: Neunreither, 2002). In his report, Provan (2001) defines 'political' assistance in relation to providing policy definitions, political coordination within the political group, with other groups, national delegations, party constituencies, and suchlike. In his examination of the role of Council Secretariat officials in the EU legislative cycle, Christiansen (2002) posits that the support to ministers and member state representatives concerns 'highly political matters'. They actively assist the Council presidency in finding a compromise by maintaining relationships with officials from the European Commission (EC) and the EP throughout the legislative process.

In sum, considering the distinction between the technical and political dimensions as a mere difference in responsibility or authority is insufficient for the study of political advice. Although correct, more is needed to account for the overlapping spheres of activity. The political aspects identified in this sub-section occur in the process of preparing political decisions. Advisors' contribution to this process is further conceptualised in the remainder of the chapter.

\subsubsection{Political advice: a mixed sphere of activity}

The aim of this study is to examine advice provided by non-elected actors to elected actors in the preparation of political positions, decisions, and negotiations. 2.1.1 determined that in such activities the technical and political activity spheres are hard to disentangle. 'Political' action is driven by value choices and ideology and is the responsibility of the elected actors. The 'technical' level is determined and often equated with 'expertise'. However, expertise is not by definition non-political and advisors can build 
and use political competence. This sub-section sets out to define political advice beyond a mere difference in responsibility and develops a conceptual working definition.

Political delegation theory generally emphasises on outcomes instead of exploring the process leading up to a decision. The position of non-elected actors is examined questioning accountability, autonomy and what drives actors. It is found that officials' activities enhance efficiency, stability and continuity in decision-making and their (political) role is determined by the prevailing needs for expertise or information legislators may have (see Introduction). Previous studies have also shown that officials anticipate priorities and preferences of the politician and base their actions on these insights (Patterson, 1970; Page and Jenkins, 2005; Olsen, 2006). From the discussion it is inferred that the informal contribution of advisors may reinforce the position of the politician. The dissertation adds a new dimension to the debate on the role of officials by conceptualising what a 'political role' by advisors might entail, and theorising a positive relation between the contribution of non-elected actors and the position of the elected representatives.

It has been established that in practice the technical and political spheres of activity overlap. As part of the framework that is developed in this chapter, political advice is construed as an alternative category positioned in a mixed activity sphere in which the 'political' and 'technical' functions meet. This mixed sphere is illustrated by figure 2.1.2. For the study of political advice an analytical separation based on a difference in responsibility (politics-administration dichotomy theory) does not suffice. To further and more clearly define the political dimension of advice, the following additions are derived from the literature: (1) Anticipation of 
political priorities and desired outcomes (Patterson, 1970; Page and Jenkins, 2005; Olsen, 2006), and (2) the use of implicit knowledge and tactics to formulate and execute strategies to realise the desired outcome (Brante in: Romzek and Utter, 1997).

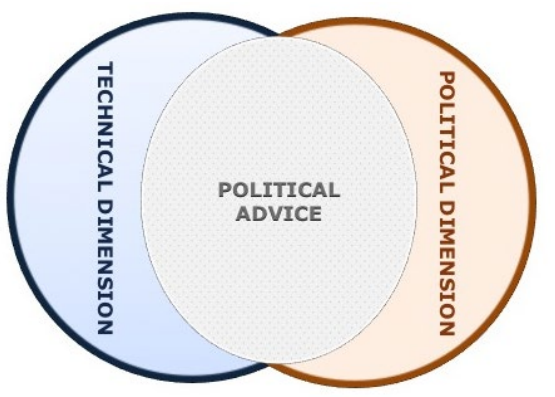

Figure 2.1.2

Mixed sphere of activity

The methodology section of this chapter addresses the application of the analytical framework in detail (see 2.5.1). For each of the types of political advice - developed below in 2.2 - the hypothetical technical and political elements are introduced (chapters 4-7). In light of the empirical research, an assessment of these elements is then made in order to find whether the mixed sphere of activity indeed holds true.

\subsubsection{Conceptualising the scope of political advice}

The previous sub-section defined political advice, drawing from political delegation theory and the body of research on the role of legislative staff. It was established that in addition to a difference in responsibility, the level of improvisation manifested by the advisor is key to the demarcation between the technical and political spheres. His or her judgement, anticipation, and the choice of tactics all relate to forms of improvisation. Building on the existing literature, it is inferred that within the category of political advice activities can be executed in various manners. To assess the extent to which the role is political three incremental modes are proposed that are tied to the discretion of the advisor: routine, reactive, and proactive behaviour. The role becomes more pro-active as the advisor's room for improvisation increases. These modes are further explained below and derived from the logic of appropriateness theory (in particular Page and 
Jenkins, 2005) and organisational behaviour literature (in particular Mayes and Allen, 1977).

The institutionalist logic rejects Weber's approach to bureaucracy characterised by a focus on hierarchical authority and formal rules or instructions. Instead, it is argued that officials anticipate the preferred outcome and improvise the appropriate line of action guided by their expertise and experience (Patterson, 1970; Page and Jenkins, 2005; Olsen, 2006). Discretion can be exercised without interfering with authority or hierarchy, which 'are ever present' (Page and Jenkins, 2005: 128). Rather, it is exercised where hierarchical measures or political authority are not directly applied. If instructions are lacking, the question arises what 'cues' advisors use to determine the appropriate course of action (Page and Jenkins, 2005: 108).

To further conceptualise the discretion of advisors in political processes, inspiration is drawn from the definition of 'organisational politics' introduced by Mayes and Allen (1977). These scholars put forward that 'politics' take place in varying degrees in all organisations, yet, not all behaviour can be categorised as 'political'. They argue that outcomes alone are insufficient to define political behaviour and that the process whereby the outcomes are achieved (or influenced) must be taken into account. In that way, their approach allows for the inclusion of behaviour or influence that is not typically labelled as political. Mayes and Allen (1977) provide the following definition:

"Organisational politics is the management of influence to obtain ends not sanctioned by the organisation, or to obtain sanctioned ends through nonsanctioned influence means."

Applying this definition to the context of political advice renders two dimensions along which the contribution of advisors may be considered: 
(1) 'Ends' versus 'means'. The 'ends', in this regard, are translated into objectives or priorities, i.e. the desired political outcome. The 'means' relate to the process that takes place in order to achieve the desired outcome, i.e. the selected tactics and approach of the advisors.

\section{(2) Explicit instructions versus no instructions (i.e. improvisation).} Instructions relate to the advisor's mandate. In theory, both 'ends' and 'means' can be either instructed or improvised. For example, the outcome may be derived from the ideology of the party group. In the context of legislative decision-making processes and particularly in the case of the EP, which is the focus of this study, multiple desirable outcomes are at play. In the EP the outcome that a party group pursues is the product of intra-group coordination (see 1.3.1). When instructions or clear guidance are lacking, advisors have to rely on their interpretation and judgement to conceive an outcome that is acceptable to the majority. In such situations, the selection of the required 'means' is guided by what the advisor deems appropriate or necessary. Alternatively, the 'means' could be instructed or implied in unwritten rules or common working methods within the party group. In that case, the discretionary behaviour in attaining the desired outcome is delineated by those informal norms.

Building on the logic of anticipation, three modes are conceptualised to assess the level of discretion of advisors:

a) 'Routine mode': activities are guided by an explicit mandate.

b) 'Reactive mode': either the 'means' or the 'ends' require improvisation on the part of the advisor.

c) 'Pro-active mode': the advisor has the room to determine both the 'means' and 'ends', based on his or her interpretation or judgement.

According to Mayes and Allen (1977), activities that are 'sanctioned' by the organisation are considered to be non-political. This relates to routine job 
performance. Behaviour is categorised as political when either the ends or the means are not sanctioned. Tying this theory to the definition of political advice that was developed in 2.1.2, it can be inferred that the political scope of advice hinges on the level of initiative and improvisation by the advisor.

Figure 2.1.3 illustrates the three modes. The political scope of advice thus increases as the need to improvise grows. The role is most political (proactive mode) in situations in which advisors not only have the discretion to construe what a desirable compromise (end) may be, they also determine the type of assistance or information required in the process towards achieving that goal (means). In the empirical analysis the modes of discretion are used to evaluate the political behaviour of advisors. As part of the framework, the modes will allow for the examination of the extent to which a (reactive or pro-active) role is acceptable, in the eyes of the elected representatives as well as from a normative point of view.

ENDS

Explicit instructions No instructions

(improvisation)

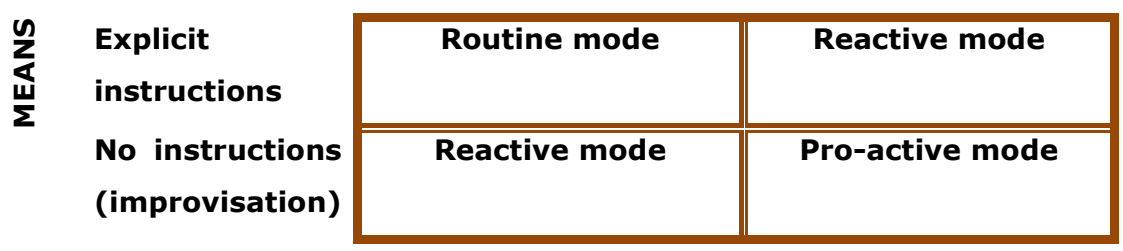

Figure 2.1.3 Conceptualising the political scope of the role of advisors

In sum, the political scope of the role of advisors is assessed across two dimensions. To label the role as routine, reactive, or pro-active the following is examined:

(i) The way in which advisors receive instructions or construct their mandate.

(ii) The extent to which advisors have room to improvise in the provision of political advice. 
The next section develops four types of political advice. In chapters 4-7, the assessment of the political scope is presented per type of advice based on the empirical findings.

\subsection{Towards a typology: the functions and nature of political advice}

The previous section developed a definition for political advice. To explore the provision of such advice, a better understanding is required of the scope of activities it entails. To that end, 2.2.1 identifies the general elements of the function and nature of advice. Building on existing classifications of the role of officials, 2.2.2 maps the types of support required by legislators. This typology of political advice translates into four distinct ideal-type roles that advisors may adopt, each containing technical and political elements.

\subsubsection{The function and nature of advice}

Policy advice is provided in different institutional settings. The introduction of this thesis offers an overview of the key studies that set out to understand the role of officials at the executive level (Page and Jenkins, 2005; Peters, 2009), in the US Congress (Patterson, 1970; Price, 1971; Fox and Hammond, 1977; Burks and Cole, 1978; Hammond, 1984 and 1996;), in EU Member State parliaments (Blischke, 1981; Campbell and Laporte, 1981; Ryle, 1981; Winzen, 2014; and Högenauer and Neuhold, 2015); in the Council of Ministers (Christiansen, 2002; Tallberg, 2004; Fouilleux et al, 2005), and in the EP (Provan in: Neunreither, 2002; Winzen, 2011; Dobbels and Neuhold, 2013; Busby, 2013; Neuhold and Dobbels, 2014). These scholarly discussions provide the analytical building blocks to develop a framework to study political advice. Building on the assumption that the activities of officials are determined by politicians' information needs, a clearer understanding and categorisation of these needs is necessary to 
explore the (multiple) role(s) from which advisors can choose. First, some general elements of the function and nature of advice are distilled from the literature. The next sub-section maps the types of support required by legislators and develops a typology of political advice.

Considering the body of literature on the role of legislative staff, 'political advice' has hitherto not been studied as a separate category or type of expertise (see 2.1). Yet, as stated above, existing studies offer insights as to the needs of legislators and the activities of officials to meet these needs. From these requirements, the following general elements of political advice are inferred: (1) Expertise offered by political advisors is an internal resource for the politician to tackle efficiency problems (e.g. Christiansen, 2002; Tallberg, 2004; Winzen, 2011; Busby, 2013); (2) and to maintain an independent position from the executive (Hammond, 1984 and 1996; Blischke, 1981; Campbell and Laporte, 1981; and Ryle, 1981; European Parliament, 2000); (3) Expertise is not subject-based and rather related to a general mastery of the organisational process of law-making and the anticipation of needs of legislators (cf. Page and Jenkins' 'improvised expertise'); (4) Political advisors act on a type of unwritten, tacit knowledge acquired through their experience within the institution (cf. Brante's 'specific expertise' of political professionals in: Romzek and Utter, 1997; Page and Jenkins' 'improvised expertise, 2005).

Drawing from the anticipation logic theory, advisors are expected to base their actions, or construct their role, on what the circumstances demand (e.g. Page and Jenkins, 2005; Olsen, 2006; Peters, 2009). It is therefore expected that there are multiple (political) roles and that adoption of a given role may depend on several personal and contextual factors. The latter is further addressed in 2.3. The next sub-section develops four ideal-type roles for political advice. 


\subsubsection{A typology of political advice}

The literature that aims to understand the role of officials in political processes shows that advisors' input into the legislative process can take various forms. The literature review showed that previous studies have identified important technical and political aspects of this role (see Introduction). Yet, existing classifications are either non-exhaustive or they appear to unite different activities into one category. For example, Provan's category 'political assistance' entails the formulation of policy definitions as well as the coordination of political positions. Although these activities both entail political elements they are likely to require very different things from the advisor. Winzen's 'Informant' comprises the processing of information as well as the provision of substance-related expertise. Again, this may call for different skills or efforts on the part of the advisor. The assessment of political advice, thus, calls for clearly defined analytical categories to delineate the various types of input.

Drawing from and building on the reviewed body of literature, four categories of legislators' needs for information and expertise are identified and translated into a typology of political advice. They are briefly introduced below and the sources for inspiration are summed up in table 2.2.

(1) Process management: organisational support; (tactical) advice on the legislative process, parliamentary procedures, and informal practices of the institution; agenda management; and actor involvement (Congressional 'Office of the Parliamentarian' in: European Parliament, 2000; Ryle, 1981; Provan in: Neunreither, 2002; Tallberg, 2004; Winzen, 2011; Busby, 2013; Högenauer and Neuhold, 2015). 
Chapter 2

Table 2.2 Typology of political advice

Process management

\begin{tabular}{|c|c|}
\hline $\begin{array}{l}\text { Advice on parliamentary rules and procedures ('office of } \\
\text { the Parliamentarian') }\end{array}$ & $\begin{array}{l}\text { European Parliament, } \\
2000\end{array}$ \\
\hline Advice on procedures and administrative services & Ryle, 1981 \\
\hline $\begin{array}{l}\text { Advice on procedures, legal issues; } \\
\text { Organisational support for meetings }\end{array}$ & $\begin{array}{l}\text { Provan in: Neunreither, } \\
2002\end{array}$ \\
\hline $\begin{array}{l}\text { Staffers' procedural resources facilitate } \\
\text { multilateral brokerage }\end{array}$ & Tallberg, 2004 \\
\hline $\begin{array}{l}\text { Organising meetings, structuring the agenda, actor } \\
\text { involvement }\end{array}$ & Winzen, 2011 \\
\hline Agenda management & Busby, 2013 \\
\hline Legal and procedural advice ('analyst role') & $\begin{array}{l}\text { Högenauer and } \\
\text { Neuhold, } 2015\end{array}$ \\
\hline \multicolumn{2}{|l|}{ Information management } \\
\hline Intelligence & Patterson, 1970 \\
\hline Exchange information with lobbyists, interest groups & $\begin{array}{l}\text { Fox and Hammond, } \\
1977\end{array}$ \\
\hline Research assistance & $\begin{array}{l}\text { Provan in: Neunreither, } \\
2002\end{array}$ \\
\hline Informal exchange of information at staff level & Christiansen, 2002 \\
\hline Informational resource & Tallberg, 2004 \\
\hline $\begin{array}{l}\text { In touch with the broader interests at stake ('democrat } \\
\text { role') }\end{array}$ & Peters, 2009 \\
\hline $\begin{array}{l}\text { Officials provide the information foundation by pre- } \\
\text { selecting issues }\end{array}$ & Winzen, 2011 \\
\hline Assistants are the information interface & Busby, 2013 \\
\hline $\begin{array}{l}\text { Gather and forward summarised information } \\
\text { ('administrative assistant role'); and the pre-selection } \\
\text { of information ('agenda shaper role') }\end{array}$ & $\begin{array}{l}\text { Högenauer and } \\
\text { Neuhold, } 2015\end{array}$ \\
\hline
\end{tabular}




\begin{tabular}{|c|c|}
\hline \multicolumn{2}{|l|}{ Policy expertise } \\
\hline Innovation ('shaping policy') & Patterson, 1970 \\
\hline Policy entrepreneurs & Price, 1971 \\
\hline $\begin{array}{l}\text { Provide policy-oriented briefings to the members ('US } \\
\text { Congress' Research Service') }\end{array}$ & $\begin{array}{l}\text { European Parliament, } \\
2000\end{array}$ \\
\hline $\begin{array}{l}\text { Support in the drafting of proposed legislation ('US } \\
\text { Congress' Office of the Legislative Council') }\end{array}$ & $\begin{array}{l}\text { European Parliament, } \\
2000\end{array}$ \\
\hline $\begin{array}{l}\text { Assisting the rapporteur in the examination of } \\
\text { legislative proposals }\end{array}$ & $\begin{array}{l}\text { Campbell and Laporte, } \\
1981\end{array}$ \\
\hline Substantive advice & Blitschke, 1981 \\
\hline Providing policy definitions; drafting documents & $\begin{array}{l}\text { Provan in: Neunreither, } \\
2002\end{array}$ \\
\hline Policy work ('production role') & Page and Jenkins, 2005 \\
\hline $\begin{array}{l}\text { Involvement in policy-making by giving advice } \\
\text { ('policy maker role') }\end{array}$ & Peters, 2009 \\
\hline $\begin{array}{l}\text { Providing expertise regarding the substantive content } \\
\text { of policy proposals ('informants') }\end{array}$ & Winzen, 2011 \\
\hline Policy-shaping tasks ('policy-making role') & $\begin{array}{l}\text { Dobbels and Neuhold, } \\
2013\end{array}$ \\
\hline $\begin{array}{l}\text { Content-related advice and interpretation } \\
\text { ('advisor role') }\end{array}$ & $\begin{array}{l}\text { Högenauer and } \\
\text { Neuhold, } 2015\end{array}$ \\
\hline \multicolumn{2}{|l|}{ Brokering } \\
\hline Intra-institutional as well as inter-institutional integration & Patterson, 1970 \\
\hline Organising floor support & Burks and Cole, 1978 \\
\hline Facilitating compromises & Christiansen, 2002 \\
\hline Political coordination & $\begin{array}{l}\text { Provan in: Neunreither, } \\
2002\end{array}$ \\
\hline Negotiate compromises that form the basis of a decision & Fouilleux et al, 2005 \\
\hline $\begin{array}{l}\text { Mediating function through which officials build and } \\
\text { maintain relationships with the outside world } \\
\text { ('negotiator role') }\end{array}$ & Peters, 2009 \\
\hline $\begin{array}{l}\text { Mediating function with other institutions } \\
\text { ('coordinator role') }\end{array}$ & $\begin{array}{l}\text { Högenauer and } \\
\text { Neuhold, } 2015\end{array}$ \\
\hline
\end{tabular}


(2) Information management: gathering and processing information in order to create overview, filter or select the most relevant (sources of) information, and provide legislators with political intelligence through informal information exchange (Patterson, 1970; Fox and Hammond, 1977; Provan in: Neunreither, 2002; Christiansen, 2002; Tallberg, 2004; Peters, 2009; Winzen, 2011; Busby, 2013; Högenauer and Neuhold, 2015).

(3) Policy expertise: substantive, content-related advice that includes policy orientations, definitions and interpretations, and the formulation of (draft) legislative texts (Patterson, 1970; Price, 1971; Congressional 'Research service' in: European Parliament, 2000; Blitschke, 1981; Campbell and Laporte, 1981; Provan in: Neunreither, 2002; Peters, 2009; Winzen, 2011; Dobbels and Neuhold, 2013; Högenauer and Neuhold, 2015).

(4) Brokering: fulfilling a mediating function and facilitating compromises by providing internal and external political coordination, advice on negotiation strategy and organising support for political positions (Patterson, 1970; Burks and Cole, 1978; Christiansen, 2002; Provan in: Neunreither, 2002; Fouilleux et al, 2005; Peters, 2009; Högenauer and Neuhold, 2015).

From the typology four distinct, yet non-exclusive, ideal-type roles are developed that advisors may adopt, each containing a both technical and political elements. Table 2.2 sums up the various elements of political advice that are borrowed from the literature including their sources. Chapters 4-7 discuss the theoretical elements of each of the categories in further detail and apply the empirical data to the roles. 


\subsection{Factors that affect the discretion of the advisor}

In the previous sections the 'political dimension' of advice and the various types of advice have been conceptualised. The next step is to identify the conditions under which political advice may be provided. Drawing from the anticipation logic theory, advisors are expected to base their actions, or construct their role, on what the circumstances demand (e.g. Page and Jenkins, 2005; Olsen, 2006). Hence, the adoption of a given role is expected to depend on the context as well as on certain personal competencies or attributes.

From the literature seven factors are identified that affect politicians' evaluation to delegate or restrict the activities of their advisors. An overview of the factors with the major sources for inspiration is set out below. In the analysis, they are used to assess whether the factor facilitates or restricts a political role.

\subsubsection{Personal factors}

Drawing from the literature regarding the position of officials in public administration four personal factors are expected to affect advisors' mandate and room for improvisation: Trust, institutional memory, informal network, and political sensitivity. For the selection of the factors, the feasibility of assessing the impact of each factor was an important consideration. The personality of advisors, their ambition, and their sensitivity to social norms are for example individual traits that may account for differences in behaviour. Not only would such personal characteristics be hard to 'measure', the aim of this dissertation is to better understand the process of providing advice. Rather than focusing on individual differences between advisors, this process-oriented approach sets out to identify activity and behaviour patterns in the provision of advice. 


\section{Trust}

The type of tasks delegated and advisors' discretion to execute these tasks is affected by the relationship between the politician and the advisor. Personal relationships and the interplay between officials and the elected representatives are characterised by mutual understanding, loyalty, and trust (e.g. Patterson, 1970; Dobbels and Neuhold, 2013). In the debate on delegation, ample attention is devoted to measures to control the behaviour or influence of officials. Political oversight measures are generally too formal to be applied to legislative staff, which leads to the idea that politicians' main form of control, is trust (Högenauer and Neuhold, 2015). However, the literature typically ties the concept of trust to neutrality (e.g. Neunreither, 2002; Winzen, 2011). Yet, following the anticipation logic that has been used to conceptualise the political role of advisors (see 2.1) a more substantial role is construed for advisors who the delegating politician trusts to have a shared ideology and political affiliation. In a discussion of parliamentary party staff in the German Bundestag, Blischke (1981) supports this idea. He claims that the position of party officials is one of 'special trust' and that the extent to which Members of the EP (MEPs) accept their advice depends on this relationship of trust.

Conceptually, 'trust' is hard to grasp. A common theory regarding the discretion granted to officials, however, is that politicians are likely to empower agents whose 'ideal outcomes' lie close to or converge with their own, thus keeping administrative actions as close as possible to their own values and ideas (e.g. Arnold, 1987; Gailmard and Patty, 2012). Egeberg and colleagues (2013) examined levels of loyalty or affiliation driving EP staff by way of an online survey and find European allegiance to overall outweigh national concerns considerably. Whereas EP secretariat officials tend to give priority to sectoral concerns, political group advisors are mostly 
committed to the ideological values of their group. They therefore tend to prioritise the arguments of external actors with similar affiliations.

Building on these discussions, trust is likely to depend on the advisor's proven knowledge of and affinity with the ideological orientations and policy priorities of the political party. In addition to (past) political experience, duration in office (seniority) and track record could lie at the basis of trust.

\section{Informal network}

Politicians rely on supporting staff to contribute to fulfilling their needs for information and expertise (Arnold, 1987; Hammond, 1984 and 1996). The problem of information asymmetry in public administration upholds that the myriad of actors involved in decision-making processes are rarely endowed with all the relevant information. The influence of officials arises from the 'private information' they are able to gather (Gailmard and Patty, 2012). In this line of thought, analysis of the relationship between elected and nonelected actors centres on how politicians can overcome this 'information asymmetry' (Moe, 2005; Gailmard and Patty, 2012). Information is often gathered and exchanged through informal channels (Busby, 2013). Officials can have a substantial contribution in legislative negotiations through their informal connections, thus constituting a valuable resource that allows for 'privileged access' to information (Christiansen, 2002). This privileged information results from the cooperation and exchange of information with officials from the other EU institutions. Their insight into the different interests and sensitivities facilitates compromise building at EU level.

From the theory, the assumption is derived that exchange of information is necessary and can take place through informal networks. The exchange goes beyond the interplay between elected and non-elected actors and reaches further than the scope of the institution. The definition of informal network relates to the overall network of the advisor, thus comprising the 
exchange of information with various internal and external actors. The degree to which advisors are allowed or inclined to meet with external stakeholders will therefore in part determine the extent of their network.

\section{Institutional memory}

The contribution of officials to political processes is justified through reasons of efficiency, stability and continuity (Weber in: Roth and Wittich, 1978; Peters, 2009). Politicians delegate tasks motivated through a need for information and a lack of resources. Officials can be the constant factors in institutions where politicians come and go, and contribute through their knowledge of internal rules and procedures. They are a valuable source of information for the elected representatives because they embody the 'institutional memory' (Romzek and Utter, 1997; Egeberg et al, 2013) and ensure continuity in policy-making (Romzek and Utter, 1997; Peters, 2009).

Along these lines, Christiansen (2002) identifies 'bureaucratic memory' of the Council Secretariat as an important resource in the legislative negotiations between the EU Member States. The idea is that officials have knowledge of or easy access to the institutional records and contribute through 'personal insights' resulting from their involvement over time in the policy process or in party politics. The extent to which officials successfully employ these assets determines their contribution. In their capacity as a source of information regarding past decisions and proposals, they operate mostly in the background giving advice to ambassadors and ministers. Lacking any kind of formal powers, their role is one of 'quiet influence' in the words of Christiansen. While they have opportunities to contribute to the political process, officials' actions are limited to reacting to the policy proposals or pieces of draft legislation that enter the house. 
Drawing from this work, institutional memory is expected to depend on the advisor's knowledge of or access to the institution's track record complemented with personal insights acquired through duration in office and (prior) political experience.

\section{Political sensitivity}

In dynamic political coordination processes clear instructions are often lacking or tend to be implicit or implied. Under these circumstances advisors pro-actively seek political direction, or a 'steer' (Page and Jenkins, 2005: 149). The institutionalist logic presumes officials to use their expertise and experience in anticipating the appropriate course of action. They base their forecasts on the priorities and orientation of the politician (Patterson, 1970) and 'indicators of what is likely to be acceptable to ministers' guide their actions (Page and Jenkins, 2005: 108). This requires the ability to recognise and pursue political and administrative cues (Page and Jenkins, 2005: 165). The capability to do so comes with experience in a certain field or institution and empathy with the political views and priorities the advisor is serving. It involves gaining an understanding of how things work in practice and abiding by the prevailing informal code of conduct, as well as exploiting these insights to anticipate strategies (Busby, 2013: 136). All things considered, it implies that advisors are able to acquire and develop 'a feel for the game' (Adler-Nissen, 2009). For the analysis this attribute advisors may possess or develop is defined as political sensitivity.

Building on the literature discussion, political sensitivity is expected to depend on the advisor's personal insights acquired through duration in office and (prior) political experience or involvement. 


\subsubsection{Contextual factors}

Drawing from the literature regarding the position of officials in public administration three contextual factors are identified that play a role in politicians' evaluation to delegate (political) activities or restrict the advisor's room for improvisation: Political direction, complexity, and politicisation. The major sources for inspiration are set out below.

\section{Complexity}

Officials' expertise on technical matters is considered as a source of influence (Moe, 2005; Gailmard and Patty, 2012). The notion that politicians simply do not have the time or the knowledge to master all issues in detail and therefore rely on (expert) advice in shaping their views and decisions is generally accepted. Delegation in part is explained through the complexity of policy issues. In 'technically complex' legislative proposals staff involvement increases (e.g. DeGregorio, 1994; Wilson in: Kettl, 2000).

In the context of the US Congress, Manley (1968) contends that due to the increased scope and complexity of governmental activity, legislators rely on staff assistance to be duly informed and remain independent of the executive branch: "As the complexity of the decisions facing legislators increases so too does the likelihood that the staff will exert influence on the outcomes." In their exploration of the role of EP officials in committee secretariats, Dobbels and Neuhold (2013) also find that the opportunity for intervention increases in highly technical or complicated policy areas.

Following these interpretations, it is assumed that when 'complexity' increases legislators are more likely to seek assistance and grant advisors a political role. Complexity is defined in relation to the subject matter and thus expected to vary across policy domains of parliamentary committees or specific policy or legislative proposals. 


\section{Political direction}

This dissertation theorises a positive relation between the contribution of non-elected advisors to the legislative process and the position of the elected representatives. Advisors provide expertise tailored to the needs of the legislator therefore strengthening his or her position. The hypothesis is that this reinforcement is mutual, thus positioning the relationship between advisors and elected representatives as one of interdependent strength.

The effectiveness of politicians depends on their position in the field (Wodak, 2009: 14-15). By extension, the role of advisors is expected to be tied to the position of the politician. If the politician's position (or reputation) is strong the advisor can more easily anticipate the desired process or outcome. In the absence of a political steer advisors look for cues to base their behaviour on (Page and Jenkins, 2005: 149). It is assumed that advisors' ability to identify such cues depends on the extent to which the politician - or political party - they serve is outspoken and reputed.

Political direction is thus defined in relation to the superior of the advisor: The reputation and experience of the politician or political party the advisor works for affect the degree to which they can assume a political role.

\section{Politicisation}

Politicisation manifests itself in differentiated forms and degrees (De Wilde et al, 2016). To facilitate the empirical analysis of the concept, De Wilde and colleagues developed a three-dimensional approach. The first dimension is 'salience' which is tied to the attributed importance and outside awareness of the issue. 'Polarisation' as a measure of disagreement is the second dimension. Finally, 'actor and audience expansion' is included in their framework as the extent to which external actors are engaged in policy making. 
The role of staff is affected by the scope of the decision that is being prepared. "The more salient the issue is to a large number of participants the less likely the judgment of the staff will direct the decision" (Manley, 1968). Salience combines the characteristics 'importance attributed to the issue' and 'the degree to which issues are (perceived as) problems'. "It is possible for something to be a problem but of little importance. It also is possible for something to be important but not a problem. Whether something is an 'important problem' reflects the combined effect of the two" Wlezien, 2005).

In the context of the EP, Neuhold and Dobbels (2014) show that the role of officials in committee secretariats is reduced in dossiers that cause division within and across the political groups. Clearly, as polarisation grows the need for coordination in the House also increases, which allows for a greater potential role for the advisor. Staff members keep each other abreast of the latest developments and controversial issues (Busby, 2013: 191). Although the advisors' amount of work may increase, their room for manoeuvre is predicted to decline as MEPs become less inclined to delegate. Busby furthermore reports that MEPs are more likely to follow their own interpretation and 'make an independent decision' when it concerns a 'controversial issue'. Controversy of legislation is related to specific implications for the Member State or salience (Busby, 2013: 193).

For the analysis, politicisation is assessed in relation to attributed importance (important problems), outside attention and involvement, and division in Parliament. It is something that can change over time and vary across policy areas.

Table 2.3 sums up the personal and contextual factors that are hypothesised to either facilitate or restrict the adoption of a political role. The analysis explores whether one or several of these factors are decisive. 
The aim is to explain the circumstances under which legislators delegate political tasks to their advisors (chapters 4-7).

Table 2.3 Factors that affect the discretion of the advisor

\begin{tabular}{|c|c|}
\hline \multicolumn{2}{|r|}{ Personal factors } \\
\hline Trust & $\begin{array}{l}\text { Linked to mutual understanding, loyalty, knowledge of and } \\
\text { affinity with party ideology and priorities (Arnold, 1987; } \\
\text { Patterson, 1970; Blischke, 1981; Neunreither, 2002; Winzen, } \\
\text { 2011; Gailmard and Patty, 2012; Dobbels and Neuhold, 2013; } \\
\text { Egeberg et al, 2013; Högenauer and Neuhold, 2015). }\end{array}$ \\
\hline $\begin{array}{l}\text { Informal } \\
\text { network }\end{array}$ & $\begin{array}{l}\text { Access to and exchange of private information through informal } \\
\text { connections within and outside the institution (Arnold, 1987; } \\
\text { Hammond, } 1984 \text { and 1996; Christiansen, 2002; Moe, 2005; } \\
\text { Gailmard and Patty, 2012; Busby, 2013). }\end{array}$ \\
\hline $\begin{array}{l}\text { Institutional } \\
\text { memory }\end{array}$ & $\begin{array}{l}\text { Insight in and access to the institutional track record (Romzek } \\
\text { and Utter, 1997; Christiansen, 2002; Peters, 2009; Egeberg et al, } \\
\text { 2013). }\end{array}$ \\
\hline $\begin{array}{l}\text { Political } \\
\text { sensitivity }\end{array}$ & $\begin{array}{l}\text { Understanding of the institution's informal code of conduct and } \\
\text { the ability to recognise political and administrative cues, allowing } \\
\text { for the anticipation of (negotiation) strategies (Patterson, 1970; } \\
\text { Page and Jenkins, 2005; Adler-Nissen, 2009; Busby, 2013). }\end{array}$ \\
\hline \multicolumn{2}{|r|}{ Contextual factors } \\
\hline Complexity & $\begin{array}{l}\text { Defined in relation to the issue under consideration and the } \\
\text { process of coordination (Manley, 1968; DeGregorio, 1994; Wilson } \\
\text { in: Kettl, 2000; Moe, 2005; Gailmard and Patty, 2012; Dobbels } \\
\text { and Neuhold, 2013). }\end{array}$ \\
\hline $\begin{array}{l}\text { Political } \\
\text { Direction }\end{array}$ & $\begin{array}{l}\text { Tied to the position of the politician based on his/her reputation } \\
\text { and experience (Page and Jenkins, 2005; Wodak, 2009). }\end{array}$ \\
\hline Politicisation & $\begin{array}{l}\text { Tied to the importance attributed to an issue, outside attention } \\
\text { and involvement, and division in Parliament (Manley, 1968; } \\
\text { Wlezien, 2005; Busby, 2013; Neuhold and Dobbels, 2014; De } \\
\text { Wilde et al, 2016). }\end{array}$ \\
\hline
\end{tabular}




\subsection{The analytical framework for political advice}

The previous sections of this chapter have delineated the concepts that together constitute the analytical framework for political advice:

Political advice is defined as a mixed sphere of activity where technical and political functions meet. The analytical separation of 'technical' and 'political' tasks is more than a difference in responsibility alone (politicsadministration dichotomy theory). It comprises the anticipation of political priorities or desired outcomes and involves the use of tactics to formulate and execute strategies to realise these desired outcomes.

Political advice is theorised to manifest itself in three incremental modes of discretion: routine, reactive, and pro-active. The scope of advice is assessed according to the degree to which activities are guided by a clear mandate (instructed) or by the advisor's interpretation and judgement (improvised).

The examination of the function and nature of advice requires clearly defined analytical categories. While building on existing classifications of the role of officials, a typology was developed that specifically aims to capture political advice. It translates into the following ideal-type roles: Process Manager, Information Manager, Policy Expert, and Broker. The proposition is that advisors may adopt all four roles depending on what the circumstances require.

Finally, seven factors that affect political delegation are distilled from the literature. The personal attributes trust, informal network, institutional memory, and political sensitivity are expected to have an impact on the advisor's discretion. Three levels of the context are expected to affect delegation and trigger potential differences across the groups, committees, 
policy domains, or specific files: political direction (the advisor's superior), complexity (the substance matter), and politicisation (political landscape). The idea is that the factors are instrumental in predicting the (optimal) circumstances in which political advice may be provided.

The framework was developed in such a way that it may be applied in various institutional settings. In this study it is implemented to explore how political advice provided by group advisors contributes to the informal process of coordinating political positions and decisions in the EP. The next section discusses how the framework will be implemented.

\subsection{Methodology}

This chapter has developed an analytical framework to study political advice. This section discusses the methodological approach to the implementation of the framework to the specific context of group advisors in the EP. A mixed methods approach has been selected for the study. 2.5.1 considers the rationale behind this choice. The following sub-sections introduce the qualitative methods (2.5.2) and the quantitative method (2.5.3). The first entails document analysis and interviews. The qualitative research was complemented with an online survey among political group staff in the EP. Finally, 2.5.4 discusses how the framework developed in this chapter is implemented by way of combining the qualitative and quantitative data in the empirical analysis.

\subsubsection{Mixed methods research}

During the last decades, mixed methods research has evolved and can be considered the 'third methodological movement' in addition to quantitative and qualitative approaches (Tashakkori and Teddlie, 2003 in: Creswell and Plano Clark, 2011). The combination of methods can relate to mixing viewpoints, data collection, analysis, and inference techniques for 'purposes 
of breadth and depth of understanding and corroboration' (Johnson et al, 2007). It is based on the assumption that the combined use of quantitative and qualitative approaches provides a more complete understanding of research problems than either approach alone (Creswell and Plano Clark, 2011). The approach is particularly suited to the inquiry of social processes because it allows 'multiple ways of seeing and hearing, and making sense of the social world' (Greene, 2007: 20). Creswell and Plano Clark therefore call mixed methods an 'intuitive' approach to research that closely relates to what we encounter in everyday life $(2011: 1)$ : i.e. the tendency to present a convincing quantitative perspective - numbers and trends together with individual stories and examples to provide colour (Creswell and Plano Clark, 2011: 1). According to the scholars we find such tendencies for example in documentaries, newspaper articles, and also in political speeches or debates.

Mixed methods research thus allows for a more comprehensive approach and enables the collection of both statistical trends and personal narratives. It is fitting to the study of political advisors because it allows for an exploratory design. As no existing framework for political advice was available, a typology was developed from the theory. The choice for the mixed methods approach is further motivated due to the very limited existing empirical evidence on political advisors. From a qualitative perspective, this study aims to broaden our understanding of what political advice entails and how it is provided. From a quantitative perspective, it sets out to test the framework and identify some generalisable patterns in relation to political advice.

The combined design was intended from the outset. The study is conducted according to the convergent parallel design (Creswell and Plano Clark, 2011: 80). Each strand is discussed in further detail below (2.5.2 and 
2.5.3), followed by a sub-section on implementation and how the two strands are brought together in the analysis (2.5.4).

\subsubsection{Qualitative strands: document analysis and interviews}

Document analysis

Document analysis entails finding, selecting, appraising, and synthesising specific content to disclose insights or contexts relevant to the inquiry (Bowen, 2009). The rationale for document analysis lies in data triangulation, supplementary data, background and context, or tracking change and development (Bowen, 2009).

The process-oriented approach of the study requires an in-depth understanding of the evolution of the intra-parliamentary coordination process, its internal procedures and informal practices. In part this is based on evidence provided by the literature review on group cohesion and competition (e.g. Kreppel, 2002; Hix et al, 2007) and literature on the internal functioning of the EP (Corbett et al, 2011 and 2016). In addition, a range of EP reports, briefings and online sources were studied. A complete overview of all analysed documents is included in Appendix I. Here, the main data analysed and logic behind it is mentioned.

The EP Rules of Procedure were studied to acquire further insight into the EP structures and functioning. A particular important development that was tracked between 2009-2017 was the subsequent rounds of change in the Rules that led to a formalisation of the EP's dealings with inter-institutional trilogues. The Rules of Procedure of the ALDE, EPP, Greens/EFA and S\&D groups rendered information about their internal organisation. The specific working structures of each of the group secretariats were identified from the EP party groups' websites. 
The EP establishment plan 2014 was used to obtain figures to establish the total number of group staff. Yet, these numbers did not specify the share of political or policy advisors. To determine the (approximate) amount of political advisors per group the staff sections on the respective group websites provided the required data.

EPRS Facts \& Figures briefings $(2014,2016,2017)$ offered both background information as useful statistics regarding for example the legislative activity of the EP and the various parliamentary committees in the $7^{\text {th }}$ parliamentary term. In addition, several internal briefings were studied to appreciate the EP's strategy to deal with its evolving legislative powers, and most significantly its role in the inter-institutional dialogue (see Appendix I).

Finally, an analysis was conducted of vacancy notices published on the EP party groups' websites between 2011 and 2016 (see Appendix I). Unfortunately, the amount of published vacancy notices did not yield a balanced picture across the groups. Nonetheless, supplementary data apropos group advisors' job profile and an indication of their responsibilities could be inferred from the documents. These insights were used for the operationalisation of the theoretical framework to the case of the EP, and for the survey design (see 2.5.3). The operationalisation is further addressed in chapter 3 and in the first sections of the four analytical chapters.

\section{Interview design}

The aim of the qualitative interviews was twofold: First, to further explore the issues and process central to the research question (Weiss, 1994: 1011). In this regard, data collection took place by way of six informal, exploratory interviews. In February 2012, interviews were held with a former group advisor, two MEP assistants, one former MEP assistant, and 
an EP official. In October 2013, a final exploratory interview was held with a national delegation advisor within one of the EP group secretariats. These interviews formed part of the preparatory design phase and helped shape the interview and survey design.

The second aim was to 'integrate multiple perspectives' on the role of political advice in the EP (Weiss, 1994: 10). Although case studies are a common strategy for 'how' and 'why' questions that facilitates the analysis narrative of social processes (Gerring, 2001), this study takes a different approach. The principal motivation is that with a common sample size somewhere between one and four, generalisation of a theory is impossible (King et al, 1994). A case-study approach would thus not be in keeping with the (qualitative and quantitative) aims of the study (see 2.5.1). Instead, the interviews explore all conceivable activities political advisors in the EP may be involved in. The integrative approach of the study allows for testing the framework and assessing the factors in a variety of contexts. An advisor's role may be limited to Process Manager in one dossier while in another (s)he acts as Policy Expert, and a combination of roles is also conceivable. Alternatively, within one dossier the advisor of group A may adopt different roles in comparison to the advisor of group B. In sum, the main reason for this approach is to keep all probabilities open and explore generalisable patterns in relation to political advice. Moreover, the traceability of advisors linked to a specific 'case' would likely significantly decrease their willingness to cooperate, as it would be problematic to uphold the guarantee of anonymity.

The following guidelines were considered in the selection of interviewees: (1) Variation in the nature of parliamentary committees, including both legislative-intensive committees and committees of a more political 
nature ${ }^{15}$; and (2) a distributed participation across the political groups active at the time. ${ }^{16}$ The first and second guidelines combined resulted in an initial sample illustrated in table 2.5.2a. Advisors assigned to the respective committees from each of the political groups were approached.

Table 2.5.2a Initial sample interviewees

\begin{tabular}{|l|c|c|c|c|c|}
\hline & Other* & AFET & INTA & ITRE & ECON \\
\hline $\begin{array}{l}\text { Potential } \\
\text { interviewees }\end{array}$ & 1 & 7 & 7 & 7 & 7 \\
\hline Actual interviewees & 1 & 5 & 2 & 3 & 4 \\
\hline
\end{tabular}

* A Head of unit (and former group advisor) was approached as 'key informant' (Weiss, 1994: 20). This happened on the introduction by one of the interviewees following the exploratory interview.

Table 2.5.2b Final sample interviewees

\begin{tabular}{|l|c|c|c|c|c|c|c|c|c|}
\hline & Other & AFET & INTA & ITRE & ECON & IMCO & LIBE & FEMM & ENVI \\
\hline $\begin{array}{l}\text { Potential } \\
\text { interviewees }\end{array}$ & 1 & 7 & 7 & 7 & 7 & & & & \\
\hline $\begin{array}{l}\text { Actual } \\
\text { interviewees }\end{array}$ & 3 & 5 & 2 & 3 & 4 & 3 & 2 & 1 & 1 \\
\hline
\end{tabular}

Interviewees were always asked to recommend colleagues that could be approached for an interview. This was very helpful in recruiting interviewees because advisors proved overall more willing to cooperate following introductions. Yet, this practice to some extent interfered with the purposive selection of the sample, as table $2.5 .2 \mathrm{~b}$ illustrates. Nonetheless, the guideline with regard to the variation in the nature of committees is respected. The legislative activity of the AFET, INTA, and FEMM committees

\footnotetext{
${ }^{15}$ See figure 1.2.2 that illustrates the legislative activity of the EP committees.

16 The ENF group is not represented as the empirical data collection took place before its foundation, i.e. between November 2013 and July 2014.
} 
is low (8 interviews), whereas that of ITRE, ECON, IMCO, and ENVI is high (11 interviews). The LIBE committee combines a legislative and political nature. ${ }^{17}$ The two interviews with advisors in this committee thus collect examples of procedures of legislative texts and political resolutions.

In total, 22 semi-structured in-depth interviews were conducted with (former) group advisors between November 2013 and June 2014. In 2018, another two interviews were held to triangulate the findings. A full list of (anonymised) interviewees is included in Appendix V. In respect to the second guideline for selection, the overview of the distribution of interviewees shows an overrepresentation of two groups (see table 2.5.3 below). ALDE and Greens/EFA advisors were particularly willing to cooperate and are as such overrepresented in the findings. Given the aim of integrating multiple perspectives in a qualitative manner and the absence of case studies, this overrepresentation does not significantly affect the empirical analysis.

The interviews were structured around a listing of topics with questions and possible follow-up questions used as the 'interview guide' (Weiss, 1994: 48). The interview guide is included in Appendix IV. The questions were phrased in an open way and special care was taken to not lead the interviewee in a particular direction in both the questions and the introduction of the study. For example, the four roles of the framework were not explicitly introduced, nor were the factors.

The 22 semi-structured interviews (2013-2014) were all conducted in Brussels, either in group advisors' offices or in one of the coffee bars of the $E P$, or outside the Parliament. The interviews lasted somewhere between 30 minutes and an hour. The choice of location was left up to the preference

\footnotetext{
17 See 1.2 .3 for an introduction of the 20 standing committees in the EP.
} 
and convenience of the interviewee. One of the triangulation interviews (2018) was conducted in The Hague and another via Skype. Eleven of the interviews were recorded with the permission of the interviewee. For the remainder, notes were taken either because the interviewee declined to be taped or because the interview took place in a noisy setting.

\subsubsection{Quantitative strand: survey design}

The qualitative data have been complemented with an online survey among political group staff in the EP. The aim is to explore political advisors' profile and main activities, as this group of actors have not previously been documented in a structured way. In addition to exploring generalisable patterns in relation to political advice, the survey is used to test the analytical framework.

The exploratory interviews and document analysis (see above) provided inspiration in the development of the questionnaire. In particular, this was the case for the questions regarding the advisor's skills, core activities and interlocutors (see Appendix II, questions 5, 7, 8, 12). A 'pilot test' is a critical component of survey designs and helps identify technical errors or problems with wording (Iarossi, 2006: 11). A trial run took place (3 individuals) and led to a slight revision of the questions for the sake of clarity. In addition, a printed version of the questionnaire was discussed with three interviewees. The objective was to evaluate the length and comprehensibility of the survey and the extent to which answer options were considered exhaustive. Another important check was whether advisors would feel comfortable answering the questions.

The survey consists of 20 questions: 13 multiple-choice and seven openended questions. As a rule, participation was estimated to take between 10 and 20 minutes of their time. To that end, the number of questions was 
limited in order to attain the largest possible response rate. For the same reason, no 'required' questions are included that respondents are obligated to answer in order to continue. The survey is divided into three parts and a progress indicator was used to stimulate completion (Couper et al, 2001). No word limit was set for the answers to open-ended questions providing room for personal accounts or examples, which generally led to detailed responses. Moreover, six multiple-choice questions include a category 'other' giving respondents the chance to add information or answer in their own words. The closed questions that do not include this option for example inquire after the group and parliamentary committee the respondent works for, his or her professional working experience, and linguistic capabilities. The final question is whether advisors have any comments or suggestions to add. The complete questionnaire is provided in Appendix II.

The survey was conducted between May and July 2014. To offset the risk of a biased estimate and to collect as many responses as possible, the complete target population of 308 EP group advisors was invited to participate in the survey. They were approached via e-mail introducing the research project and leading them to the survey via a link. Participation was under the guarantee that all provided information remains strictly confidential and is aggregated and analysed in a non-personalised way only. 99 individual responses were collected, which amounts to an overall response rate of 32 per cent. Table 2.5.3 reports the response rate broken down per political group.

In terms of gender, the survey response rate shows a fairly balanced picture: 56 respondents are male and 43 are female. However, in terms of affiliation to the political groups, the data are not representative due to the differential response rates of the seven EP party groups (sub-groups of the population). Like in the interview sample, a response bias is observed among the ALDE and Greens/EFA advisors. In the presentation of the data, 
the issue of representativity is handled by always considering the overall picture as well as potential differences across or within the groups. Any significant variations are reported. Where it concerns variation between the groups the interviews serve as an additional empirical source.

Table 2.5.3 Overview of survey respondents and interviewees

\begin{tabular}{|l|c|c|c|c|c|c|c|c|}
\hline $\begin{array}{l}\text { Political group } \\
\text { advisors }\end{array}$ & EPP & S\&D & ALDE & $\begin{array}{c}\text { Greens/ } \\
\text { EFA }\end{array}$ & ECR & $\begin{array}{l}\text { GUE/ } \\
\text { NGL }\end{array}$ & EFD & Total \\
\hline $\begin{array}{l}\text { Target population } \\
\text { (January 2014) }\end{array}$ & 55 & 55 & 39 & 53 & 40 & 37 & 29 & $\mathbf{3 0 8}$ \\
\hline $\begin{array}{l}\text { Interviewees } \\
(2012-2014)\end{array}$ & 6 & 5 & 6 & 6 & 2 & 1 & 1 & $\mathbf{2 7}$ \\
\hline $\begin{array}{l}\text { Survey } \\
\text { respondents } \\
\text { (May-July 2014) }\end{array}$ & $\begin{array}{c}24 \% \\
\text { Ma }\end{array}$ & $\begin{array}{c}14 \\
25 \%\end{array}$ & $\begin{array}{c}19 \\
49\end{array}$ & $\begin{array}{c}42 \% \\
30 \%\end{array}$ & $\begin{array}{c}35 \% \\
21 \%\end{array}$ & $\mathbf{3 2 \%}$ \\
\hline
\end{tabular}

NB - 12 interviewees also participated in the survey (See Appendices III and V).

Appendix III provides a more elaborate picture of the survey response, including figures on the distribution across parliamentary committees and the response rate per question. It furthermore provides an overview of the main findings. The way in which these findings are analysed in connection to the qualitative data is considered below.

\subsubsection{Implementation: mixing the data}

The aim is to implement the framework to address the question under which conditions political advisors can assume a political role. Although the empirical analysis focuses on political advice in the context of the EP party group secretariats, the framework may be replicated to explore other legislator-advisor relationships. The following set of propositions forms the starting point for the analysis: (1) Advisors provide advice through four conceptualised ideal-type roles that are non-exclusive; (2) Each of the roles 
can be assumed in a more or less political manner (routine, reactive, or pro-active); and (3) The discretion of advisors - and the likelihood that they may fulfil the political dimension of the role - depends on a set of personal and contextual factors. The three propositions translate into three analytical steps. Each is considered below with the way in which the qualitative and quantitative data interact.

Level of interaction between the qualitative and quantitative strands

The interaction of the data at the design level was minimal. As pointed out, the document analysis and exploratory interviews contributed to the development of the questionnaire. The collection took place separately conform the 'convergent parallel design' and was administered in two 'parallel databases' (Creswell and Plano Clark, 2011: 80).

First, the data are applied to the four roles to establish whether each of the ideal types is indeed assumed. Each analytical chapter first reflects on the theoretical concepts related to the respective category of political advice (4.1.1, 5.1.1, 6.1.1, and 7.1.1). The theory is then considered in light of the collected qualitative and quantitative data $(4.1 .2,5.1 .2,6.1 .2$, and 7.1.2). The survey findings are displayed through inferential statistics supplemented with graphical statistics to corroborate the specific elements of political advice that have been identified as part of the framework. The interview findings are connected to these inferences and provide further detail, not only as to what advisors do but also as to why they do it.

Second, the political scope of the role is considered by examining advisors' mandate and the extent to which they have room to improvise in the provision of political advice. This step is of a predominantly qualitative nature. Merging the interview accounts and the responses to the open- 
ended survey questions, an assessment is made as to how pro-active advisors are (perceived to be).

Third, the extent to which the seven identified factors affect role construction and adoption is assessed. The overall strategy of the study was not to explicitly present the roles and factors to the survey respondents and interviewees. Rather, the chosen approach was to examine the responses and check whether they bring up the theoretical elements on their own accord. The objective is to find whether one or a combination of factors can be considered indispensable for the provision of political advice and how this may differ per role. Based on the collected data a qualification is added to each of the factors by probing its (deemed) impact: Indispensable $(++)$, positive impact $(+)$, no impact/ not relevant $(0)$, or a negative impact $(-)$. Finally, the findings are checked for factors that have not been identified from the literature review. In the example below, trust is the decisive, or indispensable, factor and network, institutional memory, political sensitivity and complexity increase the likelihood an advisor will adopt role $X$. Politicisation decreases the likelihood and political direction has no impact on the adoption of the political role.

Table 2.5.4 Example of factor assessment table

\begin{tabular}{|c|c|c|c|c|c|c|c|}
\hline & \multicolumn{4}{|c|}{ Personal factors } & \multicolumn{3}{c|}{ Contextual factors } \\
\hline & Trust & $\begin{array}{c}\text { Informal } \\
\text { Network }\end{array}$ & $\begin{array}{c}\text { Institutional } \\
\text { Memory }\end{array}$ & $\begin{array}{c}\text { Political } \\
\text { sensitivity }\end{array}$ & $\begin{array}{c}\text { Political } \\
\text { Direction }\end{array}$ & Complexity & Politicisation \\
\hline Role $X$ & ++ & + & + & + & 0 & + & - \\
\hline
\end{tabular}


Coding system survey respondents and interviewees

Appendices III and $V$ respectively provide an overview of the survey response and the interviewees. Throughout the analysis, survey respondents (SR) are coded according to the order in which the responses were received. Interviewees (I) are numbered in a similar way. In instances where the differences between the party groups are discussed, the coding is excluded to uphold the guarantee of anonymity. It is important to note that a considerable overlap between the survey respondents and interviewees exists. 12 interviewees also filled out the survey. This is indicated in Appendix V. If such an overlap occurs in the merging of the data, it is explicitly mentioned in the presentation of the findings.

\subsection{Concluding remarks}

This study advances the sociological institutionalist logic of appropriateness and argues that to appropriately advise and support legislators, non-elected actors inevitably enter the political sphere of activity. It builds on studies that have strived to disentangle the technical from the political dimension. These exercises have demonstrated that disentangling overtly 'technical' and 'political' tasks is not straightforward. The thesis adds a new dimension to the scholarly debate on the role of officials by conceptualising what a 'political role' by advisors might entail. While building on the literature of the role of non-elected actors, it proposes 'political advice' as a distinct category in which technical and political dimensions 'meet'. The relationship between the political and technical levels is approached as a complementary rather than an antagonistic process. The argument is that both dimensions are necessary for and feed into political advice.

Since no existing theory was considered suitable for capturing the concept of a mixed sphere of activity, an analytical framework for the study of political advice has been developed. The framework allows for the 
consideration of various functions of advice (typology), and the assessment of the political scope of advisors' input (modes of discretion). Chapters 4-7 apply the collected quantitative and qualitative data to the framework, according to the methodology described in 2.5. Three analytical steps are carried out for each of the ideal-type roles: First, the collection of data is applied to establish whether the technical and political functions of the role are indeed assumed. Second, the political scope of the role is considered by examining advisors' mandate and the extent to which they have room to improvise in the provision of political advice. Third, the extent to which the factors affect role construction and adoption is assessed.

Before the empirical analysis is presented, however, the next chapter operationalises the framework for the case of the EP. Given that EP group advisors, up until now, have only received marginal scholarly attention, it is deemed necessary to provide some background information on this particular group of actors. The description of who group advisors are and what they do is based on the conducted literature review, document analysis and online survey. 




\section{CHAPTER 3. OPERATIONALISING POLITICAL ADVICE IN THE EUROPEAN PARLIAMENT}

The previous chapter defined the theoretical concepts to address the question under which conditions advisors can assume a political role and developed a framework to study this phenomenon. The operationalisation of the general concepts to the specifics of the European Parliament (EP) commands a certain understanding of who group advisors are and what they do. Owing to the limited existing empirical evidence, it is deemed relevant to describe their profile and activities before discussing the analysis. The purpose is to then relate this information as far as possible to the concepts of the framework. The material presented in this chapter is based on the literature review, conducted document analysis and online survey.

In order to operationalise the scope of political advice, section 3.1 discusses the major internal sources that are involved in the intra-EP decision-making process. 3.1.1 introduces the central actors at staff level that are consulted by the Members of the EP (MEPs) in relation to their activities in committee. Three groups of staff are considered in this regard: EP officials in the committee secretariats, group advisors, and MEP assistants. 3.1.2 reflects on existing academic discussions about the function and nature of in-house advice to MEPs. The aim is to uncover what we know about the discretion of EP staff, their (various) role(s), their cooperation or competition in the support of MEPs, the technical or political elements of these roles, and possible differences across the findings so far.

The second section of the chapter describes the profile and background of group advisors. 3.2.1 considers the contractual status of the group advisor and discusses employment criteria, and advisors' overall experience in their 
current position. 3.2.2 presents the required education, professional and political experience of advisors and the related collected survey data. In a similar way, 3.2.3 assesses the desired knowledge and skills as obtained through document analysis in light of the gathered perceptions of group advisors through the survey. The acquired information is related to the definition of political advice, the typology, and factors of the framework. The aim is to pinpoint, on the one hand, the general characteristics of group advisors. On the other hand, the background information is instrumental in exposing potential differentiating features within this specific group of actors. In the empirical analysis (chapters 4-7) these features are then considered to assess and explain possible variation in the way in which group advisors fulfil their roles.

The key activities and responsibilities of group advisors are identified from the literature and the analysis of a series of vacancy notices posted on the groups' website. These duties are respectively related to the Process Manager (3.3.1), Information Manager (3.3.2), Policy Expert (3.3.3), and Broker (3.3.4) roles. The aim is to formulate preliminary expectations regarding the adoption of the four ideal-type roles. The following chapters (4-7) apply the framework to the collected empirical data and consecutively present the analysis for each of the four roles.

\subsection{Sources of internal advice in relation to the framework}

This study construes political advice as advice offered to politicians by nonelected actors. In the context of the EP various internal and external sources of such advice are conceivable. The focus on internal mechanisms and thus on internal political advice is motivated through the expectation that EP staff act as gatekeepers for information from the outside world (cf. Busby, 2013; Corbett et al, 2016). For that reason, the discussion below does not 
include the myriad of external sources of advice available to MEPs emanating from for instance interest groups; sectoral, regional or national interest representatives.

In the preparation of legislation and policy, Members of European Parliament (MEPs) rely on three major internal sources of advice: the EP Secretariat, the group secretariats, and their personal assistants (Neunreither, 2002; Egeberg et al, 2013; Busby, 2013, Pegan, 2015; Corbett et al, 2016). Previous research tends to concentrate on EP officials in the committee secretariats and MEP assistants. The chief motivation to study group advisors, however, lies in the distinct role they are considered to fulfil in the intra-parliamentary coordination process (see 1.3). Their unique function follows from the notion that they are employed to represent and defend the interests of the party group.

This section first introduces the three principal internal sources of advice (3.1.1), followed by a discussion of the academic literature addressing these types of support (3.1.2). The aim is to relate the state of play and the remaining open questions to the concepts of the analytical framework.

\subsubsection{Principal sources of advice at the disposal of MEPs}

Chapter 1 introduced the various stages of intra-parliamentary decisionmaking along with the main structures and actors at MEP level. This subsection presents the central actors at staff level involved in this process and constituting potential sources of political advice.

The expanded workload has increased MEPs' need for support. Over the last three decades there has been a dramatic increase in the number of Parliament staff, although this has slowed down more recently (Corbett et al, 2016: 255-256). The 1979 figure of 1,995 posts rose to 2,966 by 1984 
and amounted to 6,785 in 2014 (Corbett et al, 2011; EP Establishment Plan, 2014). Both multilingualism and geographical dispersion of the EP offices are cited reasons for this high figure (Corbett et al, 2016: 255), ${ }^{18}$ brought about by the increase of MEPs and working languages following several rounds of enlargement, and more recently, the expansion of the EP's legislative activities. The overall amount of EP staff is illustrated by table 3.1.1.

Table 3.1.1 Distribution of staff during the EP's $7^{\text {th }}$ legislature (2014)

\begin{tabular}{l|l|l|l|l} 
Function group & AD & AST & SC & Total \\
\hline Permanent officials & 2,655 & 2,950 & 30 & 5,635 \\
Political group staff & 415 & 601 & & 1,016 \\
Other staff & 66 & 68 & & 135 \\
\hline Total EP staff & & & $\mathbf{6 , 7 8 6}$ \\
\hline Accredited parliamentary assistants & & $\mathbf{1 , 7 1 6}$ \\
\hline
\end{tabular}

Sources: EP Establishment Plan 2014, own calculations based on information EP Group websites (consulted, January 2014).

Acronyms refer to the function groups of the EP: Administrators (AD), Assistants (AST), and Secretaries and Clerks (SC). The contractual situation of advisors is discussed in 3.2.1.

Considering the internal resources of MEPs in preparing their work in committee, a distinction needs to be made between institutional assistance and ideological assistance. In line with EP tradition, the EP General Secretariat fulfils the function of a central, neutral administration. Direct support related to committee business is discussed below. Other, indirect types of support offered by the EP secretariat include research, communication and legal services, as well as more administrative and

\footnotetext{
18 The European Parliament workplace is spread over Brussels. Luxembourg and Strasbourg, with additional offices in the Member States.
} 
logistical services. ${ }^{19}$ In addition to this institutional assistance, members may seek assistance from advisors of the same ideological orientation. MEPs in this case have two options: obtain advice from their political group secretariat or from their personal assistants. The three principal sources of advice to MEPs are introduced below. ${ }^{20}$

\section{EP Committee Secretariats}

Direct support to committee business is provided through the DirectoratesGeneral (DGs) of Internal Policies and External policies (Pegan, 2015). The latter comprises the secretariats for the foreign affairs committee (AFET), international trade (INTA) and the development (DEVE) committees, as well as the sub-committees security and defence (SEDE), and human rights (DROI). In addition, it assists the work of inter-parliamentary delegations. DG Internal Policies provides the secretariats for the remaining 17 standing committees and furthermore coordinates all legislative activities, mainly through the Conference of Committee Chairs (see 1.2.1).

Staff levels in EP Committee secretariats are small in comparison to the US Congress but substantial compared to the general standard in EU Member States' parliaments (Corbett et al, 2016: 175). At the start of 2015, the DGs of Internal Policies and External policies comprised around 550 and 230 EP officials respectively (Corbett et al, 2016: 265). The amount of officials staffing a committee secretariat varies somewhere between five in smaller to 15 administrators (AD) in larger committees. In addition, one or two assistants (AST) take care of the logistics (Corbett et al, 2016: 175). ${ }^{21}$

\footnotetext{
${ }^{19}$ For an overview of the structure of the EP General Secretariat and the main services, please see Corbett et al, 2016: 264-270.

${ }^{20}$ For an elaborate discussion and comparison of the legislative assistance provided by EP officials, group advisors, and MEP assistants, please see Pegan, 2015.

${ }^{21}$ Section 3.2.1 considers the different types of contract and function groups of EU officials.
} 
The committee secretariats typically assist the committee chair and the rapporteur and provide advice throughout the legislative cycle (Pegan, 2015). Once a committee is designated responsible for a legislative proposal, the administrative head of that committee secretariat assigns the file to an EP official who then becomes the 'principal administrator' (Pegan, 2015). The nature of their role varies but the overall aim is to ensure 'the smooth running' of the respective parliamentary committee's activities (Corbett et al, 2016: 265). Primarily, the committee secretariats are responsible for matters of procedure and timing but can be asked by the rapporteur to assist in the drafting of the report. Other activities may include organising meetings, collecting (background) information for the rapporteur, briefing members on past activities and positions adopted, and maintaining internal and external contacts (Corbett et al, 2016: 176).

In 2004, in a move to build in-house policy expertise, dedicated policy departments were created within the DGs Internal and External policies to respond to research requests of the committees (Ripoll Servent, 2018). Yet, an internal study in 2013 comparing the EP to the US Congress and the parliaments of France, Germany, Italy and the UK concluded that the inhouse parliamentary support structure needed to be strengthened (European Parliament, 2013). One of the identified weaknesses was the lack of 'independent scientific advice'. The need for such advice was deemed of particular importance in light of the expanded legislative powers and the ever more complicated and technical nature of MEPs' legislative work. To tackle this issue, the former EP Library service was transformed into a European Parliamentary Research Service (EPRS). As part of the EP General Secretariat, the EPRS offers a wide range of services aimed at providing MEPs with 'independent, objective and authoritative' information, analysis, and research regarding EU policy issues (EP website, consulted March 2018). Most relevant to the work in the parliamentary committees is the 
so-called Members' Research Service. ${ }^{22}$ It draws up policy briefings, analyses, and statistical overviews upon the request of individual members or in support of the parliamentary committees (EP website, consulted March 2018). It furthermore publishes notes for external purposes and aims at providing 'think tank capacity' (EPRS, 2017). The EPRS also examines the European Commission's impact assessments and provides the parliamentary committees with complementary ex-ante and ex-post impact assessments, and impact assessments of 'substantive EP amendments' (EPRS, 2017).

\section{Group Secretariats}

Group secretariats are financed from the EP's budget. The 2014 EP Establishment plan comprised a total of 1,016 political group staff posts. The majority of these posts are distributed among the groups according to size although each group receives a basic allocation of posts (Ripoll Servent, 2018). The rise in the total number of group posts - 1,016 in 2014 versus only 285 in 1982 - demonstrates a significant growth rate that is considerably higher than for the EP's permanent staff but has recently slowed down (Corbett et al, 2016: 132).

By way of document analysis (see 2.5.2 and Appendix I) the total amount of 'political' or 'policy' advisors as they are called in some groups has been estimated at 308 (January 2014). For the remainder of the study they are referred to as group advisors, or simply advisors. These advisors are responsible for following the activities of one or several parliamentary committees. Larger groups can have five advisors following a certain

\footnotetext{
22 See the EPRS website for an overview of all services provided: http://www.europarl.europa.eu/atyourservice/en/20150201PVL00031/EuropeanParliamentary-Research-Service
} 
committee, whereas an advisor in one of the smaller groups may have to follow four committees at once (Ripoll Servent, 2018).

As part of the intra-parliamentary coordination process, group advisors contribute to the organisation of the group's position on a certain file in both the committee and plenary stages of decision-making. In this process, group advisors have to consider the various national, sectoral and constituency considerations that are relevant to the members and the group as a whole (Egeberg et al, 2013; Winzen, 2011). Activities may include the preparation of background information, discussions within the group, the formulation of group positions, or maintaining external contacts (Corbett et al, 2016: 132). Advisors 'sell' the political positions of their group and advise their MEPs how to provide input for reports in a way that is acceptable to the majority of the group (Ripoll Servent, 2018). Section 3.3 addresses these activities in further detail and relates them to the analytical framework. The contractual position and employment criteria of these advisors are discussed in 3.2.1.

Group members of the same nationality and national political party are organised in national delegations. Occasionally, these delegations can take position as a bloc (Corbett et al, 2016: 139). Particularly the larger delegations have their own organisational structures and staff members, in part financed through group funds (Ripoll Servent, 2018). Their formal and informal resources make it easier to operate independently from the party group, putting them at a clear advantage over smaller national delegations.

\section{MEP assistants}

In January 2016 MEPs employed a total of 1,774 accredited assistants (EP website, consulted August 2016). These personal assistants are based in Brussels and are employed directly by Parliament (Corbett et al, 2016: 80). 
Each MEP is granted a budget to employ assistants. In addition to Brusselsbased assistants, 'local assistants' are contracted by the MEP directly and based in his or her constituency to form the liaison with national or regional interests (Pegan, 2015: 94). On average, MEPs' offices comprise two accredited and four local assistants (Pegan, 2015: 94). In this dissertation, the focus lies on the intra-parliamentary legislative coordination process. Therefore, all further mentioning of MEP assistants refers to accredited parliamentary assistants only.

MEPs are free to select their personal assistants. The Staff Regulations (2014) determine the conditions for employment. Article $5 a$ states that accredited assistants provide 'direct assistance' to members 'in the exercise of their functions' and 'under their direction and authority and in a relationship of mutual trust'. The role of assistants can differ considerably (Corbett et al, 2016: 81). They are responsible for all issues directly affecting the member, yet, some are closely involved in the legislative work while others concentrate on secretarial and organisational tasks (Corbett et al, 2016: 81). They usually follow the work in the parliamentary committees and advise the MEP on the issue at hand, e.g. the drafting of amendments to parliamentary reports, attending meetings when their MEP is engaged elsewhere and subsequently report back (Corbett et al, 2016; Busby, 2013). With MEPs generally having a busy schedule travelling, attending meetings that often run in parallel, etc., assistants are their eyes and ears (Busby, 2013).

\subsubsection{Academic discussion on advice in the EP}

The academic literature on EP supporting staff was briefly mentioned in the Introduction and is further considered here in relation to the developed framework. This sub-section reflects on the discussions about the function and nature of in-house advice to MEPs in order to unveil what we know 
about the discretion of EP staff, their (various) role(s), the technical or political elements of these roles, and possible differences across the findings so far.

\section{Function and nature of in-house advice to MEPs}

The EP's strengthened legislative role heightened academic attention for the internal administration and coordination mechanisms of the institution. Examinations of the role of officials in the EP tend to concentrate on the form of legislative assistance (Neunreither, 2002; Pegan, 2015), the activities carried out by EP officials in the committee secretariats (Neuhold, 2001; Neuhold and Settembri, 2007; Winzen, 2011; Dobbels and Neuhold, 2013) or by MEP assistants. Regarding the latter, Neunreither already in 2002 referred to personal assistants as a 'largely unused workforce' that should be strengthened. More recently, several studies explored their role in detail (Busby, 2013; Michon, 2014). Michon (2014) claims assistants perform four types of tasks: secretary, PR, legislative, and political. Busby (2013) argues that MEP assistants play an important but under-estimated backstage role in the everyday practice of politics inside the EP.

Information takes a central place in the discussions of the contribution of EP staff. This is related to various responsibilities. First, staff are said to be instrumental in tackling the information overload, by 'gate-keeping' the MEP's agenda, pre-selecting issues, and providing tailor-made information. Busby (2013) refers to these activities as the responsibility of personal assistants who she claims act as the 'information interface' for their MEP. Winzen (2011) contends that EP officials contribute to the shaping of 'the information foundation' of positions by pre-selecting issues. These activities are covered by the conceptualised Information Manager role (see 2.2.2). 
Second, the literature stresses the value of information related to the substantive content of policy proposals. Several studies argue that EP staff may provide such policy expertise. Dobbels and Neuhold (2013) find that EP officials can perform policy-shaping tasks by providing substance-related information and advice to MEPs. Former EP vice-president James Provan distinguishes 'political assistance' as one of the functions of EP staff. This category comprises the formulation of policy definitions. Another function he identifies is 'technical-substantive' assistance, which includes the drafting of documents (Neunreither, 2002). Winzen (2011) conceives two types of activities related to dealing with the flow of information. His category 'Informants' relays to the function of offering policy expertise to the MEP, something he claims EP officials in the committee secretariats provide.

The second category Winzen identifies is 'Process Manager', arguing that EP officials manage the policy process, structure the agenda, and organise meetings. Similarly, Busby (2013) discusses assistants' involvement in 'agenda management'. In line with such activities, Provan defines his category 'technical-administrative' assistance as the organisational support for meetings (Neunreither, 2002). Yet, Provan classifies advice on procedures and legal issues in the previously mentioned category of 'technical-substantive' assistance. In the framework, these activities are all considered part of process management.

The literature review above shows that there are indications that EP officials and MEP assistants adopt the Process Manager, Information Manager, and Policy Expert roles. However, hardly any evidence points to these staff members adopting the Broker role. For an exception see Romanyshyn and Neuhold (2013) who discuss the strategic facilitation of compromises by EP Conciliation Committee officials. And they themselves stress that the results of their study in the context of the Conciliation Committee - considering its 
atypical position - cannot unequivocally be projected on the broader context of the EP. In addition to the formulation of policy definitions, Provan's category of 'political' assistance comprises the political coordination within and between the political groups. This activity is typically ascribed to group advisors (Neunreither, 2002).

Who does what: competing forces in the assistance of MEPs?

Up until the 1990s, committee secretariats constituted 'by and large the sole source of support' (Corbett et al, 2016: 261). The enhanced legislative role of the $E P$, however, went hand-in-hand with an increase in numbers and involvement of group advisors and personal assistants (Corbett et al, 2011: 228). This raises the questions of how these groups of supporting staff cooperate or compete in their assistance to MEPs. Reviewing the three main sources of legislative assistance, Ripoll Servent (2018) points out that there is a considerable overlap in tasks and thus a high potential for competition or conflict. The way in which EP officials, group advisors, and personal assistants interact is considered in the empirical analysis. Existing findings are reviewed here to explore the extent to which a relationship of cooperation or competition is to be expected.

Neunreither (2002) postulates that in providing the various functions the different groups of EP staff can compete. In his view, group advisors should concentrate on political coordination and not 'interfere directly' in legislative assistance. Pegan (2017) finds that compared to EP officials, group advisors and MEP assistants are a more frequent source of advice owing to their political and tailored support. Busby (2013) draws a similar conclusion and labels the collective of accredited parliamentary assistants and group advisors as 'political sources' to which MEPs increasingly turn. 
There are no official figures available as to how often the principal assistance to the rapporteur is provided by the committee secretariat. Yet, an internal study in the 1990s showed that the support they provide goes beyond technical and procedural questions in over 80 per cent of the cases (Neunreither, 2002). According to the same study, group secretariats were completely marginalised. Since then, scholars have demonstrated that the role of committee secretariat staff is considerable and - although delegation of tasks takes place at the discretion of MEPs - officials are said to be involved in the political work of the EP with their mandate leaving certain room for interpretation (Neunreither, 2002; Winzen, 2011; Dobbels and Neuhold, 2013; Neuhold and Dobbels, 2014).

Several scholars argue that, contrary to EP officials or MEP assistants, group advisors do not directly assist the rapporteur (e.g. Neunreither, 2002; Pegan, 2015). Simultaneously, it has been argued that 'insiders' observe a considerable decrease in the direct assistance via the committee secretariats (Neunreither, 2002; Corbett et al, 2016: 261). In the 2000s the position of both the accredited parliamentary assistants and the political group secretariats strengthened, sparked by the increased impact of the EP on legislation (Hix et al, 2007; Corbett et al, 2011). In line with this observation, Winzen (2011) points to an overlap in the assistance to rapporteurs based on a set of interviews with the various types of supporting staff in the EP. His findings support the notion that MEP assistants and group advisors are explicitly charged with exploring political views, possible points of contestation, or compromise. Correspondingly, Egeberg and colleagues (2013) conclude from their survey on the behaviour of EP staff that group officials - to a greater extent than other EP staff facilitate compromises within the EP. According to the scholars this is to be expected as the activity of compromise building requires the involvement of both national and EP party groups. Alternatively, EP officials value the perception of a neutral role and generally steer clear of political controversy 
in order to avoid any impression of partisanship (Winzen, 2011; Neunreither, 2002). Nonetheless, the line between a 'neutral' draft report by an EP official and a 'politicised' report by a group advisor can be ambiguous.

In conclusion, the main divergence in the findings of the discussed research relate to the (preferred) principal assistance offered to rapporteurs. However, this appears to be rather a matter of a different focus than actual conflicting outcomes of the studies. The findings are congruent in that the source of assistance varies and that the MEP in charge selects the support he or she desires. This dissertation explores the circumstances in which MEPs are more or less inclined to delegate activities to group advisors. The analytical framework is developed in such a way that it allows for the application to other sources of advice in a legislative setting. An interesting avenue for future research would be to verify whether the (optimal) circumstances for a political role hold true or in fact differ for other types of supporting staff.

\section{Political advice in the EP}

In discussions considering the contribution of EP staff, scholars have found that the demarcation between 'political' and 'technical' tasks is blurred. Neunreither (2002) for example disclosed some of the political elements related to the 'routine administration' of committees, notably agendasetting activities, determining the order of votes, and maintaining contacts with other institutions. The problematic overlap exposes that a conclusive definition of what constitutes a political role of advisors currently remains lacking (cf. Provan in: Neunreither, 2002; Winzen, 2011). The ambiguity is not related to the final say in decision-making - which is the clear authority of the elected representatives - but rather considers the process leading up to the decision involving mixed spheres of activity (Winzen, 2011; Dobbels 
and Neuhold, 2013). A development that adds to the ambiguous demarcation between technical and political functions of support is the increasing politicisation of the EP staff brought about by staff moving from the group secretariats into the committee secretariats. No measures have been taken to tackle the so-called 'parachuting' practice (Pegan, 2015).

Connecting what we know from existing studies to the definition of political advice, leads to the inference that the activities of EP officials, group advisors, and MEP assistants overlap and are situated in the mixed sphere of activity (see 2.1.2). However, the discussions of political advice by mainly Busby (2013), Egeberg and colleagues (2013), Neunreither (2002), and Winzen (2011) lead us to believe that political advice as defined for the purpose of this study is predominantly the domain of MEP assistants and group advisors. They are explicitly charged with exploring political views, possible points of contestation, or compromise (Winzen, 2011). In addition, they often have the same political affiliation as the $\operatorname{MEP}(s)$ they work for, which enables them to anticipate political priorities and desired outcomes. Group advisors have a specific intermediary role to play with the General Secretariat on the one hand explicitly designed as an 'independent nonpartisan service' (Neunreither, 2002) acting in the general interest of the institution, and MEP assistants on the other hand looking out for the specific interests of his or her MEP (Busby, 2013; Corbett et al, 2016).

The emphasis of previous studies boils down to establishing the influence of officials on outcomes, e.g. if they can shape policy, by exploring their activities with the aim of understanding the interplay between officials and their elected superiors. These analyses share the conclusion that officials make a significant contribution to the legislative process, one that involves political assessments or judgements, or potentially has political impact. The dissertation builds on these findings and categorisations by defining and isolating the 'political role' of advisors. The aim is to further unravel the 
input that group advisors provide into EP positions and explore the conditions that either facilitate or restrict their political role. To that end, political advice is approached as a separate category, located in a mixed sphere of activity, and the political advisor as a distinct type of actor who cannot be classified as a civil servant nor as a political actor.

In sum, relating the insights provided by the literature to the framework, it is inferred that group advisors are the most likely staff actors to fulfil the Broker role. This role is key to the intra-parliamentary coordination process, which is the central motivation to focus on group advisors. Moreover, they remain a virtually unstudied group of actors, further elevating the relevance to understand their contribution to informal political processes.

\subsection{Background and profile of the EP group advisor in relation to the framework}

The previous section demonstrated that group advisors, up until now, have only received marginal scholarly attention. Therefore, before discussing the empirical analysis, it is deemed necessary to provide a descriptive overview of the acquired background information on this particular group of actors. The information presented is tied to the concepts of the analytical framework, i.e. the definition of political advice, the typology of advice, and the factors that potentially affect delegation to non-elected actors. The aim is to pinpoint, on the one hand, the general characteristics of group advisors. On the other hand, the background information is instrumental in exposing potential differentiating features within this specific group of actors. In the empirical analysis (chapters 4-7) these features are then considered to assess and explain possible variation in the way in which group advisors fulfil their roles. 
The data offered in this section are based on the performed document analysis and the survey findings (see 2.5.2 and 2.5.3 respectively). The profile of the EP group advisors was initially examined through a series of vacancy notices published between 2011 and 2016 (see Appendix I). The findings of the survey were subsequently used to corroborate the desk research.

3.2.1 considers the contractual status of the group advisor, discusses employment criteria, and advisors' overall experience in their current position. 3.2.2 presents the required education, professional and political experience of advisors, and the related collected survey data. In a similar way, 3.2.3 assesses the desired knowledge and skills of advisors - as obtained through document analysis - in light of the gathered perceptions of group advisors through the survey.

\subsubsection{Employment status, criteria and duration}

Employment status

EP staff members are contracted on a permanent, temporary, or contract basis. The latter concerns a fixed maximum period to carry out manual or administrative tasks, or to replace permanent or temporary officials (EPSO and EP websites, consulted August 2016). ${ }^{23}$ The great majority of group advisors hold a temporary status, yet, their contract is for an indefinite period of time (EU Staff Regulations 2014, Title III Temporary Staff: Article 8). The temporary status is predominantly tied to the uncertainty of (future) election results and the continuity of the political group that they work for (Corbett et al, 2011: 113). There are some exceptions of permanent officials in the group secretariats. They either successfully completed the EU open competitions (see below) or already held the permanent status and

\footnotetext{
${ }^{23}$ Among the analysed vacancy notices are some examples of contractual agent openings for the replacement of temporary agents (e.g. maternity leave).
} 
moved to one of the group secretariats from another post within the EU institutions (Corbett et al, 2011: 113). Nonetheless, group advisors enjoy a sense of job security given that in practice relatively few are made redundant due to electoral losses or group reorganisations (Corbett et al, 2016: 132).

The survey findings corroborate this status: 68 per cent of respondents are employed on a temporary contract, 16 per cent on a fixed-term contractual basis, and 16 per cent hold the status of permanent official. The results also illustrate the practice of mobility within the EP and between the EU institutions. Respondents with a permanent contract for example reported that they have previous experience in the European Commission (EC) and the EP Secretariat.

The EU civil service is divided into three function groups: administrators (AD), assistants (AST), and secretaries and clerks (SC). The latter corresponds to tasks that are not fulfilled by political advisors and therefore falls outside of the scope of this dissertation. Each function group is divided into grades. AD grades 1-12 range from scientific, linguistic tasks to analytical, conceptual and managerial duties. AST 1-11 grades comprise executive and technical duties (EU Staff Regulations 2014: Annex IA). The EP Establishment Plan (2014) provides the total AD and AST staff allocations per political group (see table 3.1.1). However, the exact number of group advisors as well as their distribution over the function groups is not specified. The party groups provide an overview of advisors per parliamentary committee on their websites (consulted January 2014 and April 2017). The ALDE, Greens/EFA, S\&D groups refer to them as 'policy advisors' and the GUE/NGL and EFDD groups designate them 'political advisors'. The ECR and EPP groups list the advisors per committee without further classification. Based on the information on these websites, the target population of 308 political advisors (2014) was determined for the 
online survey and interviews. Table 3.2.1a illustrates the overall distribution across the groups.

Table 3.2.1a Estimation of political group staff distribution (2014)

\begin{tabular}{l|l|l|l|l} 
Political group & AD & AST & Total & Political advisors \\
\hline EPP & 142 & 206 & 348 & 62 \\
S\&D & 103 & 149 & 252 & 58 \\
ALDE & 47 & 68 & 115 & 41 \\
ECR & 32 & 47 & 79 & 30 \\
GREENS/EFA & 32 & 47 & 79 & 47 \\
GUE/NGL & 23 & 33 & 56 & 37 \\
EFD & 21 & 30 & 51 & 33 \\
NI & 15 & 21 & 36 & \\
\hline Total & $\mathbf{4 1 5}$ & $\mathbf{6 0 1}$ & $\mathbf{1 , 0 1 6}$ & $\mathbf{3 0 8}$ \\
\hline
\end{tabular}

Source: calculations based on EP Establishment Plan (2014 figures) and on the information published on the EP party groups' websites (consulted, January 2014).

The vacancy notice analysis and the survey show that group advisors are employed in both AD and AST function groups. 66 per cent of survey respondents indicate to belong to the $A D$-level function group with the remainder operating at AST level. While EPP, S\&D and ALDE respondents generally hold AD-level positions, EFD respondents only included one ADlevel advisor. Illustrative of this finding, one interviewee criticised the EFD practice of hiring advisors on AST contracts while having them perform the same duties as AD-level advisors. Because AST contracts are cheaper it allows a group to hire more advisors with the resources they have (I.16). GUE/NGL respondents also show a high proportion of AST-level advisors (73\%). The level at which advisors are hired may be related to the importance of and attention for EU policy-making of the group. For example, the Eurosceptic stance of the EFD may decrease the group's interest in contributing to the drafting of legislation. Whether and how this affects the role of EFD group advisors is further considered in the empirical analysis. 
Just over half of the Greens' advisors that participated in the survey are employed at $A D$ level and for the ECR the distribution is 50-50. These findings show that there are considerable differences between the groups. In the following chapters the potential impact of an advisor's AD or AST position on the adoption of the political roles is considered, further drawing from the gathered empirical evidence. It will for instance be interesting to see whether there is a significant difference between the tasks performed by $A D$ and AST advisors.

\section{Employment criteria}

Like permanent officials, group advisors with a temporary contract are subject to the EU Staff Regulations (2014) and enjoy similar pay levels and social benefits. These regulations comprise a section laying down the Conditions of Employment of Other Servants of the EU, including those of temporary staff (Title II: Articles 8-56). Article 12(2) of this section stipulates the general conditions of employment. Temporary officials must (i) be a national of one of the EU Member States, (ii) enjoy their full rights as citizen, (iii) have fulfilled any military service obligations, (iv) produce the appropriate character references for the duties involved, (v) be physically fit to perform the duties involved, and ( $\mathrm{vi}$ ) produce evidence of a thorough knowledge of one, and a satisfactory knowledge of another language of the EU Member States.

The overall selection of group staff is based on written and oral tests modelled on the open competitions that take place for the recruitment of European civil servants. Whereas the so-called concours is organised by the European Personnel Office (EPSO), the groups are in charge of recruiting their own staff and practices may vary. ${ }^{24}$ In this regard, article $12(3)$ of the

\footnotetext{
24 Observation based on the analysis of political group vacancy notices over the period of 2010-2013.
} 
Conditions of Employment of Other Servants of the EU includes the provision that EPSO must 'ensure the transparency of selection procedures for temporary staff'. Remarkable, however, is that this provision does not apply to group staff. Recruitment policies in the EP have been changing gradually. While personal connections, political affinity and experience are still factors that should not be underestimated, a tendency toward a more objective method based on expertise and skills is observed (Corbett et al, 2016: 132; Pegan, 2015).

\section{Duration in office}

As part of the analytical framework, four personal factors have been identified that are expected to affect advisors' roles: trust, informal network, institutional memory, and political sensitivity. From the literature review, it is inferred that duration in office (seniority) is an important indicator for the presence or development of these personal attributes. On average survey respondents have been in their current position for six years, varying between seven months and 23 years. The majority have held their position for over four years (see table 3.2.1b). This is not very surprising as the investigation took place towards the end of the five-year term (2009-2014). Greens/EFA advisors appear to have the longest employment record with 36 per cent of respondents filling the post for over ten years. There is no significant variation between the time in function of $A D$ and AST advisors. Out of the 12 per cent of respondents who have only been in function up to a year, the large majority holds the contract agent status (64\%). These findings depict advisors as loyal servants to their group. More importantly, with an average duration in office of six years, advisors can be expected to build up trust of both counterpart advisors and MEPs; an informal network; institutional memory; and political sensitivity. In the empirical analysis, the years of employment and thus the potential 
differences between newcomers and experienced advisors are taken into account.

Table 3.2.1b Years of employment in current position

\begin{tabular}{l|l|l|l|l|l|l|l}
\hline $\begin{array}{l}\text { Years in current } \\
\text { position }\end{array}$ & $<\mathbf{1}$ & $\mathbf{1}$ & $\mathbf{2 - 3}$ & $\mathbf{4 - 5}$ & $\mathbf{6 - 7}$ & $\mathbf{8 - 9}$ & $>\mathbf{1 0}$ \\
\hline$\%$ total respondents & $2 \%$ & $10 \%$ & $29 \%$ & $21 \%$ & $11 \%$ & $11 \%$ & $16 \%$ \\
\% group respondents & & & & & & & \\
\hline EPP & & $8 \%$ & $23 \%$ & $31 \%$ & $15 \%$ & $15 \%$ & $8 \%$ \\
S\&D & & $14 \%$ & $50 \%$ & & $7 \%$ & $7 \%$ & $22 \%$ \\
ALDE & $5 \%$ & $5 \%$ & $21 \%$ & $21 \%$ & $11 \%$ & $26 \%$ & $11 \%$ \\
Greens/EFA & & $5 \%$ & $18 \%$ & $18 \%$ & $14 \%$ & $9 \%$ & $36 \%$ \\
ECR & & $25 \%$ & $42 \%$ & $25 \%$ & $8 \%$ & & \\
GUE/NGL & $8 \%$ & & $31 \%$ & $23 \%$ & $15 \%$ & $8 \%$ & $15 \%$ \\
EFD & & $33 \%$ & $17 \%$ & $50 \%$ & & & \\
\hline
\end{tabular}

Source: responses to survey question 3 (open-ended)

As to their future orientations, 50 per cent of respondents indicated to prefer a career within the EU institutions. This supports the idea that group advisors have a strong European allegiance (cf. Egeberg et al, 2013). However, the differences between the party groups are significant. Whereas 70 per cent of EPP advisors expressed their wish for a career in the institutions only 17 per cent of ECR advisors have a similar ambition. This may reflect the ideological orientations of the groups, and by extension their advisors. The difference may be the result of a pro-European versus a more sceptical stance towards EU integration in general (cf. Hix et al, 2007: 181). 


\subsubsection{Educational, professional, and political background}

\section{Educational background}

The employment criteria for AD and AST positions mainly differ in terms of required levels of education and experience (EPSO and EP websites). Article 5(3) of the EU Staff Regulations (2014) provides the criteria per function group. For appointments in the AD function group grades 5-6, a completed university programme is required of at least three years attested by a diploma. For grades 7-16, completed university studies of four years or more is the standard criterion. In case a candidate has only successfully completed a university education programme of three years, it should be supplemented with 'appropriate professional experience of at least one year'. Vacancy notices for EP group advisors follow these criteria (see Appendix I). The required level of education for the appointment of AST (assistant) officials differs. Generally, a completed post-secondary education attested by a diploma is demanded. Candidates holding a secondary-education diploma giving access to post-secondary education may apply if they have appropriate professional experience of at least three years.

The survey shows that group advisors are generally highly educated: 48 per cent hold multiple higher-education degrees. Referring to their highest degree obtained, 82 per cent of respondents point to a Master's degree (MA) and 11 per cent to having completed their doctoral studies (PhD). Only six respondents chose a Bachelor's degree (BA) as their principal title and only one of these Bachelor graduates functions at AST level. The findings thus indicate that group advisors' qualifications go beyond what is required in the conditions of employment. In probing the main fields of the educational background of political advisors it appears that Law and Political Science are the most common programmes - respectively accounting for 
23 and 19 per cent - followed by EU studies, Economics, and International Relations (see table 3.2.2).

Table 3.2.2 Highest obtained degrees EP group advisors

\begin{tabular}{ll|ll}
\hline \multicolumn{3}{l|}{ Degree level } & Field \\
\hline PhD & $11 \%$ & Law & $23 \%$ \\
MA & $82 \%$ & Political Science & $19 \%$ \\
BA & $7 \%$ & European Studies & $15 \%$ \\
& & Economics & $15 \%$ \\
& & International Relations & $10 \%$ \\
& & Other & $18 \%$ \\
\hline
\end{tabular}

Source: responses to survey question 17 (open-ended)

In addition to the general employment criteria, EP groups are free to set special conditions related to the professional training of the candidate 'where justified in the interests of the service' (EU Staff Regulations, 2014: Article 5). The ECR and GUE/NGL vacancy notices do not specify the field of study and only one of the EPP job openings puts forth 'completed university studies of at least three years in the field of Economics or Finance' as 'a major advantage' (EPP 2012: AD5, Latvian language). In contrast, all EFD notices set special conditions with regard to education. A full degree in Law is the most frequent, followed by Economics and International Relations. European Studies, Political Science, and International Institutions are also mentioned (see Appendix I).

These findings are consistent with the conceptual definition that ties 'political advice' to a general mastery of the organisational process of lawmaking (see 2.1.2). Whenever a degree in a certain field is specified in the vacancy notices, it concerns a relatively broad study (see table 3.2.2). Hence, education requirements appear to principally accredit for an 
understanding of the organisational process rather than being related to specific policy expertise.

\section{Prior professional working experience}

The analytical framework comprises four personal factors that are expected to affect the adoption of a political role: trust, informal network, institutional memory, and political sensitivity. In addition to duration in office, the literature review identified (prior) experience as an important indicator for the presence or development of these personal attributes.

No standard required professional experience applies (EU Staff Regulations, 2014: article 5). Similar to the educational background, party groups are allowed to specify working experience under the special conditions for recruitment 'where justified in the interests of the service' (EU Staff Regulations, 2014: article 5). The demanded professional background varies according to the function group and grade of the group advisor. However, the document analysis suggests that AD5, 6, and 7 positions are most common (see Appendix I). For AD5 positions ECR and GUE/NGL groups require completed university studies of at least three years or 'professional training or experience of an equivalent level'. The EPP asks that candidates have 'at least two years' graduate-level professional experience'. GUE/NGL and EFD groups set special conditions tied to the policy content the advisor will be working on. For AST-level positions a completed post-secondary education combined with a minimum of two years of full-time professional working experience is the standard requirement. Alternatively, candidates holding a diploma giving access to post-secondary education can only apply with additional 'appropriate professional experience of at least three years' (EU Staff Regulations, 2014: article 5). The ECR in this case demands at least six years of experience (see Appendix I). 
From the vacancy notice analysis, it is striking that the EFD group applies significantly higher standards for candidates' experience and explicitly stipulates previous professional experience within the EP as a condition for all encountered job openings. Whereas the ECR requires AD6 and AD7 candidates to respectively have two and six years of professional working experience, the EFD sets a minimum of respectively five and 15 years of experience for posts at the same grade levels.

The survey findings show that group advisors overall are experienced. ${ }^{25} 68$ per cent of respondents indicate to have at least ten years of professional working experience. Only six per cent have less than four years of experience. Respondents were also asked to specify their professional background: 42 per cent have prior working experience in the EP, as figure 3.2.2 illustrates.

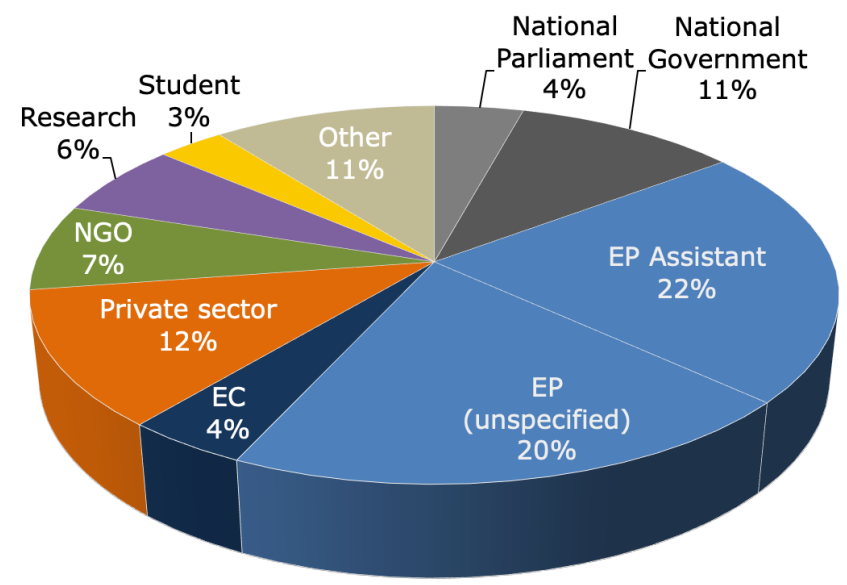

Figure 3.2.2 Survey response: Prior professional experience group advisors

The conceptual framework developed in chapter 2 defines a form of tacit knowledge through experience within the institution as one of the key elements of 'political advice (see 2.2.2). The findings reveal that 58 per cent

${ }^{25}$ See Appendix III, SQ2 and 4. 
of respondents were recruited in their current position as group advisor lacking such knowledge. Greens/EFA and GUE/NGL groups stand out in terms of employing advisors without EP experience. On the contrary, EPP appears to prefer employing people with an EP background. From the analysed vacancy notice, the EFD appears to be the only group that explicitly demands prior professional working experience in the EP. The subsequent chapters explore political advisors' responsibilities in further detail, inter alia considering the potential impact of the advisor's professional background.

\section{Political experience and affiliation}

Group recruitment policies have been observed to move toward a more objective practice mirroring the EU open competitions (Corbett et al, 2016: 132; Pegan, 2015). Nevertheless, the literature review exposes that an important relation exists between the political affinity of staff and the level of trust by the politician (e.g. Arnold, 1987; Blischke, 1981; Gailmard and Patty, 2012). The general argument is that politicians are likely to empower agents whose 'ideal outcomes' lie close to or converge with their own, keeping administrative actions as close as possible to their own values and ideas. This implies greater potential trust between actors that share political views. From this it can be inferred that MEPs are more likely to accept a political role of advisors who they trust to support similar ideas. Affinity with the group's ideology is also tied to the concept of political sensitivity. Shared political beliefs will help advisors anticipate the desired course of action or outcome that the MEP in charge envisions.

In addition to the general employment criteria, groups are free to set 'special conditions' (EU Staff Regulations, 2014: article 5). The vacancy notice analysis shows that, at least formally, only the GUE/NGL and EFD groups seize this opportunity to require a certain pre-established affinity 
with the group's ideology or priorities. EFD describes this as 'prior knowledge of the political activities of the EFD group and its members'. GUE/NGL includes a more elaborate description of their expectations from applicants as the example below illustrates.

"The GUE/NGL Group in the European Parliament brings together MEPs from a range of European left and progressive parties. In virtually all policy areas, it argues against the mainstream neo-liberal prescriptions for the EU and is focussed on presenting progressive policy alternatives. All group staff should be comfortable in this environment and at ease with, contributing and supporting our MEPs in their policy objectives, inside and outside Parliament." (Source: vacancy notices GUE-NGL 2016 - Temporary Agent AD5 Dutch language and Temporary Agent AD5 Spanish language)

Based on the assumption that surveying the advisor's affinity would not yield credible insights due to the risk of politically correct answers, membership of a political party was taken as an indicator to assess affiliation. The survey shows that the majority of respondents (66\%) are affiliated to a national party: 52 per cent was affiliated prior to their employment and 14 per cent subscribed after they started working for one of the groups. ECR and Greens advisors seem to be the least politically affiliated, respectively 50 and 55 per cent are affiliated to a national political party. In contrast, only one GUE/NGL advisor is not member of a national political party, which supports the indication from the desk research that this group highly values the political affiliation of their staff members. The affiliation with European political parties is much lower. Only 18 per cent of all respondents are member of a European political party.

Prior political experience could also be conceived as an indicator of affinity with the ideology and priorities of the group. The vacancy analysis did not encounter any specific requirements in this regard. As introduced above, only the EFD requires prior professional experience in the EP. Nonetheless, figure 3.2.2 illustrates that 22 per cent of the respondents already worked in the EP as MEP assistant. Another 20 per cent have experience in the EP, 
but did not specify their prior functions. Moreover, four per cent worked in national parliaments before joining the group secretariat. In the empirical analysis, the level of professional and political experience is assessed in relation to the personal factors. Political affiliation and experience are expected to indicate (to some extent) the level of affinity with the group's objectives. Such affinity is expected to have a positive impact on gaining politicians' trust, developing an informal network and political sensitivity. In the subsequent chapters the extent to which these personal factors determine the assumption of a political role is discussed.

Finally, advisors' sense of loyalty to the group may be a way to assess political affinity. The next sub-section addresses the survey findings in respect to the qualities that are deemed most important for group advisors. 'Loyalty to the group' was included among the answer options that respondents were asked to rank. Only 20 listed it as one of the three most important: five ECR advisors, four ALDE, EPP, and S\&D advisors, and three GUE/NGL advisors. The loyalty of advisors is expected to notably affect the extent to which they are trusted by the MEP.

\subsubsection{Competencies of the EP group advisor}

As discussed above, the Staff Regulations allow political groups to set 'special conditions' when justified in the interest of the service. This subsection considers the desired competencies of EP group advisors, drawing from the analysis of vacancy notices for group advisor posts. It subsequently addresses linguistic skills, general knowledge and skills, and the qualities deemed most important for group advisors. The conditions set by the groups are discussed in relation to the survey findings. 


\section{Linguistic skills of group advisors}

Job openings related to the support of parliamentary committees are usually connected to a specific language group (see Appendix I). Although recruitment officially is not according to nationality, the linguistic requirements produce national distributions of staff that are closely related to the national distribution of MEPs in the group. For example, Spanish or Finnish speaking advisors are recruited to support the work of respectively the Spanish and Finnish delegations (GUE/NGL, 2016 and EPP, 2011 notices). As part of the special conditions, linguistic requirements state that candidates are either native speakers or have 'a thorough knowledge' of the language in question. Additional linguistic skills generally demand candidates to be proficient in one or two other languages ('good' or 'excellent' knowledge). Sometimes a third language is mentioned as an asset and in all analysed vacancy notices candidates' knowledge of further EU languages is said to be taken into account. Most frequently, the additional linguistic requirements refer to the common EP working languages English, French, and German.

As is to be expected in an international and multicultural environment, group advisors are true polyglots according to the data gathered through the survey. More than three quarters of respondents indicate to speak at least four languages. These numbers include their mother tongue, and the languages in which they say to have full or intermediate professional proficiency. Moreover, nearly a quarter of respondents claim to be a native speaker in multiple languages. It is noteworthy, however, that despite this evidence and the linguistic requirements described above, political advisors rank 'language skills' among the least important skills required to fulfil their responsibilities (see figure 3.2 .3 ). The findings therefore lead us to believe that because multilingualism is ubiquitous in the EP it is not considered a distinctive quality of advisors. 
General knowledge and skills of group advisors

The vacancy analysis exposes a series of recurring special conditions regarding prescribed knowledge or skills (see appendix I). First of all, a thorough knowledge of the EU institutional structure and decision-making processes is basic to the desired profile of political advisors. Second, the job description for political advisors stipulates that a conceptual or methodological approach is necessary, and that suitable candidates should be able to grasp wide-ranging problems. Accordingly, in the survey both the knowledge of EP procedures and analytical skills score high among the most important qualities advisors should possess (see figure 3.2.3). ${ }^{26}$

A third prerequisite encountered in all of the vacancy notices is a certain level of flexibility. Job descriptions impose great 'availability', 'flexibility', 'adaptability' (to varying workloads), and the capacity to 'respond rapidly to changing circumstances'. Other qualities frequently listed in the profile are judgement, team player and good communication skills.

Drawing from this information gathered through document analysis as well as several informal interviews, the questionnaire was designed (see 2.5.3). One of the multiple-choice questions asked respondents to rank the top three competencies of a group advisor (out of 12 answer options). Figure 3.2.3 illustrates the response. The qualities overall rated the highest by advisors are policy expertise, able negotiator, analytical skills, and knowledge of EP procedures. Respectively 45, 42, 38, and 33 per cent of respondents mentioned these qualities. No significant variation across the groups was encountered. However, a difference is observed between advisors with and those without prior professional experience in the EP.

${ }^{26}$ See Appendix III, response to SQ5. 
Chapter 3

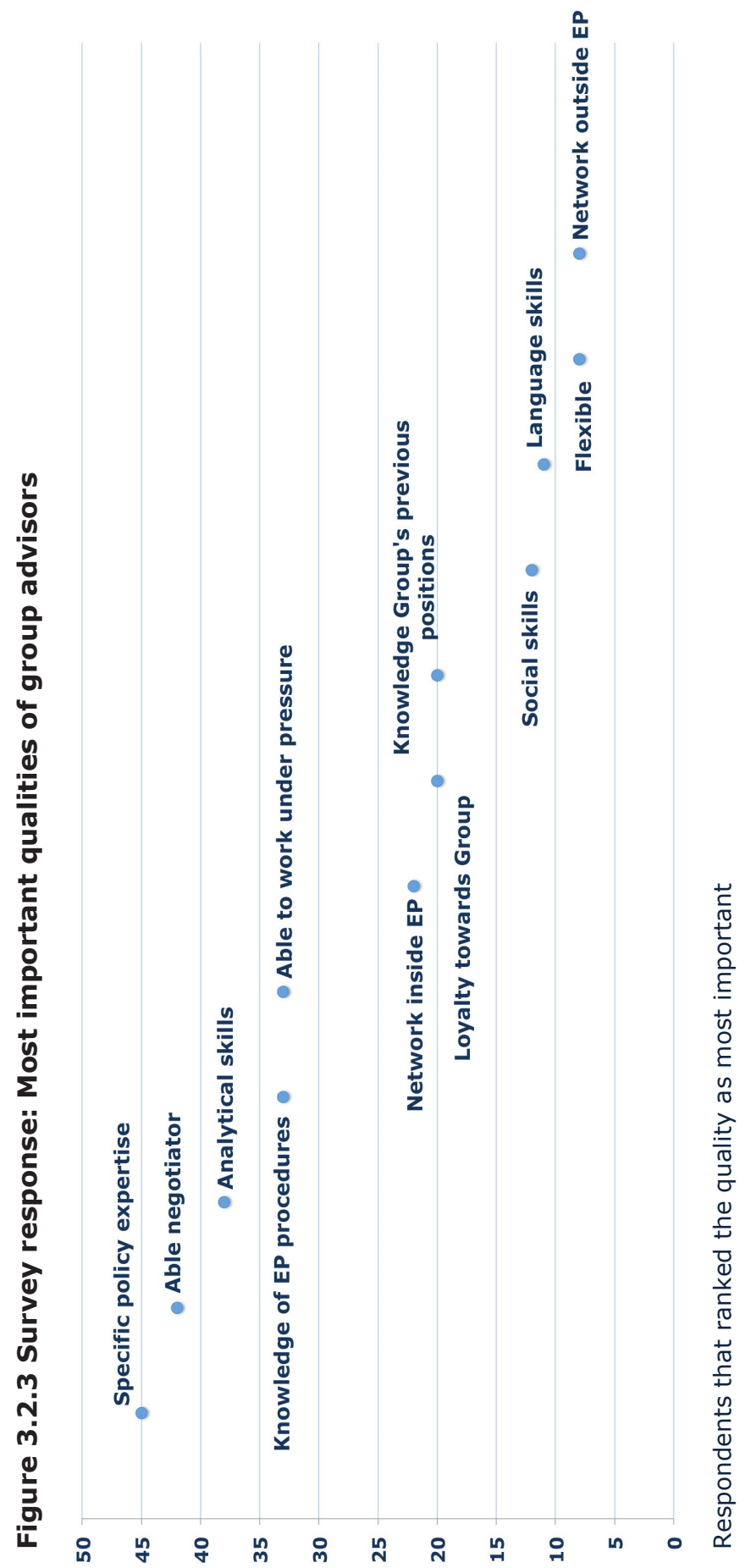


Both subsets appraise policy expertise and negotiation skills as the most important qualities needed. Yet, EP experienced respondents accredit considerable greater value to the knowledge of EP procedures: 40 per cent versus 29 per cent of those without EP experience. The opposite applies to the appraisal of analytical skills, although the variation is smaller: 33 per cent (EP experienced) versus 45 per cent (those without EP experience).

The four qualities identified (perceived) as most important closely relate to the developed typology of advice. The link between policy expertise and the Policy Expert role is rather clear-cut. The same applies to able negotiator and the Broker role. Analytical skills can be construed in relation to the analysis and pre-sorting of information (Information Manager role). Finally, the knowledge of EP procedures can be connected to advice on formal and informal procedures of the institution (Process Manager role). These findings are a first indication that group advisors perceive the four types of advice to be relevant. The next section addresses each of the roles in relation to group advisors' activities as found from the document analysis. The extent to which they in fact fulfil the four roles is then assessed by further analysis of the survey and interview data in chapters 4-7.

\subsection{Activities of the EP group advisor in relation to the framework}

The operationalisation of the general concepts to the practice of the EP commands a general understanding of the profile and activities of group advisors. In addition to the information presented in the previous section, the vacancy notices provide insight into the main activities. The document analysis has identified similar tasks and required competencies for group advisor posts, regardless of the contractual status, function group, or grade. Yet, a difference in the degree of responsibility and discretion granted to AST and AD advisors is expected. The tasks listed in the encountered AST 
job descriptions (grade 1-4) very closely resemble those of AD-level notices. However, secretarial assistance is emphasised over involvement in policy-making. Yet, the notices include activities that could be classified as process management, information management, or brokering too.

This section provides the key activities and responsibilities of advisors and relates them to the four roles of the analytical framework. It furthermore formulates some preliminary expectations regarding the adoption of the four ideal-type roles by EP group advisors. The discussion is limited to what can be derived from the literature and the analysis of group advisor vacancy notices. A more elaborate discussion of the theoretical technical and political dimensions of the roles is included as introductory sections to the chapters 4-7 that present the empirical findings.

\subsubsection{Process management activities}

From the literature, two central elements of process management are derived: (1) organisational support, and (2) advice on the legislative process, parliamentary procedures, and informal practices of the institution. In respect to the first, a standard duty that is encountered in the job description of group advisors is the organisation and follow-up of meetings (see Appendix I). Considering the literature on intra-group coordination practices, such support is likely to first of all relate to the preparation of the group meetings (Corbett et al, 2011: 113). In addition, group advisors' involvement is conceivable in the (public) seminars and conferences groups organise. These events on specific topical issues take place in cooperation with external stakeholders as a way to tap into external sources of expertise (Corbett et al, 2011: 119 and EP political groups' websites, consulted August 2016). 
With regard to the provision of procedural advice, it is important to note that matters of procedure and timing of the legislative process are generally considered the domain of the EP committee secretariats (e.g. Neunreither, 2002). Nevertheless, the vacancy notices provide cause to believe that group advisors are (at least) indirectly involved. The main indication for this expectation is the reference to drawing up the so-called 'voting lists' as part of their duties (see Appendix I). This activity is linked to the order of the votes and voting instructions that groups generally issue to their members (Corbett et al, 2011: 121). Instructions not only indicate how to vote on each amendment and text but also stipulate which votes are important (Corbett et al, 2011: 121). A second indication for group advisors' involvement in procedural matters is their responsibility for 'politically and technically coherent parliamentary positions' (see Appendix I). Considering this responsibility in relation to the voting lists raises the expectation that advisors provide advice regarding technical accuracy and political coherence of legislative texts. Chapter 4 presents the empirical analysis of the Process Manager role, exploring the technical and political dimensions and the circumstances that affect the adoption of the role in practice.

\subsubsection{Information management}

From the literature, three central elements of information management are derived: (1) gathering information, (2) processing information, and (3) distributing information. The vacancy notice analysis showed that 'information tasks' are listed as part of the standard duties of EP political group administrators (see Appendix I). Such activities can obviously entail a variety of things that remain unspecified in the job descriptions. Considering 'information tasks' in light of the scholarly debate, the expectation is that group advisors process information by selecting the 
sources and content of information in order to present the most relevant pieces of information to the MEP. ${ }^{27}$

Another rather general duty listed in the vacancy notices is 'communication tasks'. Again turning to the literature for inspiration these activities could be tied to the internal and external exchange of information. Cooperation and interplay at staff level within and between EU institutions facilitates the legislative process (Patterson, 1970; Christiansen, 2002). From this the possibility is inferred that group advisors gather and distribute information through informal interchange at staff level, both within and outside the EP. Chapter 5 presents the empirical analysis of the Information Manager role, exploring the technical and political dimensions and the circumstances that affect the adoption of the role in practice.

\subsubsection{Policy expertise}

From the literature, two central elements of policy expertise are derived: (1) providing policy-related advice and (2) drafting legislative texts or policy documents. The provision of 'policy advice' is encountered in the job description of group advisors. The duties listed in the vacancy notices also include the drawing up of 'parliamentary positions', drafting amendments, and resolutions as part of the political advisor's duties (see Appendix I).

With the expanded workload of the EP and the growing amount of informal trilogues the need for substantive policy-related input increased (see 1.1.1). Parliament values its independent information position from the executive it controls (Roederer-Rynning and Greenwood, 2017). For MEPs to be able to make an assessment of the policy or legislative proposals on

\footnotetext{
27 This expectation draws on an extensive literature review included in the introduction. The main sources for inspiration are: Neunreither, 2002, Winzen, 2011, and Busby, 2013.
} 
the table, it can be assumed that they are in need of technical assistance to match the expertise present in the Council and the EC. Among the listed responsibilities of group advisors we find 'participating in the legislative work of the parliamentary committees'. Usually one or several parliamentary committees are specified (see Appendix I). From this we can assume that the advice provided by political advisors is tied to a specific policy area. Chapter 6 presents the empirical analysis of the Policy Expert role, exploring the technical and political dimensions and the circumstances that affect the adoption of the role in practice.

\subsubsection{Brokering}

From the literature, two central elements of brokering are derived that apply both to intra- and inter-group negotiations: (1) facilitating compromises by providing advice on negotiation strategies and (2) mediating compromises on behalf of the MEP. The studies of Neunreither (2002) and Egeberg and colleagues (2013) raise the expectation that group advisors - to a greater extent than other EP staff - facilitate and coordinate compromises within the EP. The so-called 'group line' is defined by a process of internal discussion and negotiation between the national delegations of the political group (see 1.3.1). From the vacancy notice analysis the conclusion can be drawn that in this intra-group coordination process advisors are responsible for securing the group's overall objectives and preserving consistency between past and future positions (see Appendix I). Considering this responsibility in light of the groups' working methods (see 1.3.1 and 1.3.2), it is proposed that advisors mediate between (potentially) conflicting issues within the group and possibly propose or negotiate alternative or compromise positions. Since the EFD group has the lowest cohesion, advisors employed by this group are expected to form an exception and not, or to a lesser extent, adopt the intra-group Broker role. 
In the vacancy notices, GUE/NGL is the only group that explicitly refers to an intermediate function the advisor should fulfil by way of liaising with other political groups, the EP General Secretariat, and with the national press and NGOs (GUE/NGL, 2016). The Code of Conduct (2008) for interinstitutional negotiations suggests a potential role for advisors in the preparation of these negotiations. Representation of all political groups 'at least at staff level' - is prescribed. The Code of Conduct furthermore refers to an 'administrative support team' that at least includes the committee secretariat, political advisor of the rapporteur, co-decision secretariat and the legal service (see 1.3.3). The empirical analysis for the Broker role is presented in chapter 7. This examination examines whether an inter-group Broker role is assumed, and if so, how this may differ across the groups.

\subsection{Concluding remarks}

Before discussing the empirical findings, this chapter linked the abstract conceptual approaches regarding political advice to the specific context of the EP. The discussion concluded that MEPs rely on three internal sources of advice in the preparation of legislation and policy: EP officials, group advisors, and MEP assistants. The literature is congruent in finding that the source of assistance varies at the discretion of the MEP in charge. Connecting the insights from the literature to the definition of political advice leads to the expectation that the activities of EP staff are situated in the mixed sphere of activity. Notwithstanding, political advice as defined for the purpose of this study is predominantly the domain of MEP assistants and group advisors. This study focuses on the latter as they remain a virtually unstudied group of actors and fulfil a primary role in the intraparliamentary coordination of political positions. 
The second part of the chapter provided a description of group advisors' profile and background stemming from the need to acquire a basic overview of who they are and what they do. The presented findings from the survey and the document analysis already reveal considerable differences between the groups: advisors' function levels, duration in office, and prior experience varies across the groups. The differences are further explored in the empirical analysis.

The presented findings are furthermore a first indication that the role of group advisors can be associated with the four types of advice. Tasks that can be categorised as process management and policy expertise were explicitly encountered in the analysed vacancy notices. While information tasks are listed as a responsibility of the group advisor, it remains unclear from the job description what such tasks entail. Although the vacancy notices merely imply brokering activities, group advisors are expected to facilitate and coordinate compromises within the EP. With the exception of the GUE/NGL group, only the advisor's contribution to the internal coordination process is mentioned in vacancy notices. The adoption of each of the roles by EP group advisors is assessed in the following chapters, as well as the circumstances determining the provision of advice and advisors' room for improvisation. 



\section{CHAPTER 4. PROCESS MANAGER}

The analytical framework comprises four roles that advisors may adopt, each potentially containing a political dimension. The previous chapter operationalised the general concepts of the framework and applied them to the specifics of group advisors in the European Parliament (EP). ${ }^{28}$ This chapter presents the analysis of the Process Manager role. The ideal-type role comprises two central elements: (1) organisational support, and (2) procedural advice. To address the research question 'under which conditions can advisors adopt a political role' three analytical steps are carried out.

The first step is to assess whether the ideal-type role is in fact adopted and what it entails in practice. 4.1.1 examines the theoretical dimensions of process management. Expectations with regard to the adoption of the Process Manager role are put forward, drawing from the literature review (see introduction) and complemented with the performed document analysis. The discussion in 4.1.2 then assesses these projections in light of the empirical data. The findings show that group advisors assume the Process Manager role and that activities go beyond the conceptualised scope.

The second step of the analysis is to assess the political scope of the Process Manager role. The extent to which the role is political is assessed with the use of the modes of discretion that have been developed as part of the analytical framework. In this respect, section 4.2 considers advisors' room for manoeuvre when fulfilling the political dimensions of information

\footnotetext{
${ }^{28}$ Advisors employed by one of the EP party groups and assigned to follow the work of one or several of the parliamentary committees are the focus of this study. Throughout the analysis 'advisors' or 'group advisors' refers to this type of advisors.
} 
management. This is approached by, on the one hand (4.2.1), examining the extent to which advisors receive instructions or input from the Members of the EP (MEPs), and on the other hand (4.2.2), the degree to which advisors can show initiative or improvise. The research shows that in addition to practical procedural assistance and information, advisors fulfil a guiding and signalling role in which they interpret texts in relation to the position of the group and anticipate potential incoherence, conflict, or inconsistency. It is concluded that advisors manifest political behaviour for the majority of activities. Findings show that in the preparatory process in which process management is key advisors are not explicitly told what to do. Instead, the advice or support offered is guided by what advisors deem to be in line with the priorities or position of the group.

Finally, section 4.3 evaluates the impact of the personal and contextual factors on the adoption of the role by group advisors. The analysis concludes that trust and political sensitivity are indispensable for pro-active process management, whereas complexity and politicisation have a restricting impact on some of the process management activities of group advisors.

\subsection{The nature of process management in the EP}

This section introduces the theoretical dimensions of the Process Manager role (4.1.1). The ideal-type role entails two elements: (1) organisational support, and (2) advice on the legislative process, formal procedures and informal practices. These elements are explored and related to the document analysis on the profile and duties of EP group advisors in order to infer expectations regarding the adoption of the role (see 3.3.3).

4.1.2 then presents the empirical findings for the Process Manager role. The theoretical expectations are assessed in light of the collected survey and interview data. The findings disclose that while group advisors assume the 
role, the encountered organisational support goes beyond the conceptual scope of organising and following up on meetings. Instead, it encompasses the broader informal intra-group preparation of decision-making.

\subsubsection{The theoretical dimensions of process management}

This sub-section draws on the theory and document analysis with the aim of identifying the technical and political dimensions of process management. The analytical framework defines two central elements of the role: (1) organisational support, and (2) procedural advice. ${ }^{29}$

The first element of process management is operationalised as the organisation and follow-up of group meetings, seminars and conferences with external stakeholders (see 3.3.1). A standard duty that is encountered in the job description of group advisors is the organisation and follow-up of meetings (see Appendix I). The literature review on the functioning of the intra-group coordination process revealed that groups generally set out to coordinate their views internally in order to maximise their impact on a legislative outcome (see 1.3.1 for a more elaborate discussion of intragroup coordination efforts). Organisational support is therefore first of all expected to involve the preparation of 'group meetings' (Corbett et al, 2011: 113). In addition, group advisors' involvement is conceivable in the (public) seminars and conferences groups organise. These events on specific topical issues take place in cooperation with external stakeholders as a way to tap into external sources of expertise (Corbett et al, 2011: 119 and EP political groups' websites).

\footnotetext{
29 The definition is based on an extensive literature review (see introduction) and draws on Congressional 'Office of the Parliamentarian' in: European Parliament, 2000; Ryle, 1981; Provan in: Neunreither, 2002; Tallberg, 2004; Winzen, 2011; Busby, 2013; Högenauer and Neuhold, 2015.
} 
Procedural advice is conceptualised in relation to the legislative process, formal procedures and informal practices (Neunreither, 2002; Högenauer and Neuhold, 2015). It is important to note that matters of procedure and planning the decision-making process are generally considered the domain of the EP committee secretariats (Neunreither, 2002). Nevertheless, the analysis of vacancy notices provides cause to believe that group advisors are (at least) indirectly involved. Chapter 3 operationalised this element of process management as advisors' involvement in the preparation of voting lists. Prior to each vote in Parliament, members are provided with voting instructions about how to vote on each amendment and texts, and about which votes are considered important from the perspective of the group. These 'voting lists' are prepared and circulated by the group advisors in close cooperation with the group coordinator (Corbett et al, 2011: 121). ${ }^{30}$ The extent to which the groups coordinate activities and positions - and thus draw up voting instructions for their members - varies considerably (see 1.3.2). Previous studies show that the EFD has the lowest group cohesion. ${ }^{31}$ EFD advisors' involvement in the voting lists is therefore expected to be restricted to advice provided to individual MEPs, or to be irrelevant for this subset of advisors. Another activity related to decisionmaking procedures is the verification of submitted amendments. From the vacancy notices that were examined, it is inferred that advisors may be responsible for checking amendments and legislative texts on behalf of the group in order to safeguard technical accurateness and political coherence. These expectations are further supported by the literature on the working methods of the EP party groups discussing group discipline and whipping (Corbett et al, 2011: 121).

\footnotetext{
${ }^{30}$ For each committee, political groups designate a 'coordinator' (Rule 205, EP procedures) who takes the lead in developing the group's position (see 1.2.1). ${ }^{31}$ ALDE, ECR, EFD, EPP, GREENS/EFA, GUE/NGL, S\&D are the party groups considered in the analysis. See 1.3 for the discussion on intra-group coordination.
} 
In the framework, political advice is defined as a mixed sphere of activity that comprises technical and political dimensions (see 2.1.2). Political tasks are conceived to contain value or ideological appraisals, the anticipation of priorities or objectives, and the use of implicit knowledge or tactics (see 2.1.2). Technical tasks are void of such judgement by the advisor. Organisational support at the outset may appear to be of a purely technical nature. For example, it is conceivable that advisors in the organisation of meetings or conferences arrange a room or venue, provide for catering services, send out invitations, and administer attendance. Yet, activities that may require their judgment are not unthinkable in this regard. The literature offers some suggestions as to possible political aspects of process management. The role of staff is acknowledged in the pre-selection of relevant issues and actor involvement (Winzen, 2011). Relating these activities to the organisation of group meetings or events with external stakeholders, it can be proposed that advisors contribute to the shaping of the agenda. They may, for example, advise on topics or priorities for discussion, or recommend whom to invite. Similarly, the follow-up of meetings by advisors may require them to interpret certain statements or decisions, in terms of the desired outcome and strategy to realise that outcome.

Procedural advice may be based on formal documents and relate to parliamentary procedures. However, this is mostly expected to be the role of EP officials in the committee secretariat. Group officials are expected to rather advise on voting lists and the accuracy and coherence of amendments. Technical aspects of the role are conceivable in situations where the advisor merely informs MEPs on procedural matters that are not open to interpretation, or simply administers what the MEP in charge instructs. 
Figure 4.1.1 illustrates the theoretical dimensions of process management. Relating organisational support to what we know from the literature it is inferred that group advisors' responsibilities for internal and external meetings include political tasks, specifically agenda structuring and actor involvement. The political dimension of procedural advice is linked to the preparation of voting lists that entails indicating the level of importance, providing recommendations on how to vote; and to checking amendments for technical accurateness and political coherence. Technical aspects of process management are the organisation and follow-up of meetings, and advice based on formal documents and procedures.

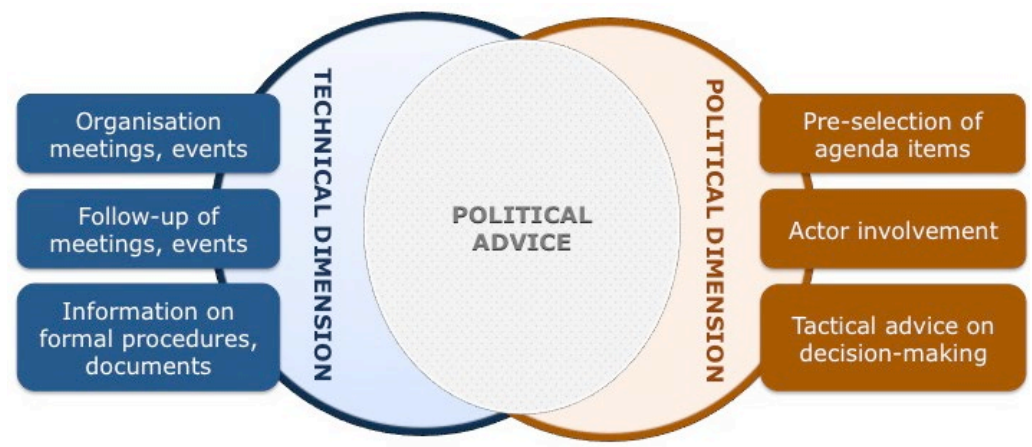

Figure 4.1.1 Theoretical dimensions of process management

\subsubsection{Adoption of the Process Manager Role in practice}

The conducted empirical research demonstrates that EP group advisors adopt the Process Manager role and that it entails both technical and political tasks. Yet, the findings suggest that advisors mainly fulfil the political dimensions of the Process Manager role. Moreover, the data reveal that organisational support goes beyond the tasks that were conceptualised from the literature and the document analysis. Organisational support is most prominently tied to the organisation of the intra-group coordination process. Advisors have the opportunity to shape the agenda of group meetings and selectively involve MEPs. The discussion below presents the survey and interview findings. It first considers the relative importance of 
process management, and then assesses the organisational and advice elements of the role.

\section{Advisors' perception of process management}

In an open-ended question, respondents were asked to name their most important responsibility. 23 per cent put forward tasks that may be labelled as process management (see figure 4.1.2).

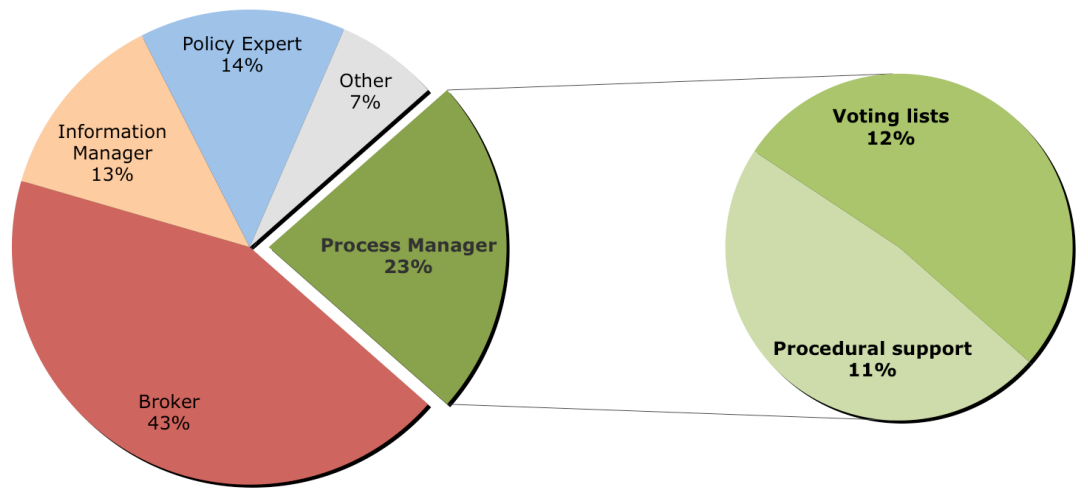

Figure 4.1.2 Relative importance attached to process management

The further analysis of the answers reveals two categories of tasks: 12 per cent refer to the preparation of voting lists while 11 per cent point to tasks that relate to the organisation of the legislative process. In the latter category, 'process management of parliamentary work' (SR52) is for example said to entail the coordination of amendments, planning of the overall coordination process and ensuring that deadlines and procedures are respected (SR13, 68, 74, 93). ${ }^{32}$ Voting lists define the group's preferred voting outcome, i.e. the adoption or rejection of amendments, and can be considered as voting advice provided to the members.

\footnotetext{
32 Survey respondents (SR) and interviewees (I) are coded according to the order in which the responses were received and the interviews conducted. See Appendices III and $\checkmark$ for an overview.
} 
Compared to the other groups, ECR and EFD appear to attach greater value to process management. Four out of 12 ECR and three out of six EFD respondents name it as most important. This finding may be interpreted in light of the nature of these groups. ECR has a rather pragmatic group culture. Internal ideological differences are small and the national delegations have a large degree of autonomy (interviews ECR advisors). These characteristics likely reduce the need for intra-group coordination (see 1.3.1). Like the ECR, the EFD group is dominated by several large national delegations. Moreover, the group does not coordinate its positions internally and is reputed for being formed for technical reasons (material and procedural benefits, see 1.1.2). Finally, the Eurosceptic stance of the EFD makes that at least a substantial part of its members are less prone to contribute to legislation (I.23).

All but three interviewees discussed the importance of preparing voting lists and providing members with advice on how to vote. This activity is considered 'a very political and influential role' of the advisor (I.3). The EFD does not draw up voting lists and advisors are assigned to a national delegation. Nonetheless, advisors may give recommendations regarding the support of specific (sets of) amendments, for example after consultation with the EPP (interview EFD advisor). The reported involvement in the organisation of the legislative process is more diffuse and further discussed below.

\section{Organisational support}

From the theory and document analysis it is inferred that advisors are involved in the organisation and follow-up of group meetings and events with external stakeholders (see 4.1.1). Survey findings demonstrate that advisors, in addition to their work within the parliamentary committees, spend time on group activities. For the majority of respondents, 
parliamentary committee work takes up 80 per cent of their time. ${ }^{33}$ Yet, 92 per cent admits that they are involved in group activities too, on which they spend around 20 per cent of their time. Drawing from the qualitative data, such tasks are expected to most prominently relate to the preparation of group meetings. 15 interviewees mention their role in these preparations, ${ }^{34}$ of whom 13 say that they pre-select issues for discussion. ${ }^{35}$ Most groups organise preparatory ('prep') meetings to coordinate their position ahead of committee meetings (see 1.3). The main task of advisors then is to make sure that contentious or sensitive issues are tabled for discussion in a subsequent group meeting in order to ensure that they are discussed at group level.

In addition to the close cooperation with the group coordinator and (shadow) rapporteur, 11 interviewees discuss the (selective) involvement of MEPs in both the informal and the formal coordination process. ${ }^{36}$ Advisors 'decide' which MEPs to (actively) involve (I.7). In the formal sense this may entail organising deputies when a member cannot be present (I.0.1-0.4, 6). Several interviewees also described a more informal role in relation to informing and involving members $(1.5,7,22)$. They see it as their responsibility to make sure that the coordination process is 'transparent' (I.22) and that the members of the group 'do not feel excluded' (I.5).

Contrary to what was hypothesised when conceiving the ideal-type role, the empirical data suggest a minor involvement in the organisation of events with external stakeholders. Only two interviewees refer to the organisation of seminars. Activities are said to include the selection of topics, titles, and

\footnotetext{
33 See Appendix III, response to SQ8.

34 I.0.2, 0.4, 1, 2, 5, 7, 10, 12-15, 17, 18, 21, 22.

35 I. $0.2,0.4,2,5,7,10,12,13,15,17,18,21,22$.

${ }^{36}$ I. $0.1,0.2,0.3,0.4,0.5,2,5,6,7,18,22$.
} 
speakers $(1.0 .3,3)$. It may be that such activities are simply not deemed important or substantial enough to bring up in the interviews or survey responses. Alternatively, only a very small proportion of advisors deal with these practical matters.

The data instead provide strong evidence of a different type of organisational support, relating to the overall coordination of the legislative process. Examples of this activity were encountered in both the survey and the interviews. Advisors should be able to 'guide MEPs through the policy process' (SR87) and facilitate 'the smooth running of the machinery' (SR81). As was discussed above, 11 per cent of survey respondents identify this form of support as their core responsibility. Additionally, all but three interviewees highlight their role in organising the legislative process. Such activities focus on the intra-group coordination process, in particular in the committee phase. They range from more administrative tasks to advice about the submission of amendments or actor involvement.

The qualitative data disclose that this kind of support relates to more practical issues such as planning issues, respecting formal EP procedures and deadlines. This responsibility was underlined in the open-ended answers of 13 survey respondents and came up in six of the interviews. ${ }^{37}$ Broadly speaking advisors take care of the 'management of reports' lifecycle' (SR49), something that requires 'good coordination work and planning' (SR50). The survey findings furthermore highlight the importance of the knowledge of EP procedures. 33 per cent of respondents rank it among the most important competencies of group advisors (see 3.2.3). From the qualitative data it is inferred that having an understanding of procedures is instrumental in the coordination of the legislative process (I.1,

37 I. $0.1,0.5,1,15,17,21$; open-ended responses of SR13, 31, 43, 49-53, 68, 74, 81, $93,98$. 
$7,21)$. More specific tasks that were identified are the distribution of speaking time that is discussed at staff level (I.17) and ensuring that 'all MEPs turn up to vote at the right time and place' (I.15).

The interview and survey findings show that for process management tasks advisors' main point of contact at the political level is the group coordinator of the respective parliamentary committee (see 1.2.1 for an introduction of the key actors at political level). All official communication about the legislative work passes through the committee secretariats. EP officials submit and distribute all the formal documents, incoming and outgoing information from and to the other EU institutions, as well as invitations for meetings between the rapporteur and shadows (I. 6, 10). Our job is to get 'the best information possible and place it at the right time and using the right tools' (SR51). Advisors state that they act as the link between the EP committee secretariat that is in charge of formal process management and the MEP. ${ }^{38}$ This cooperation is further confirmed by the survey data with regard to the interaction between EP staff. Most advisors report that they have weekly contact with EP officials (see table 5.1a).

In addition to these organisational tasks, advisors may be involved in a more strategic type of coordination. Although practices differ per group, advisors may attempt to manage the process of amendment submission. ${ }^{39}$ After the presentation of the draft report by a rapporteur in committee, a deadline for tabling amendments is set. Following the vote in committee the rapporteur amends the report to take account of the amendments adopted by the committee before it is tabled in plenary (see 1.3.4). The extent to which advisors take initiative or are allowed to coordinate amendment submission is further discussed in 4.2.2.

38 I. $0.4,0.5,1,5,6,8,10,13,14,21$; open-ended responses of SR18, 93.

${ }^{39}$ I.2, 3, 5, 10, 14, 17, 19, 20, 22; SR74. 
Another more strategic activity that can be considered in light of planning and actor involvement is advisors' contribution to the appointment of rapporteurs. In the preparatory phase of decision-making, groups determine their priorities with regard to the acquisition of rapporteurships. As part of this preparation, advisors for example provide background information as to which rapporteurships the group can attain in relation to the points system of $\mathrm{d}^{\prime} \mathrm{Hondt}{ }^{40}$ take stock of which MEPs may have a specific interest for certain files, and whether these MEPs can then count on the support of the group (I.0.1, 0.4, 0.5). One interviewee who had worked for both the IMCO and LIBE committees explained that the dynamic in committees with respect to the distribution of reports differs. In IMCO it is always the group with the highest points that gets to choose first. In LIBE advisors send out e-mails to the members listing the upcoming reports and taking stock of who is interested. This finding suggests that the working practices and culture in the various parliamentary committees vary, and that these practices may affect the role of the advisor.

\section{Procedural advice}

The empirical research confirms that group advisors provide procedural advice to MEPs. The findings, however, mainly highlight the political dimension of this type of advice. Two core activities are encountered in this respect: on the one hand, advisors advise on the accuracy and political coherence of (legislative) draft texts, and on the other hand, they issue voting recommendations. The responsibility for the so-

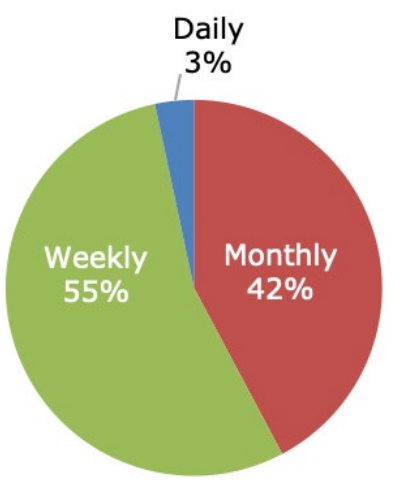

Figure 4.1.2a Preparation of voting lists

\footnotetext{
40 Rapporteurships are allotted by a points system based on groups' share of seats in Parliament. Each group receives a quota of points and the groups' coordinators bargain over the final allocation of subjects (Corbett et al, 2011). See 1.2.1 for a more elaborate discussion on the allocation of rapporteurships and the d'Hondt system.
} 
called voting lists is a core task of group advisors. Illustrated by figure 4.1.2a, all survey respondents claim that they prepare voting lists. ${ }^{41} 12$ per cent of respondents designate it their most important responsibility (see figure 4.1.2). Only three interviewees do not mention their involvement in the preparation of voting lists. ${ }^{42}$ The qualitative data reveal that the composite nature of this activity. Advisors first verify and comment on the voting list drafted by the committee secretariat. Once that list is approved, they provide their members with voting indications.

16 advisors expanded on what the preparation of voting lists entails. ${ }^{43}$ Prior to a vote in committee or plenary, the EP committee secretariat drafts a voting list that comprises all the amendments submitted. Group advisors check and comment on the list (I.18). In addition, they negotiate with the committee secretariat and counterparts on the order of the vote (I.2, 3, 10, 11, 20). Group advisors for example argue what amendment(s) should take priority in the voting order and what amendments should fall if another is adopted or rejected (I.3, 7, 11, 15, 20). In addition, 20 advisors state that they verify texts for political and technical coherence on behalf of the group. ${ }^{44}$ Advisors are responsible for avoiding any conflicting statements in amendments submitted by different members of their group, checking the 'political logic', coherence with previous group positions, and possible clashes with the overall group position (I.0.4; SR25, SR40, SR62). "We are responsible for a coherent end-product that the majority can sign up to. The worst thing would be a chaotic report" (I.11).

The second element of the preparation of voting lists relates to the voting advice provided to the members. In the run-up to a vote, advisors annotate

\footnotetext{
41 See Appendix III, analysis SQ7.

42 I. $12,16,19$.

${ }^{43}$ I. $0.1,0.3,0.4,2,3,5,7-11,14,15,20$; open-ended responses SR67, SR74.

44 I. 0.4, 2, 3, 5, 7, 8-11, 14, 17, 18, 20, 21; SR25, 28, 40, 62, 67, 74.
} 
the voting list with recommendations on how to vote. This task was highlighted by 17 interviewees. ${ }^{45}$ "Preparing voting lists is one of our clearest tasks. Sometimes if you have a reliable assistant you can send them the list and they fill it in but it is always the advisor's task to look at it and make sure that all the voting recommendations, indications are right" (I.18). Voting lists 'resumes all the work previously done' (SR48) and advisors have to ensure that the group's position is reflected in the vote (SR25, 62, 67). This illustrates that the provided voting advice is actually the outcome of the intra-group coordination process, and that the advisor bases the recommendations on prior deliberations that have taken place in the group.

Several respondents state that for MEPs the voting lists for plenary sessions are a particularly important step in the parliamentary process. This is when the group's position 'is expressed to outside world (SR75) and 'results of the vote can be accessed by journalists or the external public' (SR8).

To conclude, organisational support goes beyond the conceptual scope of organising and following up on meetings. It encompasses the overall coordination of the legislative process. The analysis shows that advisors' contribution pre-eminently lies in the informal intra-group preparation of decision-making. It is found that advisors shape the agenda of internal group meetings and play a role in (selectively) involving MEPs in the legislative process. They are furthermore closely involved in the preparation of voting lists. In this process they check the work of the EP committee secretariat and subsequently provide the group with voting recommendations. The political scope of these activities is further considered in section 4.2 .

${ }^{45}$ I. $0.1,0.3,0.4,1,2,3,5,6,8,9,10,11,14,15,17,18,21$. 


\subsection{Assessment of the political scope of process management}

The findings confirm that there are technical and political dimensions to process management in the EP context, thus characterising it as a category of political advice. The previous section presented the empirical evidence for the adoption of the role. The research displays that the role predominantly relates to the informal intra-group preparation of decisionmaking. In this process advisors inform, advise, involve, and guide MEPs. This type of support allows advisors to shape the agenda of internal group meetings and to play a role in the submission of amendments. They furthermore check and comment on the voting list drafted by the committee secretariat, and subsequently provide voting recommendations.

This section evaluates the political scope of the role. The extent to which the role is political is assessed with the use of the modes of discretion that have been developed as part of the analytical framework (see 2.1.3). The aim is to explore advisors' discretion, room for initiative and improvisation when they perform process management activities. To that end, 4.2.1 addresses the way in which advisors receive instructions from MEPs and how this input affects their role. Findings show that in the preparatory process in which process management is key advisors are not explicitly told what to do. Although several tasks require the explicit approval of the MEP in charge, the advice or support offered is guided by what advisors deem to be in line with the priorities or position of the group. If instructions are lacking the question arises what 'cues' advisors use to determine the appropriate course of action. 4.2.2 examines the extent to which advisors (need to) improvise in their process management efforts. The discussion shows that in the absence of instructions advisors are guided by what they deem appropriate or necessary. Finally, 4.2 .3 considers the three modes of 
discretion in relation to process management. It is concluded that advisors manifest political behaviour for the majority of activities.

\subsubsection{Instructions and input from the MEP}

This sub-section sets out to determine the way in which advisors receive instructions or input from MEPs and how this affects their ability to act as Process Managers. From the quantitative and qualitative data it is found that advisors work closely together with (shadow) rapporteurs and the group's coordinator of the parliamentary committee in question. The Secretary-Generals constitute the administrative heads of the groups, yet in practice, group coordinators function as advisors' principal (I.10). Thus, their explicit or implicit political instructions are most likely to emanate from this interaction. The survey explored the interaction of advisors with other actors in the EP. Over half of the respondents say to liaise with their group coordinator on a daily basis. Another 41 per cent describes the frequency as weekly. Comparable figures were collected for the interaction with (shadow) rapporteurs within the advisor's group: 45 per cent of advisors estimates the contact as daily and another 45 per cent as weekly. Interaction with the political group's Secretary-General is considerably less frequent. The majority of advisors (43\%) only interact on a monthly basis whereas 37 per cent say to do so weekly (see table 5.1a). In this context, it is important to note that advisors' activities are determined by the parliamentary calendar and thus differ one week from another. ${ }^{46}$ Nonetheless, the data clearly point to coordinators and (shadow) rapporteurs as advisors' main principals.

\footnotetext{
${ }^{46}$ In general, one week a month is dedicated to the plenary session, preceded by a week of group meetings. Furthermore, there are assigned weeks for committee meetings and for external parliamentary activities.
} 
Both the survey and interviews demonstrate that a large majority of advisors acknowledge their autonomy. In carrying out their daily tasks they are not explicitly told what to do. In respect to process management, one third of the survey respondents specifically underline the need for pro-active behaviour. Notwithstanding, advisors tend to represent their role in supportive and advisory terms, emphasising that the final responsibility and decision lie with the MEP. Only three survey respondents and five interviewees portray their role as truly 'routine', void of initiative on their part and clearly bound by the supervision or demands of the MEP. "In an ideal world, MEPs and their assistants steer parliamentary work" (SR52). Several advisors recognise that their discretion creates a certain tension. ${ }^{47}$ Lacking a political mandate, advisors must balance 'modesty and assertiveness at the same time' (I.2).

A first example of an activity that advisors fulfil without an explicit mandate is the preparation of group meetings. They are found to select issues for group debates (see 4.1.2). The interviews show that such potentially divisive issues are then picked up with the group coordinator or (shadow) rapporteur who then can decide to table and defend the issue in group discussions (I.0.1, 0.2, 2, 10, 12, 13, 16, 22). "The MEP in charge has to convince the others of his or her position. It is not common for advisors to speak during group meetings so we have to prep the MEP" (I.12). The Greens/EFA have a coordination meeting at staff level in which advisors and the Secretary-General discuss the preparation of group meetings. "We have the freedom to determine the relevance of a dossier: (A) point of information, (B) point of discussion, (C) only a briefing. MEPs can then always call for a discussion and this happens. Contentious issues are always

47 I. 2, 12, 17, 22. SR43, 46, 52, 61, 77, 78. 
discussed. And if we are voting against the compromise agreement a discussion always takes place" (interview Greens/EFA advisor).

The survey data presented in chapter 3 demonstrate that advisors attach great importance to the knowledge of EP procedures (see 3.2.3). Knowledge of the EP Rules of Procedure as well as the legislative procedures is instrumental for the Process Manager role (SR46). It helps in carrying out the practical organisational matters that, although not discussed at great length in the interviews, appear to be part of advisors' duties. Advisors manage deadlines, organise deputies, or distribute speaking time (see 4.1.2). These activities are guided by the EP RoP and the working practices of the group. Consequently, neither the ends nor the means appear to be open to interpretation.

From the qualitative data it is inferred that advisors' can show initiative in the overall organisation of the legislative process. Advisors use their procedural knowledge to guide MEPs through the intra-parliamentary process $(I .0 .5,1,15,21)$. The discussion of the empirical research revealed that advisors' guidance entails various activities in the margins of political meetings where they act as the liaison between the group and the committee secretariat (see 4.1.2). From a more practical point of view, it relates to issues of planning and managing deadlines. More substantially, advisors can have a role in the submission of amendments. Finally and most prominently, all of the advisors in the study indicate their involvement in checking the voting list drawn up by the committee secretariat. It is unlikely that for such activities they receive instructions or input, and rather it is through their familiarity with EP rules and procedures that they provide added value to the MEP or the group as a whole. Five advisors explicitly point out that advisors are influential through procedural support (I.1, 4, 7; SR8, 47). "It helps immensely if you know the rules of the House in order to influence decision-making" (SR47). An 'in-depth knowledge' of the 
procedures enables the advisor 'to achieve more results' for the group (SR8). Advisors thus use their knowledge of procedures to advance the position of the group. How they go about this is further considered in 4.2.2.

The qualitative data show that advisors generally discuss voting indications with the (shadow) rapporteur (I.0.3, 0.4, 2, 5, 7, 9, 10, 14, 15, 17, 18). The advisor makes a 'proposal' (I.7) and the MEP then 'says yes or no' (I.9). Although the voting indications are discussed with - and checked by - the MEP in charge, the advisor 'pre-filters' (I.0.4, 9). Only one interviewee stresses that the preparation of voting recommendations is purely based on 'what the coordinator wants'. Overall, the research shows that in this activity advisors are granted a great deal of discretion. They apply judgement and interpretation in order to assess what amendments should be adopted or rejected. Their assessment of the ideal outcome for the group is based on what they believe in in line with the position of the group, and thus acceptable to the majority of its members. For the voting advice provided ahead of plenary, advisors may be (indirectly) guided by group discussions that have taken place on the issue.

The analysis concludes that for most activities no explicit instructions are provided to advisors. Instead, they are guided by their understanding of the group position and priorities, as well as those of the national delegations. This is something that requires anticipation and judgement and is further discussed in 4.2.2.

\subsubsection{Improvisation by the advisor}

It is found that group advisors fulfil the political dimensions of the role (see 4.1.2). The previous sub-section concluded that, for these activities, advisors' mandate is implicit and that there is considerable room for initiative despite the finding that several process management tasks require 
explicit approval of the MEP in charge. In this sub-section group advisors' manifested level of improvisation is assessed for the process management activities that occur before the approval of the MEP or in the absence of clear input. Improvisation is construed as value or ideological appraisals by the advisor, the anticipation of priorities or objectives, or the use of implicit knowledge or tactics (see the definition of political advice in 2.1.2).

Survey and interview findings suggest that in some cases advisors attempt to manage the process of amendment submission. Group working practices differ in this regard. Advisors may use their judgement to coordinate different (sets of) amendments to ensure a coherent outcome for the group. Nonetheless, their contribution is of a reactive nature as tabling amendments is the prerogative of MEPs' offices (interviews ALDE and ECR advisors). From the data it is inferred that the Greens/EFA are the most active in this regard and the ECR the least. It is 'unusual' for the Greens/EFA to have 'a competing set of amendments' and advisors set out to 'streamline' the production of amendments (interviews Greens/EFA advisors). They have a monthly meeting with their Secretary-General in order to avoid this. An ECR advisor, on the other hand, emphasised that the group does not coordinate this process: advisors just go through all proposed amendments 'to see what everyone is saying'. "Although not always possible, we aim to coordinate the amendments submitted by MEPs of the group," an EPP advisor stated. The same interviewee admits that at times MEPs submit amendments without consulting, or even informing the group secretariat and attributes this to the fact that amendments are usually submitted very close to the deadline. It is presumed that the EFD, lacking a group discipline, does not coordinate the process of amendment submission. The GUE/NGL interviewee said that there is room for 'alternative voting' in the group and that in principle any amendment can be submitted provided that there are no inconsistencies within one 
paragraph. Any potentially problematic issues are then discussed in the group secretariat meetings.

Although the MEP in the end always decides, advisors' contribution lies in the chosen approach leading up to the decision (I.7). The overall picture is that advisors pro-actively involve MEPs in the intra-parliamentary coordination process: "We act as a coach for the members in close cooperation with the coordinator" (SR31). Concretely, several advisors state that they select 'a few competent MEPs' to involve in their work (SR92). And by doing so, advisors can (sometimes) decide who gets to decide $(1.2,6,7,12)$. Others approach the same activity as 'including the members' in order to safeguard support for the position of the (shadow) rapporteur $(1.5,9,13,18)$. "I try to get feedback from the members regarding the priorities and most important issues for the negotiations with the other groups. I do this to make them feel important and not feel excluded. If you don't do that, and carry on working only with the shadow rapporteur, the risk that the group will be split during the vote is higher. We therefore circulate the compromise amendments and ask whether they have any comments or want to add something. My aim is to make sure that the majority of my members are going to follow the rapporteur and find out if I can propose some suggestions to make them happy. For example, if there is a word or phrase that they don't like maybe we can ask for a split vote" (I.5).

As was concluded in 4.2.1, advisors enjoy room for manoeuvre in the organisation of the legislative process. "Our role is to make sure that no important steps are missed in the legislative or political process" (SR53). This shows that several elements of process management are by definition pro-active. The means and the ends are left up to the advisor's judgement or anticipation of what is necessary. A first example is found in advisors' contribution to defining the group's strategy on what reports to attain. This 
entails anticipation of what other groups want and an assessment of possible suitable candidates that are likely to gain support. In this sense it is important to establish the reputation and network of the MEP within and beyond the committee, his or her previous activities, expertise and that of the personal assistant beforehand (I.0.4). Advisors play a coordinating role and advise the group coordinator (I.0.1, 0.5, 18). They provide information as to what other reports or opinions will come up in order to plan ahead and determine what rapporteurships the group wants to acquire and where room for bargaining exists (I.0.1). "Sometimes you are approached by members who are interested in a certain file. Then it is up to us to discuss it with the coordinator whether it is in fact a priority of the political group or just a personal interest of an individual member" (I.18). Yet, the distribution of reports differs per committee and per group. An EPP interviewee said that the distribution is not discussed at group level as it would 'completely overburden the group'. The same advisor added that 'very often you already know what the priorities of your group are', confirming that advice is often based on what advisors deem appropriate.

A second activity through which advisors coordinate the legislative process is their responsibility to comment on the voting list drawn up by the committee secretariat (see 4.1.2). In this process they speak on behalf of the group and exert influence on the legislative decision-making process with only an indirect and implicit mandate (see 4.2.1). Several interviewees stress that they check the (compromise) texts to make sure that no (unapproved) 'politics' get into the amendments (I.3, 10, 17). Greater room for improvisation, however, is encountered in the process of determining the voting list that reflects the final (compromise) amendments and the voting in committee or plenary. Advisors claim to negotiate over the order of the vote with the committee secretariat (1.3, 7, 10,11, 15, 20), which is considered 'a very political and influential role' of the group advisor (I.3). These negotiations relate to what amendments are most important, and 
should thus take priority in the voting order (I.3, 7, 11, 15, 20). "We discuss what is most important, or changes the most. This is rather subjective and a political thing. It means a lot of power for the advisor who double-checks the list" (I.20). Subsequently, the voting list is approved by the committee chair (I.10).

As part of the intra-group coordination process, advisors set out to identify sensitive or potentially dividing issues, in fact fulfilling a signalling role. In this role, advisors shape the agenda of group debates by pre-selecting issues that require deliberation at MEP level. Concrete instructions in this regard are hard to conceive as the sensitivities remain to be discovered. Whether the issue is actually put on the agenda, however, depends on the MEP in charge. Another signalling function is encountered in relation to the group voting lists. It is found that advisors, before sending their voting advice to all the members of the group, discuss a draft with the (shadow) rapporteur (see 4.2.1). Nonetheless, should the advisor disagree with the voting indications as decided by the (shadow) rapporteur, he or she can intervene. "If I think the group has a completely different line, the shadow rapporteur would still put his or her voting indications in there, but I would always inform the coordinator and perhaps even other members, saying (s)he has put a plus there, but I don't think it's right because our group has decided differently in the past. You need to raise that issue. If the group then decides differently that's fine, but it's our role to point it out and alert everyone. The same goes for the plenary voting list" (I.18).

Advisors provide voting indications to the group. They are responsible for ensuring that the recommendations reflect the group's position. Based on the information they acquired through the Information Manager role (see chapter 5), advisors assess the various views, stakes, and sensitivities present in the group in order to 'sense' what is acceptable to the majority of the group (I.2). Voting advice thus not only requires that the advisor 
interprets the legislative texts in relation to the group's position, it also involves their evaluation as to what is acceptable to the members of the group.

To conclude, the analysis shows that in addition to practical procedural assistance and information advisors assume a guiding and signalling function in their Process Manager role. For these functions the desired outcome is unknown or uncertain. Advisors' improvisation is a strategy to deal with situations in which they are not explicitly told what to do and have to rely on what they feel is necessary or appropriate in light of the group's ideological views. The next sub-section concludes what this means for the political scope of the various activities that were discussed in 4.1.1 and 4.1.2.

\subsubsection{Process Management as a category of political advice}

The empirical analysis disclosed that process management entails technical and political tasks. The framework defines political advice as a mixed sphere where technical and political activities meet. The findings presented in this chapter corroborate process management as a category of political advice. Although advisors are found to provide a form of organisational support and procedural advice, the data expose that the conceptualised technical and political dimensions do not fully capture what empirically appear to be the core activities. Figure 4.2.3 illustrates the dimensions as revealed from the collected data.

To assess the political scope of the role, the framework conceptualised three incremental modes of political advice tied to the discretion of the advisor: routine, reactive, and pro-active behaviour (see 2.1.3). Discretion is exercised where hierarchical measures or political authority are not directly applied. The role thus becomes more pro-active as the advisor's room for 
improvisation increases. Figure 4.2.3 sums up the key features of the Process Manager role as found from the empirical research:

$\checkmark$ In the context of process management, routine job performance is encountered in the practical procedural assistance and information that advisors provide. Organisational support is for instance provided through arranging deputies in the absence of members, forwarding information received from the committee secretariat, or distributing speaking time. In addition, information regarding procedures and deadlines is provided. These activities are either based on the EP Rules of Procedures, working practices of the group, or on the explicit instructions of the MEP in charge. Consequently, neither the ends nor the means appear to be open to interpretation and the room for improvisation is marginal to non-existent.

$\checkmark$ Reactive process management was observed in relation to activities where the outcome is implied through or derived from group debates. Advisors rely on the various views expressed in the group in their attempts to coordinate amendments. They furthermore use this indirect input to propose voting indications that are likely to count on the support of the majority of the group. Both activities require considerable interpretation by the advisor. Nonetheless, the MEPs or national delegations submit amendments and the (shadow) rapporteur decides on the final voting indications. Advice will thus only be accepted when it reflects a position that is supported by the majority of the group.

Pro-active process management was encountered in the guiding function advisors fulfil. Advisors manage the intra-group preparations for the legislative process. At this stage of the deliberations no explicit instructions from the MEP in charge have been provided, nor can input be derived from political debates. Rather, the advisor bases the support 
offered on his or her understanding of the priorities or position of the group. As this group position is composed of various, potentially conflicting, elements advisors rely on their judgement and experience to determine what is acceptable to the (majority of) members of the group. Examples of the pro-active guiding function were encountered in advisors' input for the acquisition strategy for rapporteurships, the (selective) involvement of MEPs, and in checking the voting list drawn up by the committee secretariat.

\section{The signalling function of group advisors by definition is pro-} active. A first signalling function is found in the preparation of group meetings. Advisors signal (potentially divisive) issues to be tabled for discussion at MEP level. A second function is related to the voting list. Advisors identify potential incoherence or conflicts in the position of the group, and inconsistency with previously adopted positions. A third activity in this regard is the advisor's role to ensure that the voting indications as approved by the (shadow) rapporteur are in line with the overall group position and priorities. 


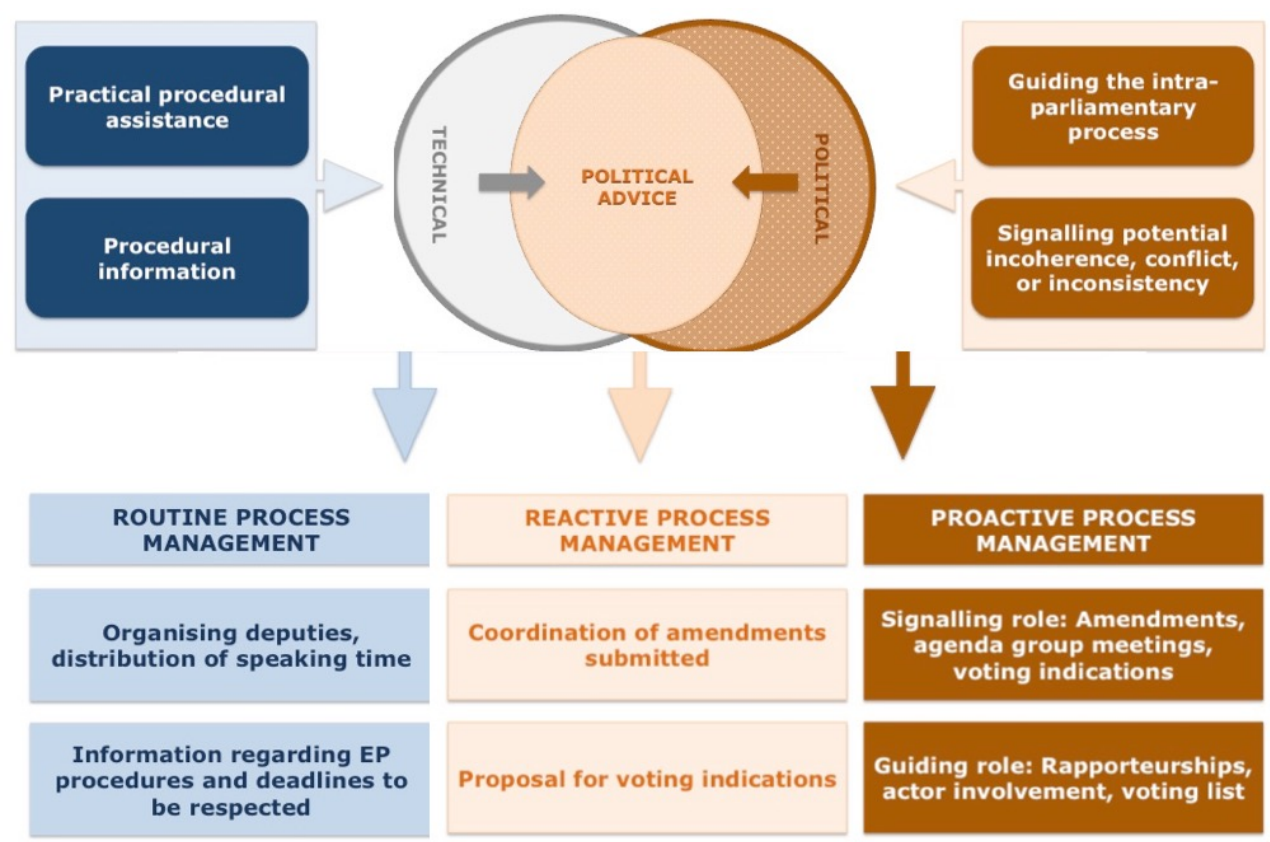

Figure 4.2.3 Empirical findings: process management as a category of political advice

\subsection{Impact of the factors on process management}

The objective of the thesis is to explore and explain the circumstances that stimulate or restrict advisors assuming a political role. From the literature a set of factors has been identified that are expected to affect the adoption of the Process Manager role (see 2.3). As a third and final step of the analysis, this section consecutively evaluates each of the personal (4.3.1) and contextual factors (4.3.2) by presenting evidence from the survey and interviews. It is found that trust and political sensitivity are indispensable for a pro-active Process Manager role, whereas complexity and politicisation may have a restricting impact. 


\subsubsection{Personal factors}

The analytical framework conceptualises four personal attributes of advisors that are theorised to facilitate political behaviour. Each is considered below in relation to process management, concluding that trust and political sensitivity are indispensable for a pro-active Process Management role. The findings are illustrated in figure 4.3.1.

\section{Trust}

In the analytical framework trust is linked to knowledge of and affinity with party ideology and priorities (see 2.3.1). A more substantial role is construed for advisors who the delegating politician trusts to have a shared ideology. It can be inferred from the survey and the interviews that trust between the advisor and the MEP is key in determining the working relationship. 25 advisors stress that their discretion depends on trust granted by the group coordinator or (shadow) rapporteur. ${ }^{48}$ In case of a high-trust relationship advisors will have 'a lot of room for manoeuvre' (I.22). These statements lead us to believe that the contrary holds true as well. Should trust be betrayed, the working relationship is disturbed.

The qualitative data highlight that collaboration at staff level also depends on trust. ${ }^{49}$ Group advisors have an interest in maintaining a good working relationship with EP officials in order to acquire procedural information at an early stage. ${ }^{50}$ Trust thus facilitates the 'liaison function' that advisors fulfil between the group and the committee secretariat.

\footnotetext{
${ }^{48}$ I. 0.2, 0.4, 4, 7-9, 11, 13, 15-18, 22; SR6, 17, 25, 31, 38-40, 52, 60, 61, 84, 99.

49 I.0.1-0.5, 1-5, 9-11, 15-19, 21; SR17, 25, 31, 38, 39, 54, 59.

${ }^{50}$ I. $3,6,8,9,10,13,17,19$.
} 
In addition, advisors rely on the trust of MEP Assistants to share their insights of the MEP's views or priorities with regard to certain files. ${ }^{51}$ The informal interviews put forward that some group advisors are reputed to provide 'biased advice' or 'try to get certain points in' that were not discussed with the MEP. MEPs and their assistants would subsequently avoid working with them. In their guiding and signalling role, advisors determine what is acceptable to the (majority of) members of the group based on their judgement and experience. Trusted advisors are more likely to fulfil these functions of the Process Manager role as they will have the ear of the MEP in charge and his or her personal assistant. More importantly, the reliability of the advisor is crucial for the input or provided voting recommendations to be followed or 'accepted'. In the end, the MEP decides who provides his or her assistance. If the trustworthiness of an advisor is questioned, the MEP will look to the committee secretariat officials for procedural guidance and to his or her personal assistant for checking the voting lists and texts as well as for advice on how to vote.

\section{Informal network}

An informal network is conceptualised as access to and exchange of private information through informal connections within and outside the institution (see 2.3.1). For process management activities, the intra-parliamentary network of the advisor is most important. Findings show that advisors' most frequent contact is with MEP assistants, generally estimated as daily (see table 5.1a). The qualitative data reveal that informal contact and personal relationships affect the collaboration and exchange at staff level. ${ }^{52}$ Contact with MEP assistants allows the advisor to assess what is acceptable to the (majority of) members of the group, which is instrumental for their guiding

\footnotetext{
${ }^{51}$ I. 2, 3, 9-11, 13, 15-17, 22.

52 See analysis SQ5, Appendix III. Responses SQ6: SR3, 5, 10, 11, 13, 14, 27, 37, 42, $43,47,51,53,55,59,60,74,79,84,88,89,92,97,98$. I.0.4, 2-4, 6-10, 13, 15-17, $19,22$.
} 
and signalling functions. In addition, advisors' relationship with EP committee officials (generally estimated as weekly) determines whether they are able to gather the relevant procedural information in an informal and timely manner. In order to guide members through the EP coordination process, advisors are the liaison between the EP administration and the MEP. They keep MEPs informed prior to the official lines of communication that run through the EP secretariat.

Advisors also work closely with their counterparts from the other party groups. In terms of process management this will allow them insight into other groups' wishes and priorities with regard to rapporteurships and their opinions on amendments. "Sometimes I call colleagues to check what they are advising their MEPs on certain amendments. When I worked for the EMPL committee I even exchanged voting lists with counterparts. For IMCO I never do that," one interviewee commented.

In sum, the informal network of advisors facilitates their various process management activities. In particular, their intra-EP network allows them to gather information that they use to organise the legislative process and appreciate the various interests at stake, both within their group and within the other groups.

\section{Institutional memory}

Institutional memory is conceptualised as the insight into - and access to the institutional track record (see 2.3.1). In the EP context the factor is interpreted as knowledge of the functioning of the institution (formal and informal rules) and an appreciation of the political group's (previous) positions. For process management institutional memory facilitates both organisational support and procedural advice. 
Overall, advisors seem to be experienced allowing them to develop a level of institutional memory, conceptualised as insight in and access to the institutional track record. Survey findings show that advisors on average have held their position for 6 years, varying between seven months and 23 years (see 3.2.1). Moreover, the survey accounts show that a background of working in the EP is common: 42 per cent of advisors have prior experience in the EP. The qualitative data support that 'knowing your way around' is an asset (I.3). Advisors recognise the significance of understanding EP procedures (see 4.2.1). In order to guide the MEP in charge through the formal coordination process, advisors should naturally possess a sound knowledge of the functioning of the EU institutions and its policies. The document analysis showed that this is one of the requirements stipulated in the vacancy notices (see Appendix I). For these reasons it is concluded that institutional memory is considered more or less a given, and not as a decisive factor in the provision of political advice.

The contribution of advisors in the informal, preparatory coordination process is found to be most significant (see 4.1.2). As part of their guiding and signalling role, advisors must understand and be able to forecast the group's objectives and priorities. This appreciation of the group line is highlighted in the quantitative and qualitative data. ${ }^{53}$ In the recruitment of advisors, familiarity with the activities and the operation of political groups are sometimes explicit requirements, notably for the GUE-NGL and EFD groups (see 3.1.5). Interviewees' accounts show that in practice political affinity and political experience are taken into account in the selection of group advisors. Advisors will benefit from a thorough understanding of the group's position when they check amendments and other parliamentary texts for 'political logic' and coherence with previous group positions. Moreover, in issuing voting recommendations their advice is most likely to

53 See Appendix III, responses to SQ5 and 6. I.0.2, 1-3, 7-9, 13, 15-17, 22. 
be followed when they remain close to the group's ideology. In the EP this only applies to the more homogeneous groups like the Greens/EFA or GUE/NGL. For the other groups - either large or heterogeneous - advisors should appreciate the different views of the national delegations within the group and take these into account when drawing up the group's voting list.

It is important to note that the previously defined factors trust and informal network may produce a similar appreciation and anticipation of the group's position. In sum, there appears to be a positive relation between advisors' institutional memory and the execution of the political process management functions but the factor is not indispensable for the adoption of the role.

\section{Political sensitivity}

The analytical framework conceptualises political sensitivity as the understanding of the institution's informal code of conduct and the ability to recognise political and administrative cues, allowing for the anticipation of (negotiation) strategies (see 2.3.1). Inquiring after the qualities advisors should possess to effectively fulfil their responsibilities, advisors conclusively cite political sensitivity as the most decisive. ${ }^{54}$

As part of their responsibility to organise the coordination process advisors identify and propose issues that require discussion at MEP level (see 4.1.2). The interviews and survey findings show that this task requires advisors to understand and predict the sensitivities within the group. 55 "One needs to be sensitive to differences existing within a political group, i.e. what divides national delegations." (SR95). Advisors should have the 'ability to provide

\footnotetext{
54 See Appendix III, responses to SQ6, 9 and 11 . Out of the 28 interviews, only 5 interviewees did not flag up political sensitivity as crucial to their role.

${ }^{55}$ I.1, 2, 8, 9, 13, 22. SR9, 15, 22, 27, 29, 43, 51, 72, 77, 89, 95.
} 
unbiased political judgement' (SR34). If advisors successfully recognise and pursue such cues, problems will be addressed informally before they arise.

In order to effectively fulfil the task of checking amendments for accuracy and political coherence advisors should recognise and appreciate the internal politics. This requires them, first of all, to understand the various stakes present within the group and within the broader EP, and subsequently anticipate the negotiation strategies of the groups. In this regard, the data show that advisors are expected to 'know' several things. They should be able to distinguish what is strategically important for the group, what points can count on a majority in the group and in plenary, and be able to hierarchise political priorities. ${ }^{56}$

Political sensitivity helps advisors in producing voting recommendations. As a successful advisor 'you share the political views of the Group you work for, so that you can intuitively feel what the group line on a certain matter would be' (SR29). Advisors must be able to 'anticipate and translate what members want' (I.1), 'have a good understanding of what is acceptable' (I.2), and 'where the red lines are' (SR41). ${ }^{57}$

In sum, political sensitivity is actually a general prerequisite for the provision of acceptable advice. This conclusion closely relates to the finding that pro-active behaviour is only acceptable when the advice reflects a position that is supported by the majority of the group.

\section{Assessment of the personal factors}

In the analytical framework it was proposed that the personal factors affect the advisor's discretion and their ability to adopt a political role. The factors

\footnotetext{
${ }^{56}$ I.1, 4, 9, 15, 17, 19. SR9, 15, 22, 24, 29, 36, 39, 41, 48, 97.

57 Similar examples were provided by SR9, 13, 15, 22, 27, 39, 41, 97.
} 
are used to assess the (optimal) circumstances in which political advice may be provided. The following values are used to qualitatively evaluate the impact of the factors on the adoption of the Process Manager role: indispensable $(++)$, positive impact $(+)$, no impact/ not relevant $(0)$, or a negative impact $(-)$. From the empirical research it is concluded that trust and political sensitivity are indispensable for political process management. The findings are illustrated in figure 4.3.1.

Table 4.3.1 Personal factor assessment for the Process Manager role

\begin{tabular}{|c|c|c|c|c|}
\hline & Trust & $\begin{array}{l}\text { Informal } \\
\text { network }\end{array}$ & $\begin{array}{c}\text { Institutional } \\
\text { memory }\end{array}$ & $\begin{array}{c}\text { Political } \\
\text { sensitivity }\end{array}$ \\
\hline \multicolumn{5}{|c|}{ ROUTINE PROCESS MANAGER } \\
\hline $\begin{array}{l}\text { Practical procedural } \\
\text { assistance }\end{array}$ & + & + & + & 0 \\
\hline Procedural information & + & + & + & 0 \\
\hline \multicolumn{5}{|c|}{ REACTIVE PROCESS MANAGER } \\
\hline $\begin{array}{l}\text { Coordination of } \\
\text { amendments }\end{array}$ & ++ & + & + & ++ \\
\hline $\begin{array}{l}\text { Proposal for voting } \\
\text { indications }\end{array}$ & ++ & + & + & ++ \\
\hline \multicolumn{5}{|c|}{ PRO-ACTIVE PROCESS MANAGER } \\
\hline Guiding function & ++ & + & + & ++ \\
\hline Signalling function & ++ & + & + & ++ \\
\hline
\end{tabular}

\subsubsection{Contextual factors}

Three contextual factors are expected to affect delegation and trigger potential differences across the groups, committees, policy domains, or specific files: political direction, complexity, and politicisation. This subsection presents the assessment of these factors. The findings are 
illustrated in table 4.3.2, concluding that political direction facilitates the Process Manager role whereas complexity and politicisation may restrict pro-active process management.

\section{Political direction}

The analytical framework defines political direction in relation to the position of the MEP or group: advisors' ability to identify political cues to guide their behaviour depends on the extent to which the MEP in charge or the group they represent is outspoken and reputed (see 2.3.2). The idea is that the clearer advisors' political direction is, the more likely they are to assume a political role.

No evidence was found that political direction affects routine job performance. In their guiding and signalling functions, however, advisors rely on their understanding of the political priorities and positions (see 4.2). Political direction facilitates the pro-active behaviour of advisors. The interviewees underline that implicit political direction is derived from the ideological principles of the group (I.11, 13, 19, 20). GUE/NGL and EFD advisors derive this mandate from their contact with the MEP in charge as no formal group discipline applies. Several interviewees claim that advisors working for a more homogeneous group, or for one MEP, enjoy more room for manoeuvre $(I .12,14)$. The idea is that for example Greens/EFA advisors can more easily assess the desired outcome for the group, which allows them to improvise in order to realise outcomes that are accepted by the (majority of the) group.

The data furthermore suggest that when the MEP in charge is actively involved on a given file advisors are more likely to manifest pro-active behaviour $(1.12,17,22)$. Furthermore, five interviewees discuss that as the experience of the MEP increases, the support they need changes (I.3, 4, 5, $13,15)$. Newcomers tend to require more guidance and information than 
experienced MEPs (I.5). In sum, a clear group line (group cohesion) appears to facilitate the guiding and signalling functions of the Process Manager role. The findings in relation to political direction derived from the position of the MEP are less clear-cut. The level of involvement of MEPs aids the advisor in process management activities. For example, for issues to be tabled (and defended) during group meetings the advisor normally relies on the MEP in charge. The level of experience of the MEP, on the other hand, may restrict the contribution of the advisor as the need for guidance and advice decreases.

\section{Complexity}

In the framework complexity is defined in relation to the subject matter and thus expected to vary across parliamentary committees or specific policy or legislative proposals (see 2.3.2). From the literature the assumption is drawn that as 'complexity' increases MEPs are more likely to seek assistance and grant advisors a political role.

The document analysis and the qualitative data reveal that advisors should have the capacity to analyse technical and complicated files. Advisors contend to have more discretion as the issue under consideration becomes more complex. Several advisors explained how the discretion of group advisors increases in 'highly technical dossiers': the more technical a file, the more room for 'influence' advisors have (I.4); or the less attention is paid by MEPs (I.15). Although those surveyed and interviewed do not discuss the matter extensively, the data suggest that complexity facilitates the role. Nonetheless, the level of complexity may negatively affect MEPs' (active) involvement $(1.15,16,17)$. This would imply that actor involvement becomes more difficult and MEPs are less inclined to bring issues up for discussion in group meetings. Thus, although the overall need for guidance throughout the intra-parliamentary process increases in complex files, 
MEPs' involvement is likely to decrease. In that case, the pro-active Process Manager role is restricted.

\section{Politicisation}

The framework conceptualises politicisation in relation to division in the EP, in general or with regard to a specific dossier (see 2.3.2). It is therefore defined as something that may change over time and vary across policy areas. Based on the theory, politicisation is expected to restrict the advisor's role.

The qualitative data show that MEPs are less likely to delegate tasks related to controversial or salient files, thus restricting the role of the group advisor. From the interviews it is found that in the preparations of amendments and voting indications, the controversial issues are dealt with at MEP level (I.11, 18). It is the advisor's responsibility to signal these controversies and make sure that a group debate takes place (see 4.1.2). Whereas politicisation thus facilitates advisors' signalling function, their ability to organise the legislative process is deemed to be restricted. Issues that divide the House are likely to be controversial in the group as well, particularly in the larger political families such as ALDE, EPP, and S\&D (I.18). Checking the voting list and providing voting recommendations will be more cumbersome and sensitive in such politicised files. In sum, politicisation facilitates advisors' signalling function but restricts the advisor's discretion to organise the legislative process.

\section{Assessment of the contextual factors}

As proposed in the framework, the context affects delegation. The factors are used to assess the (optimal) circumstances in which political advice may be acceptable to MEPs. The following values are used to qualitatively evaluate the impact of the factors on the adoption of the Process Manager 
role: indispensable $(++)$, positive impact $(+)$, no impact/ not relevant $(0)$, or a negative impact (-).

The empirical research concludes that a clear group line (group cohesion) appears to facilitate the guiding and signalling functions of the Process Manager role. Although the overall need for guidance throughout the intraparliamentary process increases in complex files, MEPs' involvement is likely to decrease. This hampers political direction and therefore restricts pro-active process management. Politicisation facilitates advisors' signalling function, yet decreases the likelihood that MEPs delegate other process management tasks. The findings are illustrated in table 4.3.2.

Table 4.3.2 Contextual factor assessment for the Process Manager role

\begin{tabular}{|c|c|c|c|}
\hline & $\begin{array}{l}\text { Political } \\
\text { direction }\end{array}$ & Complexity & Politicisation \\
\hline \multicolumn{4}{|c|}{ ROUTINE PROCESS MANAGER } \\
\hline $\begin{array}{l}\text { Practical procedural } \\
\text { assistance }\end{array}$ & 0 & + & 0 \\
\hline Procedural information & 0 & + & 0 \\
\hline \multicolumn{4}{|c|}{ REACTIVE PROCESS MANAGER } \\
\hline $\begin{array}{l}\text { Coordination of } \\
\text { amendments }\end{array}$ & + & + & - \\
\hline $\begin{array}{l}\text { Proposal for voting } \\
\text { indications }\end{array}$ & + & + & - \\
\hline \multicolumn{4}{|c|}{ PRO-ACTIVE PROCESS MANAGER } \\
\hline Guiding function & + & - & - \\
\hline Signalling function & + & - & + \\
\hline
\end{tabular}




\subsection{Concluding remarks}

The findings presented in this chapter corroborate process management as a category of political advice that combines technical and political tasks. Although advisors are found to provide a form of organisational support and procedural advice, the data expose that the former goes beyond the conceptualised scope of organising and following up on meetings. Process management is most prominently tied to the overall coordination of the intra-parliamentary legislative process: advisors fulfil a guiding function (organisational tasks) and signal issues that may cause incoherence, conflict or inconsistency in the group position (advisory tasks).

Compared to the other groups, ECR and EFD appear to attach greater value to process management. This procedure-oriented approach is interpreted in light of the nature of these groups. Internal ideological differences are small in the ECR and national delegations have a large degree of autonomy. This reduces the need for intra-group coordination. The EFD group does not formally coordinate its positions and its Eurosceptic stance generally makes it less inclined to contribute to legislation. The Greens/EFA group fulfils a relatively stronger (more pro-active) guiding role, as the indicated coordination of amendment submission reveals.

Findings have revealed that advisors perform several practical activities such as managing deadlines, organising deputies and taking care of the distribution of speaking time. These tasks are guided by - and bound to the EP RoP and working practices of the group and are therefore categorised as the routine job performance of advisors. In contrast, all other process management activities require some form of improvisation by the advisor because they are not guided by rules or instructions. It is therefore concluded that advisors manifest political behaviour for the majority of activities. Although several tasks require the explicit approval of the MEP in 
charge, the advice or support offered is generally guided by what advisors deem to be in line with the priorities or position of the group. The data suggest that advisors' improvisation is closely related to the informal nature of the intra-parliamentary decision-making process. Pro-active behaviour seems unavoidable in situations in which they are not explicitly told what to do. Advisors manage the intra-group preparations for the legislative process. At this stage of the deliberations no explicit instructions from the MEP in charge have been provided, nor can input be derived from political debates. Throughout the decision-making process advisors are furthermore expected to identify issues that potentially divide the group and are unknown to the MEP in charge. Both the guiding and signalling functions of process management thus require the advisor to operate without an explicit mandate. Advisors carry out these activities by relying on what they feel is necessary or appropriate in light of the group's ideological views. The qualitative data underline that it is only due to the derivative nature of their mandate that pro-active behaviour is accepted. Reactive behaviour is encountered in the activities of advisors that take place after group or committee deliberations, from which they can derive their mandate. For example in their efforts to coordinate amendments or propose voting indications advisors are found to enjoy considerable discretion, yet their input is based on the political views expressed.

As mentioned at the outset, the objective of the thesis is to explore and explain the circumstances that stimulate or restrict a political role by group advisors. The analysis reveals that political sensitivity is a general prerequisite for effective process management. This conclusion closely relates to the finding that pro-active behaviour is only acceptable to MEPs when the advice reflects a position that is supported by the majority of the group. A trusted working relationship with the MEP and his or her staff further adds to this by allowing the advisor to understand the MEP's views and priorities. Both personal factors are found to have a decisive impact on 
the discretion of the advisor. Politicisation facilitates advisors' signalling function because the ideological lines are then highlighted. However, MEPs tend to take care of any sensitive issues themselves, which decreases the likelihood that they delegate other process management tasks to group advisors. Although the overall need for guidance throughout the intraparliamentary process increases in complex files, MEPs' involvement is likely to decrease, which restricts pro-active process management. Finally, the guiding and signalling functions of the role are reinforced by group cohesion, as a clear group line allows the advisor to construct a clear mandate (political direction). 



\section{CHAPTER 5. INFORMATION MANAGER}

The analytical framework comprises four roles that advisors may adopt, each potentially containing a political dimension. The dissertation applies the theoretical concepts to the specific case of European Parliament (EP) group advisors ${ }^{58}$ and this chapter presents the analysis of the Information Manager role. The ideal-type role comprises three central elements: (1) gathering information, (2) processing information, and (3) distributing information. To address the research question 'under which conditions can advisors adopt a political role' three analytical steps are carried out.

The first step is to assess whether the role is adopted and what it entails in practice. To that end, 5.1.1 examines the theoretical dimensions of information management. Expectations regarding the technical and political dimensions of information management are inferred from the literature review (see introduction) and the conducted document analysis (see Appendix I). Subsequently, these expectations are considered in light of the empirical research. The discussion in 5.1.2 shows that EP group advisors assume the Information Manager role, and that their activities contain technical and political elements. In this respect, they pre-select, interpret, and present information. It is furthermore found that information serves an auxiliary function and forms the basis for the adoption of the Policy Expert and Broker roles.

The second step is to assess the extent to which the role is political, based on the three modes of discretion that have been developed as part of the analytical framework. Section 5.2 considers advisors' room for manoeuvre

\footnotetext{
${ }^{58}$ Advisors employed by one of the EP party groups and assigned to follow the work of one or several of the parliamentary committees are the focus of this study. Throughout the analysis 'advisors' or 'group advisors' refers to this type of advisor.
} 
when fulfilling the political dimensions of information management. This is approached by, on the one hand (5.2.1), examining the extent to which advisors receive instructions or input from the Members of the EP (MEPs), and on the other hand (5.2.2), the need and their capacity to improvise. The empirical research shows that in all three aspects of information management advisors enjoy considerable leeway with very little direction from their superiors. It is therefore concluded that information management is predominantly pro-active (5.2.3).

Thirdly, the impact of the personal and contextual factors on the adoption of the role is evaluated (5.3). The analysis concludes that political sensitivity combined with a context where advisors work on a policy issue or specific file that is not highly politicised in the EP are the optimal conditions for advisors to pro-actively adopt the Information Manager role.

\subsection{The nature of information management in the EP}

This section builds on a discussion of the relevant literature on information management (5.1.1). Drawing from the theory, the technical and political dimensions of the role are explored. The three central elements of the idealtype role are considered: (1) gathering, (2) processing, and (3) distributing information. These activities are discussed and related to the document analysis on the profile and duties of EP group advisors in order to infer expectations about the adoption of the role (see 3.3.3).

Subsequently, 5.1.2 presents the empirical findings for the Information Manager role. The theoretical expectations regarding the role are examined in relation to the collected survey and interview data. The empirical analysis finds that group advisors adopt the role. Furthermore, it exposes two key functions of information in the EP: policy and political intelligence. 


\subsubsection{The theoretical dimensions of information management}

The analytical framework proposes that information management entails the gathering and processing of information in order to create overview, filter or select the most relevant (sources of) information, and to provide legislators with political intelligence through informal information exchange. ${ }^{59}$ The analysis of vacancy notices identified 'information and communication tasks' as one of the standard duties of EP political group advisors (see Appendix I). Such tasks can obviously entail a variety of things that remain unspecified in the job descriptions. Drawing on the literature that explores advisors as a source of information, these activities could be tied to the Information Manager role. Advisors can for example provide MEPs with background information on files under discussion and lay out the various interests and actors involved (cf. Neunreither, 2002; Peters, 2009). Advisors furthermore act as a gatekeeper through the pre-selection of relevant information and sources, which is vital for politicians to deal with the information overload (cf. Winzen, 2011; Busby, 2013). Information management also includes the informal exchange of information by liaising with other staff members or external stakeholders (cf. Fox and Hammond, 1977; Christiansen, 2002; Busby, 2013; Högenauer and Neuhold, 2015). The role is thus expected to involve the collection and distribution of information from various sources as well as the transformation into functional information or intelligence for the MEP.

The literature has dealt extensively with the topic of information as a resource for the politician, underlining that gathering, processing, and distributing information are the central elements of the role of officials (e.g. Patterson, 1970; Tallberg, 2004). MEPs have various sources of information

\footnotetext{
59 The definition is based on an extensive literature review (see introduction) and draws on Patterson, 1970; Fox and Hammond, 1977; Provan in: Neunreither, 2002; Christiansen, 2002; Tallberg, 2004; Peters, 2009; Winzen, 2011; Busby, 2013; Högenauer and Neuhold, 2015.
} 
at their disposal that can broadly be distinguished as in-house sources, information from other institutions, and information from third parties (Dobbels and Neuhold, 2014). The latter category usually takes centre stage in academic discussions on information channels in the EP. Yet, in their discussion of how the Parliament obtains and processes information for policy-making, Dobbels and Neuhold (2014) find that in-house sources of information are crucial for the EP to fulfil its function as co-legislator. An important explanation as to why MEPs heavily rely on internal resources lies in safeguarding independence. Information from the other institutions is 'treated with caution' because both the European Commission (EC) and the Council have a stake in the outcome of the EP decision-making process (Dobbels and Neuhold, 2014). MEPs are confronted with an 'information deficit' and therefore depend on staff resources and on their colleagues for information (Ringe, 2010).

For this reason, information management is deemed to play a particularly important role in the EP. To tackle its information needs the institution continuously attempts to improve the available resources. In 1987 the EP launched the Science and Technology Options Assessment Unit (STOA) following from the need for independent, impartial information about the opportunities and risks related to scientific and technological developments (EP website, consulted March 2018). STOA carries out projects, usually with the assistance of external contractors selected on the basis of the expertise required through public tenders. In recent years, the EP has developed several new (online) information sources to facilitate MEPs in dealing with their increased workload and to increase the overall transparency of EP decision-making (EPRS, 2017). In particular, the transformation of the former EP Library service into the European Parliamentary Research Service (EPRS) has strengthened the in-house parliamentary support (European Parliament, 2013). The service draws up policy briefings, analyses, and statistical overviews upon the request of individual members or in support 
of the parliamentary committees (EP website, consulted March 2018). It furthermore publishes notes for external purposes and aims to provide 'think tank capacity' (EPRS, 2017). Publications comprise briefings, in-depth analyses, studies, and EU Fact Sheets (EP website, consulted March 2018). The EPRS also examines the EC's impact assessments and provides the parliamentary committees with complementary ex-ante and ex-post impact assessments, and impact assessments of 'substantive EP amendments' (EPRS, 2017). 60

The framework's mixed sphere of activity postulates that information management comprises both a technical and a political dimension. Following from the theory, political tasks are conceived to contain value or ideological appraisals, the anticipation of priorities or objectives, and the use of implicit knowledge or tactics (see 2.1.2). Technical tasks are void of such judgement by the advisor. The gathering of information via in-house and third-party sources for example involves political choices about which sources are consulted or are asked to provide input. The same applies to the subsequent use of the information. The Information Manager role is thus expected to comprise a technical, inventory aspect as well as a political dimension that entails the selection of the (most relevant) sources or specific elements of information.

The task of processing information is delegated to EP staff (Brandsma, 2012; Dobbels and Neuhold, 2014). Yet, only little is known about this process. Brandsma (2012) discusses information processing in the context of the EP's role to control the EC. He finds that the need to organise information only arises when there is a functional link to political action related to specific parliamentary powers. Building on these findings, it is inferred that the transformation of information by advisors into specific and

\footnotetext{
${ }^{60}$ See 3.1.1 for a more elaborate discussion of the EPRS.
} 
action-oriented intelligence is a crucial determinant for the uptake of that information by MEPs. The political dimension of information processing lies in the 'selective bias' requiring political choices (Blom and Vanhoonacker, 2014). In their Information Manager role advisors are expected to either anticipate or interpret the desired political choices.

Advisors informally exchange information with actors inside and outside the EP (Patterson, 1970; Christiansen, 2002). This activity facilitates both the collection and the distribution of information. Internally, it involves the 'free-floating information' within the Parliament mostly passed on in social encounters (cf. Kingdon in: Blom and Vanhoonacker, 2014). Externally, industry, trade associations, trade unions, employer federations, chambers of commerce, interest groups, NGOs, think tanks, consultancies, regional authorities, and third countries are the main third parties that get in touch with EP actors (cf. Greenwood, 2011). Finally, the distribution of information naturally also involves the way in which it is presented or 'framed' to MEPs. The concept of framing suggests 'purposive manipulation' and strategic attempts to influence (decision) behaviour (Blom, 2014).

Figure 5.1.1 illustrates the anticipated dimensions of information management based on the theory. Technical aspects of information management are the (i) inventory, (ii) summary, and (iii) distribution of information to MEPs. The political functions of information management in the context of the EP are expected to lie in (i) the pre-selection of issues and internal and external sources of information, (ii) the transformation of this selected information by the interpretation of political choices or preferences, and (iii) the way in which the information is finally presented to the MEP. 


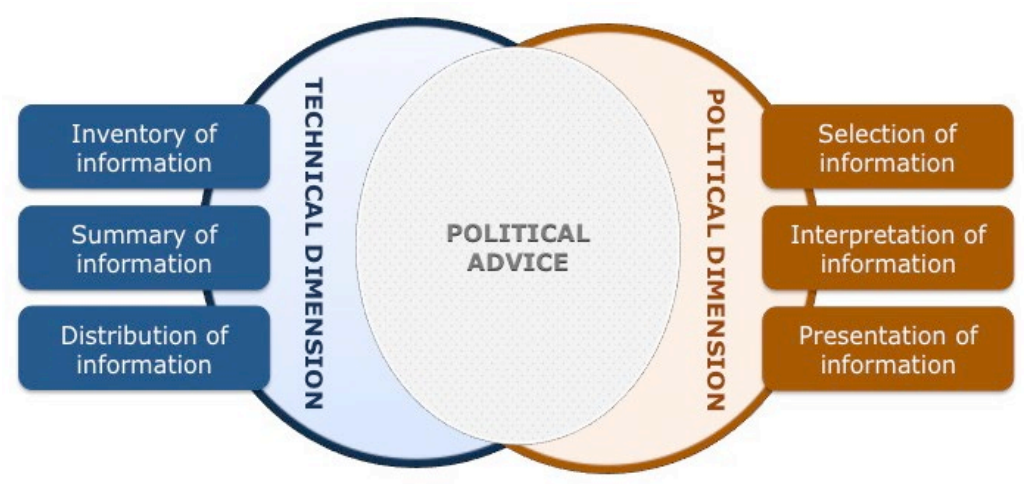

\subsubsection{Theoretical dimensions of information management}

\subsubsection{The adoption of the Information Manager role in practice}

The conducted empirical research demonstrates that EP group advisors adopt the Information Manager role, and that the role indeed involves both technical and political tasks. 70 per cent of survey respondents agreed that they manage the flow of information. The qualitative data reveal that this involves gathering, processing, and distributing information: effective advisors should have the 'ability to collect a lot of information from different sources, to process it in a short period of time, and to issue recommendations in a clear and precise language' (SR44). ${ }^{61}$

This sub-section first discusses that information serves an auxiliary function in the EP and forms the basis for the adoption of the Policy Expert and Broker roles. Subsequently, the findings related to the gathering, processing, and distribution of information are presented.

${ }^{61}$ Survey respondents (SR) and interviewees (I) are coded according to the order in which the responses were received and the interviews conducted. See Appendices III and $\checkmark$ for an overview. 


\section{Advisors' perception of information management}

The survey and interview findings reveal two key functions of information provided by group advisors. First, advisors set out to obtain knowledge about the content or implications of a given file, which can be used to provide policy-related advice or define a (group's) position (i.e. required to fulfil the Policy Expert role). A second purpose is to acquire intelligence about the overall political landscape on a given file aimed at facilitating the coordination process (i.e. required to fulfil the Broker role). In addition, advisors gather information from EP officials in the committee secretariats related to procedures (i.e. required to fulfil the Process Manager role). Accordingly, information management is found to serve an auxiliary function. This finding is further supported through the data presented below regarding the gathering, processing, and distribution of information by advisors in the EP.

Figure 5.1.2 illustrates the survey findings with respect to the relative importance attached to the four roles. 62 Only 13 respondents identified information management as their core responsibility. Nonetheless, the qualitative data show that they use and rely on information for most of their tasks. Findings show that notably Greens/EFA and GUE/NGL advisors attach value to information for the purpose of providing MEPs with policy and political intelligence. ${ }^{63}$ Of those who label information as the most important task of group advisors, seven relate this task to fulfilling MEPs' needs for substance-related information and political intelligence. For example, respondents say that it is their role to 'ensure a well-informed group position' that can count on the support of the 'EP as a whole' (SR60); and to provide the group with 'accurate' and 'politically relevant' information on

\footnotetext{
${ }^{62}$ Analysis open-ended SQ9: What is the most important task of a group advisor? See Appendix III.

63 Five Greens/EFA, three GUE/NGL, two S\&D, and one ALDE, ECR, and EFD advisor labelled information management activities as their most important tasks.
} 
a dossier (SR22, 95), while anticipating 'possible political problems' (SR95). The data thus reflect that information is deemed instrumental in the provision of policy expertise and brokering. These activities are further addressed in chapters 6 and 7 respectively.

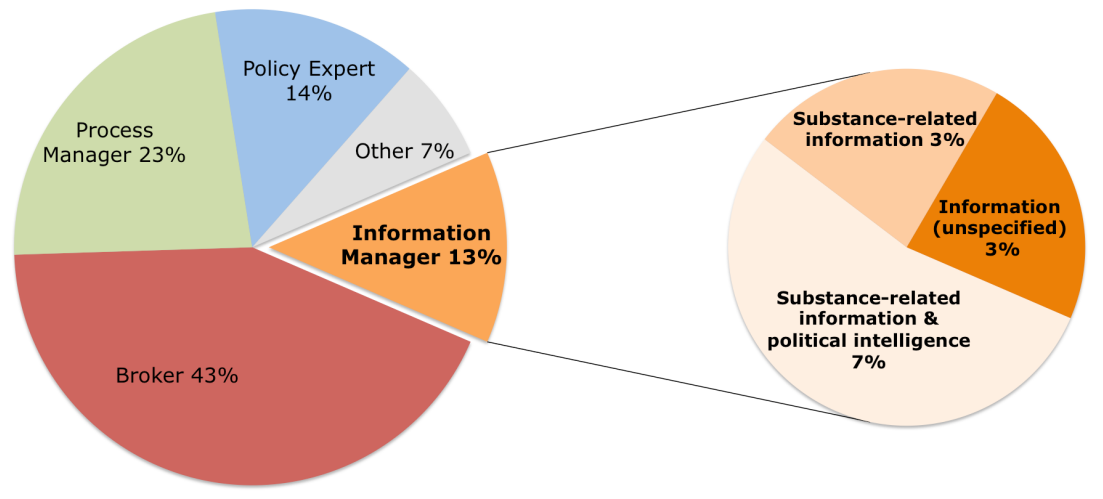

Figure 5.1.2 Relative importance attached to information management

\section{Gathering information}

20 interviewees and 31 survey respondents stated that they collect information regarding the policy content and background of a file. ${ }^{64}$ Effective advisors have a 'thorough knowledge of the topic' (SR30) by monitoring policy developments (I.7, 8, 9; SR55, 90), 'reading up on the topic' (I.0.4; SR43), and staying 'up to date' (SR8, 10, 36, 43, 50, 55, 58, $60,97)$. Several interviewees and survey respondents explain how they actively go in search of information via various internal and external sources. ${ }^{65}$ To this end, they may attend events inside and outside the Parliament (I.0.4, 3, 7, 15). In order to acquire specialist or expert information advisors can also organise events themselves (I.7, 15). In addition to substance-related information, advisors set out to gain insight into the various perspectives and stakes that are in play. This activity is

${ }^{64}$ I.0.4, 3, 4, 6-22; Open-ended responses of SR7, 8, 15, 18, 27, 30, 32, 34, 36, 39, 40, $42,43,48,51,52,55,59,60,66,67,74,77,79,86,90,91,92,95,97,99$.

${ }^{65}$ I. 3, 4, 6, 7, 13-15, 17; SR8, 10, 36, 59, 60, 74. 
interpreted as the political intelligence function of information and was put forward by 20 interviewees and 32 survey respondents. ${ }^{66}$ Some report use of collected arguments as input for the formulation of (legislative) texts, or to advise MEPs on the acceptability of certain positions or amendments (see 6.1.2 and 7.1.2 respectively).

To appreciate the various views and interests of the field, advisors liaise with external stakeholders (see figure 5.1.2a). ${ }^{67}$ The majority of respondents $(46 \%)$ say they interact on a weekly basis. Only four per cent of respondents stated that they never gather information in this way. These advisors work for different groups: EPP, S\&D, and EFD. Table 5.1 provides a specification of advisors' external contacts and the indicated frequency of their interaction. From the aggregated survey data it is deducted that

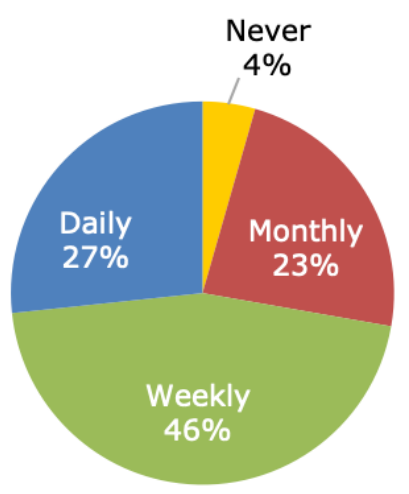

Figure 5.1.2a Gathering information from external stakeholders advisors are in touch with external stakeholders on a regular basis and that the scope of their external networks varies, most likely according to the policy area they work on. Yet, different group cultures may also affect this type of interaction with the outside world. The findings show that S\&D advisors are the least inclined to meet with industry representatives: 58 per cent report that they never interact with such stakeholders. ${ }^{68}$ Similarly, GUE/NGL advisors (50\%) also appear hesitant to take the input from industry into account. In comparison, the non-interaction of advisors of the $\operatorname{ALDE}(6 \%), \operatorname{ECR}(18 \%)$, and $\operatorname{EFD}(17 \%)$ groups is much smaller.

\footnotetext{
66 I.0.1, 0.4, 1-4, 6-8, 10-14, 16-21; Open-ended responses of SR8, 9, 15, 22, 27, 29, 34, 36, 39, 41-43, 47, 48, 51, 55, 57, 59, 60, 64-67, 72, 77, 82, 90-92, 95-97, 99. ${ }^{67}$ Analysis SQ7: Can you please estimate how much time you devote to gathering information from external stakeholders? See Appendix III Survey Response. 68 Analysis of multiple-choice SQ12 regarding the frequency of contact with various actors. See Appendix III Survey Response.
} 
Greens/EFA (38\%) and EPP (33\%) appear to be ambivalent but significantly less so than their counterparts in the groups on the left of the political spectrum. Differences between the groups are less striking for the frequency of contact with other types of external stakeholders.

Table 5.1 Contact frequency external stakeholders

\begin{tabular}{l|l|l|l|l}
\hline & Daily & Weekly & Monthly & Never \\
\hline Interest groups or NGOs & $12 \%$ & $34 \%$ & $48 \%$ & $6 \%$ \\
\hline EC staff & $8 \%$ & $35 \%$ & $46 \%$ & $11 \%$ \\
\hline Industry representatives & $4 \%$ & $22 \%$ & $46 \%$ & $28 \%$ \\
\hline Council staff & & $15 \%$ & $56 \%$ & $29 \%$ \\
\hline
\end{tabular}

Contact with staff from the other EU institutions appears to be tied to the Broker role rather than serving as a resource for the accumulation or distribution of information. ${ }^{69}$ Moreover, the findings suggest that the interaction with EC and Council officials is predominantly the domain of the committee secretariats. Only four interviewees state that they liaise with EC and Council officials to provide MEPs with information. 70 The EFD advisors interact the least with Council officials. This may be interpreted in light of the group's relatively lower involvement in the construction of compromises, and in policy-making in general. The EFD do not formulate joint group positions, which combined with their overall EU-sceptical stance does not make them likely allies. Consequently MEPs, and thus their advisors, appear to be more interested in political profiling than in contributing to legislation (I.23).

6992 per cent of survey respondents say to be involved in the technical trilogues where officials of the European Commission, Council, and European Parliament meet. Only seven respondents say that they are never involved.

${ }^{70}$ I. $7,9,10,22$. 
Important internal sources of information are MEPs and their offices. Eight interviewees underline that they turn to them for information regarding the content of a file and the prevailing perspectives thereof. ${ }^{71}$ "You should feed yourself with information from the members" (I.2). A large majority (83\%) of survey respondents report interacting with MEP assistants on a daily basis (see table 5.1a). They form the link to lobbyists and other external stakeholders $(\mathrm{I} .10,11)$ and forward the information received from these actors (I.0.4). "We work closely with the assistants because they are contacted by lobbyists. They can work on everything and are thoroughly aware of the MEP's agenda" (I.10). Moreover, assistants form an important resource of information for the advisor as they have (more) time to spend on research, thus having the capacity to examine and grasp the important details of a file (I. $0.4,6,17,20,21$ ). These findings are in line with the observation drawn from the literature that EP staff act as gatekeepers for information from the outside world (cf. Busby, 2013; Corbett et al, 2016). The interview accounts lead us to believe that the personal assistants of MEPs mainly fulfil this function. Notwithstanding, the survey findings show that only a minority of group advisors never interacts with external stakeholders (see table 5.1).

With the underlying objective of providing negotiation advice and coordinating positions (see chapter 7), 44 advisors indicate that they gather information to obtain the overview of the positions and priorities of the groups regarding a given file. ${ }^{72}$ Such 'political intelligence' is usually acquired through day-to-day informal interchange with counterparts, 22 advisors explained. ${ }^{73}$ The quantitative data gathered through the survey

\footnotetext{
${ }^{71}$ I. $0.4,2,6,10,11,17,20,21$.

72 I.0.1, 0.4, 1-4, 8, 11, 13, 16-21; open-ended responses of SR9, 15, 22, 27, 29, 34, $36,39,41,43,47,51,57,59,60,64-67,72,75,77,82,90-92,95-97,99$.

73 I.2-4, 6, 8, 11, 13, 17-22; open-ended responses of SR10, 19, 20, 51, 55, 74, 92, 96, 97.
} 
show that this interchange between group advisors occurs across the board (see table 5.1a): 49 per cent of respondents say that they exchange information on a daily basis and another 44 per cent report the frequency as weekly.

Table 5.1a Contact frequency internal actors

\begin{tabular}{l|l|l|l|l}
\hline & Daily & Weekly & Monthly & Never \\
\hline $\begin{array}{l}\text { Assistants (within the } \\
\text { group) }\end{array}$ & $83 \%$ & $16 \%$ & $1 \%$ & \\
\hline Colleague advisors & $80 \%$ & $13 \%$ & $6 \%$ & $1 \%$ \\
\hline Counterpart advisors & $49 \%$ & $44 \%$ & $6 \%$ & $1 \%$ \\
\hline $\begin{array}{l}\text { (Shadow) rapporteurs of the } \\
\text { group }\end{array}$ & $45 \%$ & $44 \%$ & $9 \%$ & $2 \%$ \\
\hline $\begin{array}{l}\text { Political coordinator of the } \\
\text { group }\end{array}$ & $51 \%$ & $40 \%$ & $4 \%$ & $5 \%$ \\
\hline Committee secretariat staff & $26 \%$ & $43 \%$ & $24 \%$ & $7 \%$ \\
\hline
\end{tabular}

The qualitative data reveal that, although formal meetings take place, the contact between advisors for the larger part is of an informal nature. Advisors liaise via e-mail, by phone, or in the Parliament's corridors. "We communicate face-to-face or by phone. In that case nothing is recorded on paper" (I.2). In their open-ended answers, several survey respondents also raise the importance of social or interpersonal skills in the cooperation with their counterparts. ${ }^{74}$ To be effective it is important to stay 'on friendly terms even with political opponents' and 'have lunch with the political advisors from the other groups once a month to talk business and to gossip about the MEPs' (SR92).

74 SR19, 51, 54, 74, 77, 92, 94, 96, 97. 
Another significant internal source of information are the committee secretariats. The survey shows that over two thirds of advisors are in regular contact with EP officials (see table 5.1a). The qualitative data offer further insight into the cooperation between advisors and committee secretariat officials. Most significantly, it appears to concern an informal exchange about procedures, planning, the content of the file and the various positions, stakes, or potentially sensitive issues. "The EP Secretariat is in charge of managing the legislative decision-making process. They organise meetings, but also map out the different views and interests in play in for example the other groups, the Council, and the European Commission" (I.6). "We contact the Secretariat to get to know more about the Commission's position, because they meet them much more frequently. And their role is to report back to Parliament on the intentions of the European Commission, the timing of the proposal, etc. If an assistant asks me about this then I will ask the Secretariat" (I.5). In addition to this informal contact, advisors rely on the committee secretariat for the distribution of all formal communication and documents. "All official communication regarding the legislative work passes through the EP Secretariat. They submit all the formal documents, information from and to the other institutions, and invitations for meetings" (I.10).

Finally, advisors can keep track of MEPs' views and core activities by monitoring online (social) media. "Nowadays, information and communication is digital. Social media are a convenient tool for gathering information, providing easier, quicker and continuous access to information. You get a good view of what is driving the members. These tools speed up the exchange of information in general, both internally and externally, and the flow of information never stops" (I.2).

In sum, the findings show that the gathering of information most prominently takes place through the informal interaction with external stakeholders and internal actors. These activities appear to comprise both 
an inventory element and a selective approach. The extent to which advisors are instructed or have room to improvise in their information management tasks is considered in section 5.2.

\section{Processing information}

All respondents acknowledge that they process information. To attend to MEPs' needs for information in their parliamentary activities, advisors filter and analyse information. "The selection and analysis of information is one of our daily activities" (I.3). The quantitative data, as illustrated by figure $5.1 .2 b^{75}$, show that the large majority (79\%) of survey respondents agree with this statement. No significant variation across groups or committees is encountered in respect of the indicated

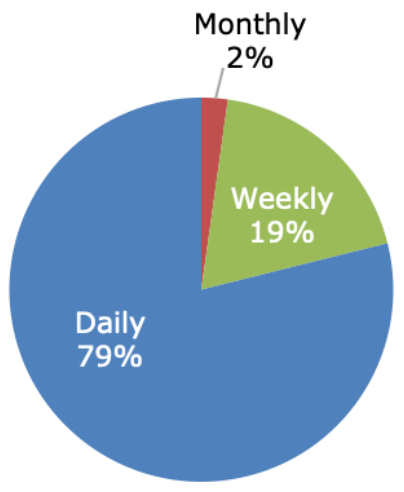

Figure 5.1.2b Filtering and analysing information frequency.

The qualitative data gathered through the interviews and the answers to the open-ended survey questions offer further details of what is understood by filtering information. 14 advisors point out that this relates to the level of relevance or importance. ${ }^{76}$ In order to be effective, advisors should have 'the capacity' to distinguish 'what is essential, important and less important or superfluous' (SR39). Advisors have to shed light on the different perspectives by 'pre-sorting content, filtering, and giving MEPs only the most essential bits of information' (I.9). Findings show that processing information applies to information about the content of a file and its

\footnotetext{
${ }^{75}$ Analysis of multiple-choice SQ 7: Can you please estimate how much time you devote to filtering and analysing information? See Appendix III Survey Response.

76 I. 0.3, 0.4, 3, 7, 8, 9, 11, 14, 16; open-ended responses of SR13, 22, 39, 44, 49, 55, $75,99$.
} 
implications, and the political viewpoints or priorities that are likely to affect the decision-making process. "You have to know how to filter, determine what ideas or input are important and what to leave aside" (I.0.4). It is the advisor's responsibility to 'point out the most political aspects of proposals' (SR99). "You need to be able to analyse, summarise, understand quickly and get across the key points to get the job done (I.11).

The empirical analysis discloses that advisors' tasks include but go beyond the technical sphere. They pre-select information through the choice of internal and external sources, and by determining what is (most) relevant for MEPs. "It is essential to understand all the political aspects of an issue, collect information, analyse it in an in-depth manner and transform it into political advice, for the MEPs following it as well as in a readable manner to the whole political group" (SR22). As discussed above, the analysis of information is generally policy-related or aimed at providing political intelligence. The aggregated survey data support this finding by showing that advisors perceive 'analytical skills' and 'policy expertise' among the most important qualities to possess in order to effectively carry out their role (see figure 3.2.3).

Policy analysis entails compounding information about the content of a file and its possible implications that allows the advisor to fulfil the Policy Expert role (see chapter 6 ). This starts with thoroughly studying the dossier's topic, understanding its content and implications, and advising the group accordingly, several advisors explained. ${ }^{77}$ Subsequently, the responsibility of the advisor is to provide MEPs with an in-depth analysis, cast light on the various aspects of a file and to put them into political context, as 16 others stated. ${ }^{78}$

\footnotetext{
77 I. 0.4 ; open-ended responses of SR7, 32, 36, 49, 90.

78 I.7, 11, 14, 17, 21; open-ended responses of SR7, 22, 34, 36, 42, 45, 60, 69, 79, 90, 95.
} 
Producing political intelligence consists of combining pieces of information, an activity that allows the advisor to provide the MEP with negotiation advice (see chapter 7). It entails the strategic analysis of the political landscape - i.e. the positions of internal and external stakeholders - as well as their various interests and possible compromises. This kind of information processing was mentioned by 49 of the advisors questioned. ${ }^{79}$ "A political advisor needs to know and understand the different political forces and interests, analyse these and map them in order to advise the members" (I.1).

From the findings it is concluded that processing includes but goes beyond the mere summary of information. The political dimension of these activities is further addressed in section 5.2.

\section{Distributing information}

From the empirical research it is found that the analysed information forms the basis for the Policy Expert and Broker roles, and to a lesser extent for the Process Manager role. Regarding the latter, advisors provide procedural assistance and advice based on the information they gather, and their sense of the broader picture. They will use their analysis and insight to, for example, comment on the voting list drafted by the committee secretariat, issue voting recommendations, or argue for a split vote (see 4.1.2).

Policy and political intelligence are distributed in briefings or exchanged face-to-face (see 6.1.2 and 7.1.2). Advisors distribute information 'to advise MEPs what is happening' (I.9). "In policy notes the state of play is evaluated: what is at stake, what are the differences, etc." (I.0.4). Face-

79 I.0.1, 0.4, 1, 2, 3, 4, 8, 9, 11, 13, 16-21; open-ended responses of SR9, 15, 22, 27, $29,30,34,36,39,41,43,47,51,52,57,59,60,64-67,69,72,75,77,82,90-92,95-$ $97,99$. 
to-face exchange of information is both an important source of information for the advisor as it is a way to communicate (group) priorities. In this respect, nine advisors underline the importance of having good communication skills in the open-ended responses of the survey. ${ }^{80}$ The informal exchange occurs internally with counterpart advisors and externally with various stakeholders (see tables 5.1 and 5.1a). In the interviews and the survey, advisors stress the importance of maintaining a good working relationship with their counterparts in the other groups. "It is important to be friends with everyone, to get information and to sell your information" (I.20). The interaction with external stakeholders can be a tactic that allows the advisor 'to test' certain ideas prevalent within the group in order to 'see how for example industry would respond to them' (I.14). Finally, as part of this distribution function some advisors report being involved in media and press activities. ${ }^{81}$

Besides merely distributing information, findings expose that the way advisors present information requires interpretation and judgement. The political scope of these activities is further discussed in the next section of this chapter.

\subsection{Assessment of the political scope of information management}

The findings confirm that there are technical and political dimensions to information management in the EP context, thus characterising it as a category of political advice. The previous section presented the empirical evidence for the adoption of the role and revealed that the Information Manager role may involve the selection of sources, the pre-sorting of

\footnotetext{
80 Open-ended responses of SR25, 27, 53, 64, 74, 75, 77, 91, 98.

${ }^{81}$ SR13, 22, 25, 55, 59, 75.
} 
content, and the framing or selling of political messages. The data show that these activities are common to group advisors. This section evaluates the political scope of information management. The extent to which the role is political is assessed with the use of the modes of discretion that have been developed as part of the analytical framework (see 2.1.3). The aim is to explore what guides the selection and interpretation by the advisor, and how they determine the appropriate way to present information. The analysis below approaches this issue by looking at advisors' discretion, room for initiative and improvisation when they adopt the role.

5.2.1 considers the way in which advisors receive instructions from MEPs and how this input affects their role. The analysis shows that advisors do not receive explicit direction or guidance in carrying out information management tasks. In order to determine the type of information required and the appropriate sources, they are guided by their understanding of the ideological priorities of the group. 5.2.2 further discusses this improvisation, which is a strategy to deal with situations in which explicit instructions are wanting. Findings show that advisors anticipate the information that is desired (ends) and use their judgement to compile and use it (means). It is therefore concluded in 5.2.3 that advisors manifest pro-active behaviour in all three information management functions. They thus have considerable room for manoeuvre with very little direction from their superiors.

\subsubsection{Instructions and input from the MEP}

This sub-section sets out to determine the way in which advisors receive instructions or input from the elected representatives and how this affects their room for initiative in the gathering, processing, and distribution of information. From the quantitative and qualitative data it is concluded that EP group advisors work closely together with (shadow) rapporteurs and the group's coordinator of the parliamentary committee in question (see 4.2.1). 
Their explicit or implicit political instructions are most likely to emanate from this interaction.

As concluded in chapter 4, the large majority of survey respondents and interviewees acknowledge their autonomy. In carrying out their daily activities they are not explicitly told what to do but expected to take initiative. Instead, advisors construct their mandate based on a certain grasp of the ideology and priorities of the group. This understanding serves as a guideline for the advisor's activities. The research shows that this in particular applies to information management because information needs generally remain implicit. 5.2.2 further addresses improvisation by advisors, which is in fact a strategy to deal with a lack of instructions or direction. Beyond the advisor's appreciation of what the position and information needs of the group or the member in charge are, no examples were encountered of explicit instructions regarding information management tasks. Ten interviewees state that MEPs' offices are an important source of information, which implies some indirect guidance as to what information is deemed relevant for the MEP.82 Overall, however, advisors report that they gather and process information at their own discretion.

For the collection of information advisors depend heavily on the exchange with internal and external actors (see 5.1). Several interviewees stated that whom they turn to for specialist or expert knowledge depends on the file. ${ }^{83}$ It was found that it is largely up to the advisor to decide who they contact or talk to. The survey analysis shows that internally MEP assistants are the group contacted most frequently (see table 5.1a), further supporting the notion that group advisors indirectly get direction with regard to the desired

\footnotetext{
82 I.0.1, 0.3, 0.4, 2, 6, 10, 11, 17, 20, 21.

${ }^{83}$ I. $4,10,11,17,18,19$.
} 
outcome and strategy. Externally, interest groups and NGOs are the most prominent groups with which advisors exchange information (see table 5.1). External stakeholders as well as the advisor can take the initiative for this exchange. The extent to which advisors interact with third parties differs per group. The culture within the group and its ideology also affect the type of actors that are consulted. The interview findings bring some interesting observations to light. For the administration of meetings with external actors, the S\&D group has formulated guidelines and the ECR group has a lobby register in place. According to two S\&D advisors, stakeholders who are aligned with the group's ideology are actively approached for their opinion or input on certain files. Another stressed that the general S\&D rule is to not meet with stakeholders individually and to only gather their input through organised hearings or workshops. The survey findings show that S\&D respondents are the least likely to meet with industry representatives (see 5.1.2).

The ECR's lobbyist register is based on the Anglo-Saxon model and 'is an incentive to inform each other as extensively as possible', one interviewee explained. Advisors have to fill in the date, related file and the name of the person they are meeting. MEPs then have to approve. ECR and EPP interviewees agree that meeting with external stakeholders happens a lot and is based on their knowledge and expertise. The Greens advisors underline that they are able to take a pro-active approach in deciding who to contact and by selecting the most relevant external stakeholders. In this regard, the advisor 'screens' external contacts for the MEP, one Greens/EFA advisor claims. An ALDE interviewee similarly describes the advisor as the 'interface' between lobbyists and the MEP. A GUE-NGL interviewee explains that contact with third parties generally runs through the MEP's office and that the selection is based on whether you need the stakeholder for your argument. All interviewees acknowledge the necessity of consulting external stakeholders for information and their room for manoeuvre in this 
regard. Only the EFD interviewee suggests that this happens significantly more when working on legislative files.

Discussing the interaction with officials of the other EU institutions, one interviewee suggested that advisors are perceived as 'pushy' because they are 'explicitly politically driven' (I.7). As discussed in 5.1.1, the EP highly values its independent (information) position within the institutional triangle, which explains the apparent inclination towards preferring knowledge or expertise provided by third parties over acquiring information from the other EU institutions.

In sum, the discussion shows that group advisors enjoy considerable discretion in their Information Manager role. No examples are encountered of explicit instructions in relation to information management tasks. Instead, advisors use their judgement and appreciation of the MEP's or group's priorities to determine the appropriate course of action. Alternatively, they seek indirect guidance from the personal assistants. Both the policy area and the group culture appear to affect the selection of preferred (sources of) information.

\subsubsection{Improvisation by the advisor}

It is found that group advisors fulfil the political dimensions of the role (see 5.1.2). The previous sub-section concluded that, for these activities, the mandate of advisors is implicit and that there is considerable room for initiative. This sub-section addresses group advisors' manifested level of improvisation in the Information Manager role. Improvisation is construed as value or ideological appraisals by the advisor, the anticipation of priorities or objectives, or the use of implicit knowledge or tactics (see the definition of political advice in 2.1.2). 
The literature has dealt extensively with information as a resource for legislators (e.g. Patterson, 1970; Tallberg, 2004) and previous studies show that MEPs rely heavily on internal sources (Dobbels and Neuhold, 2014). Information needs, however, are generally implicit and not very specific. Information management therefore by definition requires some form of anticipation and judgement by advisors. In this regard, they are found to determine what type of information is required and what the appropriate way to compile and present it entails. Advisors provide the necessary elements to help MEPs form an opinion and come to a decision (I.16). Findings reveal that, in addition to the technical inventory, summary, and distribution dimensions, information management by group advisors entails selection, interpretation, and presentation. The way in which advisors have to improvise for each activity is further discussed below.

The qualitative and quantitative data presented in 5.1.2 provided evidence that advisors actively search for information and input. ${ }^{84}$ Information management appears to be a day-to-day activity for group advisors. Activities consist of studying the file, monitoring related developments inside and outside the EP, compiling information from multiple sources, organising and attending events, exchange information with internal and external actors. However, advisors do not receive explicit direction or guidance in carrying out these tasks (see 5.2.1). The selection of information sources, for example, requires the advisor to anticipate both the desired input and the preferred provenance of the input. At their discretion, they select the sources that they deem most relevant or 'tactically' useful for MEPs (I.14). Moreover, the timeliness of information is important to appropriately support MEPs, as several survey respondents emphasise. ${ }^{85}$ Not only is it the responsibility of the advisor to keep abreast

${ }^{84}$ I. $0.4,3,4,6,7,8,9,13,14,15,17$; open-ended response of SR8, 10, 30, 32, 36, 43, $55,59,60,74,90$.

${ }^{85}$ SR8, 10, 36, 43, 50, 55, 58-60, 97. 
of any new developments and ensure up-to-date information, they also need to inform themselves and get involved at an early stage, i.e. 'prior to the publication of the EC proposal' (SR59). "You have to be informed first, before you can appropriately advise your politician" (I.7). At this stage, no formal discussions or exchange will have taken place in Parliament and advisors must therefore anticipate both the interests, potential position of their group as well as the stakes of the other groups and the other institutions.

In response to the open-ended question as to what characterises an 'excellent advisor', 48 respondents refer to political intelligence and 28 bring up policy-related information. Advisors can thus stand out by having or by showing the initiative to acquire expertise in a specific field. ${ }^{86}$ The advisor should be able 'to understand all the political dimensions of an issue and the positions of the various stakeholders' (SR22). Advisors bring added value to the group through their understanding of the topic (SR43).

The findings furthermore demonstrate that all group advisors filter information. They do so in order to provide MEPs with an overview of the broader picture. The qualitative data provided by interviewees and survey respondents illustrate that this type of information processing relates to analysing policy content, interpreting or 'translating' information (SR22), as well as to offering insight into the political landscape. In this role, advisors interpret the relevance and urgency of the policy and the political contexts. They make a selection based on their evaluation of what MEPs need to know (I.0.4, 9; SR39) and what are the 'most political' issues (SR99). Advisors can have considerable influence by distilling the relevant, or most important ideas or input and proposing these to be supported by the group (I.0.3).

${ }^{86}$ See Appendix III, responses to SQ5 and 6. 
The findings confirm that advisors structure and bundle information to make it controllable for the MEP. They use their judgement to combine policy and political intelligence, which allows advisors to grasp the broader picture. Effective advisors are able to provide MEPs with such a strategic overview, 12 of those probed say. ${ }^{87}$ It is the task of the advisor to monitor internal and external developments. "Advisors should be aware of the different stakes, views or sensitivities in the group, in the EP, and in the outside world" (I.2). It is found that advisors anticipate the strategies of internal and external stakeholders either by interpreting the information they gather, or by drawing from their experience. Advisors should furthermore have the ability to connect policy information and practical implications to the political objectives of the group, several survey respondents underline. ${ }^{88}$ These activities illustrate that advisors have considerable room for improvisation in their Information Manager role.

Advisors also apply judgement with respect to (possible) future developments that may require a response from the group. "Our most important responsibility is to keep a complete overview of all activities in a committee, understand how files intertwine, and anticipate how they may develop over time" (SR92). In addition to their interaction with external stakeholders, advisors liaise with their colleagues to be aware of relevant related issues and files in the other parliamentary committees (I.19, 22).

The data presented in 5.1.2 demonstrate that advisors' activities include but go beyond the mere distribution of information. Internally, advisors present information regarding the policy content and political stakes through briefings and in face-to-face encounters. ${ }^{89} 26$ advisors highlight

\footnotetext{
${ }^{87} \mathrm{I} .1,2,3,13,17,18,20,21$; open-ended responses of SR52, 75, 90, 92.

88 Open-ended responses of SR55, 75, 77, 82, 84, 90, 91, 97.

89 The ways in which advisors use information to provide policy-related advice and recommend negotiation strategies are addressed in respectively chapters 6 and 7 .
} 
that these activities include political analysis, interpretation, judgement, and the use of tactics on their part. ${ }^{90}$ This may relate to the timing of (not) sharing information or to the way in which the information is shared. Information exchange is a 'game of give and take': when you ask for information, you have to be willing to provide information in return. "And you don't always want to do this" (I.2). In both their internal and external communication efforts, advisors make use of framing as a tactic to test the ideas of their group and gather support. In such attempts to 'sell' information advisors 'express political ideas and messages' (I.20). By sharing information with others, advisors act as the MEP's proxy, giving visibility to his or her decisions and initiatives (SR25).

In conclusion, advisors improvise in order to deal with situations in which they are not explicitly told what to do. The adoption of the role requires improvisation because information needs remain implicit. Advisors anticipate the information that is desired and use their judgement to compile and use it. The analysis thus shows that the desired outcome, as well as the means to achieve it, are guided by the advisor's understanding of the ideological priorities of the group. The next sub-section discusses what this means for the political scope of the various information management tasks.

\subsubsection{Information management as a category of political advice}

The empirical research revealed that the core information management tasks combine technical and political elements. No evidence has been encountered of purely technical tasks. Yet, the technical inventory, summary, and distribution functions of information are part of and feed into the role. The framework conceptualises political advice as a mixed sphere

90 I.1-3, 8, 9, 17, 20, 22; open-ended responses of SR9, 13, 22, 24, 30, 34, 39, 40, 41, $44,45,49,50,51,69,89,91,99$. 
where technical and political activities meet. The findings presented in this chapter thus corroborate information management as a category of political advice.

To assess the political scope of the role, the framework conceptualised three incremental modes of political advice tied to the discretion of the advisor: routine, reactive, and pro-active behaviour. Discretion is exercised where hierarchical measures or political authority are not directly applied. The role thus becomes more pro-active as the advisor's room for improvisation increases. In the context of information management the routine mode is interpreted as follows: a situation in which the information needs (desired outcome) and the way in which to fulfil these needs (means) are explicated. No indications were encountered of either predefined information needs, or instructions about how advisors should gather, process, and distribute it. Instead, it is found that both the ends and the means in relation to information management remain implicit, which requires the advisor to improvise. The Information Manager role is thus labelled as pro-active and advisors are found to enjoy considerable room for manoeuvre with very little direction from their superiors.

Figure 5.2.3 illustrates the key features of the Information Manager role as found from the empirical research:

$\checkmark$ Advisors actively search and exchange information, for which they select the most relevant sources and content from their inventory. In the collection of information advisors are guided by their judgement and rely on their understanding of the priorities of the group.

$\checkmark$ Advisors transform information into useable intelligence. To this end, they filter information according to relevance and urgency, by interpreting substance-related content and political stakes. 
$\checkmark$ Advisors test or sell information to relay political ideas or messages. This activity involves the distribution of information to internal and external actors.
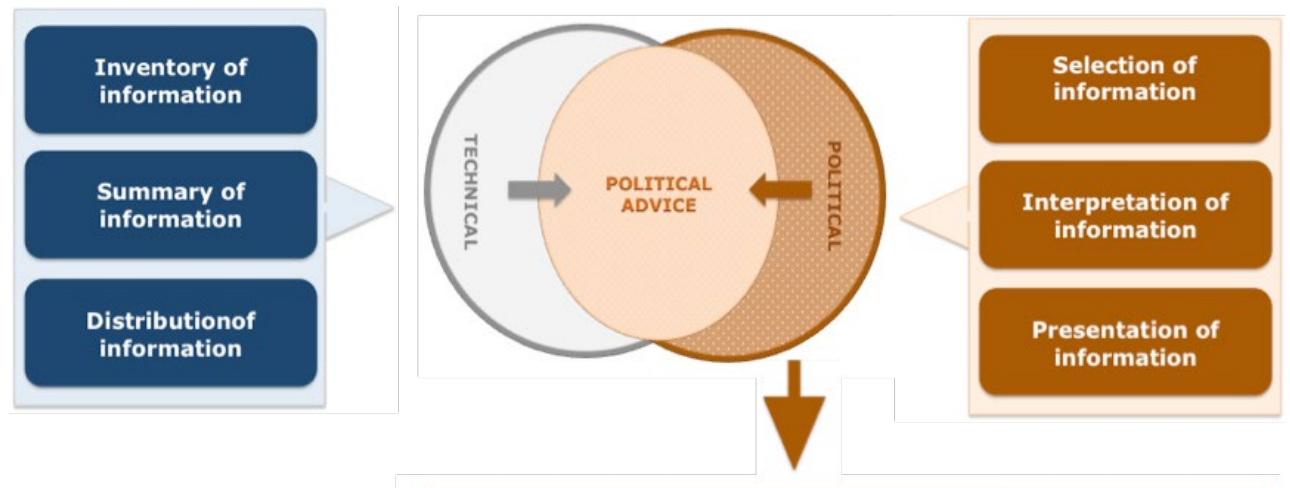

PROACTIVE INFORMATION MANAGEMENT

Actively search and exchange information

Filter information according to relevance and urgency

Test or sell information to relay political ideas or messages

Figure 5.2.3 Empirical findings: information management as a category of political advice

\subsection{Impact of the factors on information management}

The objective of the thesis is to explore and explain the circumstances that stimulate or restrict a political role by group advisors. The literature review identified a set of factors expected to affect the adoption of the Information Manager role (see 2.3). By presenting evidence from the survey and interviews this section consecutively evaluates the personal factors (5.3.1) and the contextual factors (5.3.2). The analysis concludes that political sensitivity combined with a context where advisors work on a policy issue 
or specific file that is not highly politicised in the EP are the optimal conditions for advisors to pro-actively adopt the Information Manager role.

\subsubsection{Personal factors}

The analytical framework conceptualises four personal attributes of advisors that are theorised to facilitate political behaviour. Each is assessed below in relation to information management, finding that the factor political sensitivity is indispensable for the political dimensions of the Information Manager role. Trust, informal network, and institutional memory facilitate information management activities.

\section{Trust}

The analytical framework links trust to knowledge of and affinity with party ideology and priorities (see 2.3.1). The empirical research shows that for information management trust relates to the quality and scope of information (in accumulation), the relevance and usability (processing), and reliability and acceptance of information (distribution).

17 advisors stress that trust, reliability and reputation are important for the accumulation of information. ${ }^{91} \mathrm{~A}$ trusted relationship with colleagues and counterparts in the other groups, as well as MEP Assistants facilitates the gathering and exchange of information internally. The interview and survey accounts show that the contrary holds true as well. Should trust be betrayed, the working relationship is disturbed.

25 advisors underline that trust between the advisor and the MEP is key in determining the working relationship, i.e. how much discretion the advisor

${ }^{91}$ I. $0.1-0.4,3,10,15,17,19,21$; open-ended responses of SR17, 25, 39, 40, 52, 60, 92. 
is granted by the coordinator or (shadow) rapporteur (s)he works with. ${ }^{92}$ Trust of the MEP increases the advisor's discretion to pro-actively select the sources of external information. Moreover, it is instrumental for the anticipation of the relevance and usability of information. MEPs will be more open to trusted advisors, relaying what they need to form an opinion, and more likely to give the advisor feedback on the information provided. The same reasoning applies to trust of MEP Assistants as they generally act as the interface to the MEP and screen the information provided by group advisors.

Findings illustrate that trust facilitates each of the three elements of information management. For the effective distribution of information it is even found to be indispensable. The collected data show that analysed information forms the basis for the Policy Expert and Broker roles. Policy and political intelligence are distributed in briefings or exchanged face-toface. The reliability of the advisor is crucial to ensure internal and external actors accept the advice that is provided. The factor trust is therefore found to be indispensable for the adoption of the Policy Expert and Broker roles (see 6.3.1 and 7.3.1 respectively).

\section{Informal network}

The framework conceptualises an informal network as the access to and exchange of private information through informal interactions with actors in and outside the institution (see 2.3.1). For information management the scope of the information accumulated and distributed depends on the extent of an advisor's informal network.

92 I. $0.2,0.4,4,7,8,9,11,13,15-18,22$; open-ended responses of SR6, 17, 25, 31, 38$40,52,60,61,84,99$. 
From the literature it was derived that in-house sources of information are crucial for safeguarding the Parliament's independence. The survey analysis demonstrates that advisors' networks centre on contacts within the institution. 39 advisors underline that informal contacts and personal relationships with actors inside the EP are crucial to information management. ${ }^{93}$ Internally, their most valued contacts are MEP assistants (see table 5.1a). The informal exchange with assistants facilitates the advisor to acquire insight into MEPs' views, information needs, and preferences regarding the sources or stakeholders to consult for information. The collaboration of advisors facilitates their ability to synthesise information and provide the group with a strategic overview of the policy and political context of a file. Within the group, colleagues exchange information about the key issues in the respective parliamentary committees in order to map out interconnections or possible conflicts (I.19, 22; SR92). Information exchange with counterparts in other groups allows the advisor to map out the various stakes, to test or sell information, or to give visibility to group initiatives or priorities. Finally, officials working within the EP committee secretariats are important for the pro-active search for information (I.16).

The degree to which advisors are allowed or inclined to meet with external stakeholders determines the effectiveness of their networks. The aggregated survey data reveal that advisors are in touch with external stakeholders on a regular basis (see table 5.1). Although differences exist between group cultures regarding the selection of and tendency to meet external stakeholders, the scope of advisors' external networks is most strikingly dependent on the policy area they work on, i.e. the parliamentary committee they support.

93 Open-ended responses of SR3, 5, 10, 11, 13, 14, 27, 37, 42, 43, 47, 51, 53, 55, 59, 60, 74, 79, 84, 88, 89, 92, 97, 98. I. 0.4, 2, 3, 4, 6, 7, 8, 9, 10, 13, 15, 16, 17, $19,22$. 
The findings presented in the chapter, and summed up in the discussion above, show that advisors' intra- and extra-parliamentary networks facilitate pro-active information management. "The amount of input and arguments obtained determines if you can have more or less influence as an advisor" (I.3).

\section{Institutional memory}

Institutional memory is conceptualised as the insight into - and access to the institutional track record (see 2.3.1). In the EP context the factor is interpreted as knowledge of the functioning of the institution (formal and informal rules) and an appreciation of the political group's (previous) positions. For information management institutional memory facilitates the advisor to anticipate information needs, judge information sources, as well as the relevance and usability of information.

The advisors in the study do not elaborately present institutional memory as a specific asset. 'Knowing your way around' rather seems a given for those inside (I.3). The survey finds advisors to be generally experienced. ${ }^{94}$ Moreover, nearly half of the respondents have a background of working in the EP. These figures lead to the conclusion that advisors are in a position to develop a level of 'institutional memory'. Successfully employing this knowledge and insight is instrumental for pro-active information management. Nonetheless, no evidence was found that information management is dependent on the institutional memory of the advisor.

\section{Political sensitivity}

The analytical framework conceptualises political sensitivity as the understanding of the institution's informal code of conduct and the ability

\footnotetext{
94 On average advisors are in their current position for six years, varying between seven months and 23 years.
} 
to recognise political and administrative cues (see 2.3.1). In the context of information management in the EP, the factor allows the advisor to anticipate information needs, judge the relevance and urgency of information sources and content, and employ tactics for distribution.

Political sensitivity first of all relates to understanding the information needs, which advisors deduct from the views of the MEP in charge and the ideological position of the group (see 5.2.1). 37 advisors discuss the need to know what is strategically important for MEPs and the group as a whole. ${ }^{95}$ "Advisors should be able to assess, appreciate, and predict political interests" (I.1). Political sensitivity in these terms entails the anticipation of 'what is likely to be acceptable' to the members of the group (cf. Page and Jenkins, 2005). The empirical research reveals that this is indispensable for the anticipation of information needs as well as judging the political and strategic relevance of information. Advisors must have the ability to predict and empathise with the various - possibly conflicting - views within the group. Subsequently, they tailor the information to accommodate the respective needs (SR56).

By interpreting collected information advisors provide the group with a strategic overview of the broader picture. This requires a certain insight into the priorities and strategies of the various internal and external actors and the ability to anticipate changes (I.1, 2, 15, 21). Group advisors are able to do so by drawing on their 'awareness' of what is going on inside and outside Parliament (I.3, 14, 19, 20). This can be associated with having 'a feel for the game' (Adler-Nissen, 2009), allowing advisors to understand and forecast the process of political coordination.

95 I.0.1-0.4, 1-4, 9, 13-15, 17, 18, 19, 22; SR9, 10, 13, 15, 22, 24, 29, 36, 39, 41, 48, $60,64,72,74,75,77,87,95,96,97$. 
In the presentation of information advisors enjoy considerable room for manoeuvre (see 5.2.2). Findings show that political sensitivity is in fact indispensable for these activities. In relaying political messages advisors 'need to distinguish between their personal opinion and the line of the group' (I.8) and know how to 'be diplomatic' (I.5). Advisors should have the 'ability to frame' their information in a way likely to be 'accepted' by others (I.11). Other interviewees also discuss the presentation of information in relation to political sensitivity: advisors should 'understand the skill of political presentation' (I.12) and 'the language and tone in conveying advice is an intangible skill' advisors should master (I.2). Finally, a 'feeling for the right timing' is needed (I.21).

Inquiring after the qualities advisors should possess to effectively fulfil their responsibilities, political sensitivity is cited most prominently by survey respondents. ${ }^{96}$ Interviewees are even more united in stressing the crucial importance of political sensitivity for their role. Out of 28 interviewees, only five did not discuss the concept. From the quantitative as well as the qualitative data the conclusion is drawn that the factor political sensitivity is indispensable for the adoption of the Information Manager role.

\section{Assessment of the personal factors}

In the analytical framework it was hypothesised that the personal factors affect the advisor's discretion and their ability to adopt a political role. The factors are used to assess the (optimal) circumstances in which political advice may be provided. The following values are used to qualitatively evaluate the impact of the factors on the adoption of the Information Manager role: indispensable $(++)$, positive impact $(+)$, no impact/ not relevant (0), or a negative impact (-).

${ }^{96}$ See Appendix III, responses to SQ6 and 11 . Respectively 41 per cent and 52 per cent of respondents cite political sensitivity. 
From the empirical findings as discussed above it is concluded that political sensitivity is indispensable for the political dimensions of the Information Manager role. Trust, informal network, and institutional memory also facilitate information management activities. Table 5.3.1 illustrates the outcomes of the analysis.

Table 5.3.1 Personal factor assessment for the Information Manager role PRO-ACTIVE INFORMATION MANAGER

\begin{tabular}{|l|c|c|c|c|}
\hline & Trust & $\begin{array}{c}\text { Informal } \\
\text { network }\end{array}$ & $\begin{array}{c}\text { Institutional } \\
\text { memory }\end{array}$ & $\begin{array}{c}\text { Political } \\
\text { sensitivity }\end{array}$ \\
\hline $\begin{array}{l}\text { Actively search and } \\
\text { exchange information }\end{array}$ & + & + & 0 & ++ \\
\hline $\begin{array}{l}\text { Filter according to } \\
\text { relevance and urgency }\end{array}$ & + & + & + & ++ \\
\hline Test or sell information & + & + & 0 & ++ \\
\hline
\end{tabular}

\subsubsection{Contextual factors}

Three contextual factors are expected to affect delegation and trigger potential differences across the groups, committees, policy domains, or specific files: political direction, complexity, and politicisation. The assessment in this sub-section concludes that the political functions of information management are restricted in politicised cases and enabled in highly complex cases. The Information Manager role is further stimulated if the group attaches particular importance to the policy area or file under discussion.

\section{Political direction}

The analytical framework defines political direction in relation to the position of the MEP or group: advisors' ability to identify political cues to guide their behaviour depends on the extent to which the MEP in charge or the group 
they represent is outspoken and reputed (see 2.3.2). The idea is that the clearer advisors' political direction is, the more likely they are to assume a political role.

Advisors construct political direction from their appreciation of the position(s) and ideological principles of the political group (I.13, 19, 20). The prediction of information needs is thus based on their ability to do so. Several interviewees explain that these needs are more straightforward and aligned within the smaller or more homogeneous groups than for the ALDE, EPP, or S\&D groups. ${ }^{97}$ For specific information needs, advisors look to the MEP in charge and the political coordinator of the group. The experience of MEPs affects the role of the advisor and can have both a facilitating and restricting impact. Six interviewees explain that newcomers tend to have different needs for assistance compared to 'experienced' MEPs. ${ }^{98}$ As the experience of the MEP increases, less research is necessary by the advisor (I.5). This implies that information management becomes less significant as MEPs get settled into their function. At the same time, it is harder for advisor to anticipate the information needs of newcomers and tailor their analysis of information to these needs.

The role of the advisor is furthermore affected by the extent of involvement of the MEP and his/her office. The scope of the Information Manager role decreases if the MEP Assistant is experienced, pro-active, or knowledgeable about the file under discussion (I.18, 22). Nevertheless, advisors' responsibility for informing the group (distribution function) remains unaffected by the activity of Assistants.

97 I. 3, 8, 11, 12, 14, 17, 21.

${ }^{98}$ I. $0.3,3,4,5,13,15$. 
Using the factor political direction to assess the adoption of the Information Manager role proves difficult. No examples are encountered in the data in support of an unambiguous relation (positive or negative) between political direction and the Information Manager role. Instead, findings show a mixed picture in terms of the experience of MEPs, which can have both a facilitating and restricting impact, as can their active involvement.

\section{Complexity}

In the framework complexity is defined in relation to the subject matter and thus expected to vary across parliamentary committees or specific policy or legislative proposals (see 2.3.2). From the literature the assumption is drawn that as 'complexity' increases MEPs are more likely to seek assistance and grant advisors a political role.

Both survey respondents and interviewees stress that advisors should be able to analyse technical and complicated files. Several advisors underline that political advisors have more room for manoeuvre and 'influence' as the issue under consideration becomes more complex. ${ }^{99}$ They claim that in files with a lot of technical details the 'value' of assistance and information increases considerably in such cases (I.1). In addition, it is 'more likely that MEPs follow the advisor's advice' (I.13), or are 'less controlling' (I.15). Moreover, certain files require 'specialist expertise' which MEPs do not possess and the advisor can provide (I.4). Findings presented in 5.1 and 5.2 show that advisors indeed fulfil such information or expertise requirements. These examples confirm the relevance of the policy context for the role of advisors. Four interviewees described the role of the advisor as being more significant for policy issues that are a priority of the group. ${ }^{100}$ The importance attached to files is generally bigger for legislative files, nine

99 I. $1,4,13,15,18$.

${ }^{100}$ I. 5, 7, 8, 21. 
interviewees claim. ${ }^{101}$ For example, the exchange of information with internal and external actors increases considerably on legislative files (I.6, 9).

The empirical research confirms that complexity facilitates the Information Manager role. More specifically, it is found that the policy context (file or parliamentary committee) has a significant impact on the role: the need for specialist expertise (i.e. technical files) and the attached importance (i.e. group priorities and legislative files) facilitate information management.

\section{Politicisation}

The framework conceptualises politicisation in relation to division in the EP, both in general and with regard to a specific dossier (see 2.3.2). It is therefore defined as something that may change over time and vary across policy areas. Politicisation is expected to restrict the advisor's role.

The type of parliamentary committee or file affects the type of information required. A committee or certain policy area can be technical, mostly dealing with legislative files in a compromise-oriented way. Other committees are more political, focussing on political resolutions (I.15, 20). In technical committees the ideological lines are less prominent and the work is less visible, as it receives little attention from the media. Such a situation requires increased information management from the advisor regarding the content as well as the stakes of other internal and external actors. For political resolutions, the positions are generally clearly delineated and highly visible. Thus, in these cases, policy or political intelligence offer little added value. Moreover, the interview and survey findings show that MEPs tend to be more controlling when it concerns highly

${ }^{101}$ I. $0.5,5,6,7,8,9,12,13,21$. 
visible or divisive issues. The empirical research thus confirms the expectation that politicisation restricts information management.

\section{Assessment of the contextual factors}

As hypothesised, the context affects delegation. The factors are used to assess the (optimal) circumstances in which political advice may be acceptable to MEPs. The following values are used to qualitatively evaluate the impact of the factors on the adoption of the Information Manager role: indispensable $(++)$, positive impact $(+)$, no impact/ not relevant $(0)$, or a negative impact $(-)$.

The empirical research concludes that pro-active information management is restricted in politicised cases because the added value of policy and political intelligence reduces in such cases and MEPs tend to be more controlling. On the other hand, pro-active behaviour is easier for advisors in highly complex cases where they generally have more room to improvise. More specifically, the policy context (file or parliamentary committee) is found to significantly affect the advisor's role. The role becomes more prominent when the group attaches particular importance to a given policy area or file under discussion. No examples are encountered in the data in support of an unambiguous relation (positive or negative) between political direction and the Information Manager role. Nonetheless, the level of involvement and the experience of MEPs and their offices do affect information management. 
Table 5.3.2 Contextual factor assessment for the Information Manager role

PRO-ACTIVE INFORMATION MANAGER

\begin{tabular}{|l|c|c|c|}
\hline & $\begin{array}{l}\text { Political } \\
\text { direction }\end{array}$ & Complexity & Politicisation \\
\hline $\begin{array}{l}\text { Actively search and exchange } \\
\text { information }\end{array}$ & 0 & + & - \\
\hline $\begin{array}{l}\text { Filter according to relevance } \\
\text { and urgency }\end{array}$ & 0 & + & - \\
\hline Test or sell information & 0 & + & - \\
\hline
\end{tabular}

\subsection{Concluding remarks}

The findings expose two underlying motives for gathering information: the provision of policy expertise and political intelligence. Information serves as preparation for the formulation of policy positions and political deliberations. These activities are further addressed in the next two chapters, respectively presenting the analysis of the Policy Expert (chapter 6) and Broker (chapter 7) roles. Notably the Greens/EFA and GUE/NGL advisors attach value to information management for the purpose of policy and political intelligence. However, the overall picture - encountered across the groups - supports the idea that information is instrumental to the role of advisors, yet not the key purpose as such.

The empirical analysis presented in this chapter corroborates the proposition that information management by EP group advisors can be characterised as a category of political advice. Activities comprise but go beyond the technical dimensions. Group advisors gather and summarise information, yet this technical dimension in practice cannot be separated from the political dimension of information management. For the information to be distributed to and used by MEPs, advisors transform it 
into specific and action-oriented intelligence. This requires the advisor to select the relevant and appropriate sources and to interpret the content and related political stakes. For example, the selection of (preferred) sources of information may vary across policy areas and across the groups.

No indications were encountered of either predefined information needs, or instructions about how advisors should gather, process, and distribute it. Instead, both information needs (the desired outcome) and the activities to fulfil these needs (means) remain implicit. To deal with this lack of direction, advisors improvise. The preparatory function of information - ahead of the formulation of policy positions and political deliberations - means that advisors cannot derive their mandate from political debates. The Information Manager role is thus labelled as pro-active and advisors adopt the role with very little direction from their superiors. In all three aspects of information management, they are guided by their judgement and rely on their appreciation of the priorities of the group. The findings therefore support the conclusion that the preparations made by advisors can shape the direction of policy positions, and the form of compromises forged across the groups.

The objective of the thesis is to explore and explain the circumstances that stimulate or restrict a political role by group advisors. The assessment of the factors revealed political sensitivity as an indispensable asset for effective information management. The added value of this factor lies in the advisor's 'awareness' or 'feel for the game', which allows for forecasting of and empathising with various positions and information needs. It furthermore enables the advisor to judge the political and strategic relevance of information. In light of the distributive purpose of information management, political sensitivity is indispensable for the framing of information, the assessment of the appropriate timing and tone so as to ensure that the information becomes acceptable to those targeted. This 
asset combined with a context where advisors work on a policy issue or file that is not highly politicised in the EP, are the optimal conditions for the adoption of the Information Manager role. In politicised cases, the added value of policy or political intelligence decreases because positions are generally clearly delineated and highly visible. Moreover, MEPs appear to be more controlling with regard to divisive and visible issues. On the other hand, pro-active behaviour is easier in highly complex cases where advisors generally have more room to improvise. More specifically, the policy context (file or parliamentary committee) is found to significantly affect the advisor's role. The role becomes more prominent when the group attaches particular importance to a given policy area or file under discussion. Generally, more importance is attached to legislative files over nonlegislative files, resulting in increased opportunities for advisors to proactively accumulate, process, and distribute information. No examples are encountered in the data in support of an unambiguous relation (positive or negative) between political direction and adoption of the Information Manager role. Nonetheless, the level of involvement and the experience of MEPs and their offices do affect information management. 




\section{CHAPTER 6. POLICY EXPERT}

The analytical framework conceptualised four roles that advisors may adopt, each potentially containing a political dimension. The dissertation applies the theoretical concepts to the specific case of group advisors in the European Parliament (EP) ${ }^{102}$ and this chapter presents the analysis of the Policy Expert role. The ideal-type role comprises two central functions: (1) the provision of policy-related advice and (2) the formulation of policy positions and legislative texts. To address the research question 'under which conditions can advisors adopt a political role' three analytical steps are carried out.

The first step is to assess whether the ideal-type role is in fact adopted and what it entails. To that end, 6.1.1 examines the hypothetical dimensions related to policy expertise. The theoretical expectations regarding the adoption of the Policy Expert role are put forward, drawing from the literature review (see introduction) and complemented with the performed document analysis. The discussion in 6.1.2 then assesses these theoretical expectations in light of the empirical findings. The analysis shows that EP group advisors assume the Policy Expert role, and that their activities contain technical and political elements. In this respect, they select, interpret, and articulate policy and decision options. Although advisors from across the groups claim that they provide policy-related advice and acknowledge a potential drafting role, Greens/EFA advisors most prominently consider these activities as part of their responsibility.

\footnotetext{
${ }^{102}$ Advisors employed by one of the EP party groups and assigned to follow the work of one or several of the parliamentary committees are the focus of this study. Throughout the analysis 'advisors' or 'group advisors' refers to this type of advisors.
} 
The second step is to assess the extent to which the role is political, based on the three modes of discretion that have been developed as part of the analytical framework. Section 6.2 discusses advisors' room for manoeuvre to fulfil the political dimensions of policy expertise. This is approached by on the one hand examining the extent to which advisors receive instructions or input from the elected delegates (6.2.1), and on the other hand, the need and their capacity to improvise (6.2.2). The empirical findings show that advisors have more leeway as the group's interests are more aligned. In groups with multiple and possibly conflicting policy interests, advisors' mandate is less clear and their room for improvisation declines. Consequently, ALDE, EPP, and S\&D advisors are less likely to adopt a proactive Policy Expert role (6.2.3). Conversely, Greens/EFA advisors enjoy the largest degree of autonomy to contribute to or develop policy lines.

As a third and final step, the impact of the personal and contextual factors on the adoption of the role is evaluated (6.3). From the empirical research it is found that in particular trust and political sensitivity are necessary to pro-actively provide the Members of the EP (MEPs) with policy expertise. The homogeneity or heterogeneity of the group has an important impact on the Policy Expert role. Political division within the group negatively affects the extent to which advisors are able to derive political guidance for their activities. The findings furthermore show that advisors' pro-active behaviour is stimulated by the complexity of files. However, such behaviour is restricted in politicised legislative files.

\subsection{The nature of policy expertise in the EP}

This section first introduces the various theoretical dimensions of policy expertise. Drawing from the literature, the technical and political tasks pertaining to the Policy Expert role are discussed (6.1.1). The ideal-type role comprises two central functions: (1) the provision of policy-related 
advice and (2) the formulation of policy positions and legislative texts. The theory is complemented with the document analysis on the profile and duties of EP group advisors in order to infer expectations about the adoption of the role (see 3.3.3).

Subsequently, 6.1.2 presents the empirical findings for the Policy Expert role. The theoretical expectations regarding the role are evaluated in light of the collected survey and interview data. The empirical research finds that EP group advisors adopt the Policy Expert role. They provide policy advice and are involved in formulating positions. Findings reveal that although policy expertise is considered a prerequisite for effective advisors, it is not perceived as their most important task. Greens/EFA advisors form the exception in the EP case: they are considered 'experts' and deem it their core responsibility to develop and shape policy outcomes.

\subsubsection{The theoretical dimensions of policy expertise}

MEPs require input throughout the process of examining policy and legislative proposals (Campbell and Laporte, 1981; European Parliament, 2000). With the expanded workload of the EP and the growing amount of informal trilogues the need for policy-related input increased. ${ }^{103}$ Evidently, the EP values its independent position from the executive it controls (Corbett et al, 2011: 319). For MEPs to be able to assess the proposals on the table, it can therefore be assumed that they are in need of technical assistance to match the expertise present in the Council and the European Commission (EC). Notwithstanding the creation of the European Parliament

\footnotetext{
${ }^{103}$ See 1.1.1 for a discussion of the EP's evolving legislative powers and a brief introduction of the 'Ordinary Legislative Procedure' in which the Council and the EP work in parallel as co-legislators. In the so-called trilogue negotiations EC representatives also take part.
} 
Research Service (EPRS) that in part meets this need, the expectation is that group advisors also provide MEPs with policy expertise (see 3.3.3). ${ }^{104}$

In the analytical framework policy expertise is conceptualised as substantive, content-related input that includes policy orientations, definitions and interpretations, and the formulation of (draft) legislative texts (see 2.2.2). ${ }^{105}$ The Policy Expert role is thus expected to comprise two central functions: (1) the provision of policy-related advice and (2) the formulation of policy positions and legislative texts. From the theory and document analysis it is inferred that group advisors assume the two functions. The expectations as to what such activities entail are discussed below.

The academic discussion on the role of officials in the policy process supports the distinction between the advisory and drafting functions of policy expertise. Page and Jenkins' (2005) categorisation of 'policy work' into a production (drafting documents) and a service (advice) role for example fittingly reflects this. ${ }^{106}$ Most of the vacancy notices for the recruitment of EP group advisors specify one or several parliamentary committees. We can therefore assume that the provided advice is tied to a specific policy area (see Appendix I). Policy advice relates to the substantive content of proposals or initiatives and supports the process of forming an opinion on these proposals (cf. Blischke, 1981; Peters, 2009; Winzen, 2011; Högenauer and Neuhold, 2015). Generally, it is provided to the members

\footnotetext{
104 See 5.1 .1 for a more elaborate discussion of the role of the EPRS.

105 The definition is based on an extensive literature review (see introduction) and draws on Patterson, 1970; Price, 1971; Congressional 'Research service' in: European Parliament, 2000; Blitschke, 1981; Campbell and Laporte, 1981; Provan in: Neunreither, 2002; Peters, 2009; Winzen, 2011; Dobbels and Neuhold, 2013; Högenauer and Neuhold, 2015.

106 The scholars include the management of policy implementation processes as a third element because their study focuses on civil servants' role at the executive level. This activity falls outside the scope of parliamentary responsibility.
} 
through policy-oriented briefings (European Parliament, 2000). This type of advice can entail a variety of things. For example, advisors may analyse the policy option(s) upon which the House has to form its opinion, set out the prevailing or alternative policy options (cf. Patterson, 1970; Price, 1971). As part of their advice, they may also offer policy definitions (Provan in: Neunreither, 2002).

The second function of the Policy Expert role is the formulation of policy positions or legislative texts (cf. Patterson, 1970; European Parliament, 2000; Page and Jenkins, 2005). In the context of the EP, Egeberg et al (2013) and Neunreither (2002) identify the drafting of 'documents' as one of the key supporting activities of officials. Among the listed responsibilities of EP group advisors in the vacancy notices we find 'participating in the legislative work of the parliamentary committees'. Furthermore, the drawing up of 'parliamentary positions', amendments, and resolutions is listed as one of their common duties (see Appendix I).

Drawing from the literature, EP group advisors are expected to contribute to shaping the policy outcome (cf. Patterson, 1970; Price, 1971; Dobbels and Neuhold, 2013; Högenauer and Neuhold, 2015). They may do so by showing initiative (Patterson, 1970; Price, 1971) or by 'steering' the political discussion (Dobbels and Neuhold, 2013). Information or knowledge that non-elected actors feed into the policy-making process can be of a political nature (cf. Radaelli, 1999). Radaelli ties the political role of expertise to the lack of scrutiny and political oversight of those providing the expertise. The sources on which policy-related advice or the formulation of texts is based also matter. The opportunity to shape policy increases when officials have the discretion to draw from their own ideas or research as opposed to merely registering the input expressed by MEPs (cf. Högenauer and Neuhold, 2015). 
Summing up the scholarly discussion, advisors are expected to provide policy-related advice and draft (legislative) texts within the scope of one or several parliamentary committees. The framework's mixed sphere of activity presumes that there is both a technical and a political dimension to this role. Tasks pertaining to the latter comprise value or ideological appraisals, the anticipation of priorities or objectives, and the use of implicit knowledge or tactics (see 2.1.2). Technical tasks are void of such judgement by the advisor and could for example entail the inventory of policy options that are supported by the various groups or institutions. A technical approach to drafting documents could be construed as the mere registration of input expressed by certain MEPs. The political dimension of the Policy Expert role in the context of the EP is hypothesised to involve the following: (i) the pre-selection of (the sources of) policy or decision options; (ii) the interpretation of policy or decision options and their (political) implications, and (iii) the articulation of alternative policy or decision options. Figure 6.1.1 illustrates the anticipated dimensions of policy expertise based on the theory.

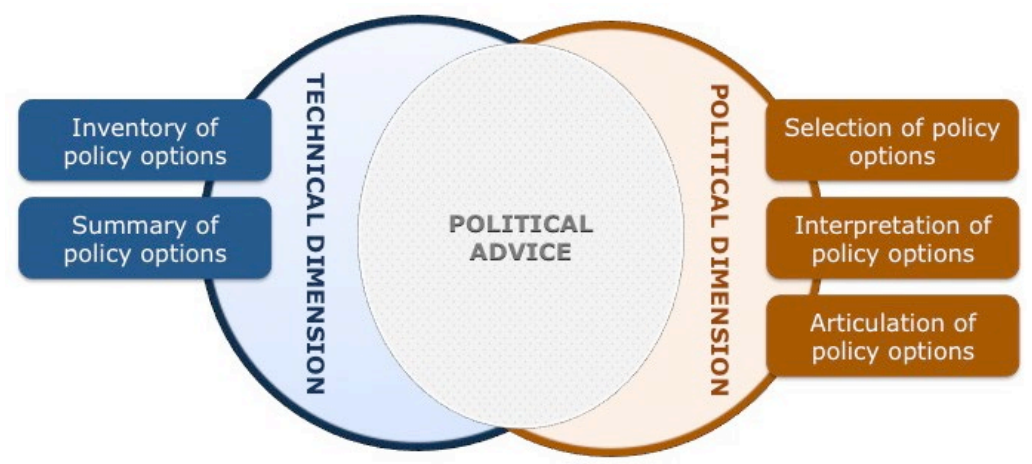

Figure 6.1.1 Theoretical dimensions of policy expertise

\subsubsection{The adoption of the Policy Expert role in practice}

The conducted empirical research demonstrates that EP group advisors adopt the Policy Expert role and that the role indeed involves both technical and political tasks. Within the scope of one or several parliamentary 
committees, they provide policy advice and are involved in formulating positions. First, the recruitment of advisors is discussed, assessing to what extent they are hired or perceived as policy experts. Next, the activities related to policy-specific advice and the formulation of positions and texts are presented.

\section{Advisors' perception of policy expertise}

The survey findings corroborate the assumption from the document analysis that EP group advisors are assigned to one or several parliamentary committees. ${ }^{107}$ The job profile of advisors, however, only puts forward a minimum level of education. In the exceptional cases where vacancy notices specify the required educational background, the studies most frequently listed are Law, Economics, and International Relations (see 3.2.2). The quantitative data furthermore expose that EP group advisors are highly educated, with 48 per cent of respondents holding multiple academic degrees. The most common programmes are Law (23\%) and Political Science $(19 \%)$, followed by EU studies, Economics, and International Relations (see table 3.2.2). These results are consistent with the theory that ties 'political advice' to a general mastery of the legislative organisational process (see 2.2.2). EP advisors' educational background thus principally provides for an understanding of the organisational process rather than specific policy content.

Survey findings demonstrate that group advisors are generally experienced professionals. Only six per cent of respondents have less than four years of working experience, whereas 68 per cent have at least ten years. Moreover, 42 per cent worked in the EP prior to taking up their current position (see 3.2.2). The vacancy analysis found that GUE/NGL and EFD groups are most

107 See Appendices III and IV for an overview of the distribution across committees of respectively the survey respondents and interviewees. 
prone to stipulate special conditions in relation to the policy content of the committee for which the advisor is recruited (see Appendix I). The interview accounts furthermore reveal that the Greens/EFA group is known for recruitment based on policy-related expertise. All six interviewed advisors from the group referred to this practice and three EPP advisors stated that the Greens employ 'experts' as advisors. Their 'specialist expertise' means that they are 'really engaged' in their role to push the Green agenda, three of them explained. Two others furthermore claim that the focus of the group lies on the substance of the file and that advisors are 'free to develop policy lines' by providing input to MEPs. They typify their counterpart advisors as 'political operatives'. An ECR interviewee said that, similar to the Greens/EFA, his group values expert knowledge and is 'led by the technical content of a file'.

The survey suggests an overall presence of policy expertise, at least according to the perception of the respondents. Among the most important qualities advisors should possess 'expertise in a specific policy area' ranks highest: 22 per cent list it as most important, 11 and 12 per cent respectively list it second

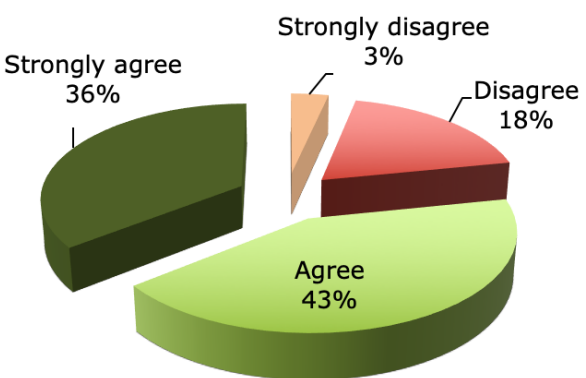

Figure 6.1.2a Policy expertise in a specific area and third (see Appendix III). Furthermore, a large majority of the respondents (79\%) claim that they are 'an expert in a specific policy area' (see figure 6.1.2a ${ }^{108}$ ). Those who disagree, state that they are generalists instead. Nonetheless, out of those who agree 28 per cent simultaneously describe themselves as generalists. On the one hand, we should bear in mind the possibility of socially desirable

108 Analysis multiple-choice SQ10: To what extent do you agree with the following statements? See Appendix III. 
answers. It seems unlikely that advisors would label policy expertise as irrelevant. On the other hand, however, it may provide further evidence for the need to master the overall organisational process (see 3.2.2). Finally, one does not necessarily exclude the other: advisors' specific policy expertise could also go hand-in-hand with having more general process expertise.

Considering the (perceived) importance of policy expertise in relation to the other types of advice leads us to believe that - similar to information management - it serves a secondary function. Although a majority ranks policy expertise as advisors' most important attribute, only 14 per cent identify the Policy Expert role as their overall most important task (see figure $\left.6.1 .2 b^{109}\right)$. The qualitative evidence gathered through in-depth interviews supports this conclusion. Although only three interviewees do not acknowledge the role, policy expertise as such is generally not depicted as the central element of their role. The Greens/EFA advisors form the exception and the Policy Expert role appears to be the most important or most frequent for this group.

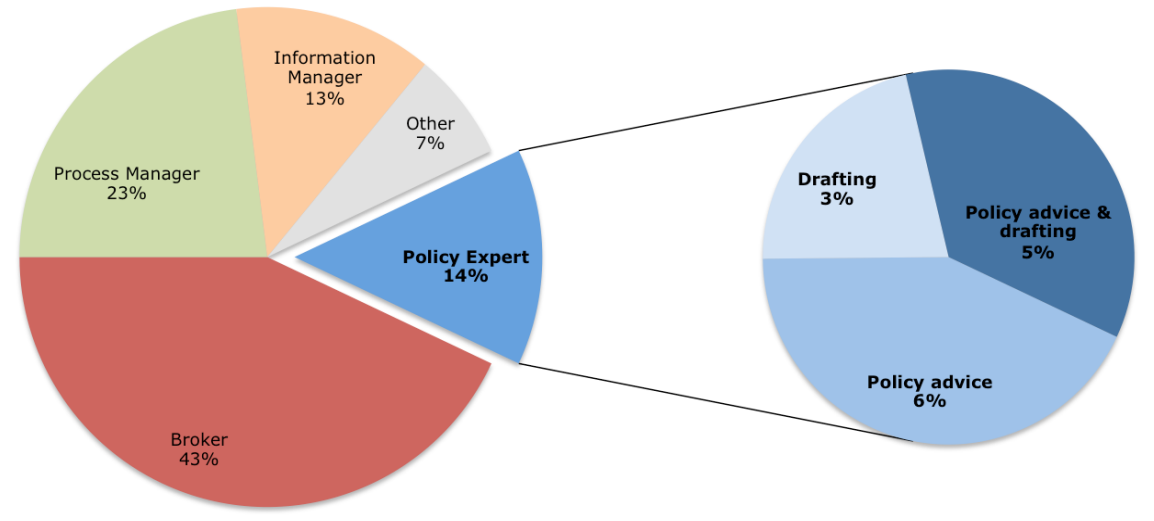

Figure 6.1.2b Relative importance attached to policy expertise

${ }^{109}$ Analysis open-ended SQ9: What is the most important task of a group advisor? See Appendix III. 
In conclusion, the empirical research finds that EP group advisors adopt the political Policy Expert role. They provide policy advice within the scope of one or several parliamentary committees and are involved in formulating positions. Both activities are further discussed below.

The provision of policy-related advice

Findings show that the provision of policy-specific advice is a common task for EP group advisors. Only one survey respondent and six interviewees did not bring up this type of advice as part of their role.

99 per cent of survey respondents claim that they provide 'specialist policy advice'. 47 per cent say to provide such advice on a daily basis, 42 per cent on a weekly basis, and 10 per cent on a monthly basis (see figure 6.1.2c). ${ }^{110}$ Survey respondents mostly relate policy expertise to knowledge of the respective topic or policy area. In response to the open-ended questions, 34 respondents identify substantive, contentrelated advice as part of their responsibility. ${ }^{111}$

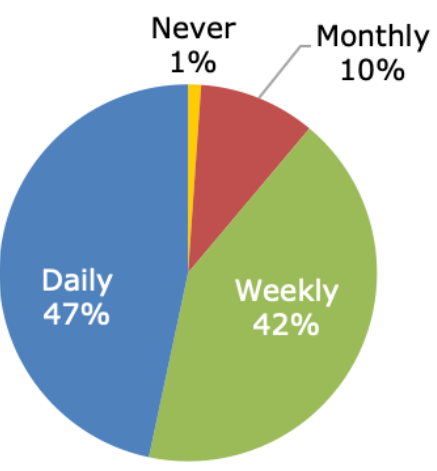

Figure 6.1.2c Providing specialist policy advice Most prominently, these are Greens/EFA and GUE/NGL advisors. In comparison, S\&D advisors hardly mention this type of advice.

The majority of interviewees also acknowledge the advisory element of their role. One ALDE and two EPP advisors stated that policy-related advice is mainly, but not exclusively, the domain of the MEP assistants. Six interviewees did not mention the provision of this type of advice at all. In

\footnotetext{
110 Analysis multiple-choice SQ7: Please estimate how much time you devote to the following activities. See Appendix III.

111 SR7, 9, 16, 18, 22, 24, 30, 40, 42-44, 46, 50, 51, 55, 57-61, 69, 70, 74, 79, 80, 82, $84,86,88,90,91,95,97,98$.
} 
this context it is important to note that particular attention was paid to not 'steering' advisors during the interviews. Open questions were asked without providing pre-fixed categories of activities. For this reason, it cannot be concluded that policy-related advice is not part of these advisors' activities simply based on the fact that they did not raise the activity.

14 interviewees indicate that they provide MEPs with briefings in which they evaluate policy options and their implications. Moreover, advisors make suggestions for alternatives that could be raised by the MEP. ${ }^{112}$ "Advisors have to have knowledge of the subject matter at hand. For legislative files we propose different alternatives to MEPs. The advisors prepare the political decisions. For consent on trade agreements we provide the MEP with arguments why the agreement is good or necessary and what the problems are" (I.9). Several interviewees break down their policy-advice role as pointing out to the MEP what is 'essential'. ${ }^{113}$ Others explain that they engage with external stakeholders to provide MEPs with pro and contra arguments for given policy options or alternatives. ${ }^{114}$

As was concluded above, the Greens/EFA advisors relatively ascribe most weight to policy-related advice. Those that were interviewed describe this advisory function at great length. Compared to their counterparts they are 'more free to develop policy' and 'have influence based on substance'. They for example prepare policy papers for internal purposes. One even claims that 'staff can be more knowledgeable than MEPs on specific issues as they have the time and role to specialise.' Interviewees from the other groups support this picture. An ALDE advisor claims that Greens advisors concentrate on policy rather than ideology 'by knowing all the details'. 'They leave the politics to the politicians', the advisor added. In line with these

\footnotetext{
112 I.0.1, 0.3, 0.4, 3, 5-9, 11, 14, 15, 19, 21.

113 I.3, 8, 20.

${ }^{114}$ I.9, 10, 14, 19, 21.
} 
remarks, an EPP interviewee noted that Greens/EFA advisors are more closely involved in the substance of files compared to their counterparts in the other groups.

The formulation of policy positions and legislative texts

The quantitative and qualitative data reveal that advisors contribute to the formulation of policy positions and legislative texts. 98 per cent of survey respondents claim that they are involved in the formulation of policy positions and legislative texts. 50 per cent say to engage in this activity weekly, 37 per cent monthly, and 11 per cent on a daily basis (see figure 6.1.2d). ${ }^{115}$ In response to the

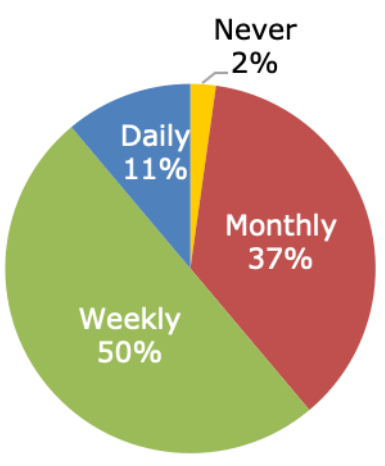

Figure 6.1.2d Drafting reports, opinions, resolutions, and amendments open-ended questions, five respondents mentioned the importance of drafting documents. Three even identify it as their most significant task. Drafting is related to formulating amendments (SR40, 91), group positions (SR80), or generally 'holding the pen for reports, resolutions, and speeches' (SR88). Another respondent claims that 'experience in drafting policy' is required to be an effective advisor (SR74).

The interview data convincingly illustrate advisors' involvement in the formulation of policy positions and legislative texts. 23 interviewees acknowledge a potential drafting role for EP group advisors. Ten of whom say they are (on occasion) responsible for drafting and finalising texts. All interviewed Greens/EFA advisors claim to engage in such activities, as well as two S\&D advisors, one ECR, and one GUE/NGL advisor. Two others state

\footnotetext{
115 Analysis multiple-choice SQ7 regarding the estimation of time spent on a series of activities. See Appendix III.
} 
they are closely involved in the process (ALDE and EFD). Six advisors affirm that they provide political input for texts (three EPP, two ALDE, and one $S \& D$ advisor). The role of the advisor is to propose changes to include the 'political accents' of the group, an EPP advisor states. Several interviewees underline that the MEP in charge decides who holds the pen. ${ }^{116}$ Depending on the MEP this may be the committee secretariat official, the group advisor, or the MEP assistant. An ALDE advisor explains that the rapporteur may ask the committee secretariat to prepare draft compromise amendments. This is 'a neutral draft', taking into account all the amendments and accommodating the different groups. Advisors and MEP assistants then take this draft as a starting point for adding 'the political message'. Finally, five interviewees claim that the committee secretariat officials write most of the texts (three EPP and two ALDE advisors).

In conclusion, the empirical research demonstrates that group advisors provide policy-specific advice and are involved in the formulation of positions and legislative texts. Findings reveal that the selection and interpretation of policy or decision options - e.g. in policy briefings - as well as the articulation of (political input for) policy options are common activities for EP group advisors. The political scope of these activities is discussed next.

\subsection{Assessment of the political scope of policy expertise}

The findings confirm that there are technical and political dimensions to policy expertise in the EP context, thus characterising it is a category of political advice. The previous section presented the empirical evidence for the adoption of the role and revealed that the Policy Expert role may involve

${ }^{116}$ I. $0.3,0.4,2,7,22$. 
the selection, interpretation, and articulation of policy or decision. This section evaluates the political scope of these activities. The extent to which the role is political is assessed with the use of the modes of discretion that have been developed as part of the analytical framework (see 2.1.3). The aim is to determine what guides the provision of policy expertise and explore advisors' discretion.

6.2.1 addresses the way in which advisors receive instructions from MEPs and how this input affects their role. Findings show that for policy-specific tasks they derive their mandate from the (assistants of the) elected representatives. If advisors primarily deal with the wishes of one MEP (EFD and GUE/NGL groups), the (implied) mandate is rather straightforward. The same applies to groups that have relatively aligned policy interests (ECR and Greens/EFA). In groups with multiple, possibly competing, policy views, however, the advisor's mandate is more elusive. 6.2.2 examines how advisors provide policy expertise in the absence of clear instructions. The findings show that in their efforts to achieve the desired outcome advisors are guided by their understanding of the priorities and interests at stake in the group. Nonetheless, advisors also perform policy tasks during the early stages of the decision-making process, i.e. ahead of group discussions or specific input from the MEP. It is therefore concluded in 6.2.3 that the Policy Expert role can be of a reactive or pro-active nature.

\subsubsection{Instructions and input from the MEP}

This sub-section sets out to determine the way in which advisors obtain instructions or input from the elected representatives for policy-related activities. The aim is to establish what essentially guides their advisory and drafting functions. From the quantitative and qualitative data it is concluded that group advisors work closely together with (shadow) rapporteurs and the group's coordinator of the parliamentary committee they are assigned 
to (see 4.2.1). Their explicit or implicit political instructions are therefore most likely to emanate from this interaction.

In discussing their discretion and the scope of their activities, interviewees overall subscribe to the fact that the MEP decides who provides support. The MEP decides 'how to organise the work'. The division is done ad hoc and the advisor's role further depends on the priorities set by the MEP. ${ }^{117}$ Drafting positions and legislative texts takes place in close coordination with the (shadow) rapporteur. Yet, the staff member who drafts the text is the most influential (I.7). A GUE/NGL interviewee explained that the mandate of advisors differs across the groups: "In the bigger groups there is a stronger collective interest. In GUE/NGL we deal with individuals". As is further discussed in chapter 7, advisors in the larger, or more heterogeneous groups, spend a lot of effort trying to internally coordinate the various views and develop a group line. In groups where advisors primarily deal with the wishes of one MEP, which is usually the case in the EFD and GUE/NGL groups, the (implied) mandate will thus be clearer. The same applies to the ECR and Greens/EFA since the policy interests in these groups are generally more aligned. ALDE, EPP and S\&D advisors have to take into account multiple, possibly competing, policy views. As a result, their mandate or instructions are more elusive.

Interviewees discuss the interplay between MEP assistants and group advisors. Mainly the ALDE and EPP advisors stress the importance of this cooperation. Assistants convey the views of their MEP and help the advisor understand how the MEP thinks. More broadly across the groups, interviewees agree that assistants promote the agenda of their MEP and safeguard that his or her wishes are followed. While advisors ensure that the formulated policy position can count on the support of the group. The

117 I. $0.3,0.4,2,7,11,15,19,22$. 
findings show that assistants can represent the MEP. The way in which MEP offices operate obviously varies but it is common for advisors - either in addition to or instead of conferring with the member - to directly liaise with assistants and acquire their mandate in this way.

From the interviews and remarks made by the survey respondents, it appears that advisors consider substantive advice - related to details of policy issues and their implications - as a technical task. "Substantive advice is a more academic, technical role of the advisor" (I.3). This type of activity requires some form of specialisation. "It is essential to be or become an expert on the policy area that you are working on" (SR7). Nonetheless, they recognise the significance of having room for manoeuvre when it concerns dossiers of a highly 'technical nature' as they cannot be instructed by an MEP who knows less or as little as they do on the issue $(I .4,13)$. This autonomy for the advisor is not exclusively the case for the Policy Expert role.

An ECR interviewee put forward that in the Greens/EFA and ECR groups, advisors are led by the technical content of the file. "It is always quite clear in our politics where we would like things to go." The advisor adds that 'expertise' is sometimes lacking in the larger groups. EPP or S\&D advisors have less freedom to develop a policy line and are 'more directed by what is decided in the Working Group structure'. Greens/EFA interviewees accede to being granted a large degree of autonomy in their Policy Expert role. They are or become experts on the policy areas in which they advise MEPs. We can provide 'instant input', one interviewee explains, tying this to the lack of internal division that allows the advisor 'a certain leverage' toward other actors in the EP. Another Greens/EFA advisor adds that they can 'easily guarantee the support of the group' and that advisors from the bigger groups 'have to be cautious'. 
These accounts provide further evidence that the mandate of ALDE, EPP and S\&D advisors is less straightforward, restricting their autonomy to substantively shape policy. Conversely, Greens/EFA advisors are able to pro-actively contribute to or develop policy lines, as the desired policy outcome of the group is more coherent. One Greens/EFA interviewee laments this independence and considers the 'inadequate knowledge and involvement of MEPs' a problem for democracy: "If you ask me whether I like the autonomy in my role, I would tell you no. I would prefer my deputy to be active and discuss with me rather than do it myself. We need input from those elected. Other advisors might be jealous, but I feel it is not the way it should be."

\subsubsection{Improvisation by the advisor}

The discussion above concluded that the mandate differs between groups. Advisors have more room for manoeuvre as the group's policy positions are more aligned. This sub-section addresses group advisors' level of improvisation in the Policy Expert role. Improvisation is construed as value or ideological appraisals by the advisor, the anticipation of priorities or objectives, or the use of implicit knowledge or tactics (see the definition of political advice in 2.1.2). The empirical research revealed that group advisors fulfil the political dimensions of the Expert role (see 6.1). The selection and interpretation of policy or decision options - e.g. in policy briefings - as well as the articulation of (political input for) policy options are further addressed below.

The research reveals that advisors weigh and present policy options. These activities by definition require the advisor's judgement with regard to the desired outcome or the (importance of) implications of certain policy 
options. 92 per cent of survey respondents admit that they weigh and present policy options (see figure 6.2.2). ${ }^{118}$

As was presented in 6.1.2, the large majority of interviewees say they prepare briefings in which they evaluate the policy options and possible implications. This then raises the question what such judgement is based on. In the previous sub-section it was found that, generally speaking, either

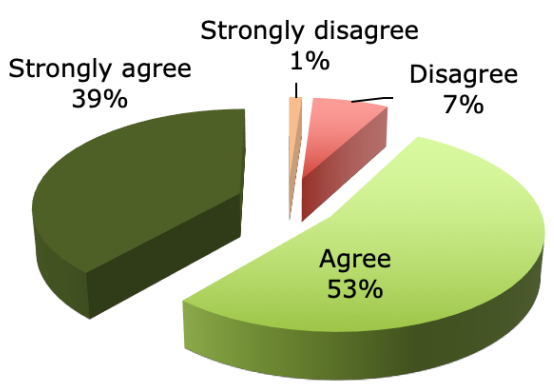

Figure 6.2.2 Weighing and presenting policy options the agenda of the MEP in charge or that of the group guides advisors' policy advice and formulation. Advisors provide policy-specific advice and formulate positions or texts linked to the values of the political group. Throughout these activities not only the mandate but also the level of improvisation varies. In a more reactive role, the advisor bases the formulation of (legislative) texts on group debates or decisions and ensures that the group's positions are represented in the parliamentary text (SR25). Alternatively, the advisor's input may be based on a discussion within the parliamentary committee, shadows' meeting, or on the specific input from the MEP in charge. In these cases the advisor 'listens' carefully to the members and 'summarises' (SR43, 46, 92) or 'synthesises' (SR49, 73) the different views.

More examples, however, were encountered of a pro-active way of weighing and presenting policy options. This for example entails pointing out the most 'important elements' of the proposal to MEPs (SR39, 99). Displaying even more initiative, eight survey respondents claim that explaining and

118 See Appendix III, analysis multiple-choice SQ10: To what extent do you agree with the following statements? 
arguing for a specific policy choice or decision is part of their role. Four of these advisors are employed by the Greens/EFA, three by the ALDE, and one by the ECR. The interview findings confirm that most notably Greens/EFA advisors have the room to show a high degree of initiative in shaping policy choices and decisions of the group. In this regard, 6.2.1 concluded that advisors have more room for improvisation as the group's interests are more aligned. This appears to be tied to their ability to identify and thus represent the collective interests of the group.

For the formulation of policy positions or legislative texts advisors may derive their mandate from group debates, input provided by the MEPs, or from the personal assistants. Alternatively, advisors base their input on the (expert) knowledge they possess or acquire through a third (expert) source. The latter demands a selective approach with regard to the sources of expertise and the advisor's interpretation of the provided expertise. These information management activities are presented in chapter 5 . The way in which the acquired input is subsequently transformed into policy advice or texts involves improvisation by the advisor. Such improvisation requires the ability of relating the (acquired) expertise to the group's political priorities $(S R 7,55)$. In this respect, it is crucial that the advisor is able to anticipate what is (and is not) acceptable to the members of the Group (I.2).

In addition to applying judgement, evidence was encountered that advisors pro-actively offer input that has the potential to shape the policy or legislative outcome. In both the survey remarks and interviews, advisors indicate that they add the political message to (legislative) texts. ${ }^{119}$ They may do so by 'translating technical information into a clear political

\footnotetext{
${ }^{119}$ In response to open-ended questions about their key responsibilities, eight survey respondents refer to being responsible for adding the political message to (legislative) texts: SR7, 9, 15, 22, 34, 61, 97, 98. Out of the 23 interviewees that see a potential drafting role for the advisor, six refer to providing this type of political input.
} 
message' (I.14), dotting the 'political i's' (I.1), or by proposing changes to include the 'political accents' of the group (I.2). Another way in which advisors contribute to EP decisions is by promoting new ideas and proposing policy alternatives (SR25, 54, 69, 85). The majority of interviewees say they provide such input through policy briefings (see 6.1.2). Two of them (ALDE and S\&D advisors) stressed that advisors can be very influential in such contributions.

Advisors can also be 'influential through drafting amendments'. Negotiations on legislative files are compromise-oriented and 'each amendment is considered' (I.13). Several survey respondents included remarks about their ability to articulate policy options on behalf of the group. ${ }^{120}$ Two claim to 'shape' policy outcomes in this manner: "Often, there are no group policies yet but you are shaping new policies by building up your own mind, and convincing your MEPs" (SR47). Another commented that the most important responsibility of the advisor is to 'shape the group's profile in the policy field' (SR98). Examples illustrating a more cautious approach are encountered too. One respondent, for example, underlined that advisors should 'have the support of the hierarchy and members to form a policy' (SR31).

Finally, advisors employ tactics in the Policy Expert role to secure the best possible outcome for their group. Working towards a compromise policy outcome, advisors may be involved in the tabling of various amendments for different MEPs within the group: "If you table both amendments you can do it in such a way that you make sure that you can work on a compromise amendment later" (I.22). As part of the Broker role, advisors then anticipate the likelihood that amendments may carry a majority (see chapter 7 ). Such political analysis facilitates the Policy Expert role in that it allows them to

${ }^{120}$ In particular SR20, 23, 47, 88, and 98. 
assess what is necessary for the adoption of the proposed texts. "We help the adoption in committee or plenary by making the text more consensual" (I.22).

The analysis shows that the desired outcome can be derived from views expressed by the elected actors. However, advisors also perform policy tasks during the early stages of the decision-making process, i.e. ahead of group discussions or specific input from the MEPs. The findings show that in their efforts to achieve the desired outcome advisors are guided by their understanding of the priorities and interests at stake in the group. The next sub-section discusses what this means for the political scope of the various information management tasks.

\subsubsection{Policy expertise as a category of political advice}

The empirical research revealed that EP group advisors fulfil the political dimensions of the role. No evidence has been encountered of purely technical tasks, as the Policy Expert's activities require at least some level of improvisation. Yet, the technical dimensions - inventory and summary of policy options - do form part of the activities and feed into the political advice category. The framework conceptualises political advice as a mixed sphere where technical and political activities meet. The findings presented in this chapter thus corroborate policy expertise as a category of political advice composed of both technical and political elements. The combination of tasks is also acknowledged among those advisors included in the survey and interviews. Referring to policy advice, one interviewee for example stated that advisors should have a 'deep knowledge of the politics and technicalities of each dossier' (SR92).

To assess the political scope of the role, the framework conceptualised three incremental modes of political advice tied to the discretion of the advisor: 
routine, reactive, and pro-active behaviour. The role becomes more proactive as the advisor's room for improvisation increases. In the context of policy expertise the routine mode is interpreted as follows: a situation in which the policy outcome and the means to achieve this outcome are instructed or clearly implied. Whereas the analysis shows that the advisor may receive input from MEPs or derive input from political debates, the realisation of the desired outcome is generally open to interpretation and thus requires at least a certain level of improvisation. It is therefore concluded that the Policy Expert role can be of a reactive or pro-active nature.

Figure 6.2.3 illustrates the key features of the Policy Expert role as found from the empirical research:

$\checkmark$ Advisors present MEPs with policy advice. They take stock and summarise the various policy options in briefings, for which they select the most important issues and interpret the respective implications. The input is of a reactive nature when advisors are guided by their understanding of the priorities and interests at stake in the group. In addition, advisors pro-actively argue for specific policy choices.

$\checkmark$ Advisors have the ability to provide input for the formulation of policy options. Their contribution can be reactive when based on the direct or indirect input from MEPs. It becomes of a pro-active nature when the advisor constructs policy options from personal or third-party expert knowledge.

$\checkmark$ Related but going even further, advisors may have the autonomy to develop policy positions. This activity would take place very early in the decision-making process, prior to any political discussions on the policy issue in question. Such a role is most likely to be adopted by 
Greens/EFA advisors, and least likely to be adopted by ALDE, EPP, and S\&D advisors.
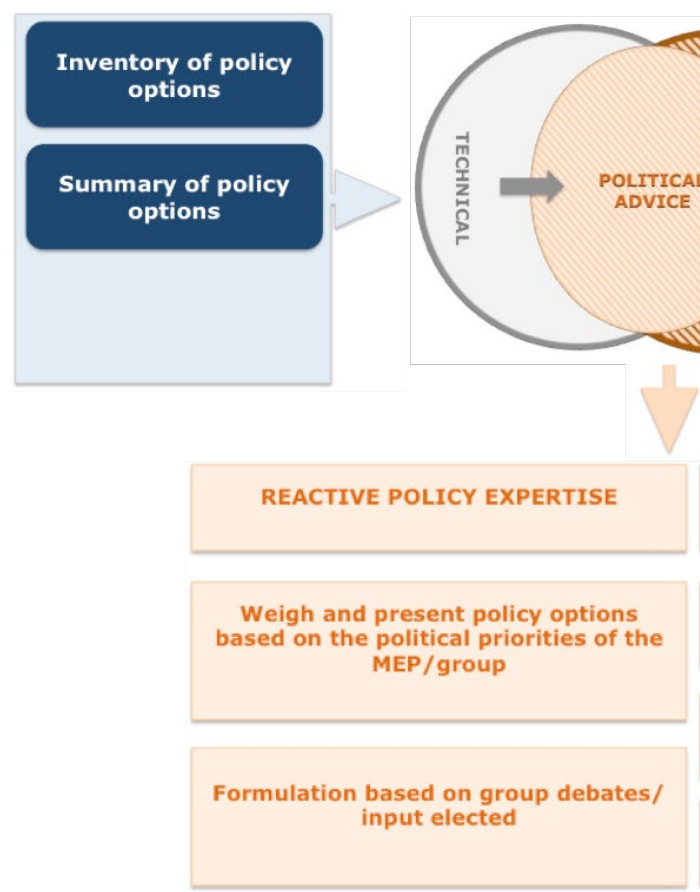

Selection of policy options

Interpretation of policy options

Articulation of policy options

Figure 6.2.3 Empirical findings: policy expertise as a category of political advice

\subsection{Impact of the factors on policy expertise}

The aim of the thesis is to explore and explain the circumstances that stimulate or restrict a political role by group advisors. Drawing on the literature, a set of factors is expected to affect the adoption of the Policy Expert role (see 2.3). As a third and final step of the analysis, this section consecutively evaluates each of the personal (6.3.1) and contextual factors (6.3.2) by presenting evidence from the survey and interviews. It is found that in particular trust and political sensitivity are necessary for the fulfilment of the political dimensions of the role. The findings furthermore 
show that advisors' pro-active behaviour is stimulated by the complexity of files. However, such behaviour is restricted in politicised legislative files.

\subsubsection{Personal factors}

The analytical framework proposes four personal factors that facilitate proactive behaviour. This sub-section presents the assessment of these factors in relation to policy expertise and in light of the empirical data. The findings reveal that trust and political sensitivity are necessary for the adoption of a pro-active Policy Expert role. The advisor's internal network facilitates the construction of their mandate whereas external networks allow for the acquirement of outside expert knowledge. Institutional memory may facilitate the role and appears to be an indispensable attribute for the shaping of policy positions.

\section{Trust}

In the analytical framework trust is linked to knowledge of and affinity with party ideology and priorities (see 2.3.1). A trusted working relationship with the MEP in charge and his/her office enables advisors to obtain their mandate for the reactive Policy Expert role. Trust is indispensable for an effective pro-active role as it forms the basis for the advice to be followed or the input to be 'accepted'.

23 advisors underline that the trust of the MEP - the political coordinator or (shadow) rapporteur - has a positive effect on the Policy Expert role. ${ }^{121}$ To develop or contribute to the articulation of policy positions, trust is a prerequisite. Trust increases when the advisor and MEP have shared (policy) affinities (I.22). And if you do not agree with the views of the MEP it is difficult to put forward your ideas $(1.4,17)$. The MEP in charge decides who

${ }^{121}$ I. $0.4,3-5,7-10,13,15-18,22 ;$ SR25, 38, 39, 40, 46, 52, 60, 61, 83. 
drafts: "This is a matter of trust, confidence, expertise, and experience" (I.0.4). The interview data show that a high level of trust can result in the advisor drafting amendments on behalf of the MEP without having to consult with them first $(I .7,16,22)$.

The extent to which the advice or input is 'accepted' depends on trust. Trust results from the previous contributions by the advisor and the demonstrated level of expertise. 12 advisors stress the importance of their reliability and reputation in this sense. ${ }^{122}$ However, views vary about what exactly amounts to trust. Two S\&D interviewees explain that it is critical to take an objective approach and not favour, or 'push for', specific positions or delegations as this will 'harm the credibility of the advisor'. Alternatively, several advisors put forward that it is essential that MEPs have 'confidence' in their work and their expertise, which can also be considered a form of trust. Finally, having the 'appropriate' political background also invokes trust $(\mathrm{I} .13,17)$.

One interviewee sums up the overall importance of trust as follows: "You will be appreciated and can do your job if the MEPs and assistants feel that they can trust you" (I.5). In both the accounts of survey respondents and interviewees, cooperation with MEP assistants is tied to trust. The analysis of advisors' instructions showed that their mandate can indirectly follow from this interaction (see 6.2.1). 19 interviewees claim that a trusted working relationship with assistants affects their role. ${ }^{123}$ Trust does not necessarily imply a personal relationship between the group advisor and the member. "Sometimes you hardly have any contact but the MEP hears from the assistant how you are working. Simply letting you do your work is also a sign of trust" (I.18).

122 I. $0.3,0.4,5,10,13,15,17 ;$ SR39, 40, 57, 58, 74.

${ }^{123}$ I. $0.1-0.5,1-5,9-11,15-19,21$ 


\section{Informal network}

The framework conceptualises an informal network as the access to and exchange of private information through informal interactions with actors in and outside the institution (see 2.3.1). For policy expertise the relevance of the internal network of advisors is tied to their ability to acquire input. As discussed above, their relationship with MEP assistants is crucial to gain insight into the views and priorities of the MEPs. Advisors' external networks are important for acquiring expert or specialist knowledge from third parties. It is found that the factor may facilitate the advisory and drafting functions of the Policy Expert role. However, no evidence was encountered that informal networks are a pre-condition for the adoption of a political role.

The way in which advisors gather and process information from external stakeholders is discussed in chapter 5 . It was found that information serves an auxiliary function and forms the basis for the adoption of the Policy Expert. Advisors set out to obtain knowledge about the content or implications of a given file, which can be used to provide policy-specific advice or for the formulation of positions or legislative texts. Interviewees acknowledge that they approach external specialists to 'find expertise' that the MEP (or advisor) does not possess (I.4). Several survey respondents underline the value of acquiring 'expert knowledge' from external stakeholders to analyse the 'in-depth substance' of policy proposals (SR60, 79). Finally, the importance of keeping close ties 'in the field' (SR51) is related to staying 'up-to-date' on the relevant policy developments (SR97). This is achieved through the interaction with external academia and NGO actors 'who hold specialist knowledge' (SR55).

The degree to which advisors are allowed or inclined to meet with external stakeholders determines the effectiveness of their networks. The 
aggregated survey data reveal that advisors are in touch with external stakeholders on a regular basis (see chapter 5 , table 5.1 ). The policy area in question most prominently determines the external networks of advisors, i.e. the parliamentary committee they support $(1.10,16,21)$.

\section{Institutional memory}

Institutional memory is conceptualised as the insight into - and access to the institutional track record (see 2.3.1). In the EP context, this factor is interpreted as knowledge of the functioning of the institution (formal and informal rules) and an appreciation of the political group's (previous) positions. Mainly the latter is significant in terms of policy expertise. One interviewee explains the importance in connection with the mobility of advisors: when advisors leave or change parliamentary committee the existing knowledge and expertise deteriorates and 'the collective memory disappears, which is problematic' (I.1).

Across the EP party groups, survey respondents acknowledged the importance of appreciating the group's (previous) positions. Awareness and understanding of the group position can form the foundation of the advisor's mandate, thus facilitating the reactive Policy Expert role. In response to the open-ended survey question what characterises an excellent advisor, 28 respondents put forward that this is related to understanding the group's position. ${ }^{124}$ To effectively fulfil the responsibilities of an advisor, it is necessary 'to relate expertise or specialist knowledge of the policy area' to the general group line (SR75). Such an understanding may furthermore improve the consistency of policy-making (SR3).

${ }^{124}$ SR: 7 ALDE, 7 Greens/EFA, 4 ECR, 3 GUE/NGL, 3 EPP, 3 S\&D, 1 EFD. 
The empirical research demonstrated that the uniformity of the advisor's (implied) mandate affects the political scope (see 6.2.1). ALDE, EPP, and S\&D advisors are less likely to adopt a pro-active Policy Expert role due to the multitude and possibly conflicting policy interests lying at the basis of their mandate. Conversely, Greens/EFA advisors enjoy the largest degree of autonomy to contribute to or develop policy options. From these findings the conclusion is drawn that the appreciation of the group's position is indispensable for shaping policy outcomes.

\section{Political sensitivity}

The analytical framework conceptualises political sensitivity as the understanding of the institution's informal code of conduct and the ability to recognise political and administrative cues (see 2.3.1). In relation to policy expertise, the factor allows advisors to anticipate what policy options are acceptable or have priority, and how to accordingly formulate positions or legislative texts.

Advisors' remarks in the survey and during the interviews show that they consider it their role to judge what is in the best interest of the group. ${ }^{125} 14$ advisors explicitly point to the need for sensitivity in relation to what is 'acceptable' to the members or national delegations. ${ }^{126}$ Effective advisors 'intuitively feel' what the group position should be (SR29). Such 'political competence' (SR15) facilitates both the reactive and pro-active Policy Expert role in that it enables advisors to construct their mandate and empowers them to improvise.

For the articulation of policy options the 'skill of political presentation' matters. As one interviewee put it: "It is important that the advisor chooses the right language and tone" (I.2). This activity forms part of the

\footnotetext{
125 Notably I.0.1-04, 1, 4 and SR9.

${ }^{126}$ I.2, 3, 8, 11, 13, 17, 19, 22; SR9, 10, 15, 17, 24, 29.
} 
presentation function of the Information Manager role and is further addressed in chapter 5 . Political sensitivity in this regard is pertinent for the advisor's autonomy to improvise and will determine whether or not the proposed policy options are in fact embraced by the group.

Assessment of the personal factors

The analytical framework proposes that the personal factors affect the advisor's discretion and their ability to adopt a political role. They are used to assess the (optimal) circumstances in which political advice may be provided. The impact of the factors on the adoption of the Policy Expert role is qualitatively evaluated by attributing the following values: indispensable $(++)$, positive impact $(+)$, no impact/ not relevant $(0)$, or a negative impact $(-)$.

It is found that trust and political sensitivity are necessary for the pro-active provision of policy expertise. The advisor's internal network facilitates the construction of their mandate whereas external networks allow for the acquirement of outside expert knowledge. Institutional memory may facilitate the role and appears to be an indispensable attribute for the shaping of policy positions. Table 6.3.1 illustrates the outcomes of the analysis. 
Table 6.3.1 Personal factor assessment for the adoption of the Policy Expert role

\begin{tabular}{|c|c|c|c|c|}
\hline & Trust & $\begin{array}{l}\text { Informal } \\
\text { network }\end{array}$ & $\begin{array}{c}\text { Institutional } \\
\text { memory }\end{array}$ & $\begin{array}{c}\text { Political } \\
\text { sensitivity }\end{array}$ \\
\hline \multicolumn{5}{|c|}{ REACTIVE POLICY EXPERT } \\
\hline $\begin{array}{l}\text { Weigh and present } \\
\text { policy options }\end{array}$ & + & + & + & + \\
\hline $\begin{array}{l}\text { Formulation based on } \\
\text { (indirect) input from the } \\
\text { MEP }\end{array}$ & + & + & + & + \\
\hline \multicolumn{5}{|c|}{ PRO-ACTIVE POLICY EXPERT } \\
\hline $\begin{array}{l}\text { Argue for specific policy } \\
\text { choices or decisions }\end{array}$ & ++ & 0 & + & ++ \\
\hline $\begin{array}{l}\text { Formulation based on } \\
\text { (third-party) expert } \\
\text { knowledge }\end{array}$ & ++ & + & + & ++ \\
\hline Shape policy positions & ++ & 0 & ++ & ++ \\
\hline
\end{tabular}

\subsubsection{Contextual factors}

Three contextual factors are expected to affect delegation and trigger potential differences across the groups, committees, policy domains, or specific files: political direction, complexity, and politicisation. Below these factors are assessed based on the empirical research. It is found that the homogeneity or heterogeneity of the group has an important impact on the advisor's role. Political division in the group, for example, negatively affects the extent to which advisors are able to derive political guidance for their activities. For complex, substance-related details of policy issues and their potential implications, advisors are more likely to adopt a pro-active role. 
Advisors enjoy considerable discretion to contribute to or develop nonlegislative policy options or political resolutions. Yet, their advisory and drafting functions are restricted in legislative files. Finally, advisors' leeway in fulfilling the drafting function increases in (controversial) dossiers that generate a high number of amendments.

\section{Political direction}

The analytical framework defines political direction in relation to the position of the MEP or group: advisors' ability to identify political cues to guide their behaviour depends on the extent to which the MEP in charge or the group they represent is outspoken and reputed (see 2.3.2). The idea is that the clearer advisors' political direction is, the more likely they are to assume a political role.

Advisors construct political direction from their appreciation of the position(s) and ideological principles of the political group. The homogeneity or heterogeneity of the group has an impact on the advisor's role. Yet, for a specific policy direction group advisors turn to the MEP in charge. The findings show that the reputation or position of the MEP may reflect on the advisor. ${ }^{127}$ More importantly, the involvement of the MEP in charge affects the advisor's mandate and room for improvisation. First of all, a clear group line depends on the MEP who should internally defend the position and stimulate discussion in the group (I.12). "There has to be a participatory process of building up a position and this can only be effective if the deputies are active in committee and in the group" (I.12). From the qualitative data, it is inferred that political direction related to the active involvement of MEPs facilitates the mandate of the group advisor. Conversely, such active involvement will restrict the advisor's autonomy (I.22). It is found that the

127 I. 3, 12, 17; SR23, 53. 
attention and involvement of MEPs is greater in legislative files (see 5.3.2). Consequently, advisors will have more room to contribute to or develop policy options that are of a non-legislative nature.

\section{Complexity}

In the framework complexity is defined in relation to the subject matter and thus expected to vary across parliamentary committees or specific policy or legislative proposals (see 2.3.2). From the literature the assumption is drawn that as 'complexity' increases MEPs are more likely to seek assistance and grant advisors a political role.

The survey and interview data suggest that activities concerning the details of policy issues and their implications are considered technical or complex tasks. In discussing their policy-related activities, respondents and interviewees do not point out that the level of complexity may be higher is certain policy areas. Moreover, 'policy expertise' is perceived as a form of (existing or acquired) 'specialisation' by the advisor for which MEPs may not have the time. This is for example illustrated by the value advisors attach to having expertise in a specific policy area (see 6.1.2).

Advisors have significant autonomy when it concerns dossiers of a highly 'technical nature' as they cannot be instructed by an MEP who knows less or as little as they do on the issue $(1.4,12,13)$. The factor thus stimulates the reactive and pro-active Policy Expert role.

\section{Politicisation}

The framework conceptualises politicisation in relation to division in the EP, in general or with regard to a specific dossier (see 2.3.2). It is therefore defined as something that may change over time and vary across policy 
areas. Based on the theory, politicisation is expected to restrict the advisor's role.

On issues that are non-controversial, for example receiving little or no media attention, MEPs may be less interested $(I .4,7,11,12,18)$. This gives advisors more 'leeway to dive into the details' of the file (I.7). These accounts suggest that advisors' contribution decreases in controversial, salient files due to a stronger intervention by the MEPs. It is therefore concluded that in politicised files advisors are less likely to provide policy advice.

In respect of advisors' drafting role, other circumstances have to be factored in to conclusively determine the impact of politicisation on policy expertise. It is found that advisors are allowed considerable discretion in drafting political resolutions (I.11, 15, 20, 21). In general, these texts reflect ideological messages that are accompanied by clear polarisation in the EP. The (potential) involvement of the advisor in drafting such political messages is higher than in legislative texts because MEPs are less inclined to delegate 'political work' to officials in the committee secretariats (I.20, 21). Advisors' role also increases on files for which many amendments are submitted (I.1). In such cases there is a need for redrafting of (compromise) amendments and for ensuring coherence among the amendments submitted or supported by the group. In summary, the advisor's ability to formulate policy options is most notably found in political resolutions and in dossiers that generate a high number of amendments. Conversely, this contribution of advisors is restricted in legislative files.

Assessment of the contextual factors

As derived from the literature, the context affects delegation. To assess the (optimal) circumstances in which political advice may be acceptable to MEPs 
the impact of the factors is evaluated by attributing the following values: indispensable $(++)$, positive impact $(+)$, no impact/ not relevant $(0)$, or a negative impact $(-)$. From the empirical research it is found that advisors' pro-active behaviour is stimulated by the complexity of files. Political direction may provide advisors' mandate and reactive role. Yet, their autonomy is restricted by the active involvement of MEPs. In politicised legislative files the acceptance of policy advice as well as advisors' ability to contribute to the formulation of policy positions is restricted. Yet, their drafting function is more prominent in political resolutions and in (controversial) dossiers that generate a high number of amendments.

Table 6.3.2 Contextual factor assessment for the adoption of the Policy Expert role

\begin{tabular}{|l|c|c|c|}
\hline & $\begin{array}{l}\text { Political } \\
\text { direction }\end{array}$ & Complexity & Politicisation \\
\hline REACTIVE POLICY EXPERT & + & + & - \\
\hline $\begin{array}{l}\text { Weigh and present policy } \\
\text { options }\end{array}$ & + & + & $+/-$ \\
\hline $\begin{array}{l}\text { Formulation based on } \\
\text { (indirect) input from the MEP }\end{array}$ & + & + & - \\
\hline $\begin{array}{l}\text { PRO-ACTIVE POLICY EXPERT } \\
\text { Argue for specific policy } \\
\text { choices or decisions }\end{array}$ & - & + & $+/-$ \\
\hline $\begin{array}{l}\text { Formulation based on (third- } \\
\text { party) expert knowledge }\end{array}$ & - & + & $+/-$ \\
\hline Shape policy positions & - & & \\
\hline
\end{tabular}




\subsection{Concluding remarks}

The findings demonstrate that policy expertise is generally perceived as an important asset, instrumental to the role of the advisor. Nonetheless, the provision of expertise does not constitute advisors' most important task. Although the Greens/EFA advisors form the exception in this regard, it can be concluded that for the other advisors policy expertise - like information - serves a secondary function. The empirical analysis presented in this chapter confirms that policy expertise can be characterised as a category of political advice. The findings demonstrate that EP group advisors adopt the Policy Expert role and that the role indeed involves both technical and political tasks. Within the scope of one or several parliamentary committees, they provide policy-specific advice and are involved in the formulation of positions and legislative texts. Advisors for example take stock and summarise the various policy options in briefings, for which they select the most important issues and interpret the respective implications. The technical and political aspects of their role thus take place in tandem.

Findings show that when adopting the Policy Expert role, advisors are guided by their understanding of the priorities and interests at stake in the group, or by the direct or indirect input from MEPs. The mandate of advisors and their capacity to improvise differs across the groups. It is relatively easy to construct a mandate for advisors who primarily deal with the wishes of one MEP (EFD and GUE/NGL groups), or who are employed by groups with (fairly) aligned policy interests (ECR and Greens/EFA). Conversely, in groups that have to take into account multiple, possibly competing, policy views the advisor's mandate is more elusive (ALDE, EPP, and S\&D). This heterogeneity negatively affects the extent to which advisors are able to derive political guidance for their activities. 
Whereas the analysis shows that advisors may receive input from MEPs, derive input from political debates or via MEP assistants, the realisation of the desired outcome is generally open to interpretation. It is therefore concluded that the Policy Expert role requires at least a certain level of improvisation and can therefore be of a reactive or pro-active nature. In addition, the data reveals that advisors provide input during the early stages of the decision-making process, i.e. ahead of group discussions or specific input from the elected representatives. Such a pro-active role is most likely to be adopted by Greens/EFA advisors, and least likely to be adopted by ALDE, EPP, and S\&D advisors. Nonetheless, other forms of proactive behaviour are encountered across the groups. Advisors may for example argue for specific policy choices, trying to convince MEPs (proactive advice). Or they may construct policy options from their personal or from acquired expert knowledge (pro-active formulation).

Finally, the assessment of the factors concludes that trust and political sensitivity are necessary for the fulfilment of the political dimensions of the role. Political sensitivity allows advisors to anticipate what policy options are acceptable or have priority and only the input from 'trusted advisors' is accepted by MEPs. It is furthermore found that advisors' pro-active behaviour is stimulated by the complexity of files. However, their autonomy reduces in politicised legislative files. Policy advice is then less likely to be accepted by MEPs and advisors' ability to contribute to the formulation of policy positions is restricted. Yet, their drafting function is found to notably increase in political resolutions and in (controversial) dossiers that generate a high number of amendments. MEPs are more inclined to delegate such political work to group advisors over, for example, committee secretariat officials. On the contrary, files of a legislative nature are often perceived as more technical due to the compromise-oriented style of decision-making in the EP. In these types of files EP officials may fulfil the drafting function. 




\section{CHAPTER 7. BROKER}

The analytical framework conceptualised four roles that advisors may adopt, each potentially containing a political dimension. The dissertation applies the theoretical concepts to the specific case of group advisors in the European Parliament (EP) and this chapter presents the analysis of the Broker role. The ideal-type role comprises two central functions: facilitation of compromises and (2) coordination of political positions within and between the groups. To address the research question 'under which conditions can advisors adopt a political role' three analytical steps are carried out.

The first step is to assess whether the functions of the ideal-type role are fulfilled by group advisors and what they entail in practice. ${ }^{128} 7.1 .1$ lays down the theoretical technical and political dimensions of brokering. It furthermore infers expectations with regard to the adoption of the role from the literature review (see introduction) and the performed document analysis. Subsequently, the empirical research is presented in 7.1.2. The findings show that group advisors assume the facilitation and coordination functions of the Broker role and that their activities contain technical and political elements. The role is found to go beyond the conceptualised scope in that advisors may actually replace the MEP in charge in intra- and intergroup coordination. Compared to the other groups, intra-group brokering is considered to be more important to ALDE, EPP, and S\&D advisors.

The second step of the analysis is to examine the political scope of the Broker role, based on the three modes of discretion that have been

\footnotetext{
128 The political group advisors assigned to follow the work of one or several of the parliamentary committees are the focus of this study. Throughout the analysis 'advisors' or 'political advisors' refers to this type of advisors in the context of the European Parliament.
} 
developed as part of the analytical framework. Section 7.2 assesses the discretion granted to the advisor in brokering activities. This is approached by on the one hand examining the extent to which advisors receive instructions or input from the elected representatives (7.2.1), and on the other hand, the need and their capacity to improvise (7.2.2). The empirical research shows that improvisation is a coping strategy and requires advisors to assess the necessary or appropriate course of action in light of the group's ideological views. It is therefore concluded that the Broker role is predominantly pro-active, with the exception of advisors' participation in the inter-institutional negotiations, which is bound by the strict and fragile mandate of the EP negotiating team and thus of a routine nature.

Thirdly and finally, the impact of the personal and contextual factors on the adoption of the role is evaluated (7.3). The analysis concludes that trust and political sensitivity are indispensable for the adoption of a pro-active Broker role. These attributes, combined with a context where advisors work on a file or a specific text that is not highly politicised in the EP, prove to be the optimal conditions for advisors to pro-actively engage in brokering.

\subsection{The nature of brokering in the EP}

This section analyses the brokering activities of EP political groups' advisors. First, the theoretical dimensions are explored (6.1.1). Drawing on the literature, the technical and political tasks of brokering are extrapolated. The ideal-type role comprises two central functions: (1) facilitation of compromises and (2) coordination of political positions within and between the groups. The latter entails intra- and inter-group coordination efforts. These elements are explored and related to the document analysis on the profile and duties of EP group advisors in order to infer expectations regarding the adoption of the role (see 3.3.3). 
Subsequently, 7.1.2 presents the empirical findings for the Broker role. The theoretical expectations regarding the role are assessed in light of the collected survey and interview data. The analysis concludes that group advisors fulfil both functions of the Broker role, yet the coordination function is considered key.

\subsubsection{Theoretical dimensions of brokering}

From the scholarly debate on the role of non-elected actors, a series of expectations about the brokering activities of advisors can be inferred (see 3.2.2). Brokering has been conceptualised in relation to legislators' need for a mediating function on their behalf. In different contexts the literature has supported the notion of such a role for officials. Advisors can provide internal and external political coordination by organising support for political positions (Burks and Cole, 1978). They serve as a strategic channel of communication through which preparatory negotiations can take place that form the basis of a compromise later reached at political level (cf. Fouilleux et al, 2005; Peters, 2009; Romanyshyn and Neuhold, 2013). Moreover, staff can facilitate compromises by providing advice on negotiation strategies (cf. Patterson, 1970; Christiansen, 2002; Provan in: Neunreither, 2002; Högenauer and Neuhold, 2015). The brokering concept thus contains a coordinating and a facilitating aspect that both can apply to intra-group and inter-group negotiations in the EP.

In the EP, the common working method to define a group's position involves a process of internal deliberations between the group's leadership, political coordinator of the committee responsible, and usually the leaders of the national delegations (Corbett et al, 2011: 121). Previous studies have shown voting behaviour to become increasingly structured and party group cohesion to strengthen (Hix et al, 2007; Kreppel, 2002; McElroy and Benoit, 2012). Research by VoteWatch Europe - examining roll call votes between 
2004 and 2014 - shows that EPP, S\&D, ALDE and the Greens/EFA all have over 90 per cent cohesion (Corbett et al, 2011). Ideally, intra-group coordination is a consensual process during which the specific interests and sensitivities within a group are weighed and aligned, resulting in a 'group line' that on the whole is acceptable to most members (Corbett et al, 2011). The desk research regarding advisors' required profile and job description revealed that they are expected to safeguard the group's overall objectives and to preserve consistency between past and future positions (see 3.3.4). Relating this responsibility to both the practice of consensual coordination and the conceptualisation of brokering raises the expectation that group advisors coordinate and facilitate positions within the political group. EFD has the lowest group cohesion, namely 47 per cent (Corbett et al, 2011). For that reason, EFD advisors are expected to form an exception and not, or to a significantly lesser extent, engage in intra-group brokering activities.

EP legislative negotiations are structured by the allocation of committee membership, (shadow) rapporteurs and group coordinator positions (Jensen and Winzen, 2012). Generally, these actors take a central role in inter-group coordination processes (see 1.2). The rapporteur of a dossier is responsible for sounding out what is acceptable across the groups and for synthesising the present views as much as possible. The appointed shadow rapporteurs of the other groups are his or her main interlocutors (Corbett et al, 2011; Jensen and Winzen, 2012). They meet during the committee phase in so-called 'shadows' meetings' to prepare the report and during the plenary phase to negotiate final compromise amendments. The EP is known for its consensual decision-making style. With the expansion of the institution's legislative powers the need for a coordinated position has become more critical than ever before. In order to make compromise deals acceptable to the other institutions, EP decision-making is characterised by cooperation in pursuit of broad consensus. This compromise-oriented approach implies a pivotal role for EP party groups. Considering the concept 
of external brokering in the setting of the EP, group advisors are first and foremost expected to coordinate or facilitate possible coalitions or compromises with the other groups. In addition, the Code of Conduct (2008) regarding inter-institutional negotiations suggests a potential interinstitutional coordination role for advisors. This code prescribes that 'political balance shall be respected and all political groups shall be represented at least at staff level in these negotiations'. Moreover, it refers to an 'administrative support team' that at least includes the committee secretariat, political advisor of the rapporteur, co-decision secretariat and the legal service (see 1.3).

Summing up the theoretical discussion, advisors are expected to facilitate and coordinate intra-group and inter-group positions, and represent the group in inter-institutional negotiations. The conceptualised mixed sphere of activity of the framework suggests that there is both a technical and a political side to the Broker role. Brokering activities can be classified as 'political' if they involve value or ideological appraisals, the anticipation of priorities or objectives, and the use of implicit knowledge or tactics (see 2.1.2). Technical tasks are void of such anticipation or interpretation. Intraand inter-group facilitation can be conceived as technical activities when advisors provide information that does not involve interpretation or political judgement. For example through the mere inventory of the various views or interests - either within the group or in other groups - which the advisor then feeds back to his or her superior. Conceivably, advisors may also provide strategic advice with regard to internal and external negotiations for which they interpret various possible scenarios. The coordination function relates to the interplay between advisors and the Members of the EP (MEPs) or other staff members. In the hypothetical technical dimension, advisors just serve as an intermediary passing on information or delineated positions formulated by their superior. The political dimension of coordination is hypothesised to entail the organisation of support and the 
pre-negotiation of compromises. The theoretical dimensions of brokering are illustrated in figure 7.1.1.

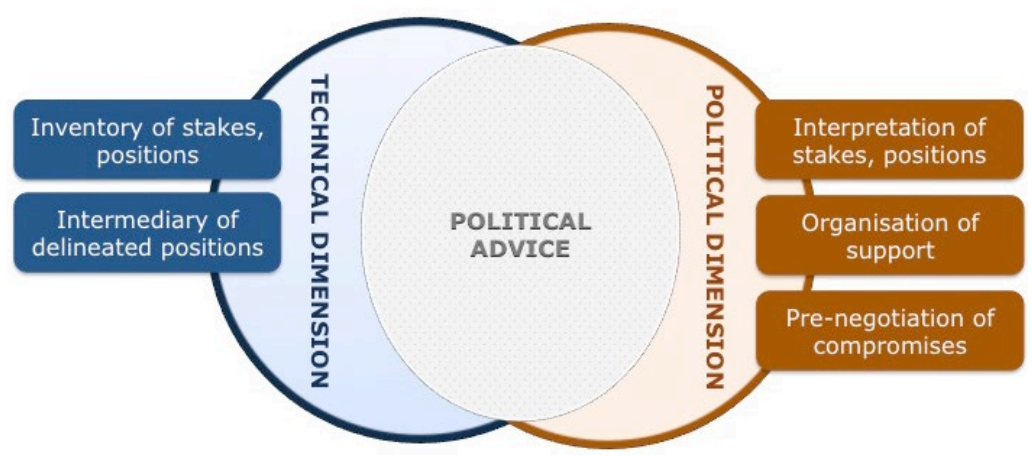

Figure 7.1.1 Theoretical dimensions of brokering

\subsubsection{Adoption of the Broker role in practice}

The conducted empirical research demonstrates that EP group advisors adopt the Broker role and that the role indeed involves both technical and political tasks. The survey and interview findings provide evidence that group advisors assume the facilitation and coordination functions of the role. Moreover, their role is found to go beyond the conceptualised scope in that advisors may replace the MEP in charge in intra- and inter-group coordination.

First, this sub-section discusses the relative importance of the role, finding that ALDE, EPP, and S\&D advisors consider brokering to be their most important responsibility. Next, the evidence is presented for advisors' facilitation of compromises and their respective involvement in intra-group, inter-group, and inter-institutional negotiations. 


\section{Advisors' perception of brokering}

As figure 7.1.2 illustrates, advisors perceive the Broker role as their most important responsibility. In response to an open-ended question, 43 per cent of respondents point to brokering activities. The categorisation of answers shows that the vast majority of these respondents (40\%) consider the coordination function to be their core task.

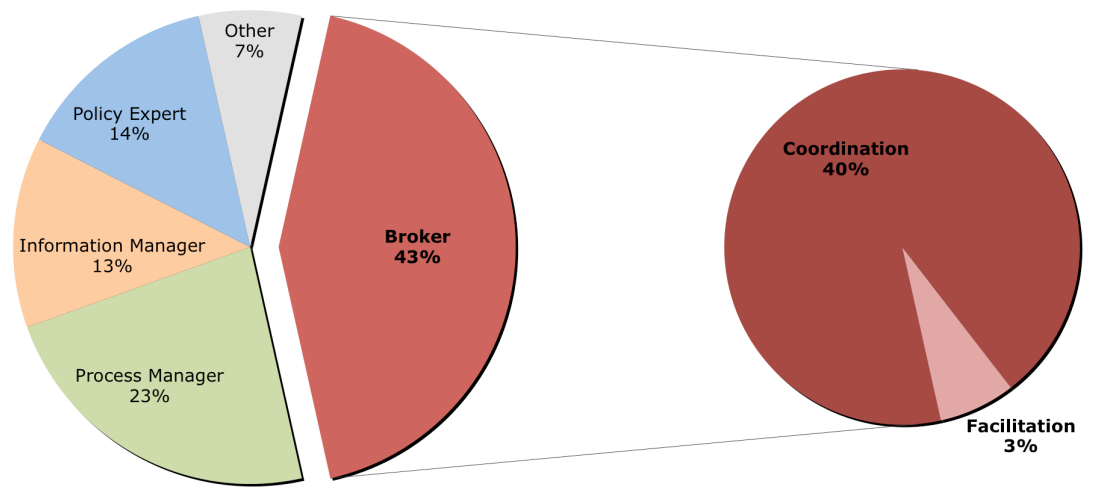

Figure 7.1.2 Relative importance attached to brokering ${ }^{1}$

The findings show that advisors from the ALDE, EPP, and S\&D groups attach relatively more weight to brokering than their counterparts in the other groups. The qualitative data confirm that in the larger groups internal coordination efforts take centre stage. Overall, advisors in these groups consider it their core responsibility to find consensus between the different (geographical) interests. Conversely, none of the EFD respondents mention it as their most important task. The qualitative data show that the EFD does not apply group discipline and thus no formal coordination takes place within the group. Similarly, the GUE/NGL group has no formal group discipline. Nonetheless, four of the 14 respondents pinpoint coordination as their most important task. This may relate to inter-group coordination. Yet, the GUE/NGL interviewee pointed out that there are significant differences between the GUE and the NGL and that potential clashes or inconsistencies are discussed. The ECR formulates a group line but national delegations 
have considerable room for autonomy (interviews ECR advisors). Four out of 12 survey respondents point to brokering as their most important task. The Greens interviewees claim that intra-group coordination is more informal than within the other groups. They say it is easier to have coherence and consistency in positions as interests are generally more aligned. EFA members, however, may have specific and diverging interests, for example the Scottish members with regard to Fisheries. In such cases each sub-group has their own voting list (interview EFA advisor).

\section{Facilitation of compromises}

The empirical research shows that advisors facilitate compromises both within and between the EP party groups. The facilitation element of brokering involves the inventory of positions and priorities as well as political analysis and advice on negotiation strategies. Each may be provided during the intra- and the inter-group coordination process.

To facilitate intra-group coordination, advisors undertake several activities. First of all, they write briefing notes aimed at establishing a position that is supported by the (majority of the) group - the so-called 'group line'. In these briefings advisors map out the prevailing positions within and outside the political group, identifying (potential) internal and external controversies. This facilitating function was pointed out in the interviews as well as in the answers to open-ended survey questions: ten interviewees, mostly EPP and S\&D advisors, and 14 survey respondents, mostly ALDE and Greens/EFA advisors said they provided such assistance to MEPs.

Beyond the mere inventory of positions, advisors underline that they provide advice on how to tackle potentially divisive issues. For example, they put forward (compromise) solutions that are likely to be acceptable to the national delegations of the group, or that are in line with the overall 
ideology of the group. ${ }^{129}$ This activity closely relates to the signalling function advisors have in the preparation of group meetings that was discussed as part of the Process Manager role (see 4.1.2).

As part of the inter-group coordination process, the vast majority of interviewees ${ }^{130}$ and 21 survey respondents ${ }^{131}$ describe their contribution to defining negotiation strategies. In this respect, they identify possible compromises that are acceptable to the group and assess the likelihood that these compromise positions will carry a majority in the House. "An advisor assesses and appreciates political interests, should be able to predict what the sensitive issues are, and assess the coalitions that are possible" (I.1). Accordingly, the qualitative data reveal that negotiation advice also entails an evaluation of prospective coalitions. ${ }^{132}$ In doing so, the advisor weighs the chances, laying out what the group can achieve and what battles to fight, several advisors explained. ${ }^{133}$ Advisors from all seven EP party groups forming part of the analysis say they carry out such inter-group facilitation. ${ }^{134}$

\section{Intra-group coordination}

The survey shows that advisors are in agreement regarding their involvement in intra-group coordination. With the exception of one EFD advisor, all respondents claim to coordinate interests and positions within

\footnotetext{
129 Only two EPP, two ALDE, and two Greens/EFA interviewees do not discuss this activity. In addition, 12 survey respondents mention it in their open-ended answers: SR25, 27, 48, 56, 60, 61, 73, 75, 85, 87, 91, 95.

130 The same advisors as mentioned in footnote 133 do not discuss this activity.

131 Open-ended responses of SR9, 38, 41, 43, 53, 64, 66, 69, 71-73, 75, 77, 85, 87, 89, 91-93, 98, 99.

132 I.1, 15, 18, 19, 22; open-ended responses of SR9, 29, 34, 36, 42, 53, 72, 73, 77, 91, 99.

${ }^{133}$ I.19, 22; open-ended responses of SR4, 9, 32, 36, 39, 40, 41, 52, 53, 55, 59, 66, $88,89,90,99$.

${ }^{134}$ ALDE, ECR, EFD, EPP, GREENS/EFA, GUE/NGL, S\&D are the seven party groups considered in the analysis.
} 
their group. The majority (40\%) indicate to do so on a weekly basis, 30 per cent on a monthly basis, and another 29 per cent see it as their every-day activity (see figure 7.1.2a). ${ }^{135}$

The interviews support this picture. Advisors acknowledge the importance of coordination with the aim of establishing a position that is supported by the majority of the group. 136 "The added value of the advisor lies in finding and stimulating a majority position within the group" (I.4). "The advisor supports the MEP in his or her committee work by coordinating different ideas within the group. There are members from different Member States, with

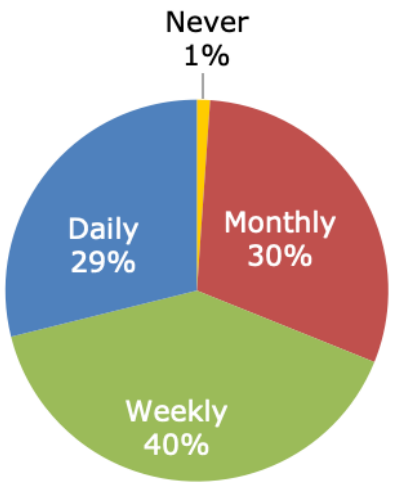

Figure 7.1.2a Intra-group coordination different approaches and cultures. You have to merge these ideas into one coherent position" (I.15). In their quest for a common group position, the advisors' role is to find a compromise between the various views of national delegations or - in the case of substantially diverging opinions - to ensure that the issue is discussed in a group meeting, ALDE, EPP, S\&D, and ECR advisors say. "We try to avoid divisions and find a common position. In case of internal division you try to reconcile between the delegations ensuring that the main points end up in the final text. If you don't succeed the other groups can take advantage of that. At all cost we have to avoid the impression that the group is split" (interview EPP advisor). In this capacity advisors negotiate on behalf of the members and set out to represent and organise support for the ideas of the MEP in charge (interviews ALDE, EPP, and S\&D advisors).

\footnotetext{
135 Analysis SQ7: Can you please estimate how much time you devote to the following activities? See Appendix III Survey Response.

136 The EFD interviewee and two Greens/EFA interviewees form the exception.
} 
The EFD group is formed for 'procedural reasons' and does not coordinate policy positions: a common group line is therefore not the objective (interview EFD advisor, see also 1.1.2). Notwithstanding, coordination at staff level occurs in relation to matters of MEPs attendance, substitution, and speaking time. These activities form part of process management (see 4.1.2). In such cases 'I do speak and operate on behalf of the group, the EFD interviewee explained, 'but this is by no means self-evident'. Findings reveal that in particular the advisors of the larger groups adopt an active internal mediating function. The coordination of positions within the group is put forward as a key activity by ALDE, EPP, and S\&D interviewees. "Advisors are trained to work towards compromises," an EPP advisor stated. The larger groups are expected to take position first. "We always have a position on a file. There is no other way," another EPP advisor explained. "You are expected to speak first, other groups wait for you." Intra-group coordination is a careful balancing act for the larger groups since there are many (potentially) diverging opinions to consider. "Sometimes the advisor needs to represent the group line internally, to convey to the members or delegations what the position of the group is" (interview S\&D advisor). It requires more effort compared to the other groups as is confirmed by their counterparts. "We negotiate within the group as to what is acceptable and what is the red line" (interview EPP advisor).

Conversely, the Greens/EFA is a more homogeneous group and advisors say that they spend relatively little time on intra-group coordination, as there is 'a greater meeting of the minds' within the group (interview Greens advisor). Yet, 'different cultures need to be balanced' within the group, another Greens advisor stated. The interviews with ECR advisors show that there commonly is a group line but national delegations have room for autonomy. "You have to mediate and reconcile different views where necessary", an ECR advisor said. Another ECR interviewee stressed that this is relatively easy as the group's position is formulated along the lines of the 
'Prague Declaration', which 'more or less is considered as our ten commandments'. 137 As a con-federal group, GUE/NGL values the preservation of its members' diversity of identities and opinions. Although the group does not have a formally coordinated position, there clearly is a group culture that advisors are expected to follow: "The GUE/NGL Group [...] argues against the mainstream neo-liberal prescriptions for the EU and is focussed on presenting progressive policy alternatives. All group staff should be comfortable in this environment and at ease with, contributing and supporting our MEPs in their policy objectives, inside and outside Parliament" (GUE-NGL vacancy notices, 2016).

\section{Inter-group coordination}

Survey findings confirm the overall involvement of advisors in inter-group coordination (see figure 7.1.2b). Only a small minority (3\%) denies their involvement in the coordination of interests and positions between the groups. ${ }^{138}$ Most advisors (49\%) do this every week while others report that they are involved on a daily (30\%) or monthly $(18 \%)$ basis.

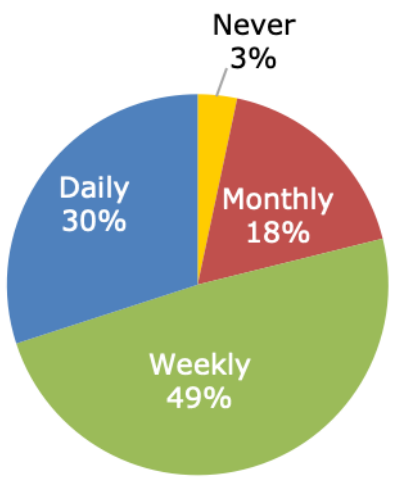

Figure 7.1.2b Intergroup coordinating

As part of their inter-group coordination activities advisors defend and promote the group position and negotiate compromises with the other

\footnotetext{
${ }^{137}$ In 2009, the ECR adopted this declaration containing the ten principles that the group share.

138 The three per cent that denies involvement in inter-group coordination represent two EFD respondents and one GREENS-EFA respondent.
} 
groups. 90 per cent of survey respondents agree with the statement that they negotiate compromises on behalf of the group (see figure 7.1.2c). ${ }^{139}$ ALDE, EPP, and S\&D interviewees describe themselves as 'compromise makers' and 'mediators'. The qualitative data

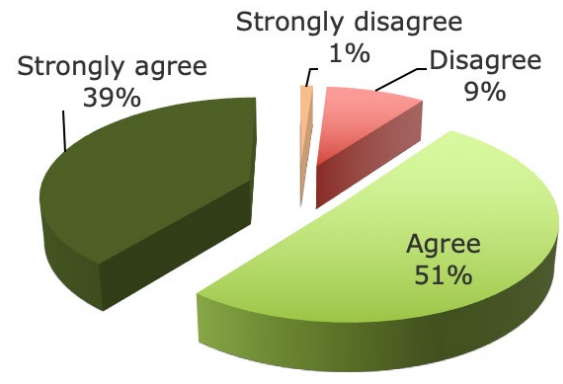

Figure 7.1.2c Negotiating compromises on behalf of the group furthermore disclose that advisors aim for the group position to be represented properly in parliamentary activities, and that it is reflected as much as possible in the legislative outcome. ${ }^{140}$

Inter-group negotiations are very informal and deliberation takes place simultaneously at political and staff level. Nearly all interviewees stressed that compromises between the groups are pre-negotiated among advisors. ${ }^{141}$ Advisors for example represent the group line in negotiations on compromise amendments with their counterparts (I.2, 11, 15, 18, 19, 22). "In order to relieve time-constraint MEPs, group advisors try to get the bulk of the issues out of the way. They negotiate with other group advisors and then report back to us, the MEPs or their assistants. Obviously, contact between natural coalition partners is easier, for example S\&D and Greens/EFA or GUE/NGL advisors. Whereas in the coordination between EPP and S\&D competition is fierce." (I.0.4). As part of the pre-negotiations at staff level it is common for advisors to check with their counterparts for potential support for an amendment, even before submitting or proposing it to the MEP $(\mathrm{I} .15,18,19)$.

\footnotetext{
139 Analysis SQ10: To what extent do you agree with the following statements? See Appendix III Survey Response.

${ }^{140}$ I.9; open-ended survey responses of SR3, 9, 18, 25, 29, 39, 40, 53, 60, 83, 87.

${ }^{141}$ Exceptions are one ALDE and one S\&D interviewee.
} 
The accounts of advisors show that throughout the informal preparations they fulfil an intermediary role, acting and speaking on behalf of the MEP in charge. ${ }^{142}$ "A very good adviser is finally the person who can or even must replace the respective member if necessary, not only in the technical meetings where the negotiations are being often already prepared at staff level but also in the official meetings with the other political groups and institutions" (SR61). 97 per cent of respondents attend shadows' meetings on behalf of the MEP (see figure 7.1.2d). Parliamentary assistants and group advisors usually prepare these meetings, in which an exchange of views between (advisors of) the rapporteur and the shadows takes place. "Before reports are drawn up there usually are one or two meetings with the rapporteur and shadows. Once the report is drawn up and amendments are submitted the real work starts, that is negotiation on a compromise. Staff then takes care of the bulk of the work. We have meetings at staff level to go through the text. This is where the bargaining starts. We talk to our counterparts in other groups to find a majority" (I.11).

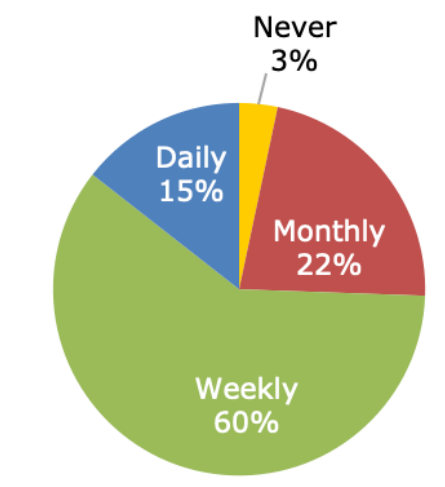

Figure 7.1.2d Attending shadows' meetings

\section{Inter-institutional coordination}

Interview and survey findings report that advisors also contribute to the inter-institutional coordination process (see 1.3). An EPP interviewee stated that group advisors are always present in the trilogue negotiations. "They have to be in order to report back to the group." The mandate for the EP negotiating team is determined beforehand and 'group advisors create the

${ }^{142}$ I. 0.1, 2, 3, 8-19, 22; SR13, 25, 56, 61. 
support within the group and ensure it throughout the process.' Another EPP advisor stated that 'it is nice to take the lead' in the technical trilogues when you are representing the rapporteur.

Overall, the findings demonstrate advisors' involvement in the trilogue preparations across the groups and across parliamentary committees. Close to the politics-administration dichotomy theory, EP practitioners use the distinction to illustrate the division of labour and authority by referring to 'technical' or 'political' meetings. Generally, a 'political' meeting between the rapporteur and the 'shadows' takes place prior to a trilogue negotiation in order to coordinate the EP's position (Corbett et al, 2011). During these shadows' meetings the decisions are taken and issues are subdivided into political topics, which are resolved in the trilogues, and into technical points that are worked out at staff level (I.4, 10, 11, 15, 17).

92 per cent of survey respondents state that they are involved in technical trilogues (see figure 7.1.2e). Only 7 respondents report never being involved and they work for different groups and committees. These meetings assemble MEP assistants, EP officials from the committee secretariats, group advisors, and representatives from the European Commission (EC) and the Council (I.4, 11). "For example, when we find and agree on the exact wording. Politicians aren't

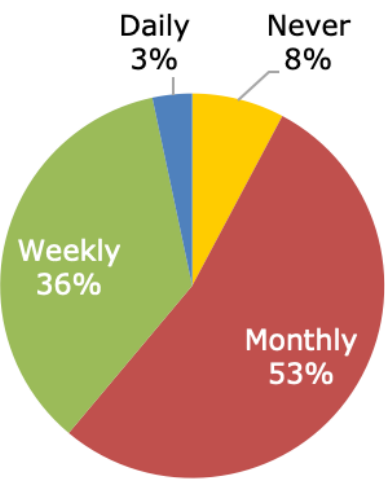

Figure 7.1.2e Participating in technical trilogues interested and don't want to spend their time on this" (I.11). 


\subsection{Assessment of the political scope of brokering}

The previous section presented the empirical evidence for the adoption of the role. The research demonstrates that advisors facilitate compromises, an activity that encompasses the inventory of positions and advice on negotiation strategy. They furthermore coordinate positions within the group, pre-negotiate compromises with their counterparts in the other groups, and participate in the technical trilogues. This section evaluates the degree to which brokering is political. The extent to which the role is political is assessed with the use of the modes of discretion that have been developed as part of the analytical framework (see 2.1.3). The aim is to explore advisors' discretion, room for initiative, and improvisation in brokering activities.

7.2.1 addresses the way in which advisors receive their instructions from the MEPs and how this input affects their role. The analysis concludes that the advisors' mandate is implicit and derived from the group's or the MEP's priorities. 7.2.2 examines the extent to which advisors (need to) anticipate or improvise in their brokering activities. The collected data suggest that ahead of explicit political input - advisors devise and propose acceptable compromises and coalitions. Throughout the informal preparations advisors have to consider multiple outcome scenarios. Their improvisation is a coping strategy and requires them to determine the necessary or appropriate course of action in light of the group's ideological views. It is therefore concluded in 7.2.3 that the role is mostly pro-active, with the exception of advisors' participation in the inter-institutional negotiations, which is tied to the strict and fragile mandate of the EP negotiating team.

\subsubsection{Instructions and input from the MEP}

This sub-section sets out to determine the way in which advisors receive instructions or input from the elected representatives and how this affects 
their ability to act as Brokers. Advisors are assigned to follow the work of one or several parliamentary committees. In the administrative hierarchy the group's Secretary General is the advisor's superior (see 1.2.2). From the quantitative and qualitative data it is found that group advisors work closely together with (shadow) rapporteurs and the group's coordinator for the parliamentary committee they are assigned to (see 4.2.1). Their explicit or implicit political instructions are most likely to emanate from this interaction. The vacancy notice analysis deduced that throughout the process of defining a political group's position advisors are responsible for safeguarding the group's overall objectives and preserving consistency between past and future positions (see Appendix I). Advisors base their actions and recommendations on the ideology and priorities of the group. They ensure that 'the group position respects the fundamental values of the group' (SR25) and they advise MEPs according to those values (SR27). These values could thus also be perceived as advisors' implicit instructions. However, and in particular for the larger and more heterogeneous ALDE, EPP, and S\&D groups, such political values are usually not clear-cut as there are great differences between their national delegations (see 1.3.1 and 7.1.2 on intra-group coordination).

Advisors consider it one of their main responsibilities to secure a common group line, in which the different ideas that exist within the group are balanced or merged into one coherent position. Advisors in the more homogeneous groups feel that they have greater discretion in formulating the group's position (i.e. Greens, ECR, GUE). As the internal divisions are smaller, they have more room to show initiative in coming up with (compromise) solutions. Notwithstanding, intra-group coordination for the larger, heterogeneous groups is more substantial. A great deal of ALDE, EPP, and S\&D advisors' time is spent on what they refer to as a careful balancing act. 
In their intra-group mediation function advisors base their actions on what (they think) the MEP in charge wants and assay these wishes to the political values and priorities of the group. Their (implicit) mandate is thus twofold. On the one hand, they consider themselves to be the MEP's proxy, and on the other, they safeguard the group's fundamental values. "The engagement of coordinators differs a lot. You have to do either whatever complements their work or invisibly replace them" (SR56). Particularly in the context of intra-group coordination, respondents alluded to 'convincing' or 'persuading' MEPs with the aim of rounding up support for the group line. ${ }^{143}$ One even claimed that an advisor should have the 'ability to convince an MEP to do what you want without him or her realising it' (SR58). The more general representation by advisors, however, is that they should be able to 'explain and argue for specific policy choices' (SR77), and 'promote new ideas and propositions' (SR55). Yet, if such ideas deviate from the convictions of the MEP in charge there is no real chance for success. "If you are not on the same page as your MEP you have less opportunities to bring your ideas forward" (I.4). "Advisors first and foremost have to support the (shadow) rapporteur, and help explain their political position to the group and other colleagues, whether this carries a majority view or not" (SR77). "In the case of a minority position we try to explain to the member or national delegation why the majority position is necessary, and why for example the MEP should withdraw a certain amendment" (I.15). These examples illustrate that the advisor acts and speaks on behalf of the MEP in charge, representing his or her views. Discretion and room for initiative of advisors decreases when their coordination activities diverge from the wishes of the MEP in charge. Exceptions to this, however, are encountered in situations where the (shadow) rapporteur does not follow the group line. As part of their Process Manager role (see 4.2.3), advisors

143 Open-ended responses of SR26, 30, 32, 33, 40, 47, 53, 55, 58, 69, 72, 74, 77. 
then pro-actively report to their political and administrative hierarchies (signalling function).

The same holds true for inter-group mediation. 90 per cent of the respondents agree with the statement that they negotiate compromises on behalf of the group. The data presented in 7.1.2 demonstrate that these compromises are (pre-)negotiated at staff level. The advisor represents the MEP and the group in meetings. The EP Rules of Procedure do not specify the precise functioning of 'shadows' meetings'. It is not stipulated who can represent the group in these meetings and the empirical data suggest that advisors may do so. "Normally the rapporteur is there, but over half of the time the group advisors are there alone" (I.22). Another interviewee cites an example of a meeting to prepare a resolution. All advisors and one member came in and somebody asked 'is this meeting open to members too?' (I.16). These examples predicate high discretion and room for initiative by the advisor. Nevertheless, advisors underline that they base such coordination activities on the (expected) group position, bearing in mind the group's priorities (SR48, 52, 53, 86). "On the basis of group decisions, advisors have to make sure these are represented in parliamentary texts and voting lines" (SR25). Although negotiations are prepared at staff level, this work needs to be confirmed at MEP level in shadows' meetings and later at the level of the group, which can be 'challenging' (I.18). "In negotiations you or your (shadow) rapporteur may agree to certain things because you understand the dynamics of the negotiation process and see that everyone is compromising. This is not necessarily obvious to the group so you then need to make this understood and defend a compromise result that maybe nobody really likes" (I.18). 
Advisors' room for manoeuvre in intra- and inter-group negotiations is higher in the committee phase. ${ }^{144}$ At this stage advisors' mandate for intergroup coordination is comparable to that for the intra-group coordination process and more flexible than during the negotiations leading up to the plenary vote. Once the group line and preferred amendments to the proposed text are discussed in the group this input forms the advisor's mandate in the plenary phase. "For the plenary, if everything runs smoothly, all we have to do is draft a voting list" (I.15). "Advisors' role is most important in committee phase. Before the plenary vote not a lot can be done" (I.2).

For inter-institutional negotiations with the Council and the EC the role of advisors is bound by a carefully defined mandate established through a decision in the parliamentary committee responsible or plenary (see 1.3). This is done to secure wider support in the EP as in the actual negotiations only a fraction of MEPs is involved, a practice that is frowned upon both within and outside the European Parliament $(\mathrm{I} .11,19)$. The task of group advisors is to ensure that the established mandate is respected in order to keep the House united. "Our job is to defend the position whether you like it or not" (I.15). All in all, this leads us to believe that the role of advisors is more restricted compared to intra-parliamentary mediation. Yet, some room for initiative remains as the advisor may be charged with working out specific details or the exact wording of texts. These inter-institutional activities at staff level, however, are preceded and delineated by a decision of the rapporteur and the shadows. Inter-institutional mediation is thus of either a routine or reactive nature.

${ }^{144}$ See 1.3.1 for an introduction to the respective stages of intra-parliamentary coordination: Preparatory, committee, plenary, and inter-institutional negotiations. 
While several advisors point out the potentially "undemocratic" nature of the informal coordination process in the EP $(\mathrm{I} .11,19)$, the majority depicts their role as benign. Advisors are in close contact with the (shadow) rapporteur and coordinator, and the final say always remains with the MEPs (I.7, 17, 18; SR25, 61, 82). However, this does not mean that in the informal process leading up to a decision by the MEP advisors follow explicit instructions. In their brokering activities advisors rather depend on their capacity to anticipate both the desired outcome for the MEP or group as well as the strategy to achieve this outcome, as the discussion below will further demonstrate.

\subsubsection{Improvisation by the advisor}

It is found that group advisors fulfil the political dimensions of the role (see 7.1.2). The previous sub-section concluded that, with the exception of their role in technical trilogues, advisors' mandate is implicit and derived from the group's or MEP's priorities. This sub-section addresses group advisors' manifested level of improvisation in the Broker role, before or in the absence of clear input from the elected actors. Improvisation is construed as value or ideological assessments by the advisor, the anticipation of priorities or objectives, and the use of implicit knowledge or tactics (see 2.1.2).

In the survey, all respondents classify their activities as 'political advice'. Interviewees and survey respondents claim that they are aware of the political implications of their role and a majority of all advisors in the study acknowledge that they can have a pro-active role. They underline the importance of anticipating the positions within the groups and showing initiative in their support provided to MEPs. Out of the advisors that describe a form of pro-active behaviour, the vast majority refer to brokering activities. 
The data corroborate that advisors facilitate compromises and that these activities can entail tactical and strategic advice (see 7.1.2). No examples were encountered of advisors facilitating compromises in a situation where both the desired outcome and the means to achieve that outcome are instructed or implied (routine mode). Instead, the empirical data highlight political analysis and judgement on the part of the advisor. ${ }^{145}$

The qualitative data show that to provide strategic negotiation advice, advisors must be able to anticipate and interpret the group's objectives as well as acquire insight into the other groups' positions and priorities. ${ }^{146}$ In briefing notes advisors 'carve out the position of the group, anticipate the positions of the other groups, and put files into a political context' (SR36). Although these activities include an inventory element the advice described by respondents and interviewees shows a high degree of improvisation. Advisors acquire this political intelligence through their Information Manager role, drawing from their experience and by liaising with their counterparts in the other groups (see chapter 5). "You get to know the strategies of the other groups. For example the Greens will push and push, negotiate and negotiate to get their points in. But in the end they will vote against the formal compromise anyway. Our role is to advise the MEPs on such strategies, anticipating what the others will do" (I.19).

Advisors furthermore assess the likelihood that a position or compromise is acceptable to the national delegations of the group or prospective allies. Advisors should have the capacity to identify 'allies and compromises with necessary majority as close as possible to the aims of his group' (SR 53).

\footnotetext{
${ }^{145}$ I.1, 2, 3, 8, 9, 17, 22; open-ended responses of SR9, 13, 24, 30, 34, 39, 40, 41, 45, $49,50,89,91,99$.

${ }_{146} \mathrm{I} .1,8,13,18,22$; open-ended responses of SR9, 13, 15, 22, 24, 29, 30, 34, 36, 39, $45,50,52,53,56,60,64,65,72,77,92,96,97,99$.
} 
"When working on a particular issue for a particular MEP, advisors should be able to identify like-minded in other groups who are able to give support to a particular opinion" (SR72).

Advisors can fulfil a pro-active role in intra- and inter-group coordination although their discretion and room for manoeuvre hinges on the accurate representation of the MEP's or group's position. The findings also show, however, that usually there is not just one desired outcome or one appropriate course of action. The role of the advisor then is to secure the best possible outcome for the group. Inevitably, this requires improvisation. Advisors for example weigh different interests and assess the likelihood of success. "Advisors can simultaneously propose different things because different MEPs ask you different things" (I.22). The interviewee described a case of a report for which his group delivered the rapporteur. He knew the rapporteur wanted a certain issue to be amended but several MEPs within the group wanted to keep it unchanged. Others wanted to go much further than the rapporteur. In the end it worked out that the compromise position was that of the rapporteur. "As an advisor you can go out and actively look for these extremes on either end, preparing the way toward a compromise."

The empirical research reveals that advisors act and speak on behalf of MEPs, both in intra- and inter-group coordination efforts. Advisors' accounts demonstrate that such 'shadowing' of MEPs, by some referred to as 'acting as $\operatorname{MEP}^{\prime}$ (I.5, 10, 12, SR99), implies anticipation and crawling into the skin of the politician. For example, not all of the groups provide a shadow rapporteur for each file. In that case, the political advisor deals with the file on behalf of the group. To prepare the shadows' meetings, meetings are convened at staff level. Moreover, advisors contact each other informally to probe the acceptability or level of support for certain amendments, and form alliances on certain issues. They then brief their members based on this information prior to the actual negotiations. Apart from a few 
exceptions, advisors stand together in their claim that in these negotiations they do not voice their own opinions. Instead, they represent the ideas and interests of the group or the individual MEP who is in charge of the file. ${ }^{147}$ The qualitative data show that in this respect the advisor needs to predict and understand what the MEP wants and be able to think as the MEP would. ${ }^{148}$ This requires them to anticipate the politician's priorities and based on that determine the appropriate strategy to realise the desired outcome.

As concluded in 7.2.1, inter-institutional mediation is bound by a carefully constructed mandate. Nevertheless, some room for improvisation remains as several examples provided by interviewees support. One advisor referred to 'tough negotiations' within the Parliament during which he was able to leverage his contacts at the Permanent Representation to change the outcome of the technical trilogue meeting (I.4). During the intraparliamentary deliberations the groups had agreed on a compromise. Nonetheless, the advisor had simultaneously coordinated with 'his' national attachés that the Council would overturn certain points that were unacceptable to his group. An ECR advisor stated that once you know a file is going into informal trilogues it becomes easier to compromise on certain issues with the other groups. "The Council's position is usually stronger in line with the ECR position and we would expect them eventually to go our way."

To conclude, the analysis shows that ahead of explicit political input advisors devise and propose acceptable compromises or coalitions. Moreover, they fulfil a backstage coordination function in relation to the intra-parliamentary negotiations. For these functions the desired outcome

\footnotetext{
${ }^{147}$ I.0.2, 1, 2, 3, 17, 18; open-ended responses of SR9, 13, 24, 43, 48, 50, 52, 53, 77, $79,86$.

${ }^{148}$ I.0.1; 0.2, 0.3, 1, 2, 3, 9, 10, 17; open-ended responses of SR9, 13, 24, 50, 64.
} 
is multifaceted or uncertain. Advisors' improvisation is a strategy to deal with situations in which there are multiple scenarios to consider. In such cases they have to rely on what they feel is necessary or appropriate in light of the group's ideological views. The next sub-section concludes what this implies for the political scope of the various brokering activities.

\subsubsection{Brokering as a category of political advice}

The empirical research revealed that EP group advisors combine technical and political tasks in their Broker role. No evidence has been encountered of purely technical tasks. Rather, advisors to a large degree depend on their capacity to anticipate both the desired outcome for the MEP or group as well as the means to achieve this outcome. The technical dimensions (inventory and intermediary) do form part of the activities and feed into the political advice category. The framework conceptualises political advice as a mixed sphere where technical and political activities meet. The findings presented in this chapter thus corroborate brokering as a category of political advice composed of technical and political elements. The combination of tasks is also acknowledged among the advisors in the survey and interviews. One interviewee summarised the role as follows: "A group advisor is a political figure and a technical figure at the same time" (I.17).

To assess the political scope of the role, the framework conceptualised three incremental modes of political advice tied to the discretion of the advisor: routine, reactive, and pro-active behaviour. Discretion is exercised where hierarchical measures or political authority are not directly applied. The role thus becomes more pro-active as the advisor's room for improvisation increases. While advisors broadly claim to act in the interest of the MEP or group, it has become apparent that these interests (the desired outcome) are not straightforward or predefined. For that reason the role is predominantly labelled as pro-active. 
The process during which compromises come about in the EP appears to be highly informal. Particularly during the early stages of this process, advisors have no explicit political instructions or debates to use as guidance for their actions. It is found that the facilitation of compromises is aimed at advising MEPs on the best conceivable strategy (means) while anticipating what is acceptable to the members of the group (desired outcome). Advisors assay what is at stake, what is acceptable, as well as the respective chances for success. These activities are thus labelled as pro-active. Ahead of meetings at MEP level, advisors devise acceptable compromises or coalitions. They advise how to tackle (potential) internal and external controversies and predict possible coalitions. In the margins of these meetings, group advisors pre-negotiate compromises with their counterparts. In this way, they represent as well as shape the position of the group. These pro-active functions of the Broker role clearly set group advisors apart from other supporting actors in the EP.

Figure 7.2.3 illustrates the key brokering activities that are found based on the empirical research:

$\checkmark$ Political analysis: advisors evaluate the different internal and external positions and provide the group with advice on negotiation strategy. These tasks require the advisor to have a feeling for what is (likely to be) acceptable to the members of the group (desired outcome) and determine the best conceivable strategy (means). The facilitation of compromises therefore requires pro-active behaviour by the advisor. 
$\checkmark$ Group advisors reconcile views internally. In their intra-group coordination function advisors pro-actively coordinate the different ideas within the group, and stimulate the support of the majority position. The desired outcome is multifaceted and advisors are guided by what they deem necessary or appropriate in light of the group's ideological views.

$\checkmark$ Group advisors negotiate compromises at staff level. In their intergroup coordination function they pro-actively defend and promote the group position ahead of the meetings that take place at MEP level.

$\checkmark$ As part of their coordination function, advisors replace their MEP. Throughout the informal preparations they fulfil an intermediary role, acting and speaking on behalf of the MEP in charge. This requires improvisation although the acceptance of their pro-active behaviour hinges on the accurate representation of the MEP's or group's position.

$\checkmark$ Although some examples were encountered of advisors executing discretion in the preparation of inter-institutional negotiations, their participation in the technical trilogues is generally deemed to be of a routine nature, given the strict and fragile mandate of the EP negotiating team. 


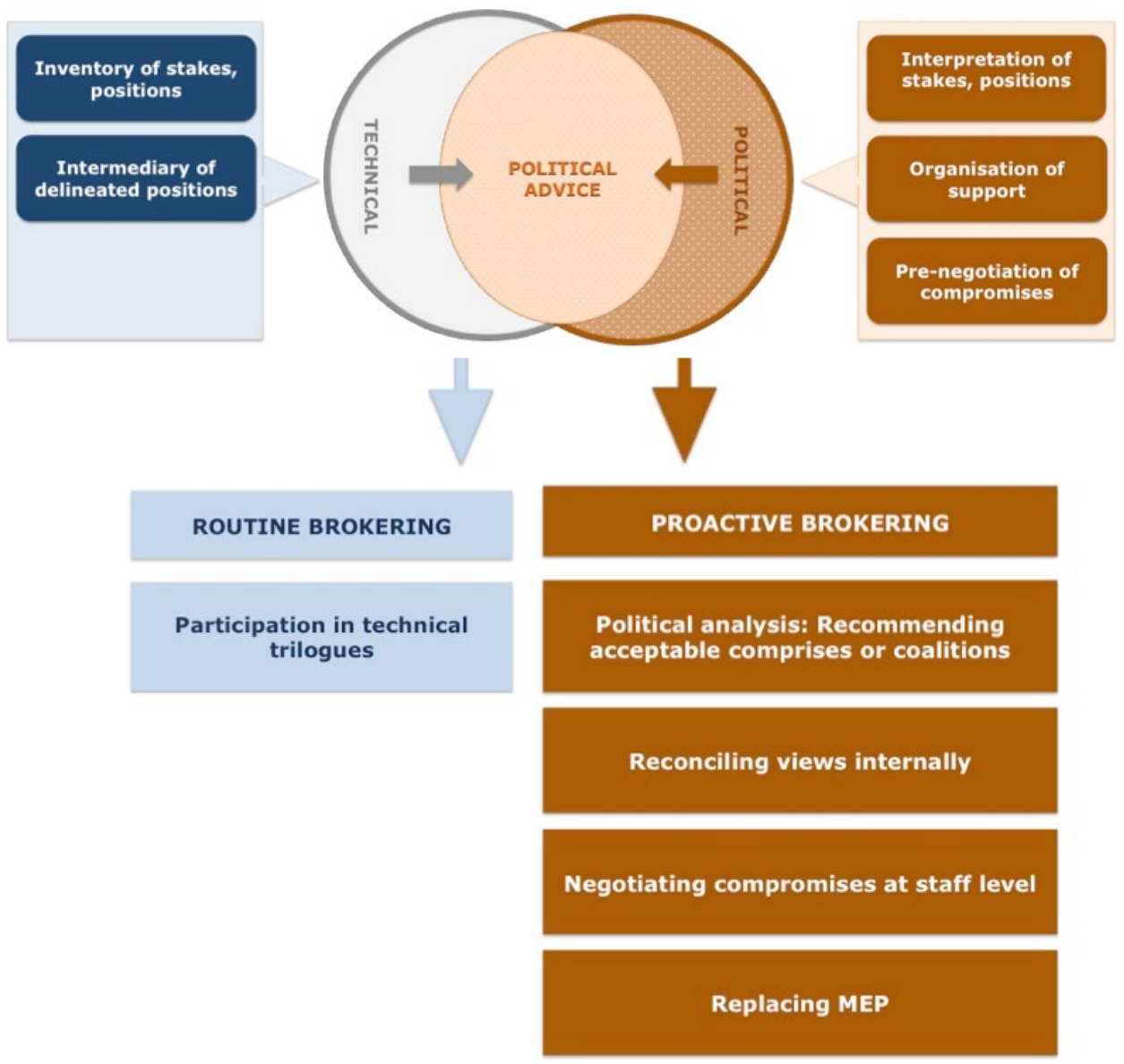

Figure 7.2.3 Empirical findings: brokering as a category of political advice

\subsection{Impact of the factors on brokering}

The objective of the thesis is to explore and explain the circumstances that stimulate or restrict a political role by group advisors. The literature review identified a set of factors that are expected to affect the adoption of the Broker role (see chapter 2.3). This section consecutively assesses each of the personal (7.3.1) and contextual factors (7.3.2) by presenting evidence from the survey and interviews. It is found that trust and political sensitivity are indispensable for the effective fulfilment of the Broker role. 
Furthermore, it is concluded that pro-active behaviour is restricted in cases that are politicised.

\subsubsection{Personal factors}

The analytical framework proposes four personal factors that facilitate proactive behaviour. This sub-section analyses the impact of these factors on the adoption of the Broker role. Findings show that trust of the MEP and of other staff members defines the advisor's room for manoeuvre. Political sensitivity enables the advisor to think as the MEP and provide tactical advice with regard to compromise-building and negotiation strategies. Intra-EP informal connections are instrumental for both the mediating and the facilitating functions of brokering as it provides the advisor with intelligence.

\section{Trust}

The analytical framework links trust to knowledge of and affinity with party ideology and priorities (see 2.3.1). It can be inferred from the survey and the interviews that trust between the advisor and the MEP is key in determining the working relationship. 25 advisors say that the discretion they are granted depends on the trust of the coordinator or (shadow) rapporteur (s)he works with. ${ }^{149}$ For MEPs to listen to the provided advice, advisors need trust and acknowledgement of their role from the members (I.18). Trust is thus indispensable for an effective pro-active role as it forms the basis for the advice to be followed or the input to be 'accepted'.

In the case of a high-trust relationship advisors will have 'a lot of room for manoeuvre' (I.22). "Definitively once you start speaking on behalf of the member when you're replacing them it is very important that you know

149 I. $0.2,0.4,4,7,8,9,11,13,15,16,17,18,22 ;$ open-ended responses of SR6, 17, $25,31,38,39,40,52,60,61,84,99$. 
where they are standing and also get the trust from them. So you can speak on behalf of them" (I.18). The interview and survey accounts show that the contrary holds true as well. Should trust be betrayed, the working relationship is disturbed. In cases where the MEP in charge and the advisor disagree or do not 'share the same affinity' (I.22), discretion 'to put forward your ideas' decreases (I.4), thus obstructing the provision of political advice. In sum, a lack or decreased sense of trust has a critical impact on the role of the advisor. In the end, the MEP decides who provides his or her assistance. If the trustworthiness of advisors is questioned, MEPs will look to their personal assistants to fulfil the brokering activities.

The empirical research shows that compromises are pre-negotiated at staff level. 19 advisors say this collaboration depends on trust. ${ }^{150}$ Reliability and the reputation of the advisor is important, i.e. 'not winning through tricks' (I.10). Trust of advisors' counterparts in the other groups is essential to effectively engage in intra-parliamentary and inter-institutional coordination. It is important 'to stay on friendly terms, even with your political opponents' (SR92).

The research shows that advisors may replace their MEP, which implies that they understand the way of thinking of the MEP and represent his or her ideas. 11 advisors state that to acquire a good sense of the MEP's priorities and understand how (s)he thinks, they rely on their relationship with both the MEP in charge and their assistants who share insights as to the MEP's views, priorities, and behaviour. ${ }^{151}$ The informal interviews put forward that some group advisors are reputed to 'try to get certain points in' that were not discussed with the MEP. MEPs and their assistants would subsequently avoid working with them.

${ }^{150}$ I.0.1, 0.2, 0.4, 2, 3, 4, 10,11,15, 17, 18, 19; open-ended responses of SR 17, 25, $31,38,39,54,59$.

${ }^{151}$ I. 2, 3, 9, 10, 11, 13, 15, 16, 17, 18, 22. 


\section{Informal network}

The framework conceptualises an informal network as the access to and exchange of private information through informal interactions with actors in and outside the institution (see 2.3.1). In respect to brokering, informal contacts are instrumental for political analysis of the various stakes, positions, and (possible) coalitions. They gather this information through the Information Manager role (see chapter 5) and use it in their facilitation and coordination efforts. The analysis demonstrates that for brokering activities the networks of advisors centre on contacts within the institution.

The findings show that informal contacts and personal relationships are crucial to collaboration and exchange at staff level: 39 advisors underline the importance. ${ }^{152}$ Chapter 5 considered the networks of group advisors. MEP assistants are found to be their main points of contact (see table 5.1a). Having close ties with assistants will allow advisors to assess or forecast what is at stake and what is acceptable to the members. This enables them to devise the appropriate negotiation strategy and accurately represent the interests of the group. Advisors also work closely, and meet socially, with their counterparts from the other groups and keep each other informed. These contacts allow them to gain insight into other groups' positions, a necessity for inter-group coordination and advice on negotiation strategy. Several advisors stress the level of informality - talking and meeting off the record - as pertinent in this regard (notably I.2, 3, 15). "We have an added value by acquiring 'new' information through informal channels" (I.2). And "if you know the people and they know you, this helps" (I.3). In sum, advisors' informal intra-parliamentary networks are instrumental to the facilitation of compromises, and even indispensable for the effective negotiation at staff level.

152 I.0.4, 2-4, 6-10,13,15-17, 19, 22; open ended responses of SR3, 5, 10, 11, 13, 14, $27,37,42,43,47,51,53,55,59,60,74,79,84,88,89,92,97,98$. 


\section{Institutional memory}

Institutional memory is conceptualised as the insight into - and access to the institutional track record (see 2.3.1). In the EP context this factor is interpreted as knowledge of the functioning of the institution (formal and informal rules) and an appreciation of the political group's (previous) positions. Though not a prerequisite, 42 per cent of advisors have a background of working in the EP and interviewees' accounts support the advantages of 'knowing your way around' (I.3). Moreover, the survey finds advisors to be experienced, on average holding their position for six years, varying between seven months and 23 years. This would allow them to develop a level of 'institutional memory'.

Survey respondents and interviewees stand together in their claim that advisors must understand and be able to forecast the group's objectives and priorities. In the recruitment of advisors, familiarity with the activities and the operation of political groups are sometimes explicit requirements, notably for the GUE-NGL and EFD groups. Interviewees' accounts show that in practice political affinity and political experience are taken into account in the selection of group advisors. An understanding of the group's position helps the advisor to fulfil the inter-group Broker role and to propose acceptable solutions or compromises (facilitation). Moreover, in the larger or more heterogeneous groups it will allow advisors to appreciate the different views of the national delegations within the group, which is important for intra-group brokering, particularly relevant for the ALDE, EPP, and S\&D advisors.

From the research it is found that institutional memory facilitates the Broker role. However, the other personal factors may produce a similar appreciation of the institution's formal and informal rules, as well as allowing for the understanding and anticipation of the group's position. In sum, there appears to be a positive relation between advisors' institutional 
memory and their brokering activities but the factor is not indispensable for the adoption of the role.

\section{Political sensitivity}

The analytical framework conceptualises political sensitivity as the understanding of the institution's informal code of conduct and the ability to recognise political and administrative cues, allowing for the anticipation of (negotiation) strategies (see 2.3.1). Inquiring after the qualities advisors should possess to effectively fulfil their responsibilities, political sensitivity is cited most prominently. ${ }^{153}$

From the interviews and survey it appears that advisors are expected to know what is strategically important for the group, what points can count on a majority in the group and in Parliament, and be able to rank political priorities (see 7.1.2 and 7.2.2). In negotiations, advisors must 'have a good understanding of what is acceptable' (I.2) and 'have a good sense as to how far they can go, making sure to not overstep their mandate' (I.8). ${ }^{154}$ For internal briefing purposes, advisors should be able to infer whether a position can count on the support of the national delegations within the group. And for negotiation advice, whether a parliamentary majority can be found for such a position. "Negotiations are usually a question of what others can live with or what will be hard for them to refuse. We have to keep the feasibility of an amendment in mind. You know this from experience, a gut feeling" (I.13). To effectively brief MEPs, advisors should have 'a feeling for possible compromise lines' which they develop through 'knowing where the red lines' on either side lie (SR41).

\footnotetext{
153 See Appendix III, responses to SQ6, 9 and 11. Out of the 28 interviews, only five interviewees did not flag up political sensitivity as crucial to their role.

${ }^{154}$ Similar examples were provided in the open-ended responses of SR9, 13, 15, 22, 27, 39, 41, 97.
} 
In their intra- and inter-group coordination activities, advisors represent the views of the group and the MEP in charge. To this end, they must be able to 'anticipate and translate what members want' (I.1). This requires advisors to crawl into the skin of the MEP, basing their actions on what is likely to be acceptable to MEPs. Rather than following a set of clearly defined instructions, Group Advisors have to trust their 'political instincts' and be able to think and act as the MEP would (I.3, 4, 17, 18). 'Good' advisors know how to make the distinction between their 'personal opinions' and the 'group line' (I.16) and can forecast the 'ideal outcome' for the MEP (I.16, 18).

As these examples illustrate, political sensitivity is a prerequisite for the adoption of the Broker role; this factor allows advisors to pro-actively prepare the intra-parliamentary negotiations. It enables them to assess acceptable compromises and the likelihood that these amendments will carry a majority in the House, which are prerequisites for devising the group's negotiation strategy. Finally, only politically sensitive advisors will be able to accurately represent the group in negotiations at staff level.

\section{Assessment of the personal factors}

The analytical framework postulates that the personal factors affect the advisor's discretion and their ability to adopt a political role. They are used to assess the (optimal) circumstances in which political advice may be provided. The impact of the factors on the adoption of the Broker role is qualitatively evaluated by attributing the following values: indispensable $(++)$, positive impact $(+)$, no impact/ not relevant $(0)$, or a negative impact $(-)$.

It is found that trust and political sensitivity are indispensable for pro-active brokering (see table 7.3.1). Political sensitivity enables advisors to assess 
acceptable compromises and the likelihood that these amendments will carry a majority in the House, which are prerequisites for devising the group's negotiation strategy. Trust forms the basis on which advice is followed or the input is 'accepted'. The advisor's informal intraparliamentary network is indispensable for the effective negotiation at staff level. And only advisors who demonstrate political sensitivity will be able to accurately represent the group in such negotiations. Although institutional memory facilitates the role, similar effects may be produced by the other factors.

Table 7.3.1 Personal factor assessment for the adoption of the Broker role

\begin{tabular}{|c|c|c|c|c|}
\hline & Trust & $\begin{array}{l}\text { Informal } \\
\text { network }\end{array}$ & $\begin{array}{l}\text { Institutional } \\
\text { memory }\end{array}$ & $\begin{array}{l}\text { Political } \\
\text { sensitivity }\end{array}$ \\
\hline \multicolumn{5}{|l|}{ ROUTINE BROKER } \\
\hline $\begin{array}{l}\text { Participation in technical } \\
\text { trilogues }\end{array}$ & + & 0 & + & + \\
\hline \multicolumn{5}{|l|}{ PRO-ACTIVE BROKER } \\
\hline Political analysis & + & + & + & ++ \\
\hline $\begin{array}{l}\text { Reconciling views } \\
\text { internally }\end{array}$ & ++ & ++ & + & ++ \\
\hline $\begin{array}{l}\text { Negotiating compromises } \\
\text { at staff level }\end{array}$ & ++ & ++ & + & ++ \\
\hline Replacing MEPs & ++ & 0 & + & ++ \\
\hline
\end{tabular}

\subsubsection{Contextual factors}

Three contextual factors are expected to affect delegation and trigger potential differences across the groups, committees, policy domains, or specific files: political direction, complexity, and politicisation. Below the contextual factors are assessed based on the empirical research. It is found that the role is enabled by political direction and complexity, although the 
latter may hamper advisors' contribution to inter-group negotiations. Politicisation increases the need for facilitation while advisors' internal and external coordination function is restricted.

\section{Political direction}

Political direction is defined in relation to the superior of the advisor: the position of the politician, or of the group the advisor works for, is expected to affect the degree to which they may assume a political role (see 2.3.2). Evidence gathered through the interviews confirms that MEPs' position and experience affect brokering activities (I.3-5, 13, 15). Four interviewees explained that the working relationship between MEPs and advisors changes over the course of a term. Advisors feel that MEPs may take a 'careful' approach, either as newcomers at the start of their term or with elections approaching (I.3, 4, 13, 15). Activities are then put under a 'magnifying glass' by the national parties. As a result, MEPs want to be as visible as possible and are less prone to delegate. This would imply that at the start and end of parliamentary terms the (scope of) brokering activities could change. What is more, newcomers to the House are unknown to advisors. They may not yet know (or be able to anticipate) the MEP's objectives and priorities, which they for example need to represent in the negotiations.

It is found that advisors derive or 'construct' political direction from their appreciation of the position(s) and values of the political group. The prediction of the group line and subsequently the appropriate course of action appears easier for advisors working for the smaller or more homogeneous groups than for ALDE, EPP, or S\&D advisors. Moreover, a coherent group line strengthens the advisor's position in the external negotiations as (s)he can more easily guarantee the support of the group (I.0.2, 8, 12, 13, 19; SR73). In the internal coordination of positions and in the external negotiation of compromises, advisors first and foremost 
represent the MEP in charge. Advisors' political role is enhanced by a strong, established position of the MEP in charge of the file. "An excellent advisor is able to add and increase the persuasiveness of his shadow MEP /group" (SR53). Not only does the reputation of the MEP reflect on the advisor as (s)he acts as the MEP's proxy, the objectives and priorities of an experienced and reputed MEP are easier to anticipate based on his or her track record (I.3, 11, 15, 22; SR23, 53). In cases where the MEP in charge voices ideas that substantially deviate from the common group line the advisor's role is to mediate, either by finding a compromise between the different ideas represented in the group or by convincing the MEP to withdraw the dissenting amendment (I.1, 15). In sum, political direction facilitates the pro-active behaviour of advisors, hence having a positive impact on their coordination activities and ability to provide compromisebuilding and negotiation strategy advice.

\section{Complexity}

The analytical framework of the thesis defines complexity in relation to the subject matter and is expected to vary across parliamentary committees or specific policy or legislative proposals (see 2.3.2). From the literature the assumption is drawn that as 'complexity' increases MEPs are more likely to seek assistance and grant advisors a political role.

Both survey respondents and interviewees stress that advisors should be able to analyse technical and complicated files. They contend that political advisors have more discretion as the issue under consideration becomes more complex (I.1, 4, 13, 15). Several advisors explained how the discretion of group advisors increases in 'highly technical dossiers'. In files with a lot of technical details, the 'value' of assistance increases (I.1), advisors have more room for 'influence' (I.4, 13), it becomes 'more likely 
that MEPs follow the advisor's advice' (I.13), or MEPs pay less attention (I.15).

An interviewee compared the Internal Market committee (IMCO) to the Employment committee (EMPL), illustrating that the level of complexity affects the degree of visibility - hence importance - MEPs ascribe to a file (I.16). Two other interviewees stressed that technical files get less attention, in terms of group debates (I.15, 17). This means that advisors cannot derive their mandate from the discussed group position. In such files 'it becomes more difficult to work with the other groups' (I.15). The complexity of files may thus have a restricting effect on group advisors' inter-group coordination function. Nevertheless, in highly complex files it is more likely that MEPs follow the suggested (compromise) positions or advice on negotiation strategy.

\section{Politicisation}

Politicisation is defined in relation to division in the EP, in general or with regard to a specific dossier (see 2.3.2). It is therefore something that can change over time and varies across policy areas. Issues that divide the EP are likely to cause division within the larger and more heterogeneous groups (I.15). A coherent group line forms the advisor's political mandate in external coordination. Thus, politicisation increases the need for intra-group coordination and for facilitating internal and external compromises.

Nonetheless, politicised issues or policy domains are likely to attract more attention from the outside world. Interviewees reported that increased attention from national political parties or the media makes MEPs less prone to delegate and results in tougher negotiations across the groups (I.1, 4, 7, 11). In salient and divisive issues, MEPs take a more active role, thus potentially restricting the coordination function of the advisor. In sum, 
politicisation increases the need for political analysis of the various stakes, while advisors' internal and external coordination functions are restricted because MEPs tend to be more controlling on salient, divisive issues.

\section{Assessment of the contextual factors}

As proposed in the framework, the context affects delegation. To assess the (optimal) circumstances in which brokering may be acceptable to MEPs the impact of the factors is evaluated by attributing the following values: indispensable $(++)$, positive impact $(+)$, no impact/ not relevant $(0)$, or a negative impact (-). The findings are illustrated in table 7.3.2.

The analysis concludes that as a group is more cohesive it becomes easier for advisors to construct political direction, or guidance for their actions. The same applies to advisors that represent experienced and reputed MEPs. Moreover, the track record of an MEP reflects on advisors in negotiations. Depending on the MEP this may facilitate or restrict their role. Complexity increases the overall need for support and thus the discretion of the advisor. However, the decreased involvement of MEPs in complex files also means that advisors cannot derive guidance for their actions from political debates held on the issue. Finally, politicisation increases the need for political analysis of the various stakes, while advisors' internal and external coordination functions are restricted because MEPs tend to be more controlling on salient, divisive issues. 
Table 7.3.2 Contextual factor assessment for the adoption of the Broker role

\begin{tabular}{|l|c|c|c|}
\hline & $\begin{array}{l}\text { Political } \\
\text { direction }\end{array}$ & Complexity & Politicisation \\
\hline ROUTINE BROKER & + & + & - \\
\hline $\begin{array}{l}\text { Participation in technical } \\
\text { trilogues }\end{array}$ & & & \\
\hline PRO-ACTIVE BROKER & + & + & + \\
\hline Political analysis & + & + & - \\
\hline Reconciling views internally & + & + & - \\
\hline $\begin{array}{l}\text { Negotiating compromises at } \\
\text { staff level }\end{array}$ & + & + & \\
\hline Replacing MEPs & + & & + \\
\hline
\end{tabular}

\subsection{Concluding remarks}

This chapter analysed the Broker role by applying the framework to the empirical data. The ideal-type Broker role entails both a facilitating and a coordination function. The former relates to advice on negotiation strategies and the latter to organising support for positions and pre-negotiating compromises. The empirical research shows that advisors from across the different groups and various parliamentary committees are responsible for both brokering functions, yet the vast majority of questioned advisors consider the coordination of positions within and between the groups to be their core task. Moreover, the findings expose that advisors from the ALDE, EPP, and S\&D groups attach relatively more weight to brokering than their counterparts in the other groups. The findings reflect that they fulfil a stronger intra-group coordination function because they have to find agreement between the multiple interests and sensitivities of the national delegations. The cohesion and priorities of a group appear to affect the 
focus of advice. It is found that coordination activities take centre stage in the larger groups and that their overall orientation is aimed at reaching agreement.

Brokering entails technical as well as political elements. Advisors' day-today activities include the inventory of positions. Yet, they facilitate compromises by advising MEPs how to overcome controversies, assessing what is acceptable to the group, and what can carry a majority in Parliament. In their coordination function advisors work towards a group line by synthesising and reconciling the different views within the group, then representing this position in external negotiations that often take place at staff level. They thus perform an intermediary function but not only by transmitting clearly delineated positions. Beyond the conceptual scope, advisors fulfil a backstage coordination function in relation to the intraparliamentary negotiations. They can shape the position of the group through their advice on how to solve internal differences and by actually setting out to resolve these divergences themselves. It is furthermore found that the advisor's role in intra-parliamentary negotiations transcends the ideal-type role in that they replace the MEP in charge, acting and speaking on his or her behalf.

The empirical evidence presented in this and the preceding chapters demonstrates that the intra-parliamentary coordination is an informal process. For the larger part it takes place outside of the formal parliamentary structures. Advisors operate ahead of political discussions and in the margins of meetings at MEP level. Interviewees and survey respondents acknowledge that their activities are of a political nature but the majority of advisors depict their role as benign, stressing that the final say always remains with the MEP. However, this does not mean that advisors follow explicit instructions in the informal process leading up to a decision by the MEP. While advisors broadly claim to act in the interest of 
the MEP or group, it has become apparent that these interests (the desired outcome) are not straightforward or predefined. For that reason the role is predominantly labelled as pro-active. The analysis concludes that the advisors' mandate is implicit and derived from the group's or the MEP's priorities. Advisors' participation in the inter-institutional negotiations forms the exception, given the strict and fragile mandate of the EP negotiating team.

Throughout the informal preparations advisors have to consider multiple outcome scenarios. Improvisation is a strategy to deal with such situations in which the desired outcome is multifaceted or uncertain. This requires the advisor to determine the necessary or appropriate course of action in light of the group's ideological views. Nonetheless, advisors' pro-active behaviour hinges on the accurate representation of the MEP's or group's position. The empirical research reveals that advisors, when replacing MEPs in negotiations, do not voice their own opinions. They rather predict and interpret what the MEP in charge wants to achieve, and what is in the general interest of the group. Although advisors enjoy significant discretion when acting as Brokers their activities are thus delineated by the ideological values of the group they work for. The role of the advisor is to secure the best possible outcome for the group. Moreover, they take action when members of the group take positions that oppose or clearly deviate from the ideology of the group. This type of intervention by the advisor shows that their discretion in intra- and inter-group coordination is high. These pro-active functions of the Broker role clearly set group advisors apart from other supporting actors in the EP.

The assessment of the seven factors of the framework concludes that trust and political sensitivity are prerequisites for pro-active brokering. These attributes, combined with a context where advisors work on a file or a specific text that is not highly politicised in the EP, prove to be the optimal 
conditions for the adoption of the role. Political sensitivity enables the advisor to assess acceptable compromises and the likelihood that these amendments will carry a majority in the House, which are prerequisites for devising the group's negotiation strategy. Trusted advisors will have the ear of the MEP in charge and his or her personal assistant, which increases the likelihood that advice is followed or the input is 'accepted'. The advisor's informal intra-parliamentary network is indispensable for the effective negotiation at staff level. And only advisors who demonstrate political sensitivity will be able to accurately represent the group in such negotiations. Although institutional memory facilitates the role, similar effects may be produced by the other factors. The context affects the discretion of advisors. First of all, advisors have greater room for manoeuvre in the committee phase because their mandate is more flexible than during the negotiations leading up to the plenary vote. The analysis furthermore concludes that when a group is more cohesive it becomes easier for advisors to construct political direction, or guidance for their actions. The same applies to advisors that represent experienced and reputed MEPs. Moreover, the track record of an MEP reflects on advisors in negotiations. Depending on the MEP this may facilitate or restrict their role. Complexity increases the overall need for support and thus the discretion of the advisor. However, the decreased involvement of MEPs in complex files also means that advisors cannot derive guidance for their actions from political debates held on the issue. Finally, politicisation increases the need for political analysis of the various stakes, while advisors' contribution to internal and external coordination is restricted because MEPs are more reluctant to delegate when it concerns salient and divisive issues. 



\section{CHAPTER 8. CONCLUSIONS: 'UNPACKING' THE POLITICS OF ADVICE}

The role of political advice in decision-making was the overarching topic of this thesis. Specifically, the thesis examined in-house political advice in the European Parliament (EP). In this respect, it has explored the question whether and under which conditions group advisors in the EP assume a political role. In addressing the research question, the thesis contributes to conceptual, empirical, and normative scholarly discussions. The key contributions are listed below. Sections 8.1-8.5 then further synthesise and reflect on these findings and their implications.

First, the developed analytical framework contributes to conceptual debates and theory building within the scope of legislative organisation and informal governance. The concept of 'political advice' has remained relatively unchartered territory thus far. The dissertation addresses this gap and contributes to the academic debate by conceptualising what a political role by advisors might entail. It proposes 'political advice' as a distinct category in which technical and political dimensions 'meet', thereby offering a novel approach to study the relationship between the two dimensions and assess the political aspects of advice (8.1).

In terms of empirical evidence, the thesis responds to a wider lack of knowledge about the preparations that precede actual decision-making within the wider EU arena. The findings increase our understanding of intraparliamentary practices and the backstage arena in which the groundwork for compromises is laid down. It has contributed to the uncovering of intraparliamentary preparations of EU trilogue negotiations that remain out of the public eye. The research has demonstrated that advice may shape group positions and inter-group compromises. Section 8.2 presents the key 
findings on which this conclusion is based. The involvement of group advisors in intra- and inter-group coordination sets them apart from other internal advisors. This distinct role of political group advisors is further discussed in section 8.3.

The empirical research has furthermore shown that advisors enjoy a great deal of autonomy and have room to improvise (adopt a pro-active role), most notably during the early stages of decision-making. It was revealed that advisors manifest pro-active behaviour in each of the four roles of the framework. The pro-active mode is, in fact, found to be common for the large majority of activities carried out by group advisors in the EP. Section 8.4 presents the circumstances that were found to affect the likelihood that advisors' pro-active behaviour is acceptable to MEPs. The analysis revealed that advisors can only manifest pro-active behaviour when they act in pursuit of the interests of their group. The assessment of the personal factors concluded that the general prerequisites for the provision of political advice are that the advisor demonstrates political sensitivity and is trusted. In respect to the contextual factors, it was found that the type of parliamentary procedure, the stage of decision-making, and the experience of MEPs and their personal assistants matter considerably. This, however, requires further investigation. Moreover, the study exposed that the importance attached to a role, as well as the likelihood that advisors take up a certain role is strongly linked to the group they represent. In this regard, section 8.5 concludes that there are three different orientations of advice.

Finally, in respect to the normative debate on EU governance, the thesis allows for a more nuanced assessment of the legitimacy of (informal) EU decision-making than is generally assumed in the rationalist politicsadministration dichotomy (see Hague and Harrop, 2010). Contributing to theory building, the framework defines the relationship between the political 
and technical spheres of activity as a complementary rather than an antagonistic process. The conceptualisation of a 'mixed sphere of activity' helps to explain how political coordination takes place at the everyday level. In terms of empirical evidence, the large-scale research that was conducted did not conclusively determine that political advice poses a threat to democratic decision-making per se. While in rational-choice and principalagent theory the dichotomy is premised on the notion that the behaviour of non-elected advisors is strictly monitored or controlled by elected representatives, no evidence for such a restriction of the advisor's room for manoeuvre was encountered. Rather, the findings support the logic of appropriateness argument, showing that advisors determine the required activities based on what they deem to be line with the political aims of their superiors. The in-depth examination of the implications of the role of political advice for legitimacy is one of the subjects proposed for a future research agenda (8.6).

\subsection{Contribution to theoretical debates: capturing the technical and political elements of advice}

The concept of 'political advice' has hitherto remained relatively unchartered territory. The dissertation addresses this gap and contributes to the academic debate by conceptualising what the political aspects of advice might entail. This section reiterates the added value of the developed analytical framework and sums up its three key contributions: (i) the framework allows for a process-oriented approach, (ii) the framework is instrumental for the analysis of the practical functions and nature of advice, and (iii) the framework offers a nuanced approach to the normative debate on the role of non-elected actors. Each of these contributions is further discussed below. 
The literature has demonstrated that advice to elected representatives may involve political aspects (Fouilleux et al, 2005; Winzen, 2011; Dobbels and Neuhold, 2013; Neuhold and Dobbels, 2014; and Högenauer and Neuhold, 2015). Yet, studies that attempted to disentangle what are overtly 'technical' or 'political' categories have shown that the two spheres are difficult to disentangle (Fouilleux et al, 2005; Winzen, 2011). The literature review conducted in this thesis concludes that the ambiguity is not related to authority as it is generally found that the final say in decision-making remains the prerogative of the elected representatives. Instead, the overlap is tied to the informal process in which political decisions are prepared. The thesis adds a new dimension to this scholarly debate by conceptualising what a 'political role' by advisors might entail (see 2.1.2).

Traditionally, public administration scholars approach the relationship between elected and non-elected actors in terms of a division of labour and authority between the political and technical spheres of activity (e.g. Moe, 2005). The developed framework proposes an alternative approach by conceptualising 'political advice' as a distinct category in which the two spheres 'meet', thereby offering a novel approach to study the relationship between the two dimensions and assess the political aspects of advice. The relationship between the political and technical categories is defined as a complementary rather than an antagonistic process. The argument is that both categories are necessary for and feed into political advice. In this way, the thesis advances the sociological institutionalist logic of appropriateness and argues that to appropriately advise and support legislators, non-elected actors inevitably enter the political sphere of activity. During the early stages of informal decision-making, advisors act without explicit instructions from the political level. They anticipate what the legislator needs or wants to achieve and apply judgement in their activities to achieve the desired outcome. It is found that this improvisation is a strategy to deal with unknown or uncertain outcomes (see 8.4). 
The significance of this novel approach is threefold. First of all, it allows for a process-oriented approach, which offers a new way of explaining how political coordination takes place at the everyday level. The aim of this dissertation was to better understand the process of providing advice. Rather than focusing on individual differences between advisors, the framework that has been developed enables the identification of general activity and behaviour patterns in the provision of advice. While the traditional politics-administration dichotomy is actor-focused (see Hague and Harrop, 2010), the developed framework thus concentrates on activity. The former considers the demarcation between the technical and political categories predominantly as a difference in responsibility or authority. The thesis postulates that this does not fully capture the overlapping spheres of activity. Building on the anticipation logic theory, advisors are expected to base their actions, or construct their role, on what the circumstances demand (see e.g. Page and Jenkins, 2005; Olsen, 2006; Peters, 2009).

As part of the framework, the following key elements have been identified that define whether an activity is labelled as political: (1) anticipation of political priorities and desired outcomes, (2) ideological assessment, and (3) the use of implicit knowledge and tactics. The first two elements are for example markedly manifested through the briefings that advisors draw up for their MEPs. They anticipate the elements MEPs need to form an opinion or take a decision. Based on their judgment as to what is acceptable to the majority of the group, they include policy options, arguments, or implications in such briefings (see 6.2.2). Advisors use implicit knowledge and tactics to formulate and execute strategies to realise the desired outcome. An example of such a political activity that was encountered across the groups is the gathering of intelligence about the various positions present in the EP, or those of external stakeholders, so as to predict acceptable compromises or coalitions. Nonetheless, advisors can only perform those political tasks based on the preparatory or practical activities 
they also execute. Therefore, each of the four roles that are constructed combines technical and political tasks. For example when drawing up a briefing note, advisors' technical tasks entail the compilation and organisation of information about procedures and content (see 6.1.2).

The second contribution lies in the framework's operational value for the analysis of the function and nature of advice. The application of the framework (chapters 4-7) has demonstrated how it is instrumental for the unpacking of political advice. Previous studies have found that advisors' input in legislative decision-making takes various forms (see e.g. Hammond, 1984, 1996). The typology that has been developed as part of the framework defines clear analytical categories that allow for the consideration of the various functions of advice (see 2.2.2). The three modes of discretion that have been construed facilitate the evaluation of the political scope of advisors' input (see 2.1.3). Finally, the factors are instrumental in predicting the optimal circumstances in which political advice may be provided (see 2.3). It is demonstrated in the thesis that the combination of these analytical tools provides for capturing and understanding the 'mixed sphere of activity' in which advisors operate. According to what the circumstances require, advisors fulfil the different types of advice (roles). The framework helps to identify activity patterns in the provision of advice, to assess the extent to which these activities can be labelled as 'political', and to evaluate the circumstances in which a 'political role' is acceptable to elected representatives.

The third contribution is related to the normative debate on informal EU governance. Academic studies on the relationship between elected and nonelected actors generally discern questions or concerns around accountability, preferences, and control (see e.g. Arnold, 1987; Moe, 2005; Peters, 2009; Gailmard and Patty, 2012). The developed concepts provide an alternative to the prevailing notion that influence of non-elected actors 
pre-supposes a threat to legitimacy. The framework offers a more nuanced perspective on this issue, demonstrating that the impact of advice on decision-making is not necessarily normatively questionable. By advancing the anticipation logic it proposes that the input by advisors in the political sphere of activity is derived from the political aims of their superiors. In other words, advisors have to anticipate what the MEP needs, or wants to achieve in order to be successful (see 8.4).

These theoretical contributions suggest the value of applying the framework to other institutional settings, or using it to compare the roles of various types of advisors within one institution. These future research avenues are further discussed in 8.6. The next section presents the central empirical findings in relation to the political scope of the role of advisors.

\subsection{The political scope of the role of advisors}

The thesis responds to a wider lack of knowledge about the preparations that precede actual decision-making within the wider EU arena. The empirical findings presented in this section increase our understanding of intra-parliamentary practices and the backstage arena in which the groundwork for compromises is laid down. The encountered evidence suggests that 'political advice' may shape group positions and inter-group compromises in the early stages of EP decision-making. However, as a legislative file progresses through Parliament, the role of advisors becomes increasingly bound by the input from MEPs, and thus less political.

The thesis has argued that non-elected actors anticipate the preferred outcome of elected actor(s) and improvise the appropriate line of action guided by their expertise and experience (cf. Patterson, 1970; Page and Jenkins, 2005; Olsen, 2006). To assess the extent to which advice is political, varying degrees of political behaviour were developed. Drawing 
inspiration from Mayes and Allen (1977), the framework proposed three incremental modes that are tied to the discretion of the advisor: routine (activities are guided by an explicit mandate), reactive (either the 'means' or the 'ends' require improvisation on the part of the advisor), and proactive behaviour (the advisor has the room to determine both the 'means' and 'ends'). In this approach, the focus lies on the process whereby the (desired) outcomes are achieved (or influenced). Activities become more pro-active as the advisor's room for improvisation in the intra-parliamentary coordination process increases (see 2.1.3).

Although the initial proposition of the study was that MEPs have the final say on the outcome, the findings have shown that the preparations by advisors can influence the direction of group positions, and of the compromises forged between the groups. The empirical research has shown that advisors enjoy a great deal of autonomy and have room to improvise (pro-active role). Such pro-active behaviour, however, appears to predominantly occur during the deliberative process through which EP party groups develop their positions on specific legislative proposals. Accordingly, the potential of advisors to shape political decisions is found to be highest during the early stages of decision-making. At that time, advisors act without explicit instructions or input from the elected representatives.

It was revealed that advisors manifest pro-active behaviour in each of the four roles of the framework. The pro-active mode is, in fact, found to be common for the large majority of activities carried out by group advisors in the EP, as figure 8.2 below illustrates. The main findings are summed up below, assorted according to the potential of advisors' activities to shape political decisions. First, advisors' key activities prior to political debates are presented. Next, their role in the margins of EP meetings is considered. Finally, the activities that are performed after political debates are discussed. 
Figure 8.2 Advisors' potential to shape political decisions

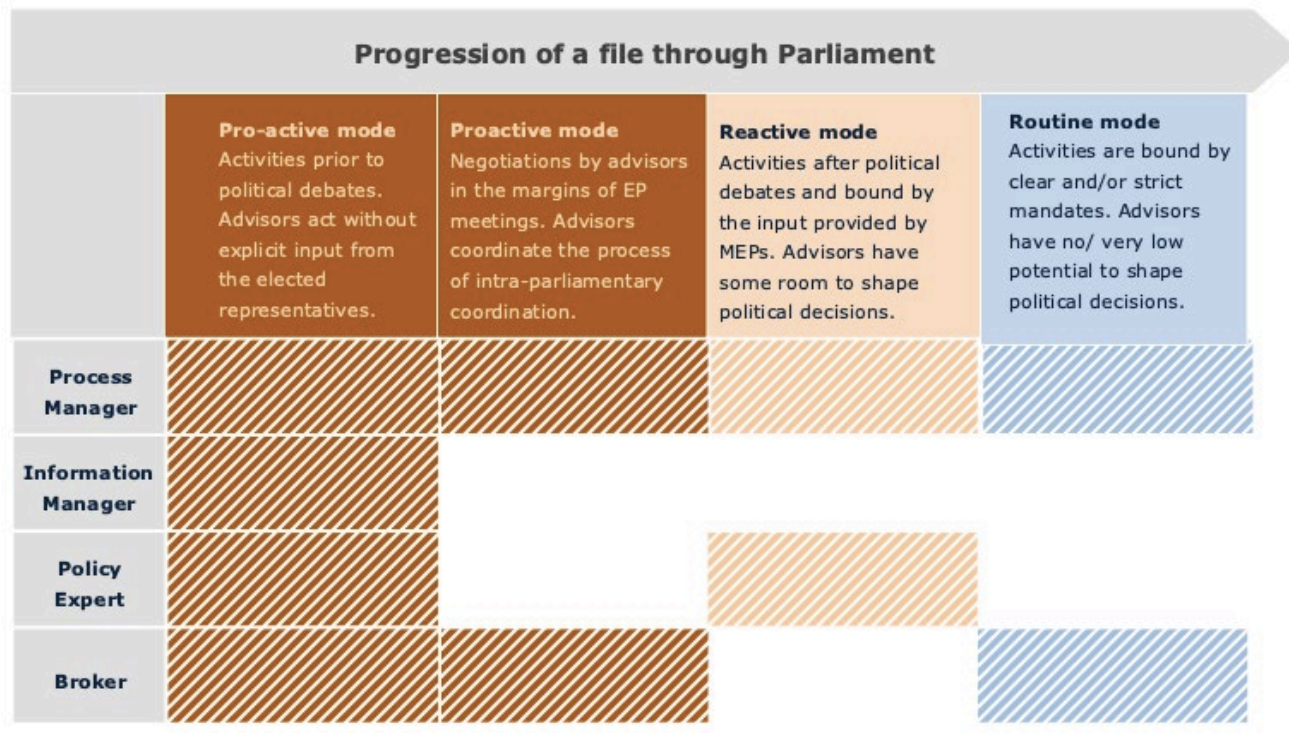

Advisors' activities prior to political debates

The empirical research has revealed that the activities of advisors notably enter the political sphere during the early stages of intra-parliamentary coordination, i.e. prior to the formulation of positions. At this point in the coordination process, advisors provide input in the absence of clearly delineated political positions. In this respect, the research identified the following activities as common to group advisors:

\section{Pro-active guidance (Process Manager role): advisors can shape} the group's priorities by advising on which rapporteurships to attain. The acquisition of rapporteurships depends on a point system and is usually a bargaining exercise between the groups (see 1.2). Advisors contribute to formulating a strategy as to the key goals and margins for negotiation. They can furthermore influence the direction of the group line by approaching and involving specific MEPs in the development of a group 
position. These preparations occur informally ahead of the group meetings (see 4.2).

$\checkmark$ Pro-active information management: advisors select and interpret (sources of) information that they then use for pro-active policy expertise and brokering. The empirical findings revealed that the information needs of MEPs are generally implicit or at least open to the interpretation (see 5.2). Advisors thus have to rely on their judgement to provide MEPs with the appropriate information.

Pro-active policy expertise: advisors argue for (or against) specific policy choices and develop policy positions based on (third-party) expert knowledge (see 5.2). With regard to the provision of policy expertise, the involvement of advisors differs significantly across the groups, which is further discussed in section 8.5.

$\checkmark$ Pro-active facilitation of compromises (Broker role): advisors devise acceptable compromises or coalitions. They advise how to tackle (potential) internal and external controversies and predict possible coalitions (see 6.2).

Negotiations by advisors in the margins of EP meetings

Since the EU does not have a government-opposition structure, the EP does not function through stable coalitions. Instead, deals are struck on a caseby-case basis (see 1.3.3). The thesis adds to the literature on coalition formation by unravelling the informal coordination process through which compromises come about. The research has shown that multiple coalitions can play a role within a certain file. In fact, the findings suggest that details of a legislative proposal are negotiated 'line by line' and that these negotiations largely take place at staff level (see 7.1.2). 
In the committee and plenary stages of EP decision-making, the role of advisors is structured around the intra- and inter-group coordination mechanisms that are in place (see 1.3). There are three EP mechanisms that are found to be central to the role of the advisor: (1) 'prep meetings' in which group coordinators convene the respective members, deputies, personal assistants, and group advisor(s) ahead of committee meetings; (2) group meetings ahead of EP plenary sessions to deliberate and work towards a final group line that is acceptable to (the majority of) the members; and (3) 'shadows' meetings' in which the appointed rapporteur and shadow rapporteurs prepare the report and negotiate compromise amendments.

The empirical research has demonstrated that advisors prepare each of these meetings. In the run-up to the meetings they engage in the four types of pro-active behaviour mentioned above. They also participate in these mechanisms, can even replace MEPs, but mostly operate in the margins. As to the latter, advisors are found to coordinate the process of intraparliamentary negotiation through their Process Manager and Broker roles. These two activities set group advisors apart from the other types of supporting staff (see 8.3 ):

$\checkmark$ Pro-active signalling (Process Manager role): advisors signal potential incoherence, conflict, or inconsistency between the various (national delegation) interests within the group. They then report such issues to the group coordinator in order for them to be addressed during group meetings. As part of their pro-active Process Manager role, advisors provide MEPs with voting indications ahead of a vote (see 4.2).

Pro-active coordination (Broker role): advisors set out to reconcile diverging views within the group, and (pre-)negotiate compromises at staff level. In these informal negotiations they speak on behalf of the 
MEP in charge, and in shadows' meeting they can even replace MEPs (see 7.2).

Advisors' activities after political debates

One of the key findings of the study is that advisors manifest pro-active behaviour in the preparation of political decisions. These activities occur ahead, or in the margins, of meetings convened at MEP level. However, advisors' capacity to influence the direction of positions decreases once political debates, either at group or committee level, have taken place. As a legislative file progresses through Parliament, the role of advisors thus becomes increasingly bound by the input from MEPs as expressed during these debates. At this point in the intra-parliamentary coordination process, advisors contribute through the reactive Process Manager and Policy Expert roles:

Reactive process management: advisors coordinate the amendments submitted by the members or national delegations of their groups. It is their responsibility to avoid conflicting amendments. Moreover, advisors propose voting indications to the MEP in charge based on the views that are present in the group (see 7.2).

$\checkmark$ Reactive policy expertise: advisors provide policy advice by weighing and presenting policy options based on the views that are present in the group. In addition, they can draft legislative or policy texts (reports, political resolutions, amendments) based on the views expressed during group debates, or specific input received from the MEPs. Exceptionally, advisors have the autonomy to develop policy positions without such input (pro-active Policy Expert role). However, findings show that such a role is most likely to be adopted by Greens/EFA advisors. ALDE, EPP, 
and S\&D advisors are least likely to assume a pro-active Policy Expert role (see 6.2).

Finally, as part of the Process Manager and Broker roles, advisors perform tasks that have no - or a very low - impact on the formation of political positions. In the routine mode activities are bound by a clear and/or strict mandate:

$\checkmark$ Routine process management: advisors provide practical organisational assistance by arranging deputies when MEPs cannot attend a committee meeting, and by distributing speaking time for the plenary sessions. They make sure that MEPs are aware of the relevant procedural information, so that EP procedures and deadlines are respected (see 4.2). In such activities advisors are led by the EP and group RoP.

$\checkmark$ Routine brokering: advisors participate in technical trilogues based on the mandate that is formulated for the EP negotiating team (see 1.3). These meetings convene the staff of the EP, Council, and EC who prepare the political trilogues and work out the details of political decisions taken in those trilogues (see 7.2).

To conclude, advisors' potential to shape political decisions is the highest during the early stages of EP decision-making. Prior to, and in the margins of, political debates advisors can influence the direction of group positions, and of compromises forged between the groups. This potential decreases as a file progresses through Parliament and the role of advisors becomes increasingly bound by the input from MEPs. The empirical research furthermore revealed that the involvement of group advisors in intra- and inter-group coordination sets them apart from other internal advisors. This distinct role of political group advisors is further discussed in section 8.3. 


\subsection{The distinct role of political advisors}

The previous section presented the key activities of EP group advisors, as have been identified from the empirical research. The analysis revealed that the involvement of group advisors in intra- and inter-group coordination sets them apart from other internal advisors. The distinct role of group advisors and the division of labour between them and other in-house sources of advice are considered in this section.

In the EP, party groups are at the heart of majority-building processes as the internal organisation and division of labour is structured around them. This thesis postulated that - by extension - group advisors are involved in the informal preparation of compromises. Their distinct role is tied to the notion that they are employed to represent and defend the interests of the party group. These interests, however, are a composite of the objectives and sensitivities present in the various national delegations that make up the group. What distinguishes group advisors is therefore closely related to the informal coordination process that occurs within and between the EP party groups. The empirical research revealed two distinct contributions in this respect.

The first task that appears to be the exclusive domain of group advisors is the signalling function they fulfil in relation to intra-group coordination (as part of the Process Manager role, see chapter 4). Advisors are responsible for identifying potential problems that need to be addressed for the formation of a coherent group position. Most prominently, this signalling function is tied to the preparation of group meetings. This could, for example, involve one or several national delegations with specific concerns regarding a given file. Advisors then ensure that the group coordinator and rapporteur are aware of potentially divisive issues, and that they are tabled for discussion at MEP level. Advisors furthermore closely monitor whether 
the (shadow) rapporteur represents the majority group line. During the preparation of the voting list, advisors identify inconsistent or conflicting amendments in the position of the group, or in relation to previously adopted positions. They also work with their colleagues in other parliamentary committees in order to avoid opposing positions. This is particularly delicate when it concerns competing policy interests in two or several committees. For example, the files for which the AGRI committee is responsible often have a regional component, and are linked to environment, health or food safety issues. Such files are therefore usually also considered by the REGI and ENVI committees. Advisors make the group's coordinator in committee aware of any potential problems in order to ensure that a group debate takes place.

The second distinctive activity is the Broker role of group advisors. In addition to signalling potential conflicts or incoherence, advisors attempt to actually mediate within the group. Nearly all the advisors in the study claim to be involved in intra-group coordination. Only one EFD survey respondent and three interviewees (EFD and Greens/ EFA) did not bring up this activity. Advisors coordinate positions internally either by talking directly to the MEPs concerned or by addressing their respective assistants. It is the advisor's role to take as much controversy out of the way as possible. Only when a solution cannot be found through this type of mediation is an issue tabled for a group discussion (i.e. at MEP level). Advisors thus enjoy a great deal of discretion in signalling and solving internal differences, which is chiefly explained by a need for efficiency. Particularly in the larger groups, there are many different views and considering all for each file that passes through Parliament would simply take up too much time. Correspondingly, the findings demonstrated that advisors from the ALDE, EPP, and S\&D groups attach relatively more weight to intra-group coordination than their counterparts in the other groups. 
In their Broker role, advisors also pre-negotiate compromises with their counterparts in the other groups. All but two interviewees brought up the common practice of 'pre-negotiating' at staff level, following which they brief their MEPs prior to the actual negotiations. The survey found that 90 per cent of the respondents negotiate compromises on behalf of the group. The data presented in 7.1.2 demonstrated that these compromises are prepared among staff. The EP RoP do not stipulate who can represent the group in shadows' meetings and the empirical data suggest advisors may do so. The qualitative data furthermore revealed that ahead of the shadows' meeting group advisors meet, or contact one another informally, to probe the acceptability or level of support for certain amendments, and form alliances on certain issues. The survey confirmed that advisors meet their counterparts very regularly: a majority of respondents reported to interact on a daily or weekly basis (respectively $49 \%$ and $44 \%$, see figure 5.1 a).

Considering the role of advisors in intra- and inter-group coordination, the study has confirmed the expectation that group advisors are - to greater extent than other staff - involved in the preparation of compromises in the EP. Although their role becomes more constrained once political discussions have taken place in the group, and a group line has been formed, advisors coordinate the negotiations backstage. As such they have an influence on the direction of political decisions, which was elaborated in the previous section.

The focus of the study was on the internal coordination mechanisms of the $E P$, and thus on in-house political advice. Three major internal sources of advice are at the disposal of MEPs for their legislative activities: i.e. their personal assistants, EP officials, and group advisors. The empirical findings corroborate the hypothesis that all three sources of assistance operate in the mixed sphere of activity. Despite some encountered exceptions of competition or wariness among staff, generally a pragmatic sense of making 
things work appears to prevail. Previous studies revealed diverging findings in respect of the (preferred) principal assistance offered to rapporteurs (e.g. Neunreither, 2002; Winzen, 2011; Egeberg et al, 2013; Pegan, 2015; see 3.1.2). In line with these findings, the empirical analysis showed that the source of assistance varies and the MEP in charge selects the support he or she desires. Apart from the two distinct contributions of group advisors set out above, EP officials and MEP assistants can thus perform the other roles. The findings demonstrated that both EP officials and group advisors can take care of the groundwork for decision-making, i.e. making sure the overall coordination process runs as smooth as possible (Process Manager role). Conversely, MEPs' assistants tend to concentrate on specific or sensitive details that are important to his or her MEP. At the discretion of the rapporteur, EP officials in the Secretariat, group advisors, and MEP assistants can be involved in the drafting process (Policy Expert). All three types of supporting staff also engage in information management. MEP assistants and group advisors are found to predominantly liaise with third stakeholders, while EP officials form the main link to the other EU institutions. As a general rule, the preparation of plenary votes is considered 'group business' for which advisors prepare briefings and voting indications. In the committee stage, personal assistants may take over these tasks, depending on their expertise.

In sum, the research has confirmed that group advisors are - to greater extent than other staff - involved in the preparation of intra- and intergroup compromises. The findings demonstrate that, apart from the distinct contributions of group advisors through the Process Manager and Broker roles, the division of labour occurs at the discretion of the (shadow) rapporteur. The next section considers the circumstances that affect the likelihood that political advice is acceptable to MEPs. 


\subsection{The pro-active behaviour of advisors}

The previous sections presented the central empirical findings regarding the role of EP group advisors. This section reflects on the discretion of advisors to contribute to decision-making. It considers what guides advisors' activities and how different circumstances affect the likelihood that proactive behaviour is acceptable to MEPs. The empirical data have revealed that advisors act without a clear mandate for the large majority of their activities and therefore have to improvise. This argument is elaborated in the first sub-section. In light of this finding, the second sub-section considers the possible implications of advisors' pro-active behaviour for the democratic legitimacy of EP decision-making. The section concludes with a discussion of the factors that enable or restrict the pro-active behaviour of group advisors.

Improvisation as a strategy to deal with unknown or uncertain outcomes

The framework that is presented in chapter 2 posits that activities are either guided by a clear mandate (instructions) or by the advisor's interpretation and judgement (improvisation) when no explicit instructions are provided. The political dimension of the role becomes more prominent as the advisors have more room to improvise. The chances for improvisation mainly lie in the early stages of decision-making, prior to any political debates on the issue (see figure 8.2). At this time, no clear demands or priorities that can serve as guidance have been formulated at the political level.

The research demonstrated that advisors work closely together with (shadow) rapporteurs, the group's coordinator of the parliamentary committee in question, and MEP assistants (see figure 5.1a). It was found that political instructions are most likely to emanate from this interaction. However, a large majority of advisors acknowledged that in carrying out their daily tasks they are not explicitly told what to do. To fulfil their duties 
advisors need to improvise, i.e. apply their judgement to anticipate the ideal outcome for the group and the means to achieve such an outcome. In fact, improvisation is the advisor's strategy to deal with uncertain or unknown outcomes. The key activities that advisors fulfil in this regard have been summed up in section 8.2. High levels of improvisation (pro-active mode) are encountered for each of the roles prior to the stage at which political debates are held. Following such debates, advisors can base their input on the political priorities and views expressed during the deliberations (reactive mode). In some of the process management and brokering activities, low levels of improvisation were encountered (routine mode) given that advisors are bound by a rather strict mandate (see 8.2).

\section{Implications for the democratic legitimacy of EP decision-making}

In light of the findings presented above, and in connection to the normative debate on EU governance, it is important to consider the possible implications of group advisors' pro-active behaviour for the legitimacy of decision-making in the EP. The research has revealed that the large majority of their actions are not based on explicit instructions from the elected representatives. Although some exceptions were encountered of advisors (accused of) chasing personal gain, the characterisation of the advisor as a Rasputin with undesirable influence on political outcomes does not ring true in light of the empirical findings. It was found that advisors can only effectively operate in the political sphere when they base their actions on what is in the interest of the party group. The basic finding that led to this conclusion is that group advisors are guided by, and thus pursue, the political agenda of the party group. They devise their actions and behaviour within the scope of these objectives. The qualitative data reflect that advisors are (perceived to be) successful when the group is successful. Therefore, they construct their role according to what they believe will advance the position of the group. It is only under these circumstances that 
their pro-active behaviour is accepted by the MEP. Conversely, findings show that actions that are unfavourable to the (collective) interest of the group are not accepted.

The findings hence offer a nuanced assessment of the input by staff in the EP decision-making process, demonstrating that the impact of advice on decision-making is not necessarily normatively questionable. The rationalist politics-administration dichotomy is premised on the notion that the actions and behaviour of non-elected advisors is strictly monitored or controlled by elected representatives (e.g. Arnold, 1987; Moe, 2005). The extensive empirical research conducted does not find any evidence for such a restriction of the advisor's room for manoeuvre. Rather, the findings support the logic of appropriateness theory, showing that advisors determine the required activities based on what they deem to be line with the political aims of their superiors.

The context determines whether pro-active behaviour is acceptable to MEPS The objective of the thesis was to explore and explain the circumstances that enable or restrict a political role by group advisors in the EP. In addition to the conclusions set out above, the analysis identified that the following factors stimulate the capacity of advisors to effectively improvise and the likelihood that such pro-active behaviour is acceptable to MEPs:

\section{Political sensitivity is found to be an indispensable asset for the} provision of effective political advice. The added value lies in the advisor's 'awareness' or 'feel for the game'. This sensitivity allows them to forecast and empathise with the various positions and needs for assistance that MEPs might have. The stimulating effect was encountered for each of the four roles and closely relates to the finding 
that advisors can only manifest pro-active behaviour in pursuit of the interests of their group.

\section{$\checkmark$ Complexity increases the overall need for support, yet can pose} a challenge to political direction. Generally, MEPs have a greater need for advice in their dealings with complex files. In this respect, the research revealed a positive effect on the adoption of the Information Manager and Policy Expert roles. Complexity obscures the explicit needs and objectives, which means that the advisor has to improvise. However, at the same time, MEPs' involvement is likely to decrease in complex files, which impairs advisors' ability to obtain political direction for their actions. For that reason, complexity is found to have a restricting effect on pro-active process management (signalling potential problems and guiding the intra-group deliberations), and on the ability of advisors to negotiate compromises with their counterparts. This follows from the finding that it is difficult for the advisor to act or speak on behalf of an 'absent' MEP.

\section{Trust increases the likelihood that advisors' pro-active behaviour} is accepted by MEPs and that advice is followed. Trusted advisors have the 'ear' of the MEP in charge and his or her personal assistant. This interaction determines whether the provided input or recommendations are followed.

From the research it can be concluded that in order to explain advisors' potential to shape political decisions a combination of factors needs to be considered. The general prerequisites are that the advisor demonstrates political sensitivity and is trusted. However, the context in the end determines whether pro-active behaviour is acceptable to MEPs. The empirical analysis demonstrated that in order to predict the pro-active behaviour of advisors the parliamentary procedure is an important 
indicator. In fact, the qualitative data suggest that the nature of the file (legislative or non-legislative) affects the three contextual levels identified from the literature: i.e. substance matter (complexity), mandate (political direction), and political landscape (politicisation). Complexity is found to be perceived higher in legislative files. Political direction is considered to be clearer for political resolutions and politicisation then is generally stronger. Overall, MEPs attach greater importance to legislative procedures compared to political resolutions. The data suggest that the need for and value of assistance is also bigger in legislative files. This in particular affects the Broker and Information Manager roles. Legislative files usually require intricate compromise building. Intelligence of the manifold positions forms an important basis for formulating policy positions and brokering deals with the other groups. The need for these activities decreases in political resolutions since the political delineations are usually clear-cut. The provision of policy expertise, on the other hand, is more likely to be delegated to advisors with respect to the formulation of political resolutions, while EP officials are often involved in the drafting of legislative texts. In summary, legislative procedures appear to strengthen the Information Manager and Broker roles whereas the Policy Expert role is stronger in political resolutions.

Two additional factors were found to increase the likelihood of delegation to group advisors over other supporting actors, namely the stage of decisionmaking and the experience of the MEP and his or her assistant. Signalling potential problems for group cohesion and pre-negotiating compromises with counterparts have been identified as the core business of group advisors, while EP officials and MEP assistants might adopt the other functions (see 8.3). The empirical research found that the division of labour occurs at the discretion of the (shadow) rapporteur. Notwithstanding, the data suggest that in this choice the stage of decision-making matters. The findings have revealed that the preparation of plenary votes is primarily 
considered 'group business'. During this stage of the decision-making process, their role is less likely to be taken over by MEP assistants than during the committee stage. Group advisors take the lead in the preparations of the plenary session. They provide MEPs with briefing notes and voting indications as to how to vote on amendments and which votes are important. These 'voting lists' are drafted and circulated by the group advisor. Finally, the experience of the MEP and his or her assistant also matters for the division of labour among staff actors. In this regard, the research shows that the need for political advice is higher among newcomers at the start of the parliamentary term. Similarly, experienced assistants can take care of much of the work that could also be delegated to group advisors.

To conclude, this section reflected on the discretion of advisors to contribute to decision-making. For the large majority of their activities, advisors have to improvise, as they cannot rely on explicit instructions or guidance. In doing so, they base their advice on what they deem to be line with the political aims of their superiors. The assessment of the personal factors concluded that the general prerequisites for the provision of political advice are that the advisor demonstrates political sensitivity and is trusted. In respect to the contextual factors, it was found that the type of parliamentary procedure, the stage of decision-making, and the experience of MEPs and their personal assistants matter considerably. This, however, requires further investigation (see 8.6). Moreover, the study exposed that the importance attached to a role, as well as the likelihood that advisors take up a certain role is strongly linked to the group they represent. In this regard, the next section presents three different orientations of advice that have been identified from the empirical findings. 


\subsection{Three orientations of advice: compromise-oriented, policy-oriented, and procedure-oriented}

The previous sections presented the key empirical findings regarding the role of EP group advisors, reflected on their discretion to contribute to decision-making, and on the factors that affect the likelihood that pro-active behaviour is acceptable to MEPs. The analysis has demonstrated that the importance attached to a role, as well as the likelihood that advisors take up a given role is strongly linked to the group they represent. The EP party groups' participation in the legislative process appears to differ, which affects the role of advisors. The data furthermore suggest that the cohesion and ideological objectives of a group determine the focus of advice. Based on the findings, three different orientations of advice have been identified that are closely linked to the framework's typology: (i) the compromiseoriented approach (ALDE, ECR, EPP, S\&D), (ii) the policy-oriented approach (ECR, Greens/EFA, GUE/NGL), and (iii) the procedure-oriented approach (ECR, EFD, GUE/NGL). The ECR and GUE/NGL groups show mixed orientations as evidence for each of these (ECR) and two of these (GUE/NGL) approaches was encountered in the qualitative data. The most apparent differences are related to the compromise-oriented and policyoriented approaches, and respectively affect the intra-group Broker and Policy Expert roles. EFD advisors do not adopt the former, and GUE/NGL advisors only marginally act as intra-group Brokers. ALDE, EPP, S\&D advisors, on the other hand, designate intra-group brokering as their core responsibility. For the Greens/EFA advisor this constitutes the Policy Expert role.

Before further presenting the three different approaches, the overall findings in respect to what advisors perceive as their most important responsibility are considered. In response to an open-ended survey question, 43 per cent of respondents identified brokering activities as their 
key role. The vast majority (40\%) consider the coordination function to be their core task (see 7.1.2). Another 23 per cent pointed to tasks that may be labelled as process management (see 4.1.2). Process management is most prominently tied to the overall coordination of the intra-parliamentary legislative process. In relation to the other types of advice, policy expertise is only identified by 14 per cent of the respondents as their most important task. Although the qualitative data demonstrate that policy expertise is considered a valuable attribute of the advisor (all but three interviewees discuss the importance of policy expertise), only the Greens/EFA advisors recognise it as their chief role (see 6.1.2). Finally, it was found that information management serves an auxiliary function and forms the basis for the adoption of the other roles (see 5.1.2). In the survey, only 13 per cent of advisors reported it as their core responsibility. Nonetheless, the qualitative evidence showed that they use and rely on information for most of their tasks.

\section{The compromise-oriented approach}

A compromise-oriented approach applies to groups that fit the following criteria: heterogeneous policy interests and pursuit of a mainstream agenda. The ALDE, EPP, and S\&D are evidently compromise-oriented. To a lesser degree, this approach is also pursued by the ECR group. The empirical analysis found that the perceived core responsibility differs per group. The empirical findings show that advisors of the large, mainstream groups (ALDE, EPP and S\&D) perceive the Broker role as their most important responsibility. The qualitative data confirm that coordination activities take centre stage in these groups and that the overall orientation of the group is aimed at reaching agreement. The findings also reflect that these groups, in comparison to the other groups, pay more attention to intra-group coordination because they comprise a multitude of national 
delegations, each having specific interests or sensitivities. ${ }^{155}$ Accordingly, coordination mechanisms are more structured and ALDE, EPP and S\&D advisors underline their contribution to coordinating a group line between the national delegations. The ECR, Greens-EFA, and GUE-NGL advisors also assume such a mediating function but the activities are less substantial. Based on the accounts of EFD survey respondents and interviewees, it was concluded that no intra-group coordination on substance occurs and that advisors' intra-group activities are thus of a technical nature.

\section{The policy-oriented approach}

The two features that characterise the policy-oriented approach are: aligned policy interests, and pursuit of an activist agenda. The survey and interview findings imply that in particular the Greens/EFA, and to a lesser extent the ECR and GUE/NGL groups qualify for this orientation. It is found that the extent to which a group's ideological or policy interests are aligned affects the (focus of the) role and the mandate of the advisor. In a relatively homogeneous group like the Greens the focus lies on shaping policy and legislation (policy-oriented approach). Furthermore, the (implied) mandate is rather straightforward for advisors of the groups that have aligned policy interests (ECR and Greens/EFA). The same applies to advisors who primarily deal with one MEP (EFD and GUE/NGL groups). The ideological scope is clearly defined in these cases, which increases their ability to improvise. Conversely, in groups that have to take into account multiple, possibly competing, policy views the advisor's mandate is more elusive (ALDE, EPP and S\&D).

\footnotetext{
155 In comparison, the EPP during the 7th parliamentary term comprised 45 national delegations compared to 21 in the Greens/EFA and only 10 in the ECR group. See table 1.3 for a complete overview.
} 


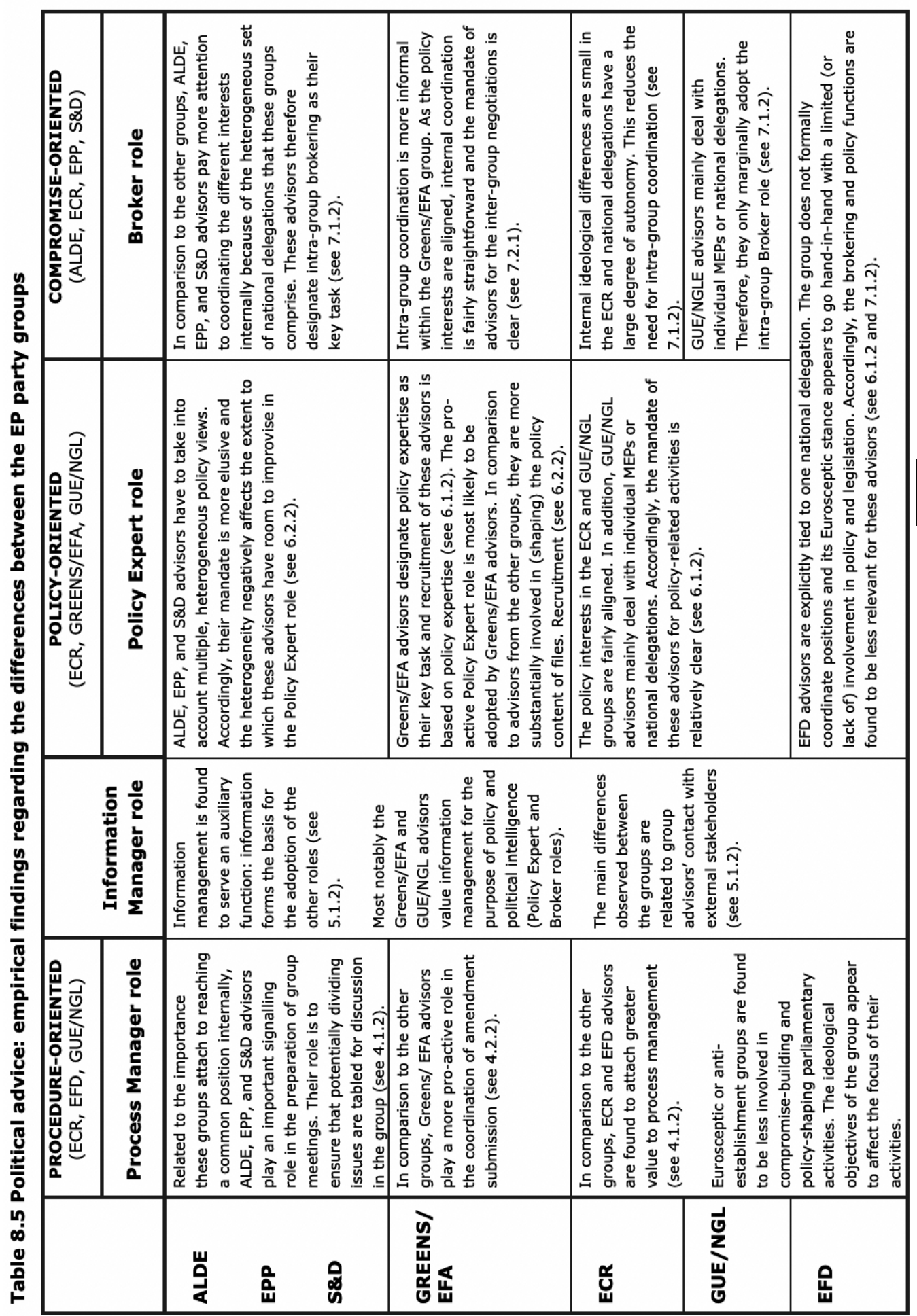


Accordingly, Greens/EFA advisors ascribe relatively more weight to the Policy Expert role. They report that they are more closely involved in content-related matters and known for their policy expertise. Their counterparts not only consider them as 'experts' but also as 'activist' in their approach, pushing the Green agenda forward and 'playing hard ball'. In line with these findings, Greens/EFA advisors play a stronger (more pro-active) role in the coordination of amendment submission (guiding function process management).

\section{The procedure-oriented approach}

The three main characteristics that sum up this orientation are: large degree of autonomy of national delegations, no or a reduced demand for intra-group coordination, and a Eurosceptic stance. The survey and interview findings imply that the ECR, EFD, and GUE/NGL groups fit these criteria. The empirical analysis suggests that ECR and EFD, compared to the other groups, attach greater value to process management. This outcome may be interpreted in light of the nature of these groups. Internal ideological differences are small in the ECR and national delegations have a large degree of autonomy. This reduces the need for intra-group coordination. Like the ECR, the EFD group is dominated by several large national delegations. Moreover, it does not formally coordinate its positions and its Eurosceptic stance appears to make the group's members less inclined to contribute to legislation.

In sum, the motives and ideological objectives related to forming a group appear to affect the (focus of the) role of advisors. Mainstream party groups take a compromise-oriented approach, groups that pursue a more extreme, or activist agenda concentrate on influencing policy positions, and antiestablishment or Eurosceptic groups are basically not interested in either approach. As Brack's elaborate study (2015) of the behaviour of Eurosceptic 
MEPs shows, and as stressed by several interviewees, anti-establishment or Eurosceptic party groups are characterised by their limited (or lack of) involvement in the traditional aspects of parliamentary activities. Their focus is rather on the denunciation of EU integration. From the qualitative data, this lack of interest in the legislative process appears to particularly relate to the EFD group. Not surprisingly, therefore, the brokering and policy functions seem less relevant to these advisors. The cooperation with EFD advisors remains rather absent in the interview accounts, although some advisors marked the relationship as problematic. Another related issue that was raised in the interviews is the EFD practice of hiring advisors on Assistant-level contracts. This might be connected to the lower importance attached to participating in the intra-parliamentary process.

\subsection{Future research agenda}

The thesis contributes to uncovering the informal practices in the EP and has shed light on the key functions of political advice. These findings have brought to light several issues that raise further questions and deserve attention in future studies. In this respect, five research avenues are proposed: (i) exploration of the perception of other actors on the political role of advisors, (ii) exploration of the combined effect of contextual factors through case studies, (iii) exploration of the scope of the 'political role' of EP officials and MEP assistants, (iv) exploration of the role of political advisors in other institutional settings, and ( $v$ ) exploration of external influences on in-house political advice. Each is considered below.

Exploration of the perception of other actors on the political role of advisors The study focused on the intra-EP coordination process and unravelled the role of group advisors in this context. These actors, up until now, have only received marginal scholarly attention. As part of the thesis, therefore, the profile and background of group advisors has been extensively portrayed. 
This was deemed necessary for the operationalisation of the theoretical concepts (see 3.2). An important next step would be to further verify the findings by exploring the perception of other actors, both inside and outside the EP, on the political role of advisors. At the start of the project six exploratory interviews were held with (former) MEP assistants and EP officials (see Appendix V). Due to time limitations, only two 'triangulation interviews' could be conducted. The outcomes of the empirical analysis, and most notably the conclusion that advisors lay the groundwork for compromises, call for further investigation. Studies in this respect could more extensively explore how MEPs, their assistants, and EP officials perceive the role of group advisors. Such examinations could also include the views of representatives of the other EU institutions that may cooperate with group advisors in the technical trilogues.

Another interesting follow-up question to the findings presented in the thesis could be which of the four roles, if any, poses the greatest threat to legitimacy. The large-scale empirical research that was conducted did not conclusively determine that political advice poses a threat to democratic decision-making. The data suggest that advisors can only successfully operate in political processes when they act in pursuit of the interests of their group. In this regard, it would be interesting to learn how MEPs, and their assistants, characterise the mandate of group advisors and their room for manoeuvre.

Exploration of the combined effect of contextual factors through case studies

The thesis has found that a combination of factors needs to be considered in order to explain advisors' potential to shape political decisions. It has concluded that the context in which advice is provided determines whether pro-active behaviour is acceptable to elected representatives. The empirical 
data have suggested that the nature of the file (legislative or nonlegislative) affects the three contextual levels identified from the literature: i.e. substance matter (complexity), mandate (political direction), and political landscape (politicisation). Furthermore, the research demonstrated that the stage of decision-making and the (in)experience of the MEP and his or her assistant are also factors that can affect the division of labour among staff actors.

Future qualitative and quantitative studies could build on these findings and further uncover the nuances of political advice in intra-parliamentary decision-making. This may be done through in-depth case studies that set out to explain the combined effect of several contextual factors on the provision of political advice. The framework could be used for case studies that for example probe the impact of the contextual factors in one or several specific legislative files, and then compare these to one or several nonlegislative files. A similar exercise is conceivable for the comparison of the different stages of decision-making: assessing the contextual factors in the committee versus the plenary stage. Another avenue could be to evaluate the impact of the experience of MEPs, or their assistants, on the provision of advice. This could be done by way of comparing the role of advice in a file with an experienced MEP to a file for which a 'newcomer' to the Parliament is appointed.

Exploration of the scope of the 'political role' of EP officials and MEP assistants

Three major internal sources of advice are at the disposal of MEPs for their legislative activities: their personal assistants, EP officials, and group advisors. The thesis has corroborated the hypothesis that all three sources of assistance operate in the 'mixed sphere of activity' and may thus adopt a political role. Two distinct contributions of group advisors were identified 
in this thesis: (i) the signalling function they fulfil in relation to intra-group coordination, as part of the Process Manager role; and (ii) their involvement in the coordination of intra- and inter-group compromises, as part of the Broker role. However, indications have been found in the data that EP officials and MEP assistants can also adopt the Information Manager and Policy Expert roles, as well as certain aspects of the Process Manager role.

In line with previous findings (e.g. Neunreither, 2002; Winzen, 2011; Egeberg et al, 2013; Pegan, 2015; see 3.1.2), the empirical data suggest that the source of assistance varies and the MEP in charge selects the support he or she desires. The thesis focused on the role of group advisors but it would be interesting to further explore the division of labour among staff actors. A comparative study between the three types of supporting staff could for example assess their involvement in the various roles of the framework by way of a survey. Alternatively, or in addition to such an exercise, interviews and case studies may be used to further uncover the scope of the political role of EP officials and MEP assistants. It would be valuable to learn the extent to which, and the circumstances under which, these staff actors indeed assume the Process Manager, Information Manager and Policy Expertise roles, and how their activities differ to those performed by group advisors.

In future studies of this kind, it is important to take into account the previous point regarding the contextual factors. In particular, the stage of decision-making (committee or plenary) and the (in)experience of MEPs and their assistants were identified as factors that may affect the division of labour among staff actors. 
Exploration of the role of political advisors in other institutional settings

The thesis construed political advice as advice offered to politicians by nonelected actors. The literature review showed that previous studies regarding the role of staff emphasised on officials who are deemed to fulfil a neutral or administrative role. The 'political advisor' forms a distinct type of actor who can neither be classified as a civil servant nor as a political actor. These advisors form part of a larger phenomenon: non-elected actors who are employed to assist in articulating and securing political positions. In this role, they negotiate with other actors (political and non-political) regarding these positions. The 'political role' of advisors differentiates them from the 'neutral' officials or civil servants that are expected to serve the general interest of the institution. In addition, these advisors as a rule do not work for one specific politician, which sets them apart from personal advisors who may also perform political roles. Although the analysis centres on advisors working within the EP party group secretariats, the developed framework is designed in such a way that it allows for the application to other legislator-advisor relationships.

Until now, this particular group of actors has remained rather eclipsed in the academic debate. Future studies could use the analytical framework to verify whether the findings of the thesis hold true for political advisors in different institutional settings. This may be done, for example, by way of a comparative study of political advice in various EU Member State parliaments. As the literature review in the introduction pointed out, hardly any empirical evidence exists regarding the role of political advisors in national parliaments. Another avenue for future research would be to compare the role of political advisors in different institutional settings: e.g. in one or several national parliaments and in the European Parliament. 


\section{Exploration of external influences on in-house political advice}

A final avenue for future research that is proposed is the study of external influences on the provision of in-house advice. The empirical analysis showed that advisors have regular contact with external stakeholders to appreciate the various views and interests of the field. In their Information Manager capacity, they pre-select the issues or information brought to the attention of MEPs. Only a small minority of respondents (4\%) reported that they never gather information in this way. Respondents stated that they regularly interact with interest groups (74\%) and industry representatives (72\%). These findings raise the expectation that external stakeholders may try to use advisors for their benefit. This could be an angle to consider in future studies addressing the impact of lobby and interest representation on EU decision-making. The data suggest that the interaction with third parties differs across the groups and across policy areas. Insight into if and how external actors attempt to influence decision-making through in-house advisors would be valuable to further appreciate informal governance.

Other conceivable external influences may come from external events or crises that could affect the role of advice in decision-making. For example, future studies about the EP could assess the impact of the (impending) Brexit on the roles and division of labour between in-house advisors: has the division of labour among staff shifted compared to the period before the UK referendum to leave the EU? Studies could also explore the extent to which external events - like animal disease outbreaks in the EU or the immigration crisis - have increased or decreased the reliance on in-house advice. It would be interesting to learn whether, at the break of a crisis, politicians turn to their 'trusted' advisors or look for 'expert' advice outside of the Parliament. 


\subsection{Final remarks}

The thesis has built on the literature regarding the relationship between elected and non-elected actors, the role of staff in decision-making, and the functioning of EU decision-making more generally. The framework adds to the academic debate by shedding light on the, until now, unseen 'political role' of advisors. This novel approach allows for a process-oriented approach, which offers a new way of explaining how political coordination takes place at the everyday level. The empirical analysis demonstrated that advisors lay the groundwork for compromises. A deeper understanding of how the decision-making process is prepared is crucial to fully appreciate political negotiation and compromise building. Moreover, the findings offer a more nuanced perspective on the normative debate regarding the role of non-elected actors. The extensive empirical research that was conducted concluded that the implications of political advice for decision-making are not necessarily normatively questionable. The thesis has argued that advisors can only successfully manifest pro-active behaviour when they act in pursuit of the interests of their group. Therefore, they devise their actions within the scope of the group's political objectives. These findings also point the way to a wider research agenda, as put forward in the previous section.

The societal relevance of the thesis is tied to the insights that are offered about the intra-parliamentary preparations of EU decisions. Generally, these practices remain undocumented and take place outside of public and political scrutiny. The empirical findings contribute to uncovering how political decisions are prepared in everyday practice, which provides a valuable contribution to the wider public debate on politics and democracy. In addition, this practical knowledge is crucial for teachers and students and should be included in future education and training programmes on public administration. Studies have shown that the lack of transparency and public involvement in EU decision-making is problematic for the democracy and 
deteriorates public trust (see e.g. Reh, 2012, 2014). Informal processes that take place behind the scenes are untraceable. Intransparency affects public scrutiny and dilutes political contestation and public-opinion formation as policy choices remain unclear. To strengthen the democratic nature of EU decision-making we need to increase the general understanding of how things work.

The conducted research has demonstrated that advisors lay the groundwork for compromises in the EP and do not operate on the basis of clearly defined instructions. This important role can on the one hand be interpreted as an affirmation of the influential back-stage role of non-elected actors. And fulfilling such a role may further feed the public distrust of political systems and expertise. However, on the other hand, the research has shown that extensive coordination and deliberation systems are in place. These processes are crucial to the functioning of a democratic system and the findings show that coordination and deliberation are significantly facilitated by non-elected actors. Moreover, the findings suggest that their activities are guided by the political ideology and aims of the group they represent. In that way, they are like the 'oil' in the legislative machinery, coordinating different views and working towards broad agreement both within and between the groups. Without their contribution, the intra-parliamentary coordination process would probably be less comprehensive given time and resources constraints of elected representatives.

These considerations do not only apply to the case of the EP, or of the EU for that matter. The added value for society, outlined above, thus illustrates why it is important that future studies consider these findings and use the developed framework for the examination of the political role of advice in other legislative settings. 



\section{REFERENCES}

Adler-Nissen, R. (2009). The diplomacy of opting out: British and Danish stigma management in the EU (Doctoral dissertation, University of Copenhagen).

Almond, G. A. (1965). A developmental approach to political systems. World Politics, 17(2): 183-214.

Arnold, R. D. (1987). Political control of administrative officials. Journal of Law, Economics, \& Organization, 3(2): 279-286.

Barbieri, J. (2018). "Trust Me! I'm Not an Expert!" The ABC of Post-Truth: Avoiding Risks, Biases, Clicks. St Antony's International Review, 13(2): 24-47.

Benedetto, G. (2005). Rapporteurs as legislative entrepreneurs: the dynamics of the codecision procedure in Europe's parliament. Journal of European Public Policy, 12(1): 67-88.

Bergman, T. and Strøm, K. (2011). The Madisonian turn: Political parties and parliamentary democracy in Nordic Europe. University of Michigan Press.

Blischke, W. (1981). Parliamentary staffs in the German Bundestag. Legislative Studies Quarterly, 6(4): 533-558.

Blom, T. (2014). The Politics of Information: An Organization-Theoretical Perspective. In: The Politics of Information. The Case of the European Union, eds. T. Blom and S. Vanhoonacker. Basingstoke: Palgrave Macmillan.

Blom, T. and Vanhoonacker, S. (2014). The Politics of Information: A New Research Agenda. In: The Politics of Information. The Case of the European Union, eds. T. Blom and S. Vanhoonacker. Basingstoke: Palgrave Macmillan.

Bovens, M., Curtin, D., and Hart, P. T. (Eds.). (2010). The real world of EU accountability: What deficit? Oxford University Press.

Bowen, G.A. (2009). Document Analysis as a Qualitative Research Method. Qualitative Research Journal, 9(2): 27-40.

Bowler, S., Farrell, D. M. (1995). The Organizing of the European Parliament: Committees, Specialization and Co-Ordination Author(s). British Journal of Political Science, 25(2): 219-243.

Bowler, S., Farrell, D. M. and Katz, R. S. (1999). Party discipline and parliamentary government. The Ohio State University Press. 
Brack, N. (2015). The Roles of Eurossceptic Members of the European Parliament and their implications for the EU. International Political Science Review, 36(3): 337-350.

Brack, N. and Startin, N. (2015). Introduction: Euroscepticism, from the margins to the mainstream. International Political Science Review, 36(3): 239249.

Brack, N., \& Costa, O. (2018). The European Parliament at a crossroads: introduction, The Journal of legislative studies, 24(1): 1-10.

Brack, N. and Costa, O. (2018a). Democracy in parliament vs. democracy through parliament? Defining the rules of the game in the European Parliament, The Journal of legislative studies, 24(1): 51-71.

Brandsma, G.J. (2012). The effect of information on oversight: The European Parliament's response to increasing information on comitology decision-making. International Review of Administrative Sciences, 78(1): 74-92.

Brandsma, G. J. (2015). Co-decision after Lisbon: The politics of informal trilogues in European Union lawmaking, European Union Politics, 16(2): 300-319.

Bressanelli, E., Koop, C., \& Reh, C. (2016). The impact of informalisation: Early agreements and voting cohesion in the European Parliament. European Union Politics, 17(1): 91-113.

Burks, S.W. and Cole R.L. (1978). Congressional Staff Personnel Role Orientations: An Empirical Examination. Politics \& Policy 6(2): 17-38.

Burns, C. (2013). The European Parliament. In: European Union Politics, eds. Cini, M. and Pérez-Solórzano Borragán, N., $4^{\text {th }}$ edition, Oxford: Oxford University Press.

Busby, A. (2013). The everyday practice and performance of European politics: An ethnography of the European parliament (Doctoral dissertation, University of Sussex).

Busby, A. (2013a). Bursting the Brussels Bubble: using ethnography to explore the European Parliament as a transnational political field. Perspectives on European Politics and Society, 14(2): 203-222.

Busby, A. and Belkacem, (2013). Coping with the Information overload: An exploration of Assistants' backstage role in the everyday practice of European Parliament politics. European Integration online Papers (EIoP) 17(2): 1-28. 
Campbell, S. and Laporte, J. (1981). The staff of the parliamentary assemblies in France. Legislative Studies Quarterly, 6(4): 521-531.

Christiansen, T. (2002). Out of the shadows: the General Secretariat of the Council of Ministers. The Journal of Legislative Studies, 8(4): 80-97.

Christiansen, T. (2013). Governance in the European Union. In: European Union Politics, eds. Cini, M. and Pérez-Solórzano Borragán, N., $4^{\text {th }}$ edition, Oxford: Oxford University Press.

Christiansen, T. and Neuhold, C. (2013). Informal Politics in the EU, Journal of Common Market Studies, 51(6): 1196-1206.

Christiansen, T., Högenauer, A. L. and Neuhold, C. (2014). National parliaments in the post-Lisbon European Union: Bureaucratization rather than democratization? Comparative European Politics, 12(2): 121-140.

Christiansen, T. (2016). After the Spitzenkandidaten: fundamental change in the EU's political system? West European Politics, 39(5): 992-1010.

Corbett, R. (2002). A Very Special Parliament: The European Parliament in the Twenty-First Century. The Journal of Legislative Studies, 8(2): 1-8.

Corbett, R., Jacobs, F. and Shackleton, M. (2011). The European Parliament, 8th edition, John Harper Publishing.

Corbett, R., Jacobs, F. and Neville, D. (2016). The European Parliament, 9th edition, John Harper Publishing.

Couper, M.P., Traugott, M.W. and Lamias, M.J. (2001). Web Survey Design and Administration. Public Opinion Quarterly, 65: 230-253.

Creswell, J.W. and Plano Clark, V.L. (2011). Designing and Conducting Mixed Methods Research. Sage Publications.

DeGregorio, C. (1994). Professional Committee Staff as Policy-Making Partners in the US Congress. Congress \& The Presidency, 21(1): 49-66.

De Ruiter, R., \& Neuhold, C. (2012). Why Is Fast Track the Way to Go? Justifications for Early Agreement in the Co-Decision Procedure and Their Effects. European Law Journal, 18(4): 536-554.

De Wilde, P., Leupold, A., \& Schmidtke, H. (2016). Introduction: The differentiated politicisation of European governance. West European Politics, 39(1): 3-22. 
Dinan, D. (2005). Ever Closer Union. An Introduction to European Integration, $3^{\text {rd }}$ edition, Basingstoke: Palgrave.

Dobbels, M. (2013). The European Parliament. A giant with feet of clay? (Doctoral dissertation, Maastricht University).

Dobbels, M. and Neuhold, C. (2013). The roles bureaucrats play. The input of European Parliament administrators into the Ordinary Legislative Procedure: A Case Study Approach. Journal of European Integration, 35(4): 375-390.

Dobbels, M. and Neuhold, C. (2014). Who Selects What and How? How the European Parliament Obtains and Processes Information for Policy-Making. In: The Politics of Information. The Case of the European Union, eds. T. Blom and S. Vanhoonacker. Basingstoke: Palgrave Macmillan.

Earnshaw, D. and Judge, D. (2002). No simple dichotomies: lobbyists and the European Parliament. Journal of Legislative Studies, 8(4): 61-79.

Earnshaw, D. and Judge, D. (2003). The European Parliament, Palgrave.

Egeberg, M., Gornitzka, A., Trondal, J., and Johannessen M. (2013). Parliament Staff. Backgrounds, Career Patterns and Behaviour of Officials in the European Parliament. Journal of European Public Policy, 20(4): 495-514.

Eichengreen, B. (2018). Is Renewed EU Optimism Justified? Intereconomics, 53(1): 47-48.

European Commission (2017a). White Paper on the Future of Europe. Reflections and scenarios for the EU27 by 2025. COM(2017)2025, 1 March 2017. European Commission (2017b). State of the Union Address. Catching the Wind in our Sails. September 2017.

EPRS (2014). Facts \& Figures Briefing, PE 542.150, November 2014.

EPRS (2016). Facts \& Figures Briefing, PE 573.919, March 2016.

EPRS (2017). Facts \& Figures Briefing, PE 599.256, March 2017.

EPRS (2018). Facts \& Figures Briefing, PE 614.733, April 2018.

European Parliament (2000). Comparison of organisational and administrative arrangement in EU national parliaments. BUDG110 EN 12-2000.

European Parliament (2008). Code of Conduct for negotiating in the context of the ordinary legislative procedures, as approved by the Conference of Presidents on 18 September 2008, Annex XX of European Parliament Rules of Procedure. 
European Parliament (2013). 'Parliamentary democracy in action. Summary comparison studies, EP Secretary General, March 2013.

European Parliament (2015). 'Strategic Planning for the Secretariat General of the European Parliament', EP Secretary General, PE 539.927 version 2.0, March 2015.

European Parliament Establishment Plan (2014).

European Parliament Rules of Procedure (2014). Rules of Procedure $7^{\text {th }}$ parliamentary term, March 2014.

European Parliament Rules of Procedure (2016). Rules of Procedure 8th parliamentary term. Online, consulted August 2016.

European Parliament Rules of Procedure (2017). Rules of Procedure 8th parliamentary term. Online, consulted March 2018.

European Parliament, Council, European Commission (2007). Joint declaration on practical arrangements for the Co-decision Procedure, Official Journal of the European Union 145, 30 June 2007.

European Union Staff Regulations (2014). Staff regulations of Officials of the European Union and the Conditions of Employment of Other Servants of the European Union, Regulation No 31 (EEC), 11 (EAEC). 1962 (2014 amended).

Faas, T. (2003). To defect or not to defect? National, institutional and party group pressures on MEPs and their consequences for party group cohesion in the European Parliament. European Journal of Political Research, 42(6): 841-866.

Farrell, H. and Héritier, A. (2004). Interorganizational Negotiation and Intraorganizational Power in Shared Decision Making Early Agreements Under Codecision and Their Impact on the European Parliament and Council. Comparative political studies, 37(10): 1184-1212.

Fouilleux, E., Maillard, J. D. and Smith, A. (2005). Technical or political? The working groups of the EU Council of Ministers. Journal of European Public Policy, 12(4), 609-623.

Fox, H. W., \& Hammond, S. W. (1977). Congressional staffs: The invisible force in American lawmaking. Free Press.

Georgakakis, D. and Rowell, J. (2013). The Field of Eurocracy: Mapping EU Actors and Professionals. Basingstoke: Palgrave MacMillan. 
Gerring, J. (2001). What is a Case Study and What is it Good For? American Political Science Review, 98(2): 341-354.

Greene, J.C. (2007). Mixed methods in social inquiry, Volume 9, John Wiley \& Sons.

Greenwood, J. (2011). Interest Representation in the European Union, $3^{\text {rd }}$ edition, Basingstoke: Palgrave Macmillan.

Gailmard, S. and Patty, J. W. (2012). Formal models of bureaucracy. Annual Review of Political Science, 15: 353-377.

Häge, F. M. and Kaeding, M. (2007). Reconsidering the European Parliament's legislative influence: Formal vs. informal procedures. European Integration, 29(3), 341-361.

Hague, R. and Harrop, M. (2010). Comparative government and politics. An Introduction, $8^{\text {th }}$ edition. Basingstoke: Palgrave Macmillan Press.

Hammond, S. W. (1984). Legislative staffs. Legislative Studies Quarterly, 9(2): 271-317.

Hammond, S. W. (1996). Recent research on legislative staffs. Legislative Studies Quarterly, 21(4): 543-576.

Häge, F. M. and Naurin, D. (2013). The effect of codecision on Council decisionmaking: Informalization, politicization and power. Journal of European Public Policy, 20(7): 953-971.

Hanké, B. (2010). Intelligent Research Design: A guide for beginning researchers in the social sciences. Oxford: Oxford University Press.

Heisenberg (2005). The institution of 'consensus' in the European Union: Formal versus informal decision-making in the Council. European Journal of Political Research, 44(1): 65-90.

Héritier, A. (2012). Institutional Change in Europe: Co-decision and Comitology Transformed. Journal of Common Market Studies, 50(s1): 38-54.

Héritier, A. and Reh, C. (2012). Codecision and its discontents: IntraOrganisational Politics and Institutional Reform in the European Parliament. West European Politics, 35(5): 1134-1157.

Hermansen, S. S. L. (2018). (Self-) selection and expertise among decisionmakers in the European Parliament. The Journal of Legislative Studies, 24(1): 148172. 
Hix, S. and Lord, C. (1997). Political parties in the European Union. New York: St. Martin's Press.

Hix, S. (2002). Parliamentary Behavior with two principals: Preferences, Parties, and Voting in the European Parliament. American Journal of Political Science, 46(3):688-698.

Hix, S., Kreppel, A. and Noury, A. (2003a). The party system in the European Parliament: Collusive or competitive? Journal of Common Market Studies, 41(2): 309-331.

Hix, S., Raunio, T, Scully, R. (2003b). Fifty years on: Research on the European Parliament. Journal of Common Market Studies, 41(2): 191-202.

Hix, S., Noury, A. G. and Roland, G. (2007). Democratic politics in the European Parliament. Cambridge University Press.

Hix, S. and Noury, A. (2009). After enlargement: Voting patterns in the sixth European Parliament. Legislative Studies Quarterly, 34(2): 159-174.

Hix, S. (2009). What to Expect in the 2009-14 European Parliament: Return of the Grand Coalition? Sieps European Policy Analyis, 8: 1-12.

Hobolt, S. B. (2014). A vote for the President? The role of Spitzenkandidaten in the 2014 European Parliament elections. Journal of European Public Policy, 21(10): 1528-1540.

Högenauer, A. L., \& Neuhold, C. (2015). National parliaments after Lisbon: Administrations on the rise? West European Politics, 38(2), 335-354.

Huber, K. and Shackleton, M. (2013). Codecision: a practitioner's view from inside the Parliament. Journal of European Public Policy, 20(7): 1040-1055.

Iarossi, G. (2006). The Power of Survey Design: A User's Guide for Managing Surveys, Interpreting Results, and Influencing Respondents. Washington, D.C.: The World Bank.

Jensen, T. and Winzen, T. (2012). Legislative negotiations in the European Parliament. European Union Politics, 13(1): 118-149.

Johnson, R.B., Onwuegbuzie, A.J., and Turner, L.A. (2007). Toward a definition of mixed methods research. Journal of Mixed Methods Research 1(2): 112-133. 
Judge, D. and Earnshaw, D. (2011). 'Relais actors' and co-decision first reading agreements in the European Parliament: the case of the advanced therapies regulation. Journal of European Public Policy, 18(1): 53-71.

Kettl, D. F. (2000). Public administration at the millennium: The state of the field. Journal of public administration research and theory, 10(1): 7-34.

King, G., Keohane, R. and Verba, S. (1994). Designing Social Inquiry. Princeton University Press.

Kleine, M. (2013). Informal governance in the European Union: How governments make international organizations work. Cornell University Press.

Kohler-Koch, B. and Rittberger, B. (2007). Debating the Democratic Legitimacy of the European Union. Rowman \& Littlefield Publishers, Inc.

Kreppel, A. and Tsebelis, G. (1999). Coalition formation in the European Parliament. Comparative Political Studies, 32(8): 933-966.

Kreppel, A. (2002). The European Parliament and Supranational Party System: A study in institutional development. Cambridge University Press.

Kreppel, A. (2018). Bicameralism and the balance of power in EU legislative politics. The Journal of legislative studies, 24(1): 11-33.

Lord, C. (2018). The European Parliament: A working parliament without a public? The Journal of legislative studies, 24(1): 34-50.

Manley, J.F. (1968). Congressional Staff and Public Policy-Making: The Joint Committee on International Revenue Taxation. The Journal of Politics, 30(4): 1046-1067.

March, J. G. and Olsen, J. P. (1998). The institutional dynamics of international political orders. International organization, 52(4): 943-969.

Marks, G. and Steenbergen, M.R. (2004). European Integration \& Political Conflict. Cambridge University Press.

Marshall, D. (2012). Do rapporteurs receive independent expert policy advice? Indirect lobbying via the European Parliament's committee secretariat. Journal of European Public Policy, 19(9): 1377-1395.

Mayes, B. T. and Allen, R. W. (1977). Toward a definition of organizational politics. Academy of management review, 2(4): 672-678.

McElroy, G. and Benoit, K. (2012). Policy positioning in the European Parliament. European Union Politics, 13(1): 150-167. 
Michon, S. (2008). Assistant parlementaire au Parlement européen : un tremplin pour une carrière européenne. Sociologie du travail, 50(2), 169-183.

Michon, S. (2014). Les équipes parlementaires des eurodéputés: entreprises politiques et rites d'institution. Primento.

Moe, T. M. (2006). Political Control and the Power of the Agent. Journal of Law, Economics, and Organization, 22(1): 1-29.

Naurin, D. (2010). Most common when least important: deliberation in the European Union Council of Ministers. British Journal of Political Science, 40(1), 3150.

Neuhold, C. (2001). The "Legislative Backbone" keeping the Institution upright? The Role of European Parliament Committees in the EU Policy-Making Process. European Integration Papers Online, 5(10): http://eiop.or.at/eiop/texte/2001010a.htm.

Neuhold, C. and Settembri, P. (2007). The role of European Parliament committees in the EU policy-making process. In: The Role of Committees in the Policy-Process of the European Union, eds. T. Christiansen, T. Larsson. Cheltenham: Edward Elgar.

Neuhold, C. and Dobbels, M. (2014). Paper-keepers or policy shapers? The conditions under which EP officials impact on the EU policy process. Comparative European Politics, online publication DOI 10.1057/cep.2014.7.

Neuhold, C., Vanhoonacker, S. and Verhey, L. (Eds.). (2013). Civil servants and politics: a delicate balance. Springer.

Neunreither, K. (2002). Elected legislators and their unelected assistants in the European Parliament. The journal of legislative studies, 8(4): 40-60.

Olsen, J.P (2006). Maybe it is Time to Rediscover Bureaucracy. Journal of Public Administration Research and Theory, 16(1): 1-24.

Page, E.C. and Jenkins, B. (2005). Policy Bureaucracy: Government with a cast of thousands. Oxford University Press.

Page, E.C. (2010). Bureaucrats and expertise: Elucidating a problematic relationship in three tableaux and six jurisdictions. Sociologie du travail, No. 52(2): 255-273.

Parlameter (2017). Eurobarometer survey commissioned by the European Parliament. 
Patterson, S. C. (1970). The professional staffs of congressional committees. Administrative Science Quarterly, 15(1): 22-37.

Pegan, A. (2015). An Analysis of the Legislative Assistance in the European Parliament (Doctoral dissertation, University of Luxembourg).

Pegan, A. (2017). The role of personal parliamentary assistants in the European Parliament. West European Politics, 40(2): 1-21.

Peters, B. G. (2009). Still the century of bureaucracy? The roles of public servants. Public Policy and Administration, 30: 7-21.

Peters, B.G. (2013). Politicisation: What is it and why should we care? In: Civil Servants and Politics: A delicate balance, eds. C. Neuhold, S. Vanhoonacker, and L. Verhey. Basingstoke: Palgrave Macmillan.

Pollack, M.A. (2009). The new institutionalisms and European integration. In: European Integration Theory, $2^{\text {nd }}$ edition, eds. A.Wiener and T. Diez. New York: Oxford University Press.

Price, D. E. (1971). Professionals and "entrepreneurs": Staff orientations and policy making on three senate committees. The Journal of Politics, 33(02): 316336.

Pridham, G. and Pridham, P. (1981). Transnational party co-operation and European integration: The process towards direct elections. London: Allen \& Unwin.

Radaelli, C. M. (1999). The public policy of the European Union: Whither politics of expertise? Journal of European public policy, 6(5): 757-774.

Rasmussen, A. (2011). Early conclusion in bicameral bargaining: Evidence from the co-decision legislative procedure of the European Union. European Union Politics, 12(1): 41-64.

Rasmussen, A. and Reh, C. (2013). The consequences of concluding codecision early: trilogues and intra-institutional bargaining success. Journal of European Public Policy, 20(7): 1006-1024.

Raunio, T. (1999). The challenge of diversity: Party cohesion in the European parliament. In: Party discipline and parliamentary government, eds. S. Bowler, D.M. Farrell and R.S. Katz. The Ohio State University Press. 
Reh, C. (2012). Informal Politics: The normative challenge. In: International Handbook on Informal Governance, eds. T. Christiansen and C. Neuhold. Cheltenham: Edward Elgar.

Reh, C., Héritier, A., Bressanelli, E., \& Koop, C. (2013). The informal politics of legislation: Explaining secluded decision-making in the European Union. Comparative Political Studies, 46(9): 1112-1142.

Reh, C. (2014). Is informal politics undemocratic? Trilogues, early agreements and the selection model of representation. Journal of European Public Policy, 21(6): 822-841.

Rhodes, R.A.W., 't Hart, P. and Noordegraaf, M. (2007). Observing Government Elites. Up Close and Personal, Basingstoke: Pallgrave Macmillan.

Ringe, N. (2010). Who decides, and How? Preferences, Uncertainty, and Policy Choice in the European Parliament. New York: Oxford University Press.

Ripoll Servent A (2012). Playing the co-decision game? Rules' changes and institutional adaptation at the LIBE committee. Journal of European Integration 34(1): 55-73.

Ripoll Servent, A. (2018). The European Parliament. London: Palgrave Macmillan. E-book version.

Risse, T. and Kleine, M. (2010). Deliberation in negotiations, Journal of European Public Policy, 17(5): 708-726.

Risse, T. (2009). Social constructivism and European integration. In: European Integration Theory, $2^{\text {nd }}$ edition, eds. A.Wiener and T. Diez. New York: Oxford University Press.

Rittberger, B. (2003). The Creation and Empowerment of the European Parliament. Journal of Common Market Studies, 41(2): 203-225.

Rittberger, B. (2012). Institutionalizing Representative Democracy in the European Union: The Case of the European Parliament. Journal of Common Market Studies, 50(1): 18-37.

Rittberger, B. (2014). Integration without representation? The European Parliament and the reform of economic governance in the EU. Journal of Common Market Studies, 52(6): 1174-1183.

Roederer-Rynning, C., \& Greenwood, J. (2015). The culture of trilogues. Journal of European Public Policy, 22(8): 1148-1165. 
Roederer-Rynning, C., \& Greenwood, J. (2017). The European Parliament as a developing legislature: coming of age in trilogues? Journal of European Public Policy, 24(5): 735-754.

Romanyshyn, I. and Neuhold, C. (2013). The European Parliament's Administration: Between Neutral and Politicised Competence. In: Civil Servants and Politics: A delicate balance, eds. C. Neuhold, S. Vanhoonacker, and L. Verhey. London: Palgrave Macmillan.

Romzek and Utter (1997). Congressional staff: Professionals or Clerks? American Journal of Political Science, 41(4): 1251-1279.

Ryle, M.T. (1981). The Legislative Staff of the British House of Commons. Legislative Studies Quarterly 6(4): 497-519.

Sager, F. and Rosser, C. (2009). Weber, Wilson and Hegel: Theories of Modern Bureaucracy. Public Administration Review, 69(6): 1136-1147.

Settembri, P. and Neuhold, C. (2009). Achieving Consensus Through Consensus: Does the European Parliament Manage? Journal of Common Market Studies, 47(1): 127-151.

Shackleton, M. (2000). The politics of codecision. Journal of Common Market Studies, 38(2): 325-342.

Shackleton, M., \& Raunio, T. (2003). Codecision since Amsterdam: a laboratory for institutional innovation and change. Journal of European Public Policy, 10(2): 171-188.

Smismans, S. (2013). Democracy and Legitimacy in the European Union. In: European Union Politics, eds. M. Cini and Pérez-Solórzano Borragán, N., $4^{\text {th }}$ edition. Oxford: Oxford University Press.

Strøm, K., Müller, W. and Bergman, T (2006). Delegation and accountability in parliamentary democracies (eds.). Oxford University Press.

Tallberg, J. (2004). The Power of the Presidency: Brokerage, Efficiency and Distribution in EU negotiations. Journal of Common Market Studies, 42(5): 9991022.

Tsebelis, G., Jensen, C.B., Kalandrakis, A. and Kreppel, A. (2001). Legislative Procedures in the European Union: An Empirical Analysis. British Journal of Political Science, 31(4): 573-599. 
VoteWatch Europe (2015). Who holds the power in the new European Parliament? Analysis of the MEPs' votes and activities in the first 6 months of the 2014-2019 term. VoteWatch Europe Special Report, 27 February 2015.

Warntjen, A. (2010). Between Bargaining and deliberation: decision-making in the Council of the European Union, Journal of European Public Policy, 17(5): 665679.

Weber, M. (1978). Economy and Society. An Outline of Interpretive Sociology, eds. G. Roth, and C. Wittich, trans. E. Fischoff et al, Vol. 2. University of California Press.

Weiss, R.S. (1994). Learning from Strangers. The art and Method of Qualitative Interview Studies. The Free Press.

Westlake, M. (2018). Conclusions: The European Parliament - coming of age. The Journal of legislative studies, 24(1): 173-178.

Whitaker, R. (2011). The European Parliament's Committees: National Party Influence and Legislative empowerment. Taylor \& Francis.

Wiener, A and Diez, T (2009). European Integration Theory, second edition. Oxford: Oxford University Press.

Winzen, T. (2011). Technical or Political? An Exploration of the Work of Officials in Committees of the European Parliament. Journal of Legislative Studies, 17(1): 27-44.

Winzen, T. (2014). Bureaucracy and Democracy: Intra-Parliamentary Delegation in European Union Affairs. Journal of European Integration, 36(7): 677-95.

Wlezien, C. (2005) On the salience of political issues: the problem with 'most important problem'. Electoral Studies 24: 555-79.

Wodak, R. (2009). The discourse of politics in action: Politics as usual. London: Palgrave Macmillan.

Yordanova, N. (2013). Organising the European Parliament. The Role of Committees and their legislative influence. ECPR Press. 


\section{VALORISATION ADDENDUM}

\section{Introduction}

This valorisation addendum aims to illustrate how the findings presented in my dissertation can be informative for and used by various target groups, both within academia as well as in the public arena.

"Knowledge utilisation is the process of making scientific knowledge suitable and available for use outside of the academic world and/or use within other scientific disciplines. This is not a linear process but a continuous exchange between research and practice." (NWO, Manual Knowledge Utilisation in the social and behavioural sciences, September 2014).

One of the reasons for starting this research project was the aim to further connect the theoretical discussions on the functioning of the European Parliament to everyday practice. Scholarly discussions on the role of nonelected actors in decision-making processes tend to focus on the perspective of the elected representatives and the way in which they can or should control the behaviour of their staff. In the public debate, the EU's said backroom politics is one of the popular arguments that spark the polity's negative image. A (potential) political role of advisors thus raises important questions about the legitimacy of decision-making, both in the eye of the academic world as well as in the eye of the public.

One of the objectives that this dissertation has pursued is to show how advice works in practice. In fact, the connection and translation between the academic theory and everyday practice has been the driving force behind the chosen approach in which the focus lies on how advisors deal with delegated responsibilities. The dissertation provides two key contributions in this sense. First, a link is made between the theoretical and 
practical perspectives by providing an analytical tool to enable the separate assessment of the political and technical dimensions. Second, the largescale empirical study of EP group advisors sheds light on how advisors operate in EP negotiations. The implications of these contributions are elaborated in this valorisation addendum. The following sections consecutively discuss the potential for knowledge utilisation (section II), the interested parties and the way in which the knowledge can be usable and made available to these target groups (section III).

\section{Relevance: the potential for knowledge utilisation}

The potential knowledge utilisation of the conducted research resides in the manner in which the findings presented in this dissertation can inform and feed into broader discussions on the EU's democratic legitimacy, and more generally, into discussions regarding the role of advice in the coming about of legislation.

For years, the democratic quality of the decision-making processes that result in EU laws has been subject to academic and public criticism. As a supranational polity, the EU faces several democratic 'challenges' in relation to transparency and popular support. The empowerment of both the EP and national parliaments in EU decision-making has been one of the responses to this critique (see Introduction). In this context, the role of 'back-stage' advisors has given rise to a normative debate regarding their influence or capacity to have an impact on EU policymaking. The research findings have demonstrated that key stages of the decision-making process are informal, and thus generally provide no access to observers. The trend towards informal decision-making raises the value of political advice and elevates the importance of understanding the intra-institutional preparatory dynamics. The informal stages take place behind the scenes and prior to the 'actual' decision-making in parliamentary committees or in the plenary. 
Not only does this mean that these stages take place outside of public and political scrutiny, they can also be difficult to follow for societal and other stakeholders. Moreover, the lack of information and insight regarding crucial aspects of certain compromises means that outcomes can be difficult to comprehend for the wider public.

The societal relevance of the thesis is tied to the insights that are offered about the informal intra-parliamentary preparations of EU decisions. A deeper understanding of how the decision-making process is prepared is crucial to fully appreciate political negotiation and compromise building. In my opinion, media reports more often than not lack nuance and fall short in addressing the details of how things work. The findings presented in this dissertation may contribute to a more nuanced public debate of how decisions come about in practice. The empirical findings contribute to uncovering how political decisions are prepared, which provides a valuable contribution to the wider public debate and opinion-formation on EU politics and democracy and may inspire similar discussions in relation to national legislatures.

Studies have shown that the lack of transparency and public involvement in EU decision-making is problematic for democracy and deteriorates public trust. Informal processes that take place behind the scenes are untraceable. Intransparency affects public scrutiny and dilutes political contestation and public-opinion formation as policy choices remain unclear. It is necessary to increase the general understanding of how things work in order to strengthen the democratic nature of EU decision-making. Increased insight into the informal stages that result in compromises can assist opinionformation on EU policies. This may be helpful for national, regional, and local policymakers, the media, and the general public. Similarly, the unravelling of the internal machinery of the EP may be beneficial to interest 
representation. These are just a few of the interested parties for whom the research findings can be useable. This is further discussed in section III.

The conducted research has demonstrated that group advisors lay the groundwork for compromises in the EP and do not operate on the basis of clearly defined instructions. Their important role can on the one hand be interpreted as an affirmation of the influential back-stage role of nonelected actors. And fulfilling such a role may further feed the public distrust of political systems and expertise. However, on the other hand, the research has shown that extensive coordination and deliberation systems are in place. These processes are crucial to the functioning of a democratic system and the findings show that coordination and deliberation are significantly facilitated by non-elected actors. Moreover, the findings suggest that activities carried out by advisors are guided by the ideology and aims of the political group they represent. In that way, they are like the 'oil' in the legislative machinery, coordinating different views and working towards broad agreement both within and between the EP party groups. Without their contribution, the intra-parliamentary coordination process would probably be less comprehensive given time and resources constraints of elected representatives.

Gaining a better understanding of the politics of advice is increasingly significant against the backdrop of a changing public policy landscape. The advent of post-factual politics and the emergence of populist right-wing parties as mainstream have created a crisis of trust. Under the banner of 'alternative facts', the fading trust in expertise or objective knowledge substitutes rational proof with emotional appeals. This development is illustrated by the election of President Trump in the United States, the Brexit vote in the UK, Russian propaganda, and the electoral success of populist movements across Europe. These examples furthermore demonstrate a deteriorating sense of trust in the political establishment and a rise of anti- 
EU sentiments. On the one hand, they raise the importance of the legitimacy of advice, while on the other hand, internal resources that cater to the politician's information needs become ever more important for the navigation through a complex arena. The latter is illustrative of the tradeoff between efficiency and legitimacy that characterises EU decision-making (see Introduction).

A negative image, lack of understanding or disinterest in the EU'S functioning, and thus the added value of the polity, are among the causes for the low turnout in EP elections. The findings have the potential to better inform policymakers, opinion leaders, media, and the general public. A wellinformed and more nuanced public debate on the European Parliament is necessary to improve the attention for and participation in EU democracy. The upcoming EP elections form an opportune moment to test and shape this potential. This is further discussed in the next section.

\section{Target groups \& implementation}

The previous section discussed the potential knowledge utilisation of the conducted research. This section specifies the interested parties in respect to the definition and typology of political advice that are advanced in the thesis, as well as to the presented findings about how decisions are prepared by advisors. It suggests how the research may be used by the various target groups and offers possible avenues to make the conducted research available and suitable for future knowledge utilisation.

First of all, both the conceptual approach and the analysed empirical material are valuable to scholars working on the EP, informal politics in the $\mathrm{EU}$, and the politics of expertise in the EU. More generally, the conceptual framework may be employed to assess power structures in other legislatures or institutions and tease out the political dimensions of activities 
carried out by advisors. Academic discussions on political delegation tend to focus on the perspective of the elected (why do politicians delegate, how do they try to control their advisors, etc.). The framework offers a novel approach to take into account both the personal and contextual perspectives for the assessment of the discretion of advisors. In this way it enables the connection between theory and practice. Moreover, advisors serving a collective of political superiors (e.g. a political party) form a distinct group of actors that have so far only received marginal scholarly consideration. The findings demonstrate how advisors operate in everyday practice which can inform and inspire future studies on EP staff, their cooperation, division of labour, and the possible influence of external stakeholders or events on their activities. Furthermore, the conducted research can be used as a starting point for the study of political advisors in other legislative settings (see chapter 8.6 for a more detailed description of the future research agenda).

Second, the knowledge and insight regarding the practice of decisionmaking rendered by the thesis is crucial for teachers and students. It could be included in future education and training programmes on European studies, public administration, or political science. Several propositions for dissemination are proposed below.

Third, politicians and opinion leaders can use this practical knowledge to prepare for public debates, the campaign leading up to the $2019 \mathrm{EP}$ elections, or for upcoming national elections in which EU integration may be on the agenda.

Fourth, the findings can be informative and instructive for a variety of professionals involved in interest representation. Representatives of national, regional, and local governments, interest groups, lobbyists, and consultants could benefit from the information that the thesis offers on the 
functioning of the informal stages of decision-making. During these early preparations and negotiations, the need for policy input will be the highest among politicians and their advisors. Thus, this stage in the decisionmaking process provides the best opportunity for influencing legislation.

Fifth, the leadership and human resource managers of the EP party groups can use the findings to gain insight into the performance of their advisors. In the dissemination proposal below, an instrument is suggested that could be developed for the evaluation of the performance and/or the recruitment of (successful) group advisors.

Journalists are the sixth target group that can benefit from the research conducted. The findings presented in this dissertation may contribute to a more nuanced public debate of how decisions come about in practice. The empirical findings contribute to uncovering how political decisions are prepared, which provides a valuable contribution to the wider public debate and opinion-formation on EU politics and democracy and may inspire similar discussions in relation to national legislatures.

Finally, as implied earlier, the findings have an important potential contribution to informing the general public. Several suggestions to engage are proposed below and the upcoming 2019 EP election campaign is considered to provide the right momentum.

The abovementioned target groups may be reached through various channels. The following avenues are proposed for future dissemination of the research results:

(i) Instrument for the performance assessment of EP group advisors, and/or recommendations to the leadership of the EP party groups. 
(ii) Infographic about the various activities that take place during the early and informal stages of EP decision-making.

(iii) You tube video that explains the various activities that take place during the early and informal stages of EP decision-making.

(iv) (Digital) toolkit for teachers providing information about the practice of decision-making. Topical examples of files progressing through Parliament could be used to give students practical assignments.

(v) Handbook targeting students of political science, public administration or governance, and European studies.

(vi) Guest lectures for students and professionals (e.g. teachers, civil servants, public affairs managers).

(vii) Participation in the public debate to increase the general public's knowledge of this subject: e.g. through newspaper articles and reaching out via social media. The upcoming EP elections provide momentum to raise awareness of how things work in practice, and why that matters.

(viii) Other forms of dissemination could be achieved through copublications or events with societal stakeholders (e.g. local and regional authorities trying to reach their citizens, the representation of the EP and/or EC in The Hague).

In sum, the knowledge and insights that this research project have generated are useful and can be made available to a variety of stakeholders. This is something that I, and hopefully others with me, will continue to pursue from this moment onwards. 


\section{NEDERLANDSE SAMENVATTING}

Het overkoepelende thema van deze dissertatie is de rol van advies in politieke besluitvormingsprocessen. Het onderzoek richt zich in het bijzonder op interne advisering in het Europees Parlement (EP). De vraag die in dit kader onder de loep wordt genomen, is onder welke voorwaarden fractieadviseurs in het EP een politieke rol kunnen vervullen. De dissertatie beoogt inzicht te bieden in de voorbereiding van politieke besluitvorming. Een diepgaand en meer genuanceerd beeld van de totstandkoming van besluiten is fundamenteel voor een goed begrip van hoe onderhandelingsprocessen verlopen en compromissen gesloten worden. Deze processen vinden over het algemeen achter de schermen plaats, zonder publieke of politieke verantwoording. Bovendien kennen zij een hoog informeel gehalte, wat betekent dat zelfs interne belanghebbenden (de wetgevers en hun adviseurs) niet allemaal over dezelfde informatie beschikken. De dissertatie legt de interne dynamiek waar dit mee gepaard gaat bloot. Aangetoond wordt dat de voorbereidingen, getroffen door fractieadviseurs, de bouwstenen vormen voor de compromissen bereikt door de wetgevers.

Het EP heeft zich de afgelopen decennia significant ontwikkeld in termen van politieke autoriteit en wetgevende machten. Sinds de inwerkingtreding van het Verdrag van Maastricht (2009) is het medewetgever op vrijwel alle beleidsterreinen. Deze uitbreiding van verantwoordelijkheden en invloed heeft gevolgen voor de interne organisatie. Vanuit een streven naar meer transparantie en het opbouwen van expertise op nieuwe beleidsterreinen, heeft de instelling zich recentelijk ingezet voor de verdere ontwikkeling en professionalisering van het administratieve ondersteuningsapparaat. In de voorbereiding van standpunten op wetgeving of beleid kunnen Europarlementariërs een beroep doen op drie interne adviesbronnen: (1) 
het Secretariaat-Generaal dat ten dienste staat van de instelling als geheel, (2) de secretariaten van de verschillende transnationale fracties die de ideologische belangen van de fractie behartigen (3) de persoonlijke assistenten die zich voor de agenda van individuele Europarlementariërs inzetten. In de literatuur over het functioneren van het EP blijft de rol van fractieadviseurs onderbelicht en lag de focus tot nu toe op de andere twee bronnen van advies. EP-fracties staan centraal in het besluitvormingsproces omdat de interne structuren en de werkverdeling op basis van deze fracties bepaald worden. De verwachting was daarom dat fractieadviseurs in grotere mate dan andere adviseurs in het EP bijdragen aan de voorbereiding van politieke compromissen.

De rol van het EP als medewetgever, alsmede het gebruik om de onderhandelingen tussen de EU-instellingen (in de zogenaamde trilogen) informeel te starten in een vroeg stadium, vergroten de relevantie van onderzoek naar de interne coördinatiemechanismes van het EP. De toegenomen inter-institutionele dialoog politiseert EU-besluitvorming maar gaat gepaard met zorgen over 'achterkamertjespolitiek' waarbij slechts een handvol Europarlementariërs is betrokken. De bevindingen van de dissertatie werpen licht op het coördinatieproces dat hieraan voorafgaat in het EP.

Voor de beantwoording van de onderzoeksvraag is het in de eerste plaats nodig om 'politiek advies' te conceptualiseren, een fenomeen dat tot nu toe onderbelicht is gebleven in de literatuur. Hiertoe is een theoretisch kader ontwikkeld dat 'politiek advies' definieert als een gemengde 'activiteitsfeer' waarin administratieve en politieke functies overlappen en complementair zijn aan elkaar. De dissertatie bouwt voort op de theorieën van het sociaal constructivisme en de 'logica van gepastheid' (logic of appropriateness). Beargumenteerd wordt dat om wetgevers van geschikt advies te voorzien het onvermijdelijk is dat adviseurs een politieke bijdrage leveren. Voor het 
grootste deel van hun activiteiten opereren adviseurs niet op basis van expliciete instructies of input van de Europarlementariër (proactieve rol). $\mathrm{Zij}$ anticiperen de wensen en prioriteiten van de wetgever en beoordelen vervolgens zelf wat er nodig is om die te vervullen. Voortbouwend op bestaande theorieën over de interactie tussen politieke en niet-politieke actoren zijn vier categorieën van politiek advies ontwikkeld, die zich in de volgende vier rollen laten vertalen: (1) procesmanager (Process Manager), (2) informatiemanager (Information Manager), (3) beleidsexpert (Policy Expert) en (4) tussenpersoon (Broker).

De empirische analyse is gebaseerd op een online enquête onder fractieadviseurs ( $\mathrm{N}=99)$ en 30 interviews met (voormalig) betrokkenen bij het EP-besluitvormingsproces. De bevindingen laten zien dat fractieadviseurs in het EP bovengenoemde vier typen van advies verlenen. Het belang dat adviseurs aan een rol hechten, evenals de mate waarin zij een rol vervullen, hangt af van de fractie die zij vertegenwoordigen. Uit de resultaten zijn drie oriëntaties voor advies gedistilleerd. In de grote, mainstream fracties van de Christen-Democraten (EPP), Liberalen (ALDE) en Sociaal-Democraten (S\&D) ligt de nadruk op het bemiddelen van interne compromissen aangezien deze fracties vele, verschillende nationale partijen verenigen (compromise-oriented approach). Bij de Groenen (Greens/EFA), en in mindere mate bij de Conservatieven (ECR) en de linkse fractie GUE/NGL, ligt de nadruk op het aanreiken van beleidsgerichte expertise aangezien de ideologische belangen binnen deze fracties redelijk overeenstemmen (policy-oriented approach). Procesbeheersing is het meest van belang bij fracties die gekenmerkt worden door een grote mate van autonomie van de nationale partijen en een zekere euroscepsis (procedure-oriented approach). Dit geldt voor de ECR, de rechtse fractie EFD en de linkse fractie GUE/NGL. 
Het onderzoek toont verder aan dat de rol van fractieadviseurs in de onderhandelingen die binnen en tussen de EP-fracties plaatsvinden hen onderscheidt van andere interne adviseurs. Hoewel de Europarlementariër de uiteindelijke taakverdeling bepaalt, worden de volgende taken beschouwd als het exclusieve domein van de fractieadviseur: (i) signaleren en identificeren van potentieel conflicterende of inconsistente posities binnen de fractie (onderdeel van de procesmanager rol); (ii) afstemmen van standpunten binnen de fractie (interne tussenpersoon rol); en (iii) onderhandelen met de andere fracties (externe tussenpersoon rol). De rollen van informatiemanager en beleidsexpert kunnen daarentegen ook door medewerkers van het EP-secretariaat of door de persoonlijke assistenten van Europarlementariërs worden vervuld.

De analyse demonstreert dat adviseurs alleen proactief gedrag kunnen vertonen mits zij in hun activiteiten de belangen en politieke agenda van de fractie nastreven. Onmisbare factoren voor het vervullen van een proactieve rol zijn een vertrouwensrelatie met de Europarlementariër en diens persoonlijke assistent en het vermogen om zich in de Europarlementariër te kunnen verplaatsen (politieke sensitiviteit). Daarnaast bepaalt de context in hoeverre proactief gedrag door adviseurs acceptabel is voor Europarlementariërs. Uit de bevindingen wordt geconcludeerd dat de parlementaire procedure, de fase van besluitvorming en de ervaring van Europarlementariërs beslissende indicatoren zijn voor de voorspelling van proactief gedrag door adviseurs.

De proactieve rol is het meest omvangrijk gedurende de vroege fase van besluitvorming. De adviseurs hebben dan de meeste kans om de uitkomsten van politieke standpunten en compromissen vorm te geven. De mogelijkheden om initiatief te nemen worden minder naarmate een wetgevend voorstel de verschillende stappen van besluitvorming doorloopt. De bijdrage van de adviseur wordt dan beperkt door de politieke debatten 
die plaatsvinden binnen de fracties (reactieve rol). Ten slotte vervullen adviseurs ook taken die gebonden zijn aan strikte instructies van de Europarlementariër, vastgestelde procedures of mandaten (routine rol). Deze activiteiten hebben weinig of geen impact op de vormgeving van politieke standpunten. 


\section{ACKNOWLEDGEMENTS}

The years spent living in Brussels and working in EU public affairs are what inspired me to investigate the topic of EP group advisors. As a lobbyist I often encountered the different types of EP staff and became intrigued with the special position of political group advisors.

First and foremost, I owe the final result of this project for a great deal to my interviewees and survey respondents who were all so kind and helpful. Their open and candid accounts truly allowed me a glimpse into the backstage arena of the EP.

Secondly, I want to thank my supervisors Christine Neuhold and Thomas Christiansen for their invaluable advice, enthusiastic encouragement and for incessantly challenging me throughout this lengthy process. They were always willing to provide me with feedback, even when (more often than not) I would send them something at the very last minute.

I would like to thank Paulina Bury for starting this exciting (prolonged!) journey together and for seeing it through to the end by providing me with much appreciated practical tips and organising my mock defence. Special thanks and credits go to Merlijn van Hulst for being an important source of inspiration for the venn-diagram that I developed to visualise political advice. Furthermore, I am very grateful to Bea Krenn, Femke van der Geest, Helen Dyson, Mirre Stallen and Zoe Ditch for proofreading parts of the dissertation. In this respect, I want to particularly thank John Ditch for his detailed corrections and valued suggestions that have improved my thesis enormously. 
Further thanks go to my employer and all of my colleagues at Utrecht University. I cherish their continuous interest in how the project was progressing and their understanding when I once again needed to take time off to ensure that progress was made. Such a work environment truly helped me to complete this part-time PhD.

The same goes for all of my friends who, throughout the years, never stopped encouraging me and have always been extremely supportive despite my cancelling or being distracted with all the things that yet remained to be done for the dissertation. Thank you all for being there and for lending a listening ear when I desperately needed one.

These acknowledgments cannot go without mentioning the fantastic view that has inspired me during the final stretch of writing. I will forever treasure the wonderful and plentiful cows, ducks, swans, sheep, cats and birds that would make my days in PhD confinement just a little bit brighter.

I want to thank my parents Gerrit and Lyn Ruiter to whom I owe my perseverance, probably the crucial characteristic to see this through! And last but certainly not least, a big thank you goes out to Manne van der Zee for his loving support through both the ups and downs, for believing in me, for patiently dealing with my absence, but most importantly, for making me smile every day. 


\section{ABOUT THE AUTHOR}

Emmy Ruiter (1979) was born in Hoorn, The Netherlands. She obtained a bachelor's degree in International Business (2002) and in European Studies (2004). In 2007, Emmy completed her master's degree honours programme European Policy at the University of Amsterdam (UvA). She graduated with distinction after having submitted her thesis titled 'Double Crisis in Europe. Tackling the legitimacy and identity crises.' During her studies, she did an internship at the European Parliament. Between 2007 and 2013, Emmy held various public affairs positions, representing Dutch regional and local governments in Brussels. Since 2013, she is the EU Liaison Officer of Utrecht University. As an external fellow, Emmy Ruiter started her PhD studies at the Brussels Campus of Maastricht University in October 2011. 


\section{APPENDIX I. DOCUMENT ANALYSIS}

\section{EP online sources and papers}

\begin{tabular}{|c|c|}
\hline Data/ information analysed & Use \\
\hline $\begin{array}{l}\text { EP website (consulted August } \\
\text { 2016) }\end{array}$ & $\begin{array}{l}- \text { Composition of Parliament (1.1.3) } \\
- \text { Amount of accredited MEP assistants } \\
(3.1 .1)\end{array}$ \\
\hline $\begin{array}{l}\text { EP website (consulted March } \\
\text { 2018) }\end{array}$ & Functioning and services of the EPRS (3.1.1) \\
\hline $\begin{array}{l}\text { EP party group websites } \\
\text { (consulted January 2014) }\end{array}$ & $\begin{array}{l}\text { Staff distribution and estimation number of } \\
\text { group advisors/ target population }(2.5 .3 \text {, } \\
3.1 .1,3.2 .1) \text {. }\end{array}$ \\
\hline $\begin{array}{l}\text { EP party group websites } \\
\text { (consulted August 2016) }\end{array}$ & $\begin{array}{l}\text { Internal organisation structures of the } \\
\text { group (1.2.2). }\end{array}$ \\
\hline $\begin{array}{l}\text { EP party group websites } \\
\text { (consulted April 2017) }\end{array}$ & Function titles group advisors (3.1.1). \\
\hline $\begin{array}{l}\text { EP Working Paper 'Comparison } \\
\text { of organisational and } \\
\text { administrative arrangement in } \\
\text { EU national parliaments' } \\
(2000)\end{array}$ & $\begin{array}{l}\text { Comparative data about the role of } \\
\text { parliamentary staff in the Member States, } \\
\text { the US Congress, and the EP (introduction, } \\
2.2,3.1 \text {, and } 3.3 \text { ). }\end{array}$ \\
\hline $\begin{array}{l}\text { EP paper 'Parliamentary } \\
\text { democracy in action. Summary } \\
\text { comparison studies' (2013) }\end{array}$ & $\begin{array}{l}\text { - } \text { Assessment of EP in-house support } \\
\text { (3.1.1) } \\
\text { - } \text { Insight into the EP's strategy to deal } \\
\text { with its evolving workload ( } 3.1 \text { and } 3.3 \text { ) }\end{array}$ \\
\hline $\begin{array}{l}\text { Report from the EP Secretary } \\
\text { General, 'Strategic Planning for } \\
\text { the Secretariat General of the } \\
\text { European Parliament' (2015) }\end{array}$ & $\begin{array}{l}\text { Insight into the EP's strategy to deal with its } \\
\text { evolving legislative powers, and most } \\
\text { significantly its role in the inter-institutional } \\
\text { dialogue }(1.1 .1,1.3 .3) \text {. }\end{array}$ \\
\hline EP Establishment Plan (2014) & $\begin{array}{ll}- & \text { EP staff distribution }(2.4,3.1) \\
- & \text { Staff allocations per group }(3.2)\end{array}$ \\
\hline
\end{tabular}




\begin{tabular}{|c|c|}
\hline $\begin{array}{l}\text { EP Rules of Procedure, } 7^{\text {th }} \\
\text { parliamentary term }(2014)\end{array}$ & \multirow{3}{*}{$\begin{array}{l}\text { Understanding of the EP structures and } \\
\text { functioning, as well as the key actors } \\
\text { (chapter } 1 \text { ). }\end{array}$} \\
\hline $\begin{array}{l}\text { EP Rules of Procedure, } 8^{\text {th }} \\
\text { parliamentary term }(2016)\end{array}$ & \\
\hline $\begin{array}{l}\text { EP Rules of Procedure, } 8^{\text {th }} \\
\text { parliamentary term }(2017)\end{array}$ & \\
\hline $\begin{array}{l}\text { EP Code of Conduct for } \\
\text { negotiating in the context of } \\
\text { the ordinary legislative } \\
\text { procedures (2008) }\end{array}$ & $\begin{array}{l}\text { Functioning of inter-institutional trilogues } \\
\text { and internal preparations of the EP (1.3.3). }\end{array}$ \\
\hline ALDE Rules of Procedure (2009) & \multirow{4}{*}{$\begin{array}{l}\text { The groups' Rules of Procedure rendered } \\
\text { information about their internal organisation } \\
(1.2 .2) \text {. }\end{array}$} \\
\hline Greens/EFA Statutes (2009) & \\
\hline EPP Rules of Procedure (2013) & \\
\hline S\&D Rules of Procedure (2014) & \\
\hline $\begin{array}{l}\text { EPRS, Facts \& Figures Briefing } \\
(2014)\end{array}$ & \multirow{4}{*}{ 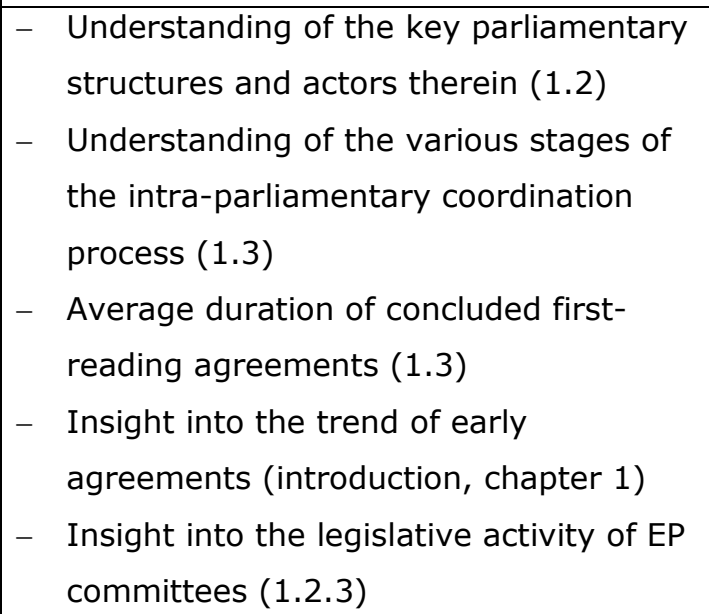 } \\
\hline $\begin{array}{l}\text { EPRS, Facts \& Figures Briefing } \\
(2016)\end{array}$ & \\
\hline $\begin{array}{l}\text { EPRS, Facts \& Figures Briefing } \\
\text { (2017) }\end{array}$ & \\
\hline $\begin{array}{l}\text { EPRS, Facts \& Figures Briefing } \\
(2018)\end{array}$ & \\
\hline
\end{tabular}

\section{Other sources}

\begin{tabular}{|l|l|}
\hline Data/ information analysed & Use \\
\hline EU Staff Regulations (2014) & $\begin{array}{r}\text { Article 5: General and special conditions } \\
\text { of employment (3.2) }\end{array}$ \\
\hline
\end{tabular}




\begin{tabular}{|c|c|}
\hline & $\begin{array}{l}- \text { Conditions of employment of other } \\
\text { servants of the EU, including those of } \\
\text { temporary staff, Title II, Articles 8-56: } \\
\text { Conditions of employment and } \\
\text { recruitment of temporary staff (3.2.1) } \\
- \text { Title III, article } 8 \text { and Annex IA: } \\
\text { Employment status of temporary staff } \\
\text { (3.2.2) }\end{array}$ \\
\hline $\begin{array}{l}\text { EPSO website (consulted } \\
\text { August 2016) }\end{array}$ & $\begin{aligned}- & \text { Employment status of group advisors } \\
& (3.2 .1) \\
- & \text { Required levels of education and } \\
& \text { experience of temporary staff }(3.2 .2)\end{aligned}$ \\
\hline $\begin{array}{l}\text { Joint declaration of the } \\
\text { European Parliament, the } \\
\text { Council and the Commission on } \\
\text { practical arrangements for the } \\
\text { Co-decision Procedure ( } 2007)\end{array}$ & $\begin{array}{l}\text { Functioning of inter-institutional trilogues } \\
(1.3 .3)\end{array}$ \\
\hline
\end{tabular}

\section{Vacancy notices}

\begin{tabular}{|l|l|}
\hline $\begin{array}{l}\text { Data/ information } \\
\text { analysed }\end{array}$ & Use \\
\hline $\begin{array}{l}\text { See the selection of notices } \\
\text { below (2011-2016) }\end{array}$ & $\begin{array}{l}\text { The analysis of vacancy notices was used for } \\
\text { the operationalisation of the framework to the } \\
\text { specifics of the EP (chapter 3) and the design } \\
\text { of the survey (Appendix II). It yielded data } \\
\text { apropos the following topics: } \\
\text { Employment status (3.2.1) } \\
- \text { General employment criteria and special } \\
\text { conditions (3.2.2) }\end{array}$ \\
\hline
\end{tabular}




\begin{tabular}{|c|c|}
\hline & 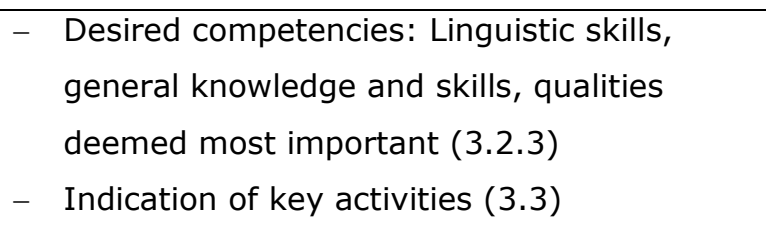 \\
\hline Source & Overview key findings \\
\hline $\begin{array}{l}\text { ECR, EFD(D), EPP, } \\
\text { Greens/EFA, and GUE/NGL } \\
\text { notices* }\end{array}$ & $\begin{array}{l}\text { - General conditions of employment are the } \\
\text { same for all political group staff. The notices } \\
\text { refer to article } 12(2) \text { of the Conditions of } \\
\text { Employment of Other Servants of the } \\
\text { European Communities, and to article } 28 \text { of } \\
\text { the EU Staff Regulations } 2014 \\
\text { - Linguistic requirements are tied to a specific } \\
\text { language group and vary per vacancy. } \\
\text { Additional requirements most commonly } \\
\text { include English, French, German }\end{array}$ \\
\hline $\begin{array}{l}\mathrm{ECR}, \mathrm{EFD}(\mathrm{D}), \mathrm{EPP}, \\
\text { Greens/EFA, and GUE/NGL } \\
\text { notices* }\end{array}$ & $\begin{array}{l}\text { Requirements encountered in all studied } \\
\text { vacancy notices (although formulated slightly } \\
\text { different in the GUE/NGL notices): } \\
\text { - A 'very good knowledge of the functioning } \\
\text { of the European Union Institutions and of } \\
\text { the political systems within the EU' } \\
\text { - } \text { Great availability (e.g. irregular working } \\
\text { hours, frequent travel to Strasbourg) } \\
\text { - } \text { Flexibility } \\
\text { - Judgment } \\
\text { - Methodological approach, } \\
\text { - } \text { Discretion } \\
\text { - } \text { Capaptability to varying workloads } \\
\text { - } \text { environment }\end{array}$ \\
\hline
\end{tabular}




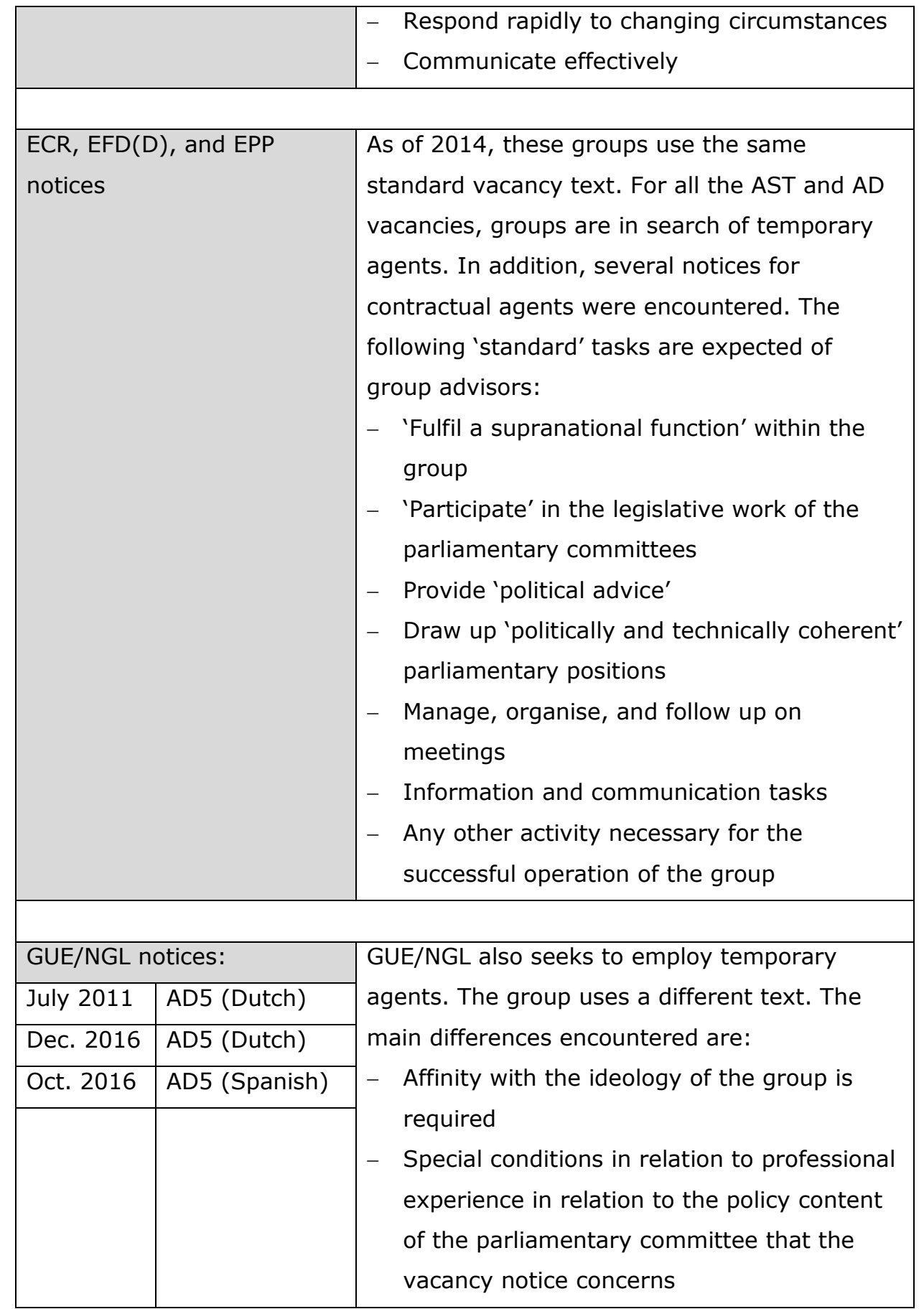




\begin{tabular}{|c|c|c|}
\hline & & $\begin{array}{l}\text { - Drafting of reports, amendments, } \\
\text { resolutions, voting lists, and briefing notes } \\
\text { are explicitly included as duties of the } \\
\text { advisor } \\
\text { _ The advisor is expected to fulfil an } \\
\text { 'intermediate function' vis-à-vis the other } \\
\text { political groups, the EP General Secretariat, } \\
\text { NGOs and the national press } \\
\text { - Additional duties are 'research tasks' and } \\
\text { 'representing and coordinating the work of } \\
\text { the national delegation in the political } \\
\text { secretariat of the GUE group' } \\
\text { - The advisor ensures that 'views and } \\
\text { requirements are anticipated and reflected } \\
\text { in draft resolutions or decisions prepared by } \\
\text { the political secretariat' }\end{array}$ \\
\hline \multicolumn{2}{|c|}{ EFD(D) notices: } & $\begin{array}{l}\text { - Special conditions in relation to educational } \\
\text { background, professional experience and/or } \\
\text { the policy content } \\
\text { - } \text { Higher requirements regarding professional } \\
\text { experience } \\
\text { - Knowledge of the political activities of the } \\
\text { group }\end{array}$ \\
\hline Jan. 2012 & AD7 (Dutch) & $\begin{array}{l}\text { - } \text { At least five years of working experience } \\
\text { within the EP is required } \\
\text { - Specific mentioning of the required field of } \\
\text { expertise, i.e. Law, European Studies }\end{array}$ \\
\hline Jan. 2013 & AST3 (English) & \multirow{2}{*}{$\begin{array}{l}\text { Both notices elaborately describe the } \\
\text { recruitment process and indicate that those } \\
\text { included on 'the list of suitable candidates' } \\
\text { will be eligible for recruitment as the need } \\
\text { arises in the group }\end{array}$} \\
\hline Oct. 2014 & AST2 (Italian) & \\
\hline
\end{tabular}




\begin{tabular}{|c|c|c|}
\hline & & $\begin{array}{l}\text { - Tasks/duties are standardised and the same } \\
\text { as those for AD candidates } \\
\text { - Special conditions are set in relation to } \\
\text { educational background and professional } \\
\text { experience }\end{array}$ \\
\hline Oct. 2014 & AD5 (Italian) & $\begin{array}{l}- \text { At least ten years of professional working } \\
\text { experience, of which at least five in } \\
\text { international environments, in particular in } \\
\text { EU institutions } \\
- \text { Specific mentioning of the required field of } \\
\text { expertise, i.e. EU research and innovation } \\
\text { policy } \\
- \text { Degree in International Relations or Law } \\
- \text { Knowledge of the political activities of the } \\
\text { EFDD group and its members }\end{array}$ \\
\hline $\begin{array}{l}\text { Oct. } \\
2014 a\end{array}$ & AD6 (Italian) & $\begin{array}{l}\text { - At least three years of working experience } \\
\text { within the EP is required, preferably } \\
\text { concerning the BUDG and ECON committees } \\
- \text { Knowledge of the political activities of the } \\
\text { EFDD group and its members } \\
- \text { Degree in Economics, Politics, and } \\
\text { International Relations would be an asset }\end{array}$ \\
\hline $\begin{array}{l}\text { Oct. } \\
2014 b\end{array}$ & AD6 (Italian) & $\begin{array}{l}-\quad \text { A minimum of five years of professional } \\
\text { working experience } \\
-\quad \text { Previous professional experience in the } \\
\text { European Parliament is required } \\
-\quad \text { Knowledge of the political activities of the } \\
\text { EFDD group and its members } \\
-\quad \text { Proven experience in the organization of } \\
\text { public events } \\
-\quad \text { Degree in Economics is an asset }\end{array}$ \\
\hline Oct. 2014 & AD7 (Italian) & $\begin{array}{l}\text { - A minimum of } 15 \text { years of professional } \\
\text { working experience }\end{array}$ \\
\hline
\end{tabular}




\begin{tabular}{|c|c|c|}
\hline & & 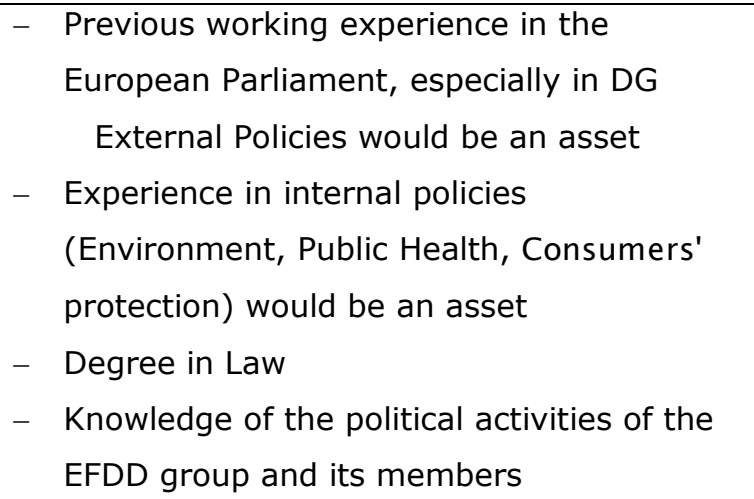 \\
\hline \multicolumn{2}{|c|}{ ECR notices: } & $\begin{array}{l}\text { Special conditions 'in the interest of the } \\
\text { service': } \\
-\quad \text { Proven ability to carry out conceptual } \\
\text { analytical work } \\
-\quad \text { Knowledge of the political activities of the } \\
\text { ECR Group and its members; and } \\
\text { sometimes 'committed supporter' }\end{array}$ \\
\hline Jan. 2013 & $\begin{array}{l}\text { Contractual } \\
\text { agent }\end{array}$ & $\begin{array}{l}\text { The following tasks are described: } \\
\text { _ } \text { Following the work of two parliamentary } \\
\text { committees } \\
\text { - } \text { Preparing summaries, position papers, and } \\
\text { minutes of meetings } \\
\text { - } \text { Drafting amendments and preparing } \\
\text { possible voting lists } \\
-\quad \text { Ensuring the group's objectives are pursued } \\
\text { throughout the a legislative or } \\
\text { parliamentary process } \\
\text { - Working with counterparts in other groups } \\
\text { to advance the objectives of the group, } \\
\text { under supervision of the relevant members }\end{array}$ \\
\hline July 2012 & AST2 (Czech) & \multirow{3}{*}{$\begin{array}{l}\text { - Notices elaborately describe the recruitment } \\
\text { process and indicate that those included on } \\
\text { 'the list of suitable candidates' will be }\end{array}$} \\
\hline Nov. 2012 & AST4 (Italian) & \\
\hline Nov. 2012 & AST4 (English) & \\
\hline
\end{tabular}




\begin{tabular}{|c|c|c|}
\hline $\begin{array}{l}\text { Sept. } \\
2014\end{array}$ & $\begin{array}{l}\text { AST1 (Croatian/ } \\
\text { English) }\end{array}$ & $\begin{array}{l}\text { eligible for recruitment as the need arises in } \\
\text { the group. The list is valid for one year and }\end{array}$ \\
\hline Oct. 2014 & AST4 (Danish) & $\begin{array}{l}\text { can be extended } \\
\text { _ } \text { Tasks/duties are standardised and similar to } \\
\text { those for AD candidates } \\
\text { _ } \text { The AST1 and AST2 notices are an } \\
\text { exception and only include the following } \\
\text { tasks: Assistance at Group meetings; } \\
\text { preparation of parliamentary work } \\
\text { - } \text { In the AST4 (English) notice, at least two } \\
\text { years of professional experience within the } \\
\text { EP is demanded }\end{array}$ \\
\hline $\begin{array}{l}\text { Sept. } \\
2014\end{array}$ & AD5 (Finnish) & No specifics encountered. \\
\hline $\begin{array}{l}\text { Sept. } \\
2014\end{array}$ & AD5 (Greek) & \\
\hline $\begin{array}{l}\text { Sept. } \\
2014\end{array}$ & AD6 (Spanish) & $\begin{array}{l}\text { Two years of professional working experience } \\
\text { required. }\end{array}$ \\
\hline $\begin{array}{l}\text { Sept. } \\
2014\end{array}$ & AD7 (Italian) & $\begin{array}{l}\text { Six years of professional working experience } \\
\text { required. }\end{array}$ \\
\hline \multicolumn{2}{|c|}{ EPP notices: } & \\
\hline Jan. 2012 & AD5 (Italian) & $\begin{array}{l}\text { Two years of professional working experience } \\
\text { required. }\end{array}$ \\
\hline May 2012 & AD5 (Latvian) & $\begin{array}{l}\text { - } \text { Two years of professional working } \\
\text { experience required } \\
\text { - } \text { Specific mentioning of the required field of } \\
\text { expertise, i.e. Economics or Finance }\end{array}$ \\
\hline $\begin{array}{l}\text { March } \\
2012\end{array}$ & $\begin{array}{l}\text { Contractual } \\
\text { agent }\end{array}$ & $\begin{array}{l}\text { At least two years of secretarial experience } \\
\text { required. }\end{array}$ \\
\hline \multicolumn{2}{|c|}{$\begin{array}{l}\text { Greens/EFA, 2016, } \\
\text { contractual agent }\end{array}$} & The following tasks are described: \\
\hline
\end{tabular}




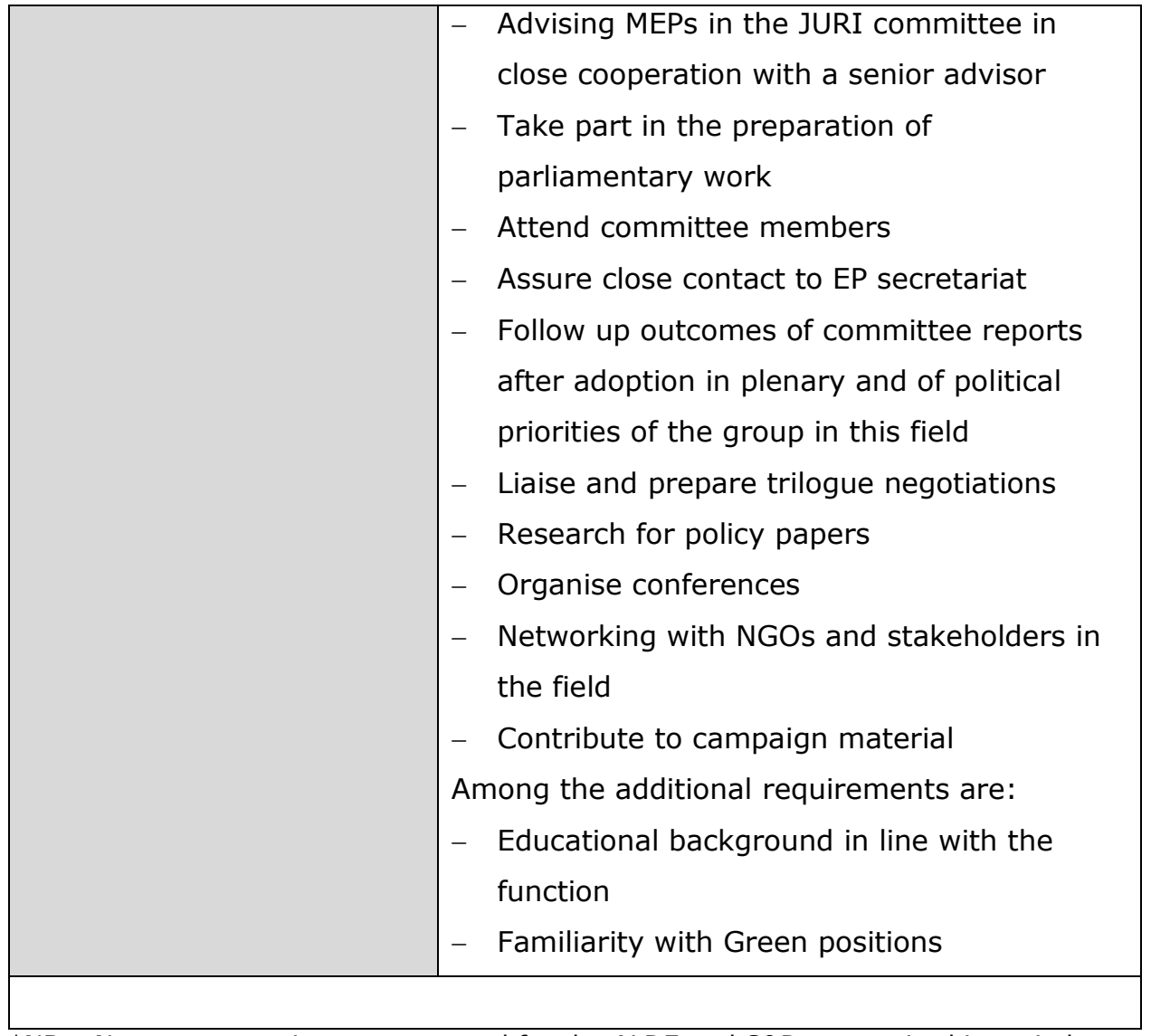

*NB - No vacancy notices encountered for the ALDE and S\&D groups in this period. 


\section{APPENDIX II. SURVEY DESIGN}

\section{PART 1/3 EXPERTISE}

Please note that all provided details will be kept strictly confidential and used for research purposes only. The information you provide will be aggregated and analysed in a non-personalised way. You will not be contacted following this survey.

1. Can you please indicate which parliamentary committee(s) fall(s) under your responsibilities?
$\square$ AFCO
$\square$ DEVE
ए JURI
$\square$ AFET
$\square$ ECON
$\square$ LIBE
$\lceil$ DROI
$\square$ EMPL
$\square \mathrm{PECH}$
Г SEDE
$\square$ ENVI
$\square$ PETI
— AGRI
$\square$ FEMM
$\square$ REGI
$\sqsubset$ BUDG
$\square$ IMCO
$\square$ TRAN
$\ulcorner$ CONT
$\ulcorner$ INTA
C CULT
Г ITRE

2. Can you please state the total amount of professional working experience you have (post-graduation):
Up to 1 year
1-3 years
4-6 years
7-9 years
10 years or more

3. How long have you been in your current position for the political group secretariat?

Years

Months

\section{What did you do prior to your current position?}




\section{In your view, what are the most important skills, knowledge, or characteristics of a} Group policy advisor?

\section{Please choose a maximum of three answers}

$\begin{array}{lll}\square \text { Knowledge of EP procedures } & \square \text { Social skills } & \square \text { Network inside the EP } \\ \square \quad \text { Flexible } & \square \text { Analytical skills } & \square \text { Network outside the EP } \\ \square \text { Knowledge of the Group's (previous) } & \square \text { Expertise in a specific policy field } & \square \text { Able negotiator } \\ \text { positions } & \square \text { Able to work under pressure } & \square \text { Loyalty towards the Group } \\ \square \quad \text { Language skills } & \\ \square \text { Other (please specify) }\end{array}$

\section{What distinguishes an excellent advisor from a good advisor?}

\section{PART 2 / 3 RESPONSIBILITIES}

Please note that all provided details will be kept strictly confidential and used for research purposes only. The information you provide will be aggregated and analysed in a non-personalised way. You will not be contacted following this survey.

\section{Can you please estimate how much time you devote to the following activities?}

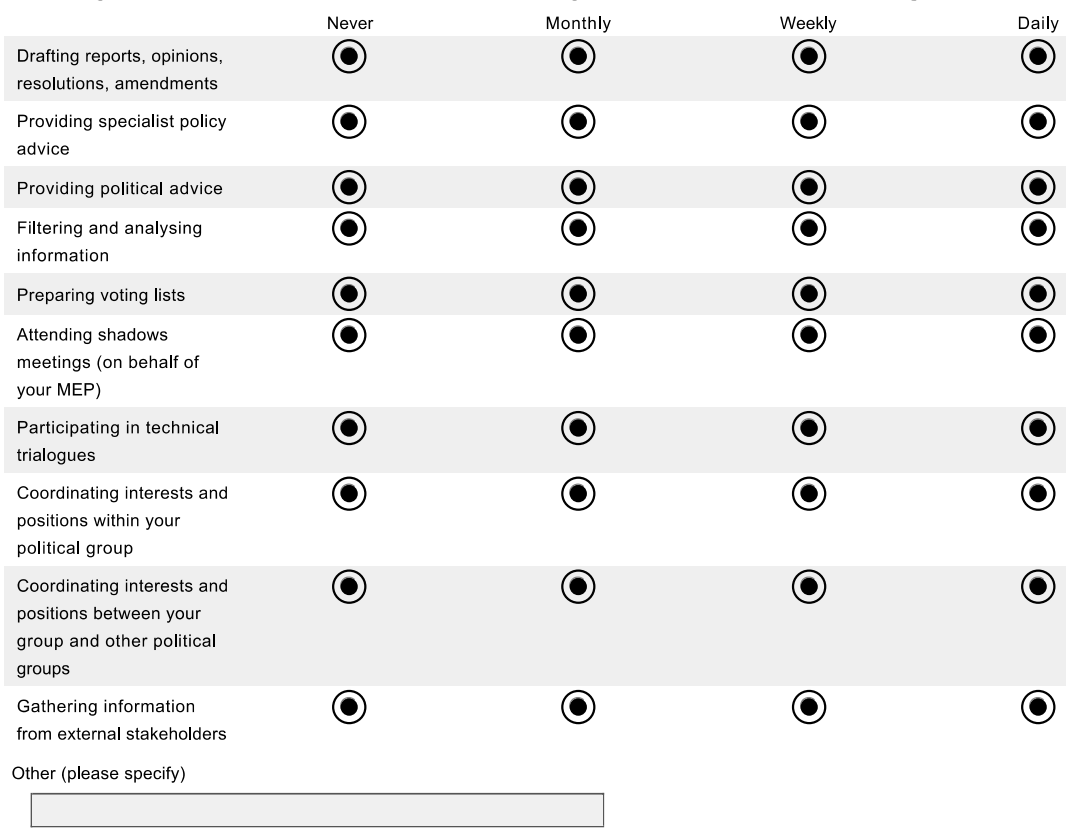


8. Can you estimate how your time is divided among the following activities?

\begin{tabular}{|c|c|c|c|c|c|c|c|c|c|c|c|}
\hline $\begin{array}{l}\text { Parliamentary work } \\
\text { (following files/ dossiers, } \\
\text { committees) }\end{array}$ & $\overbrace{}^{10 \%}$ & $\overbrace{}^{20 \%}$ & $\overbrace{}^{30 \%}$ & $\stackrel{40 \%}{(-)}$ & (20\% & $\overbrace{}^{60 \%}$ & $\stackrel{70 \%}{(2)}$ & $\overbrace{}^{80 \%}$ & (7) & $\stackrel{100 \%}{0}$ & (2) \\
\hline National delegation work & (-) & (2) & (a) & (-) & (-) & (-) & (-) & (a) & (-) & (-) & \\
\hline Political Group activities & () & () & () & () & () & () & () & () & () & (2) & () \\
\hline Other & () & () & (2) & (2) & () & (-) & (2) & (2) & () & (2) & (0) \\
\hline
\end{tabular}

Please specify

9. In your opinion, what is the most important responsibility of a Group policy advisor? And can you indicate why?

Responsibility

Motivation (optional)

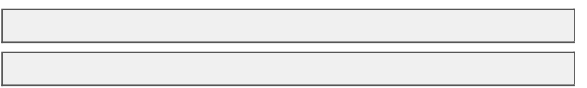

10. To what extent do you agree with the following statements?

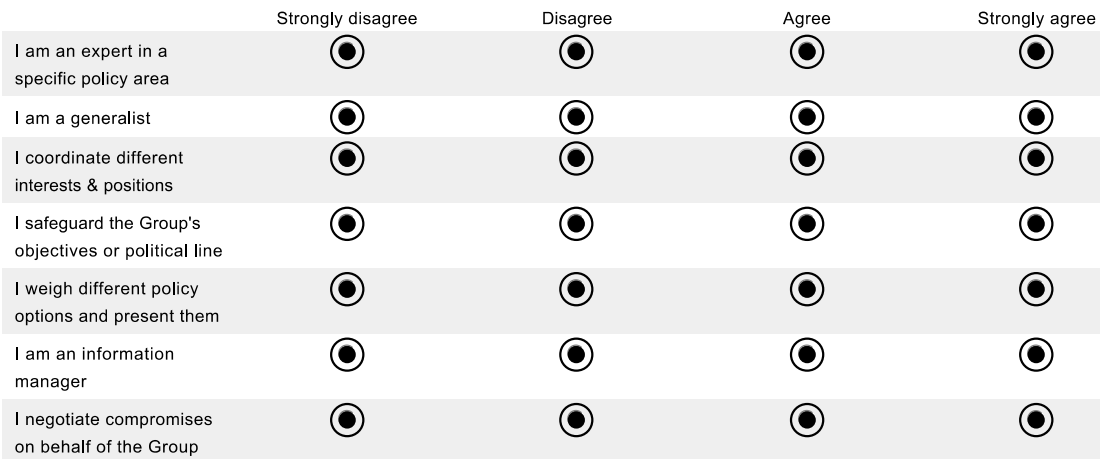

11. In your view, what is essential in order to most effectively fulfil your responsibilities as a policy advisor? 
12. Can you please indicate how often you are in contact with the following groups of people?

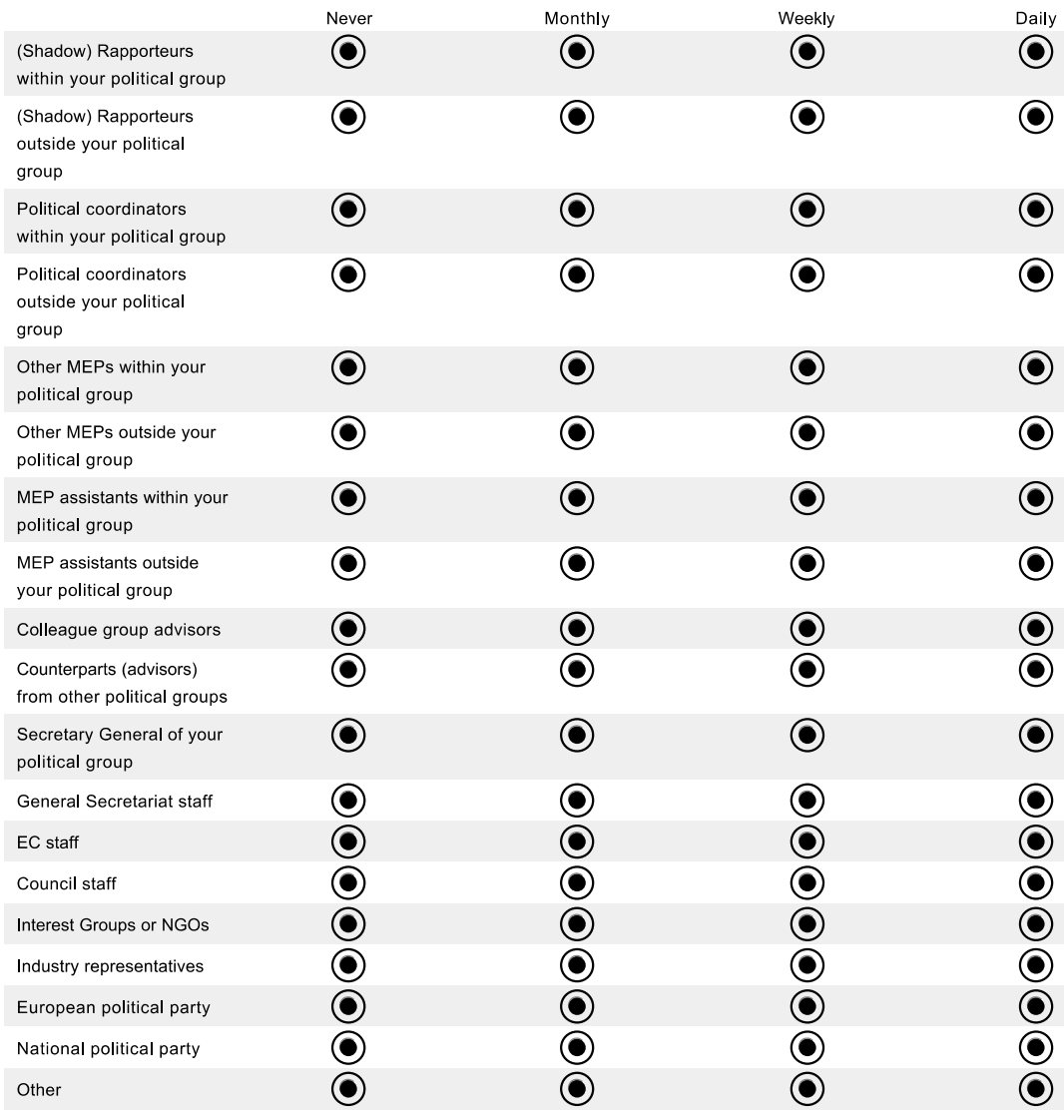

Other (please specify)

\section{PART 3 / 3 PROFILE}

Please note that all provided details will be kept strictly confidential and used for research purposes only. The information you provide will be aggregated and analysed in a non-personalised way. You will not be contacted following this survey. 


\section{How many languages do you speak?}

Native speaker

Full professional

proficiency

Intermediate proficiency

Basic proficiency

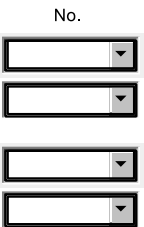

14. Can you please indicate the political group you work for:

(2) EPP

(2) S\&D

(2) ALDE

(-) Greens-EFA

(O) ECR

(2) GUE-NGL

(O) EFD

15. Are you a member of a national political party?

(-) Yes, I was a member before I started working as a Group policy advisor

(-) Yes, I became a member after I started working as a Group policy advisor

() No

16. Are you a member of a European political party?

(-) Yes, I was a member before I started working as a Group policy advisor

(-) Yes, I became a member after I started working as a Group policy advisor

(C) No

17. Can you please indicate which degrees you have attained?

$\mathrm{PhD}$

MBA

MA or equivalent

$B A$ or equivalent

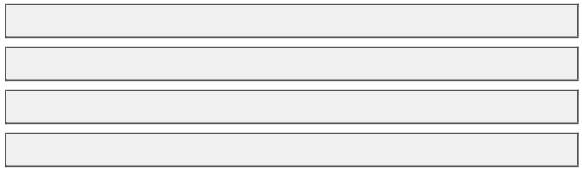

18. Can you please indicate what type of contract you currently have?

Fonctionnaire

Contract Agent

Temporary Agent

Other (please specify)

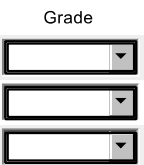


Appendix

19. What are your career aspirations?

(.) Inside EU institutions

(.) Public sector (other than EU)

(2) Private sector

(2) Politics

Other (please specify)

20. Do you have any other comments, questions, or concerns?

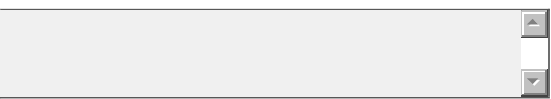




\section{APPENDIX III. SURVEY RESPONSE}

\section{Survey response per EP party group (Q14)}

\begin{tabular}{l|l|l|l}
$\begin{array}{l}\text { Political } \\
\text { group }\end{array}$ & Population* & Respondents & $\begin{array}{l}\text { Response } \\
\text { rate }\end{array}$ \\
\hline EPP & 62 & 13 & $21 \%$ \\
S\&D & 58 & 14 & $24 \%$ \\
ALDE & 41 & 19 & $46 \%$ \\
ECR & 30 & 12 & $40 \%$ \\
GREENS/EFA & 47 & 22 & $47 \%$ \\
GUE/NGL & 37 & 13 & $35 \%$ \\
EFD & 33 & 6 & $18 \%$ \\
\hline Total & $\mathbf{3 0 8}$ & $\mathbf{9 9}$ & $\mathbf{3 2 . 1 4 \%}$ \\
\hline
\end{tabular}

* Number of group advisors as published on the websites of the EP party groups (consulted, January 2014)

\section{Response across parliamentary committees (Q1)}

Responses obtained: 99

Advisors could select multiple committees.

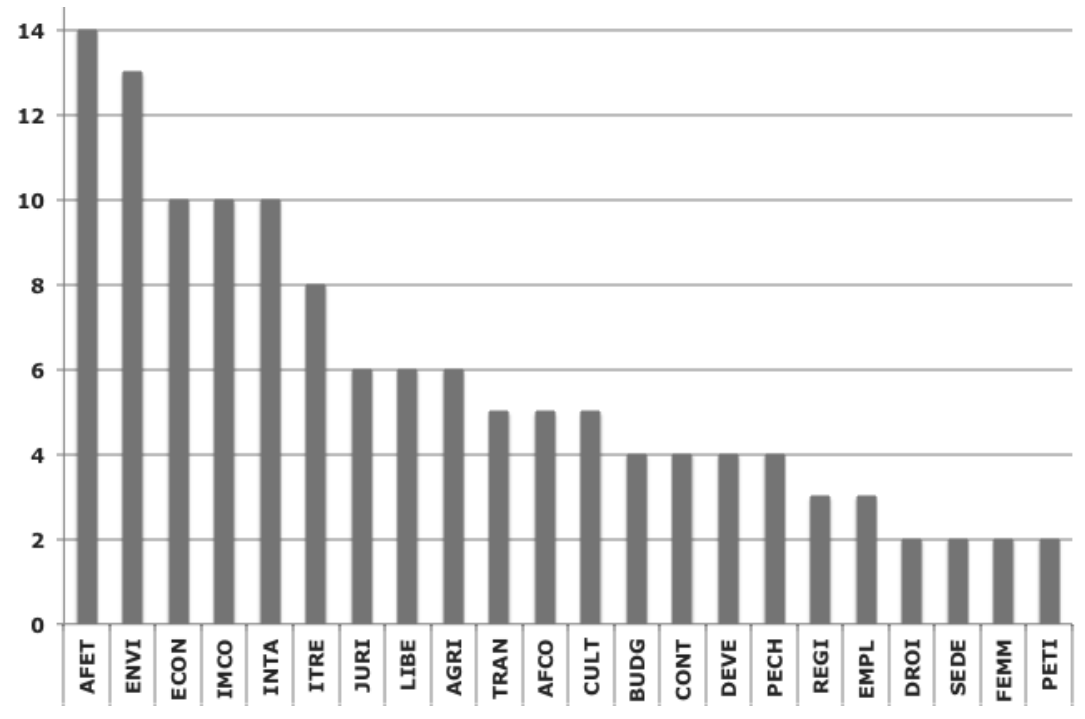


Appendix

\section{Amount of professional working experience (Q2)}

Responses obtained: 99

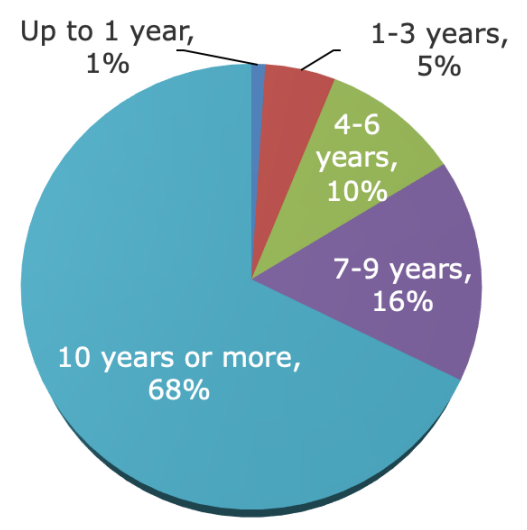

Time in current position (Q3)

Responses obtained: 99. See table 3.2.1b (pag 157).

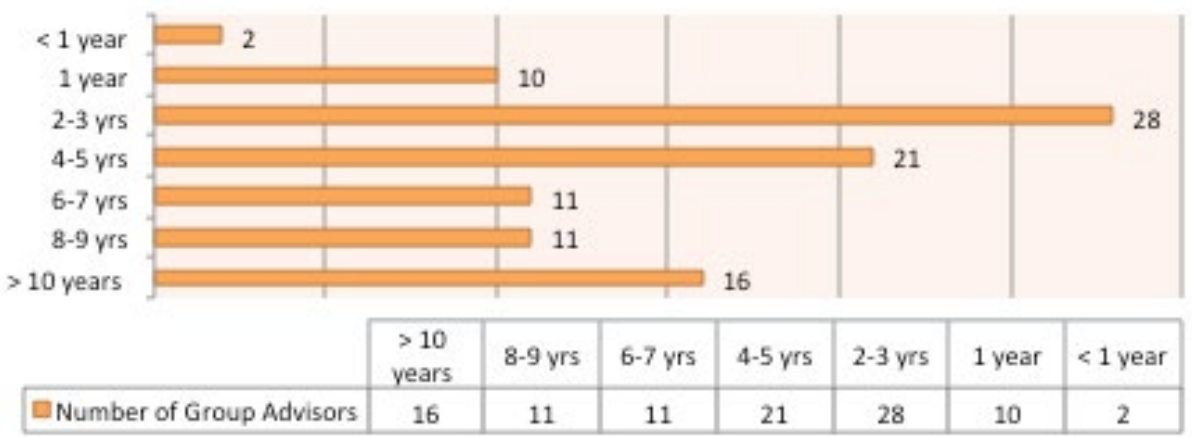

\section{Prior experience (Q4)}

Responses obtained: 95. See figure 3.2.2 (page 161).

\section{Degrees obtained (Q17)}

Responses obtained: 85. Highest obtained degrees: PhD (11\%), MA (82\%), BA (7\%). Most frequent fields of study: Law (23\%), Political Science (19\%), European Studies (15\%), Economics (15\%), International Relations (10\%), Other (18\%). See table 3.2.2 (page 159). 
Type of contract (Q18)

Responses obtained: 88

\begin{tabular}{l|l|l|l|l|l|l|l|l} 
& EPP & $\begin{array}{l}\text { S\& } \\
\text { D }\end{array}$ & $\begin{array}{l}\text { ALD } \\
\text { E }\end{array}$ & $\begin{array}{l}\text { Greens/ } \\
\text { EFA }\end{array}$ & ECR & $\begin{array}{l}\text { GUE } \\
\text { / } \\
\text { NGL }\end{array}$ & EFD & Total \\
\hline Temp agents & & & & & & & & \\
\hline AD level & 8 & 7 & 11 & 8 & 4 & 1 & 0 & 39 \\
\hline AST level & 1 & 0 & 1 & 6 & 4 & 6 & 3 & 21 \\
\hline Fonctionnaires & & & & & & & & \\
\hline AD level & 3 & 3 & 0 & 4 & 0 & 1 & 1 & 12 \\
\hline AST level & 0 & 0 & 0 & 1 & 0 & 0 & 1 & 2 \\
\hline $\begin{array}{l}\text { Contract } \\
\text { agents }\end{array}$ & & & & & & & & \\
\hline AD level & 0 & 2 & 3 & 0 & 1 & 1 & 0 & 7 \\
\hline AST level & 0 & 0 & 0 & 2 & 2 & 2 & 1 & 7 \\
\hline
\end{tabular}

\section{Career aspirations (Q19)}

Responses obtained: 79

\begin{tabular}{l|l} 
& $\begin{array}{l}\text { Career aspirations } \\
\text { inside the EU } \\
\text { institutions }\end{array}$ \\
\hline EPP & $70 \%$ \\
\hline S\&D & $50 \%$ \\
\hline ALDE & $37 \%$ \\
\hline Greens/EFA & $45 \%$ \\
\hline ECR & $17 \%$ \\
\hline GUE/NGL & $46 \%$ \\
\hline EFD & $50 \%$ \\
\hline
\end{tabular}

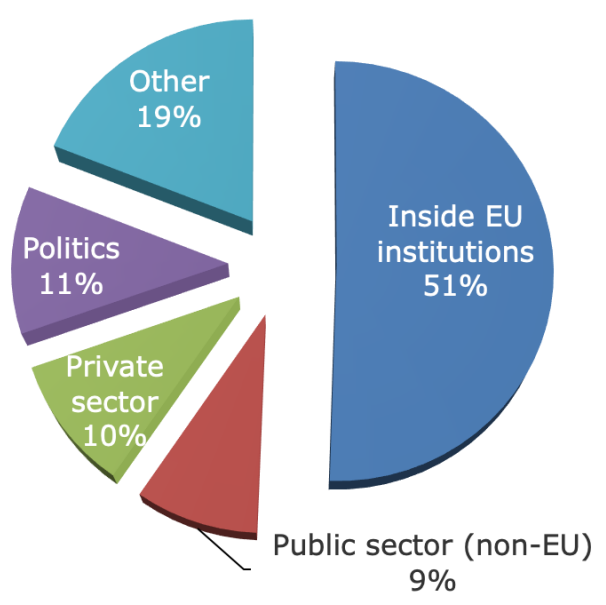




\section{Membership of national political parties (Q15)}

Responses obtained: $88.66 \%$ are member of a national political party, mostly GUE/NGL (91\%), S\&D (80\%), and EPP (70\%) respondents.

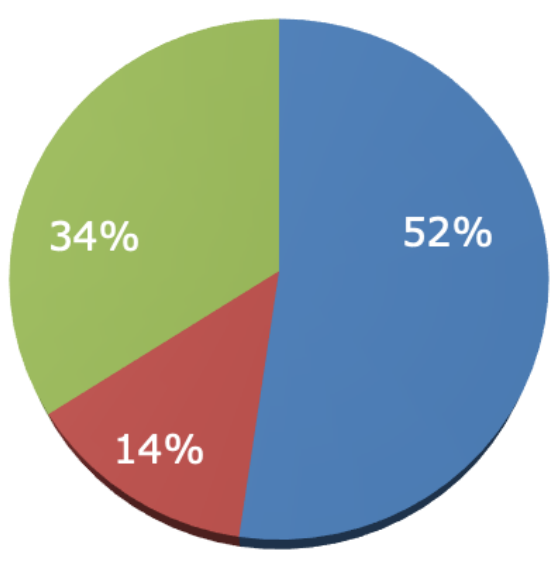

- Yes, I was a member before I started working as a Group policy advisor

- Yes, I became a member after I started working as a Group policy advisor

No

\section{Membership of European political parties (Q16)}

Responses obtained: 87 . Only $18 \%$ are member of a European political party.

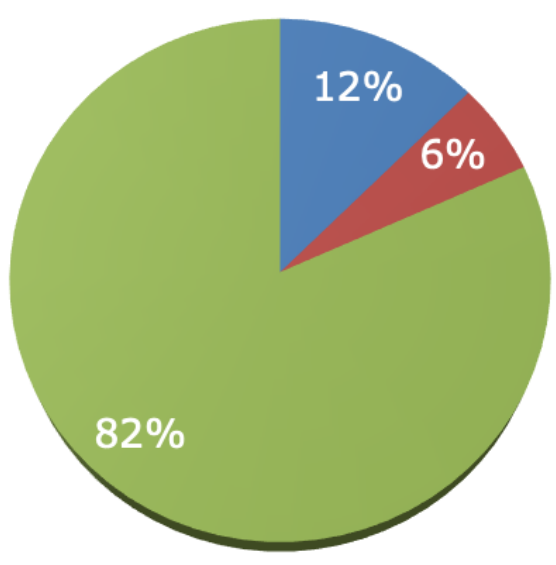

- Yes, I was a member before I started working as a Group policy advisor

- Yes, I became a member after I started working as a Group policy advisor

- No 


\section{Linguistic skills (Q13)}

Responses obtained: 88. More than three quarters of respondents claimed that they speak at least four languages. These numbers include their mother tongue, and the languages in which they say to have full or intermediate professional proficiency. Moreover, nearly a quarter of respondents claim to be a native speaker in multiple languages.

\begin{tabular}{l|l|l|l|l|l|l}
$\begin{array}{l}\text { Number of } \\
\text { languages }\end{array}$ & Two & Three & Four & Five & Six & $\begin{array}{l}\text { Seven } \\
\text { or more }\end{array}$ \\
\hline EPP & 0 & 3 & 5 & 4 & 0 & 0 \\
\hline S\&D & 0 & 0 & 6 & 2 & 2 & 2 \\
\hline ALDE & 1 & 5 & 4 & 3 & 2 & 0 \\
\hline Greens/EFA & 1 & 1 & 12 & 4 & 2 & 1 \\
\hline ECR & 3 & 2 & 4 & 2 & 0 & 0 \\
\hline GUE/NGL & 1 & 1 & 3 & 1 & 5 & 0 \\
\hline EFD & 1 & 2 & 1 & 1 & 0 & 1 \\
\hline & $\mathbf{7}$ & $\mathbf{1 4}$ & $\mathbf{3 5}$ & $\mathbf{1 7}$ & $\mathbf{1 1}$ & $\mathbf{4}$
\end{tabular}

Most important skills, knowledge, or characteristics (Q5)

Responses obtained: 99. See figure 3.2.3 (page168). 
Appendix

Distinguishing features of an 'excellent advisor' (Q6)

Responses obtained: 87. Categorised responses per political group (openended question)

\begin{tabular}{|c|c|c|c|c|c|c|c|c|}
\hline LABELS & EPP & S\&D & ALDE & $\begin{array}{l}\text { GREENS- } \\
\text { EFA }\end{array}$ & ECR & $\begin{array}{l}\text { GUE/ } \\
\text { NGL }\end{array}$ & EFD & TOTAL \\
\hline Political sensitivity & 9 & 6 & 11 & 10 & 3 & 4 & 3 & 32 \\
\hline Negotiation & 5 & 4 & 7 & 8 & 2 & 4 & 1 & 31 \\
\hline $\begin{array}{l}\text { Understand group } \\
\text { position }\end{array}$ & 4 & 3 & 7 & 6 & 4 & 3 & 1 & 28 \\
\hline Policy expertise & 4 & 3 & 5 & 7 & 3 & 5 & 1 & 28 \\
\hline Network EP & 4 & 2 & 5 & 7 & 2 & 1 & 2 & 23 \\
\hline Network external & 4 & 2 & 1 & 7 & 2 & 2 & 1 & 19 \\
\hline $\begin{array}{l}\text { Strategic } \\
\text { behaviour }\end{array}$ & 4 & 2 & 3 & 4 & 2 & 2 & 2 & 19 \\
\hline Analytical skills & 3 & 3 & 3 & 5 & 1 & 1 & 2 & 18 \\
\hline Defend group line & 1 & 1 & 8 & 5 & & 2 & 1 & 18 \\
\hline Find group line & 3 & 1 & 6 & 5 & & 2 & & 17 \\
\hline Intelligence & & & 6 & 7 & & 1 & 2 & 16 \\
\hline EP procedures & 4 & 2 & 4 & 2 & 1 & 1 & 1 & 15 \\
\hline Social skills & 3 & 3 & 2 & 4 & & & & 12 \\
\hline Conviction & & & 3 & 5 & 1 & & 1 & 10 \\
\hline Flexibility & 2 & 3 & & 3 & 1 & 1 & & 10 \\
\hline Loyalty & 4 & 1 & 2 & 2 & & & 1 & 10 \\
\hline $\begin{array}{l}\text { Compromise- } \\
\text { oriented }\end{array}$ & 2 & & 2 & 3 & 1 & & 1 & 9 \\
\hline Initiative & 2 & & 2 & 3 & 1 & 1 & & 9 \\
\hline Language & 2 & 2 & 1 & 3 & & 1 & & 9 \\
\hline $\begin{array}{l}\text { Institutional } \\
\text { memory }\end{array}$ & 2 & & 1 & & 3 & & 1 & 7 \\
\hline $\begin{array}{l}\text { Work under } \\
\text { pressure }\end{array}$ & 2 & 2 & 1 & 2 & & & & 7 \\
\hline Media relations & & & 1 & 3 & & 1 & 1 & 6 \\
\hline $\begin{array}{l}\text { Information } \\
\text { processing }\end{array}$ & & & & 3 & 1 & & 1 & 5 \\
\hline Creativity & 1 & 1 & 1 & & & & 1 & 4 \\
\hline Helicopter view & 1 & 1 & & 1 & & & 1 & 4 \\
\hline Shadow MEPs & 1 & & & 1 & 1 & 1 & & 4 \\
\hline Solution-oriented & & 1 & 1 & & & & 1 & 3 \\
\hline Trust & 1 & & & 1 & 1 & & & 3 \\
\hline Writing skills & & 1 & 1 & & & & & 2 \\
\hline Motivation & & 1 & & & & & & 1 \\
\hline
\end{tabular}




\section{Activities of the group advisor (Q7-10)}

\section{Indicated time spent on activities (Q7)}

Responses obtained: 90

\begin{tabular}{l|l|l|l|l|l} 
Answer options & Never & Monthly & Weekly & Daily & $\begin{array}{l}\text { Total } \\
\text { response }\end{array}$ \\
\hline $\begin{array}{l}\text { Drafting reports, opinions, } \\
\text { resolutions, amendments }\end{array}$ & 2 & 33 & 45 & 10 & 90 \\
\hline $\begin{array}{l}\text { Providing specialist policy } \\
\text { advice }\end{array}$ & 1 & 9 & 38 & 42 & 90 \\
\hline $\begin{array}{l}\text { Providing political advice } \\
\text { Filtering and analysing } \\
\text { information }\end{array}$ & 0 & 3 & 31 & 56 & 90 \\
\hline $\begin{array}{l}\text { Preparing voting lists } \\
\text { Attending Group meetings }\end{array}$ & 0 & 44 & 44 & 2 & 90 \\
\hline $\begin{array}{l}\text { Attending shadows meetings } \\
\text { (on behalf of your MEP) }\end{array}$ & 3 & 20 & 54 & 13 & 90 \\
\hline $\begin{array}{l}\text { Participating in technical } \\
\text { trialogues }\end{array}$ & 3 & 20 & 54 & 13 & 90 \\
\hline $\begin{array}{l}\text { Coordinating interests and } \\
\text { positions within your political } \\
\text { group }\end{array}$ & 1 & 27 & 36 & 26 & 90 \\
\hline $\begin{array}{l}\text { Coordinating interests and } \\
\text { positions within your political } \\
\text { group }\end{array}$ & 3 & 16 & 44 & 27 & 90 \\
\hline $\begin{array}{l}\text { Gathering information from } \\
\text { external stakeholders }\end{array}$ & 4 & 21 & 41 & 24 & 90 \\
\hline
\end{tabular}


Appendix

Estimated division of time on activities (Q8)

Responses obtained: 90

\begin{tabular}{l|l|l|l|l} 
\% of time & $\begin{array}{l}\text { Parliamentary } \\
\text { work }\end{array}$ & $\begin{array}{l}\text { National } \\
\text { delegation work }\end{array}$ & $\begin{array}{l}\text { Political Group } \\
\text { activities }\end{array}$ & Other \\
\hline $\mathbf{1 0 \%}$ & 1 & 31 & 16 & 3 \\
\hline $\mathbf{2 0 \%}$ & 1 & 13 & 32 & 6 \\
\hline $\mathbf{3 0 \%}$ & 7 & 5 & 19 & 2 \\
\hline $\mathbf{4 0 \%}$ & 9 & 6 & 11 & 1 \\
\hline $\mathbf{5 0 \%}$ & 12 & 1 & 3 & 1 \\
\hline $\mathbf{6 0 \%}$ & 11 & 2 & 0 & 0 \\
\hline $\mathbf{7 0} \%$ & 12 & 0 & 1 & 0 \\
\hline $\mathbf{8 0} \%$ & 25 & 0 & 1 & 0 \\
\hline $\mathbf{9 0} \%$ & 9 & 0 & 0 & 0 \\
\hline $\mathbf{1 0 0} \%$ & 3 & 0 & 0 & 0 \\
\hline & & & & \\
\hline
\end{tabular}




\section{Most important responsibility of the group advisor (Q9)}

Responses obtained: 97

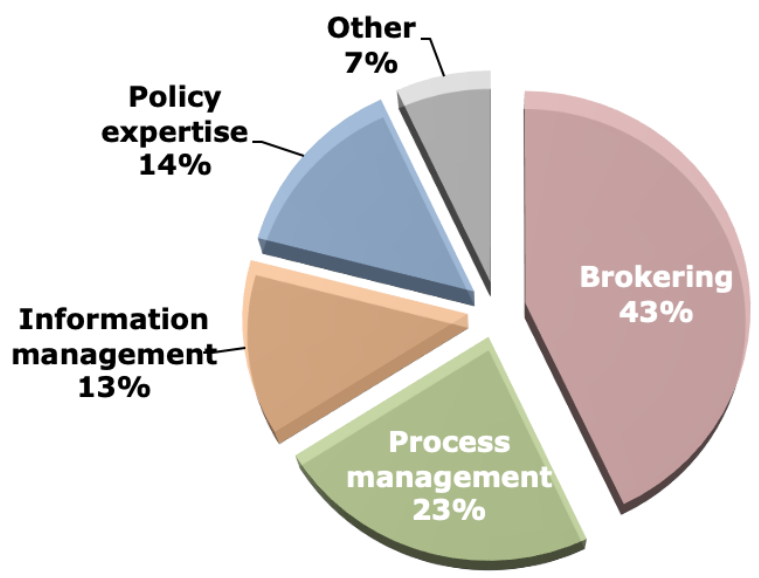

Number of respondents that agree with the following statements (Q10)

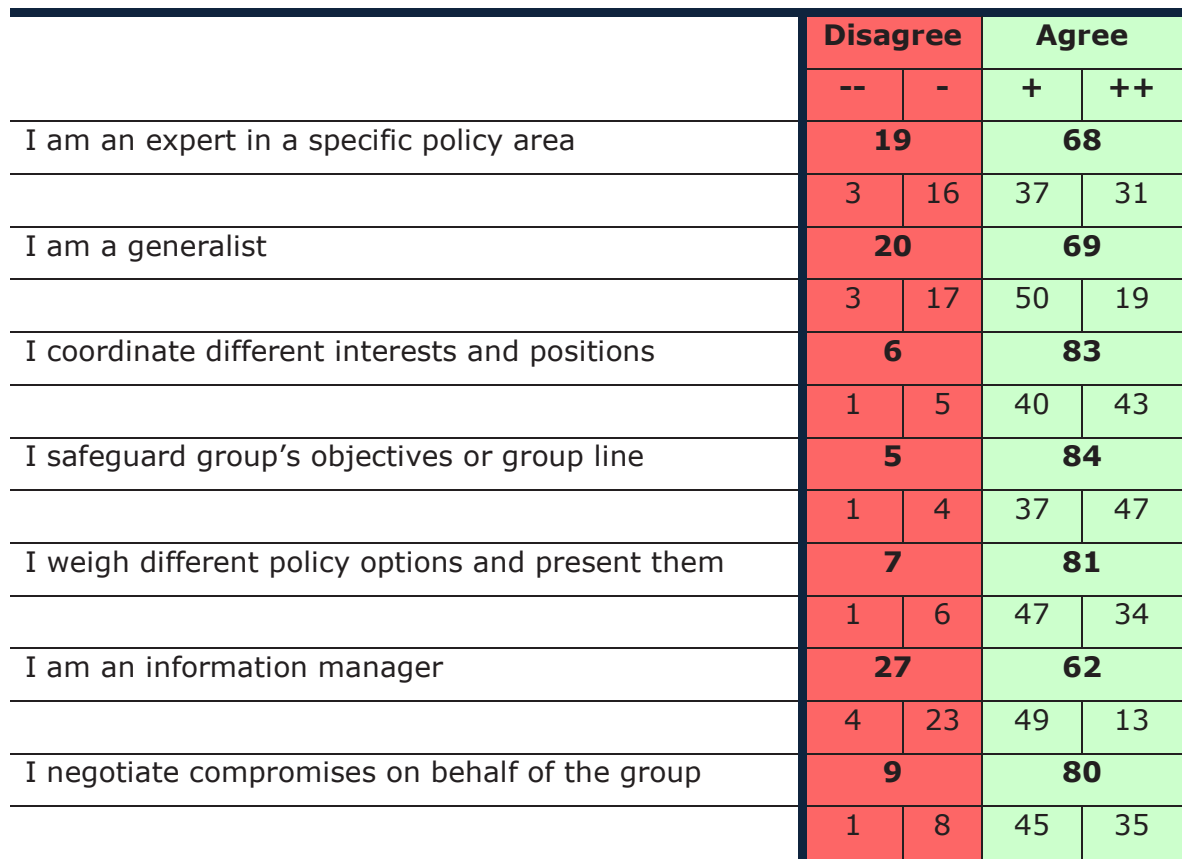


Appendix

\section{What advisors need to fulfil their role (Q11)}

Responses obtained: 70. 60 respondents identified the most important factor(s). Others only pointed to their most important task(s). 48 respondents identified one single most important factor and 12 respondents mentioned several factors.

\begin{tabular}{l|l|l|l|l} 
Factor & \multicolumn{1}{|c|}{$\begin{array}{c}\text { Political } \\
\text { sensitivity }\end{array}$} & Network & Trust & \multicolumn{1}{c}{$\begin{array}{c}\text { Political } \\
\text { direction }\end{array}$} \\
\hline Single most important & 23 & 8 & 5 & 4 \\
\hline $\begin{array}{l}\text { Mentioned in } \\
\text { combination with other } \\
\text { factors }\end{array}$ & 8 & 9 & 6 & 1
\end{tabular}

\begin{tabular}{l|l|l|l|l} 
Factor & \multicolumn{1}{|c|}{$\begin{array}{c}\text { Institutional } \\
\text { memory }\end{array}$} & Motivation & Time & Other \\
\hline Single most important & 0 & 3 & 1 & 5 \\
\hline $\begin{array}{l}\text { Mentioned in } \\
\text { combination with other } \\
\text { factors }\end{array}$ & 1 & 0 & 2 & \\
\end{tabular}




\section{Advisors' contacts (Q12)}

Responses obtained: 80

\begin{tabular}{|c|c|c|c|c|c|}
\hline Answer options & Never & Monthly & Weekly & Daily & $\begin{array}{l}\text { Total } \\
\text { response }\end{array}$ \\
\hline $\begin{array}{l}\text { (Shadow) Rapporteurs within your } \\
\text { political group }\end{array}$ & 2 & 7 & 35 & 36 & 80 \\
\hline $\begin{array}{l}\text { (Shadow) Rapporteurs outside your } \\
\text { political group }\end{array}$ & 7 & 31 & 36 & 5 & 79 \\
\hline $\begin{array}{l}\text { Political coordinators within your } \\
\text { political group }\end{array}$ & 4 & 3 & 32 & 40 & 79 \\
\hline $\begin{array}{l}\text { Political coordinators outside your } \\
\text { political group }\end{array}$ & 18 & 28 & 32 & 1 & 79 \\
\hline $\begin{array}{l}\text { Other MEPs within your political } \\
\text { group }\end{array}$ & 1 & 12 & 28 & 39 & 80 \\
\hline $\begin{array}{l}\text { Other MEPs outside your political } \\
\text { group }\end{array}$ & 12 & 29 & 33 & 6 & 80 \\
\hline $\begin{array}{l}\text { MEP assistants within your political } \\
\text { group }\end{array}$ & 0 & 1 & 13 & 66 & 80 \\
\hline $\begin{array}{l}\text { MEP assistants outside your political } \\
\text { group }\end{array}$ & 2 & 20 & 44 & 14 & 80 \\
\hline Colleague group advisors & 1 & 5 & 10 & 62 & 78 \\
\hline $\begin{array}{l}\text { Counterparts (advisors) from other } \\
\text { political groups }\end{array}$ & 1 & 5 & 34 & 38 & 78 \\
\hline $\begin{array}{l}\text { Secretary General of your political } \\
\text { group }\end{array}$ & 9 & 34 & 29 & 7 & 79 \\
\hline General Secretariat staff & 6 & 19 & 34 & 21 & 80 \\
\hline EC staff & 9 & 37 & 28 & 6 & 80 \\
\hline Council staff & 23 & 44 & 12 & 0 & 79 \\
\hline Interest Groups or NGOs & 5 & 38 & 27 & 10 & 80 \\
\hline Industry representatives & 22 & 37 & 18 & 3 & 80 \\
\hline European political party & 34 & 34 & 10 & 1 & 79 \\
\hline National political party & 21 & 35 & 16 & 6 & 78 \\
\hline
\end{tabular}




\section{APPENDIX IV. INTERVIEW DESIGN}

\begin{tabular}{|c|c|c|c|}
\hline \# & Questions & Follow-up & What do I want to learn \\
\hline 1 & $\begin{array}{l}\text { a) Can you introduce your } \\
\text { tasks, responsibilities, and } \\
\text { explain how you see the } \\
\text { role of group advisors in } \\
\text { the EP? } \\
\text { b) As to your role: } \\
\text { What makes a good } \\
\text { advisor? What (attributes } \\
\text { are) is necessary to be a } \\
\text { good political advisor? }\end{array}$ & $\begin{array}{l}\text { Could you describe a } \\
\text { day in the life of a } \\
\text { group advisor? } \\
\text { With whom do you } \\
\text { collaborate/ talk to } \\
\text { on a regular basis, } \\
\text { etc. }\end{array}$ & $\begin{array}{l}\text { What do they do? How do } \\
\text { they perceive their role? } \\
\text { What is their mandate/ how } \\
\text { do they receive instructions? } \\
\text { How strict is this mandate? } \\
\text { Who are their main points of } \\
\text { contact? } \\
\text { What is necessary to } \\
\text { effectively fulfil that role? }\end{array}$ \\
\hline 2 & $\begin{array}{l}\text { Could you tell me a bit } \\
\text { more about the internal } \\
\text { coordination process within } \\
\text { your group: } \\
\text { a) How do coordinated } \\
\text { group positions come } \\
\text { about? } \\
\text { b) the negotiations } \\
\text { between your group and } \\
\text { the other groups? } \\
\text { c) and the trilogues and } \\
\text { preparation of these } \\
\text { trilogue meetings (at } \\
\text { technical level)? }\end{array}$ & $\begin{array}{l}\text { What happens in the } \\
\text { committee phase? } \\
\text { What happens in the } \\
\text { plenary phase? } \\
\text { Who does what? } \\
\text { Do your activities/ } \\
\text { responsibilities differ } \\
\text { in each of these } \\
\text { stages? }\end{array}$ & $\begin{array}{l}\text { How does the coordination } \\
\text { process (intra and inter } \\
\text { group) work and what is the } \\
\text { role of advisors in this } \\
\text { process? } \\
\text { What is their mandate/ how } \\
\text { do they receive instructions? } \\
\text { How strict is this mandate? } \\
\text { How does this differ across } \\
\text { the groups? }\end{array}$ \\
\hline 3 & $\begin{array}{l}\text { How do you see your role } \\
\text { in relation to the } \\
\text { committee secretariat? } \\
\text { And to the MEP assistants? }\end{array}$ & $\begin{array}{l}\text { How and when do } \\
\text { you collaborate with } \\
\text { the Secretariat? - } \\
\text { and MEP assistants? } \\
\text { In your view, in what } \\
\text { type of activities } \\
\text { does the added value } \\
\text { of group advisors lie? }\end{array}$ & $\begin{array}{l}\text { Insights into the } \\
\text { (collaborative/ competing) } \\
\text { relationships between the } \\
\text { different types of supporting } \\
\text { staff in the EP. } \\
\text { What is typically the domain } \\
\text { of the group advisor? And } \\
\text { what isn't? }\end{array}$ \\
\hline
\end{tabular}




\section{APPENDIX V. INTERVIEWEES}

\section{Exploratory interviews}

\section{February 2012 and October 2013}

Political group representation: EPP (2), S\&D (2) and ALDE (1).

I.01. Former accredited parliamentary assistant, February 2012

I.02. Accredited parliamentary assistant, February 2012

I.03. Former accredited parliamentary assistant, February 2012

I.04. Former political group advisor, February 2012

I.05. National delegation advisor, October 2013

I.06. EP official committee secretariat, October 2013

\section{In-depth, semi-structured interviews}

\section{November 2013 - June 2014}

Political group representation: Greens/EFA (6), ALDE (5), EPP (4), S\&D (3), ECR (2), GUE/NGL (1), EFD (1).

Parliamentary committee representation: AFET (5), ECON (4), IMCO (3), ITRE (3), LIBE (2), INTA (2), ENVI (1), FEMM (1).

I.1. Head of unit political group secretariat and former group advisor, 6 November 2013

I.2. Group advisor, 2 December 2013

I.3. Group advisor, 18 December 2013 (SR67)

I.4. Group advisor, 20 January 2014

I.5. Group advisor, 20 January 2014 (SR48)

I.6. Group advisor, 21 January 2014

I.7. Group advisor, 21 January 2014

I.8. Group advisor, 27 January 2014 
Appendix

I.9. Group advisor, 27 January 2014 (SR39)

I.10. Group advisor, 28 January 2014 (SR53)

I.11. Group advisor, 28 January 2014

I.12. Group advisor, 28 January 2014 (SR17)

I.13. Group advisor, 29 January 2014 (SR52)

I.14. Group advisor, 21 February 2014 (SR49)

I.15. Group advisor, 4 March 2014

I.16. Group advisor, 4 March 2014

I.17. Group advisor, 18 March (SR99)

I.18. Group advisor, 24 March 2014

I.19. Group advisor, 24 March 2014 (SR6)

I.20. Group advisor, 23 May 2014 (SR73)

I.21. Group advisor, 10 June 2014 (SR97)

I.22. Group advisor, 11 June 2014 (SR25)

\section{Triangulation}

\section{Spring 2018}

I.23. Former EP committee secretariat official, 4 April 2018

I.24. Former EP committee secretariat official, 15 May 2018 